UNIVERSIDADE DE SÃO PAULO

FACULDADE DE ECONOMIA, ADMINISTRAÇÃO E CONTABILIDADE DEPARTAMENTO DE ADMINISTRAÇÃO

PROGRAMA DE PÓS-GRADUAÇÃO EM ADMINISTRAÇÃO

A GESTÃO DO DESENVOLVIMENTO DE PRODUTOS NA INDÚSTRIA DE MATERIAIS DE CONSTRUÇÃO

Daniela Dutra da Costa

Orientador: Prof. Dr. Paulo Tromboni de Souza Nascimento

SÃO PAULO 
Profa. Dra. Suely Vilela

Reitora da Universidade de São Paulo

Prof. Dr. Carlos Roberto Azzoni

Diretor da Faculdade de Economia, Administração e Contabilidade

Prof. Dr. Isak Kruglianskas

Chefe do Departamento de Administração

Prof. Dr. Lindolfo Galvão de Albuquerque Coordenador do Programa de Pós-Graduação em Administração 
DANIELA DUTRA DA COSTA

\section{A GESTÃO DO DESENVOLVIMENTO DE PRODUTOS NA INDÚSTRIA DE MATERIAIS DE CONSTRUÇÃO}

Dissertação apresentada ao Departamento de Administração da Faculdade de Economia, Administração e Contabilidade da Universidade de São Paulo como requisito para a obtenção do título de Mestre em Administração.

Orientador: Prof. Dr. Paulo Tromboni de Souza Nascimento

SÃO PAULO 
FICHA CATALOGRÁFICA

Elaborada pela Seção de Processamento Técnico do SBD/FEA/USP

Costa, Daniela Dutra da

A gestão do desenvolvimento de produtos na indústria de materiais de construção / Daniela Dutra da Costa. -- São Paulo, 2008.

259 p.

Dissertação (Mestrado) - Universidade de São Paulo, 2008

Bibliografia.

1. Desenvolvimento de produtos 2. Desenvolvimento de produtos Processos 3. Materiais de construção 4. Elementos e componentes da construção I. Universidade de São Paulo. Faculdade de Economia, Administração e Contabilidade II. Título.

$$
\text { CDD - } 658.575
$$




\begin{abstract}
À minha avó querida, Maria Bettina, pelo exemplo de vida e pelas palavras de força que sempre foram e continuarão sendo essenciais para trilhar meu caminho. (in memoriam)
\end{abstract}


Inicialmente, agradeço ao meu orientador, Prof. Dr. Paulo Tromboni de Souza Nascimento, pela paciência, apoio e orientação na condução deste trabalho, o que contribuiu fundamentalmente para a conclusão desta etapa. Aos Professores Dr. Abraham Yu e Dr. Vahan Agopyan, pelas valiosas contribuições dadas durante a minha qualificação, assim como pelo estímulo e confiança que demonstraram. Ao Prof. Dr. Marilson Gonçalves, pela receptividade, atenção e ensinamentos. Aos demais professores da FEA USP. Aos funcionários da biblioteca, da secretaria do PPGA e da UPD da FEA USP. Como também, aos meus amigos do mestrado Iná Barreto, Olga Miranda, Ailton Conde Jussani, Barry Cuellar e Franciane Silveira, pelas dicas, amizade e atenção.

Agradeço também aos participantes das pesquisas. Tive a sorte de encontrar profissionais sérios, atenciosos e dispostos a participar.

Por último, mas não menos importante, agradeço à minha família. Ao meu pai, pelo modelo de profissional competente e em constante renovação, e pelos conselhos essenciais para o meu desenvolvimento. À minha querida mãe, pela presença e amor incondicional, mas acima de tudo, pelo estímulo diário para seguir em frente. À minha irmã, pelo exemplo de estudo, confiança e fortaleza. Agradeço também ao meu noivo, pelo seu amor e apoio que foram essenciais para a realização deste trabalho, sempre acreditando em mim. 


\section{RESUMO}

A presente pesquisa procurou aperfeiçoar os conhecimentos no que se refere à gestão do desenvolvimento de novos produtos no segmento de componentes da indústria de materiais de construção. Não obstante a vasta literatura sobre a gestão do desenvolvimento de produtos, ainda existe uma lacuna no que diz respeito a este tema no setor. Procurou-se, então, identificar o grau de formalização, as etapas e as características da gestão do desenvolvimento de produtos na indústria de materiais de construção, como também as convergências e divergências entre os casos práticos e a literatura levantada. O desdobramento teórico desta pesquisa teve por base uma compilação dos principais modelos de gestão do processo de criação, como também do mapeamento do setor da indústria de materiais de construção. Por sua vez, o desenvolvimento empírico amparou-se na pesquisa qualitativa, predominantemente exploratória, baseada na técnica de estudo de casos múltiplos, contando com uma amostra de quatro empresas: Perflex, Deca, Cecrisa e Tigre. Verificou-se que existe um razoável nível de aderência entre o que preconiza a literatura e o que de fato acontece nas empresas pesquisadas, todavia, existem algumas contribuições relevantes que podem ser consideradas. Observou-se que nesse setor industrial os projetos derivativos são predominantes, com grande direcionamento para projetos topológicos; que o processo de captação de idéias realizado pela Cecrisa e pela Tigre diferenciase das demais empresas, obtendo as mais diferentes informações; que na etapa de desenvolvimento do conceito do produto a Cecrisa sobressai por inserir depoimentos de especialistas sobre a imagem da linha e a atualidade da idéia, o que poderá ser utilizado nas suas peças promocionais. Destaca-se, ainda, na montagem do produto, pois o faz em etapas iniciais, utilizando a matéria-prima e o processo produtivo finais. E a Deca, Cecrisa e Tigre realizam o lançamento interno do produto, distinguindo-se pela forma como é feito, e por não ter sido encontrado nenhum caso na literatura que inclua essa etapa no processo. É importante ressaltar a falta de aplicação de alguns critérios de Clark e Wheelwright (1993) nas empresas estudadas. Estas se diferenciam bastante das empresas utilizadas na pesquisa dos autores citados, pois são empresas pequenas com distâncias hierárquicas menores, onde acontecem constantemente reuniões formais e encontros informais para discussões e esclarecimentos sobre projetos. Com este estudo foi possível conhecer a realidade das indústrias de materiais de construção, a qual não se encontra em más condições, pelo contrário, está atualizada com os novos conceitos que envolvem o tema deste trabalho, gestão do desenvolvimento de novos produtos, com um processo e uma estrutura formal e organizada. 


\begin{abstract}
This study tries to improve the knowledge of the management of new products development in the industry of construction materials. Despite the vast literature on the management of the development of the products, there is still a gap in this subject related to the sector. For this reason, this study also tries to identify the degree of formalization, the phases and the characteristics of the management of the products in the industry of construction material, as well as the convergences and divergences between the practical cases and the literature studied. The empirical development of this research was based upon the compilation of the chief models of management of the process of creation, as well as the mapping of the sector of the industry of construction materials. In its turn, the empirical development had as its base a qualitative, prevailingly exploratory, research, based on the technique of study of multiple cases, counting on a sample of four companies: Perflex, Deca, Cecrisa and Tigre. It was verified that there is a reasonable degree of disparity between what the relevant literature states and what it is done in the target companies; nevertheless, there are some excellent contributions that can be taken into consideration. It was noticed that in this industrial sector derivative projects prevail, many oriented to topological projects; that the process of capture of ideas and information carried out by Cecrisa and by Tigre is different from that of the other companies, getting the most varied information; that in the face of the conceptual development of the product Cecrisa stands out for inserting testimonials of experts on the image of the line and the up-dated character of the idea, which may be used in the advertising pieces. It also stands out in the assembling of the products for doing it in the initial phases using raw material and the final productive process. Deca, Cecrisa and Tigre make the internal launching of the product, differing from others by the form of doing it, and for the effect that no similar case has been found in the relevant literature that includes this phase into the process. It is important to note the lack of application of some of Clark and Wheelwright's principles (1993) in the companies studied. This target companies differ largely from the companies used in the research of the authors mentioned, for they are small companies with smaller hierarchical distances, where formal and informal meetings taken place, constantly, for discussions and clarifications about projects. With this study it was possible to learn about the reality of the construction materials industries, which, by the way, is not badly off; on the contrary, it is up to date with the new concepts of the theme of this study, the management of new products development, with a process and a formal and organized structure.
\end{abstract}




\section{SUMÁRIO}

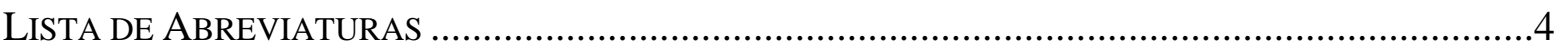

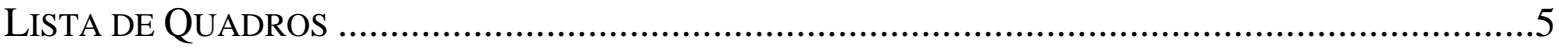

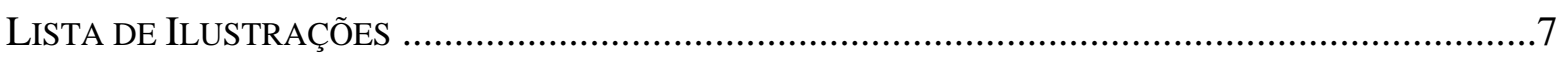

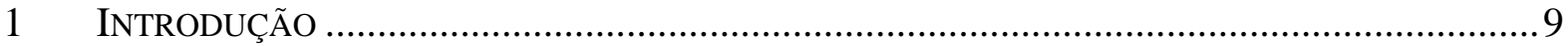

$1.1 \quad$ Problema de pesquisa e objetivo do estudo .......................................................... 12

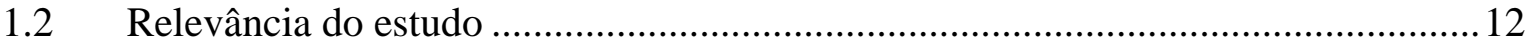

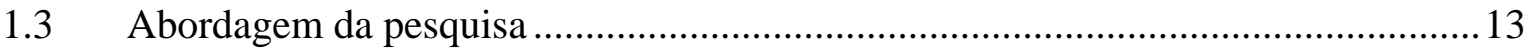

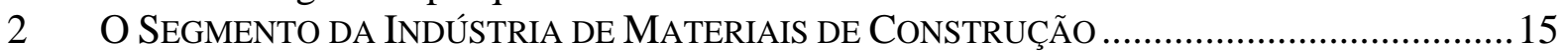

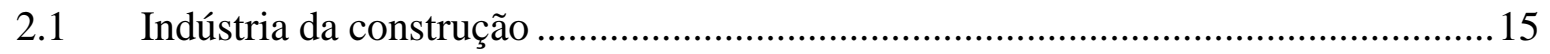



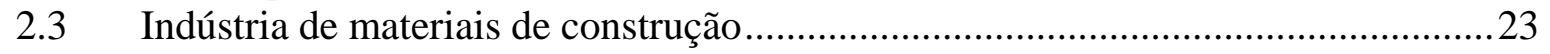



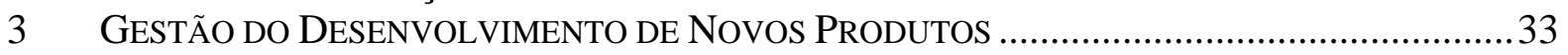

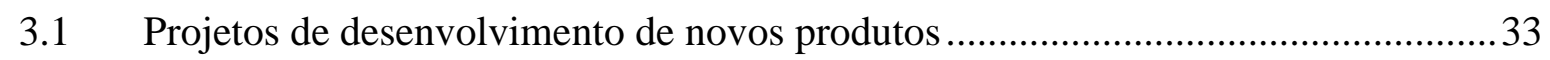

3.2 Gestão de projetos de desenvolvimento de novos produtos ....................................37

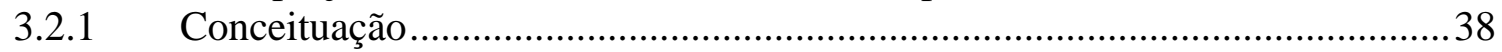

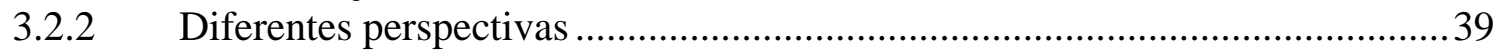

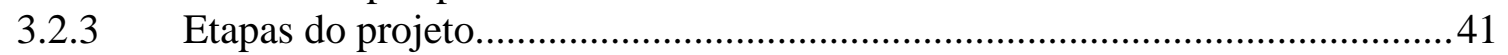

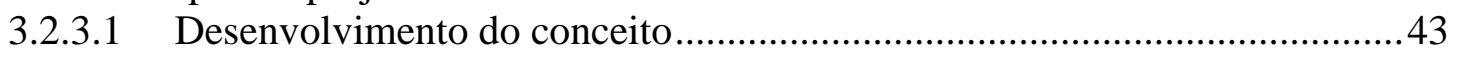

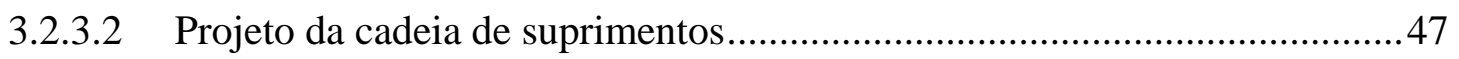

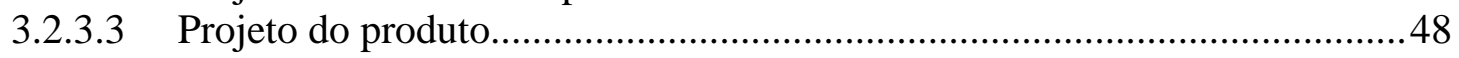

3.2.3.4 Teste e validação de desempenho ................................................................ 49

3.2.3.5 Ramp-up e lançamento .............................................................................. 52

3.2.4 Decisões para organização de projetos de desenvolvimento ............................53

3.2.4.1 Estratégia e planejamento do produto ......................................................53

3.2.4.2 Organização do desenvolvimento do produto...............................................56

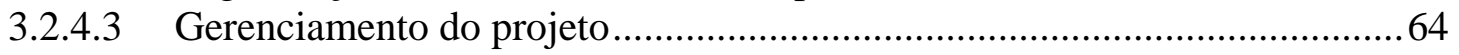

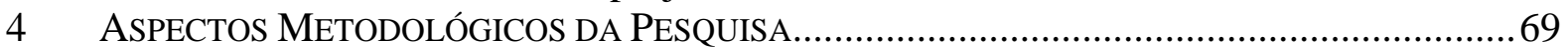

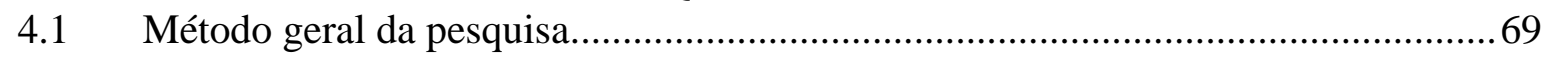

4.1.1 Dados secundários - levantamento bibliográfico e documental......................... 70

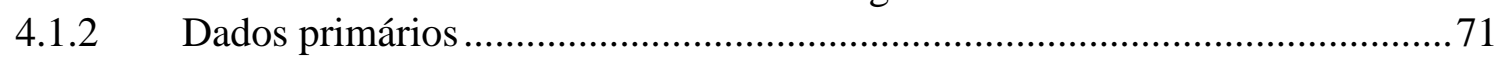

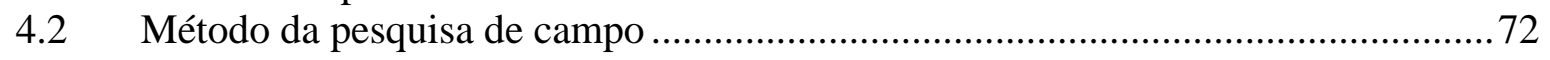





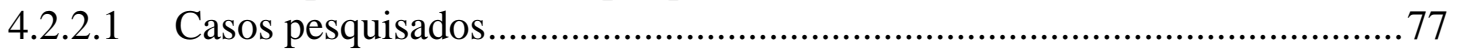

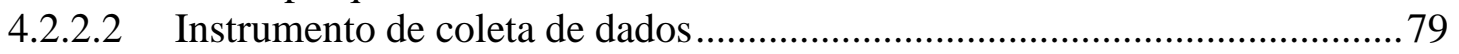

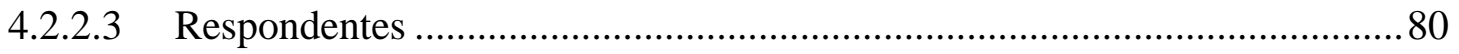

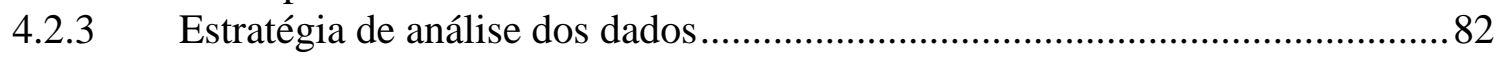

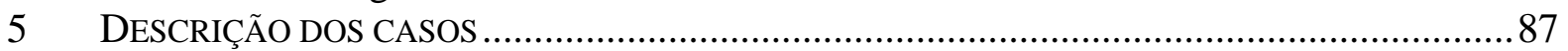

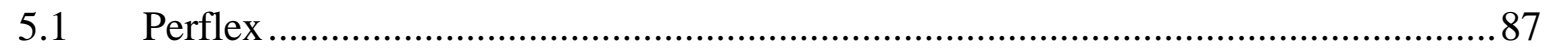

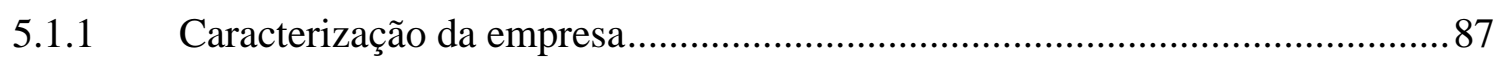

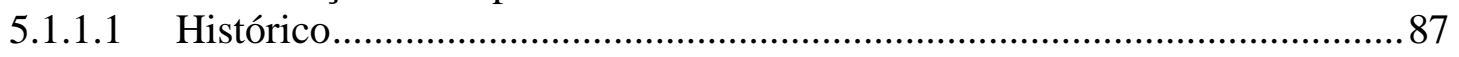

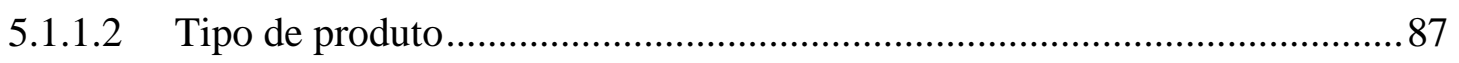

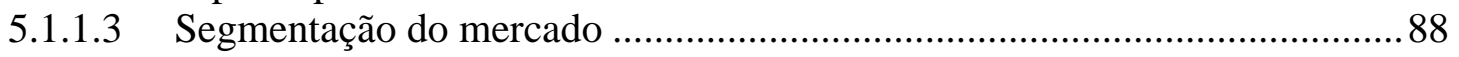

5.1.2 Gestão do desenvolvimento dos produtos Perflex .......................................... 88

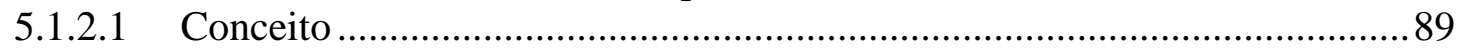

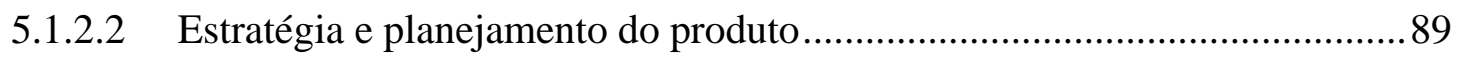




\begin{tabular}{|c|c|c|}
\hline & & 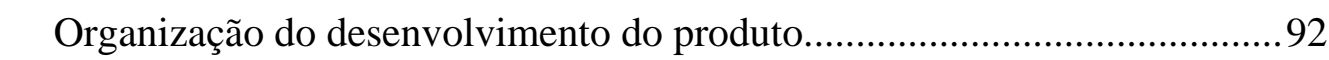 \\
\hline & 2.4 & ento do projeto. \\
\hline & 1.2 .5 & Etapas de desenvolvimento. \\
\hline & & Conclusões \\
\hline & Dec &. .106 \\
\hline 5.2 & & Caracterização da empresa... \\
\hline & 5.2.1.1 & Histórico.............................. \\
\hline & 5.2.1.2 & Tipo de produto.. \\
\hline & 5.2.1.3 & Segmentação do mercado .. \\
\hline 5.2 & & 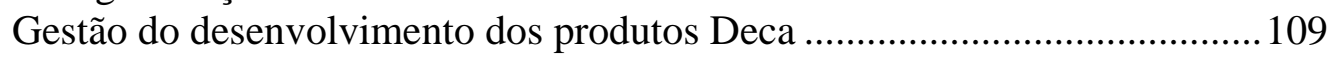 \\
\hline & 5.2.2.1 & 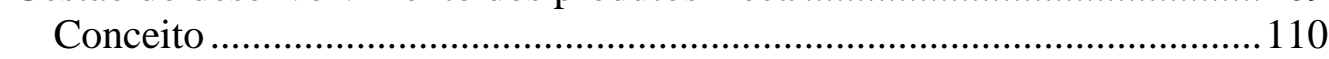 \\
\hline & 5.2 .2 .2 & Estratégia e planejamento do produto...... \\
\hline & 5.2.2.3 & 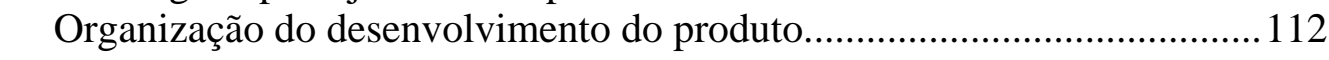 \\
\hline & 5.2.2.4 & 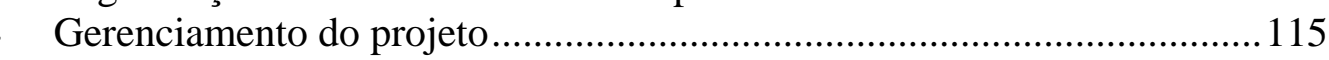 \\
\hline & 5.2.2.5 & jolvimento... \\
\hline 5.2 & & Conclusões. \\
\hline & Cecr & risa........ \\
\hline 5.3 & & Caracterização da empresa. \\
\hline & 5.3.1.1 & $\ldots 129$ \\
\hline & 5.3.1.2 & Tipo de produto.. \\
\hline & 5.3.1.3 & ado ....... \\
\hline 5.3 & & Gestão do desenvolvimento de produtos Cecrisa ... \\
\hline & 5.3.2.1 & 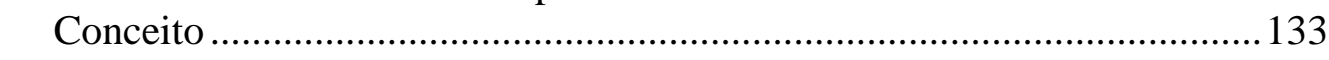 \\
\hline & 5.3.2.2 &  \\
\hline & 5.3.2.3 & 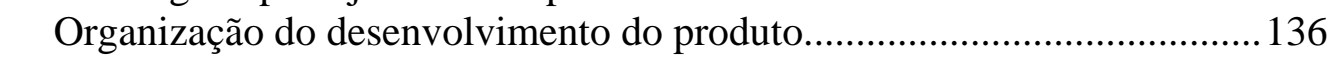 \\
\hline & 5.3.2.4 & Gerenciamento do projeto.. \\
\hline & 5.3.2.5 & Etapas de desenvolvimento. \\
\hline 5.3 & & Conclu \\
\hline & Tigre &. .154 \\
\hline 5.4 & & Caracte \\
\hline & 5.4.1.1 & Histórico.. \\
\hline & 5.4.1.2 & $\ldots 156$ \\
\hline & 5.4.1.3 & $\ldots 157$ \\
\hline 5.4 & &  \\
\hline & 5.4.2.1 & 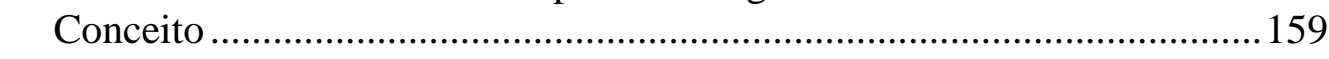 \\
\hline & 5.4 .2 .2 & Estratégia e planejamento do produto .................................... \\
\hline & 5.4 .2 .3 & 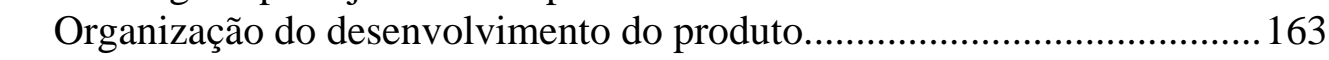 \\
\hline & 5.4 .2 .4 & 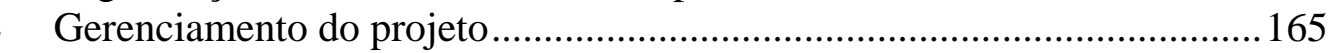 \\
\hline & 5.4.2.5 & 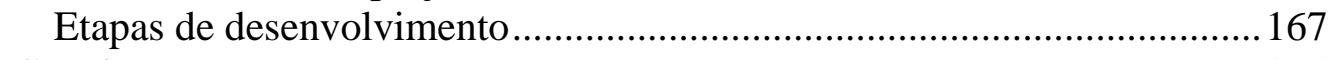 \\
\hline 5.4 & & 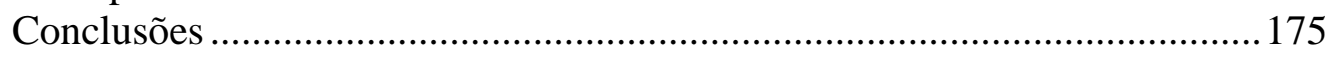 \\
\hline & RESEN & JTAÇÃO COMPARADA DOS RESULTADOS ........ \\
\hline 6.1 & Histé & 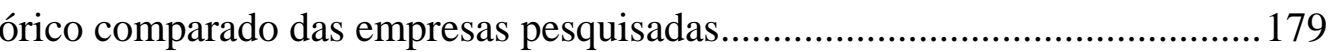 \\
\hline 6.2 & Tipo & 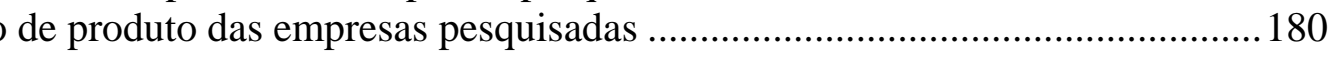 \\
\hline 6.3 & Segn & 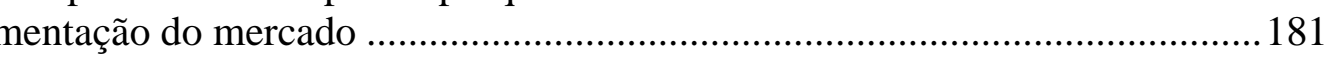 \\
\hline 6.4 & Gest & tão do desenvolvimento de produtos .. \\
\hline 6.4 & & Conceito da GDP ...................... \\
\hline 6.4 & & Estra \\
\hline 6.4 & & 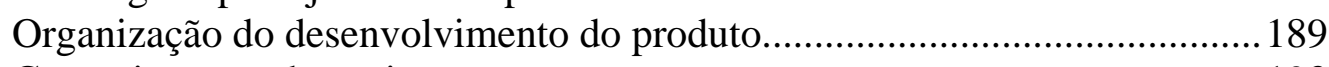 \\
\hline 6.4 & & Gerenciamento do projeto....................... \\
\hline 6.4 & & Etapas de desenvolvimento...... \\
\hline
\end{tabular}




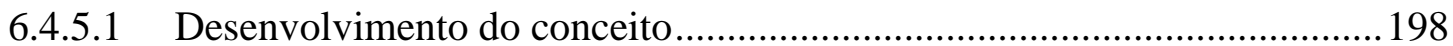



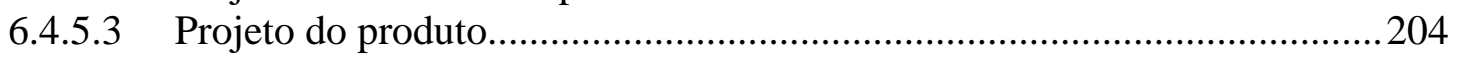

6.4.5.4 Teste e validação de desempenho ............................................................206

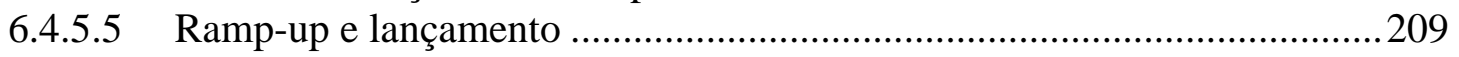



7.1 Projetos de desenvolvimento de novos produtos na IMC .......................................213

7.2 Gestão do desenvolvimento de produtos .........................................................214

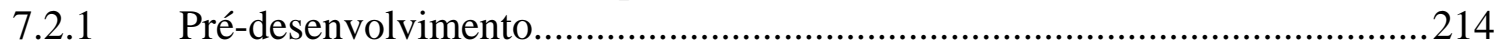



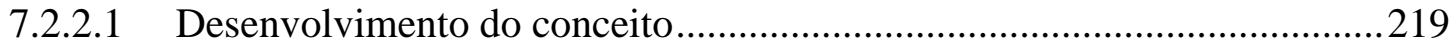

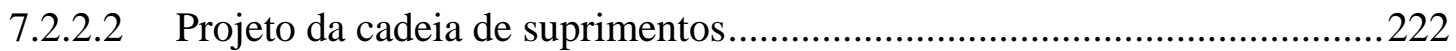



7.2.2.4 Teste e validação de desempenho ..........................................................224

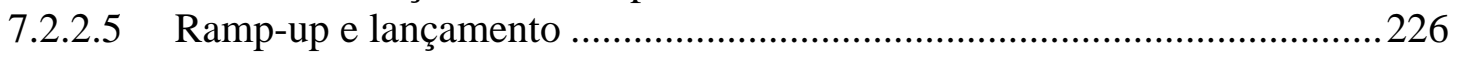

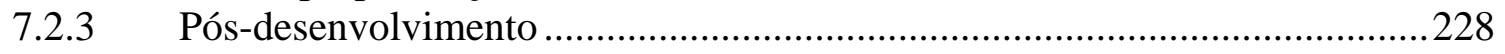

8 CONSIDERAÇÕES FINAIS, LIMITAÇÕES E IMPLICAÇÕES GERENCIAIS...............................229

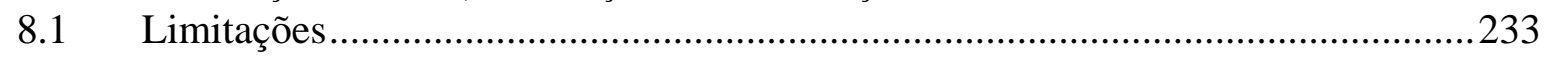



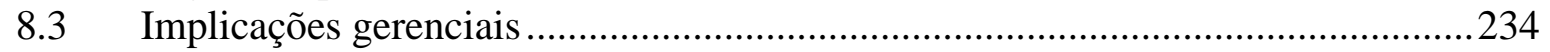

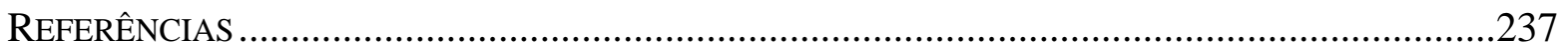

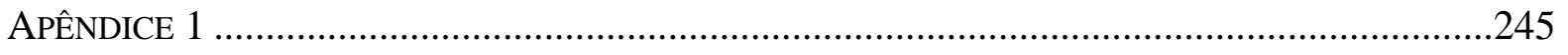







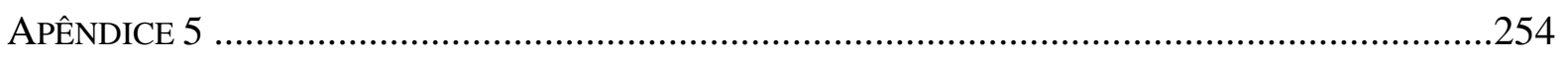

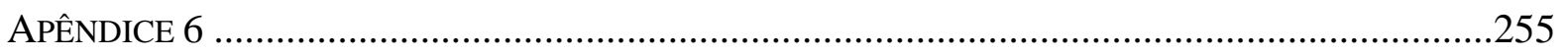

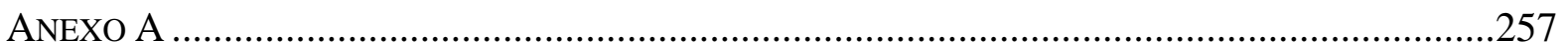

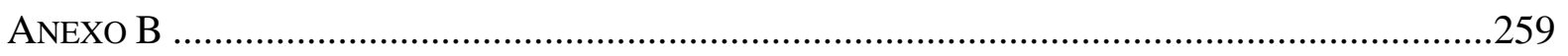




\section{LISTA DE SIGLAS}

ABCP: $\quad$ Associação Brasileira de Cimento Portland

ABNT: Associação Brasileira de Normas Técnicas

ABRAMAT: Associação Brasileira da Indústria de Materiais de Construção

ANAMACO: Associação Nacional dos Comerciantes de Material de Construção

B2B: Business to Business

B2C: Business to Consumer

CAD: Computer-Aided Design

DFM: Design For Manufacturability

FGV PROJETOS: Fundação Getúlio Vargas Projetos

GDP: Gestão do Desenvolvimento de Produtos

IA: Instrução Administrativa

IC: Indústria da Construção

IMC: Indústria de Materiais de Construção

ISO: International Organization for Standardization

P\&D: Pesquisa e Desenvolvimento

PAC: Programa de Aceleração do Crescimento

PBQP-H: Programa Brasileiro de Qualidade e Produtividade do Habitat

PD\&E: Pesquisa, Desenvolvimento e Engenharia

PIB: Produto Interno Bruto

QFD: Quality Function Deployment

QUALIHAB: Programa da Qualidade da Construção Habitacional

UNC: União Nacional da Construção 


\section{LISTA DE QUADROS}

Quadro 1 - Desafios da gestão da inovação competitiva .....................................................11

Quadro 2 - Valor adicionado da cadeia produtiva da IC .....................................................22

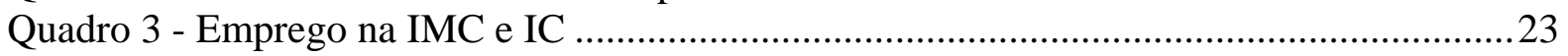

Quadro 4 - Valor adicionado e pessoal ocupado na IMC, 2004 ...........................................24

Quadro 5 - Segmentos que liberaram a geração de emprego em 2007 ...................................25

Quadro 6 - Geração de empregos por estados em 2007..........................................................26

Quadro 7 - Comparação das perspectivas das comunidades acadêmicas de marketing, organizações, engenharia de projeto e administração da produção ......................................... 39

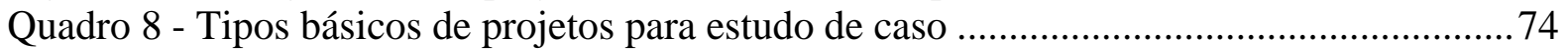

Quadro 9 - Decisões para organização de projetos de desenvolvimento ..................................83

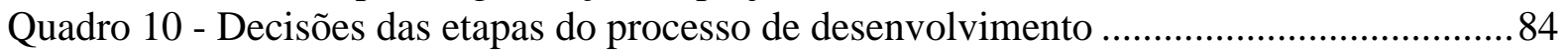

Quadro 11 - Etapas e subetapas do processo de GDP da Perflex ..........................................8

Quadro 12 - Decisões Perflex - estratégia e planejamento do produto...................................92

Quadro 13 - Decisões Perflex - organização do desenvolvimento do produto.........................93

Quadro 14 - Decisões Perflex - gerenciamento do projeto ...................................................95

Quadro 15 - Quadro comparativo das etapas de Krishnan e Ulrich (2001) versus etapas

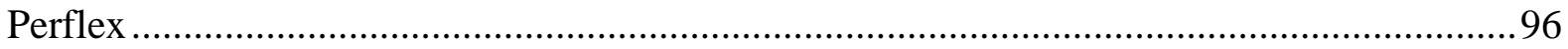

Quadro 16 - Decisões Perflex - desenvolvimento do conceito ...............................................98

Quadro 17 - Decisões Perflex - projeto da cadeia de suprimentos e projeto do produto.......100

Quadro 18 - Decisões Perflex - teste e validação de desempenho..........................................101

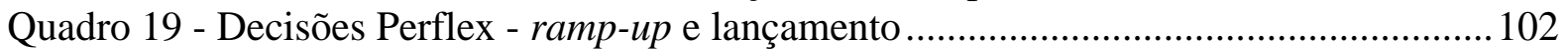

Quadro 20 - Etapas e subetapas do processo de GDP da Deca ...........................................110

Quadro 21 - Decisões Deca - estratégia e planejamento do produto .....................................112

Quadro 22 - Decisões Deca - organização do desenvolvimento do produto ...........................115

Quadro 23 - Decisões Deca - gerenciamento do projeto .....................................................118

Quadro 24 - Quadro comparativo etapas de Krishnan e Ulrich (2001) versus etapas Deca..119

Quadro 25 - Decisões Deca - desenvolvimento do conceito ..............................................120

Quadro 26 - Decisões Deca - projeto da cadeia de suprimentos e projeto do produto ...........123

Quadro 27 - Decisões Deca - teste e validação de desempenho ............................................125



Quadro 29 - Etapas e subetapas do processo de GDP da Cecrisa........................................133

Quadro 30 - Decisões Cecrisa - estratégia e planejamento do produto ..................................136

Quadro 31 - Decisões Cecrisa - organização do desenvolvimento do projeto ........................139

Quadro 32 - Decisões Cecrisa - gerenciamento do projeto.................................................... 141

Quadro 33 - Quadro comparativo etapas de Krishnan e Ulrich (2001) versus etapas Cecrisa

Quadro 34 - Decisões Cecrisa - desenvolvimento do conceito............................................146

Quadro 35 - Decisões Cecrisa - projeto da cadeia de suprimentos e projeto do produto .......148

Quadro 36 - Decisões Cecrisa - teste e validação de desempenho .........................................150

Quadro 37 - Decisões Cecrisa - ramp-up e lançamento ......................................................151

Quadro 38 - Etapas e subetapas do processo de GDP da Tigre ............................................158

Quadro 39- Decisão Tigre - estratégia e planejamento do produto ........................................ 163

Quadro 40 - Decisões Tigre - organização do desenvolvimento do produto........................... 165

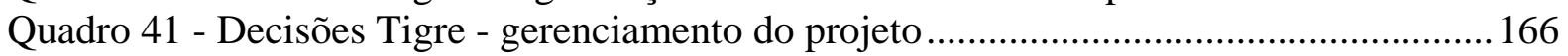

Quadro 42 - Quadro comparativo etapas Krishnan e Ulrich (2001) versus etapas Tigre ......167

Quadro 43 - Decisões Tigre - desenvolvimento do conceito ................................................168

Quadro 44 - Decisões Tigre - projeto da cadeia de suprimentos .......................................... 170

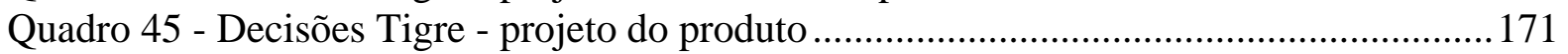


Quadro 46 - Decisões Tigre - teste e validação de desempenho..........................................173

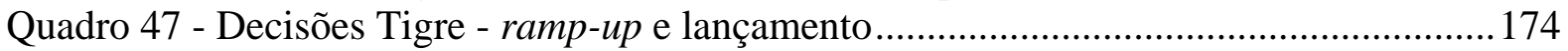

Quadro 48 - Comparação das características das empresas estudadas ..................................179

Quadro 49 - Etapas de Krishnan e Ulrich (2001) versus etapas das empresas pesquisadas .. 182 Quadro 50 - Decisões Perflex, Deca, Cecrisa e Tigre - estratégia e planejamento do produto

Quadro 51 - Decisões Perflex, Deca, Cecrisa e Tigre - organização do desenvolvimento do

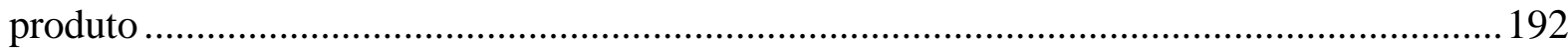

Quadro 52 - Protótipo no processo de GDP das empresas pesquisadas .................................196

Quadro 53 - Decisões Perflex, Deca, Cecrisa e Tigre - gerenciamento do projeto ................197

Quadro 54 - Decisões Perflex, Deca, Cecrisa e Tigre - desenvolvimento do conceito ..........201

Quadro 55 - Decisões Tigre - projeto da cadeia de suprimentos .........................................204

Quadro 56 - Decisões Perflex, Deca, Cecrisa e Tigre - projeto do produto ............................206

Quadro 57 - Decisões Perflex, Deca, Cecrisa e Tigre - teste e validação de desempenho ....208

Quadro 58 - Decisões Perflex, Deca, Cecrisa e Tigre - ramp-up e lançamento ......................211

Quadro 59 - Decisões comuns à Perflex, Deca, Cecrisa e Tigre - pré-desenvolvimento ......214

Quadro 60 - Decisões comuns à Perflex, Deca, Cecrisa e Tigre - desenvolvimento do conceito

Quadro 61 - Decisões comuns à Perflex, Deca, Cecrisa e Tigre - projeto da cadeia de

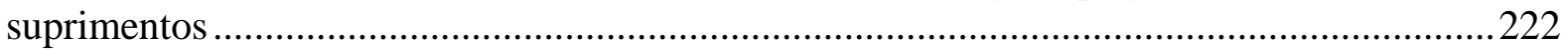

Quadro 62 - Decisões comuns à Perflex, Deca, Cecrisa e Tigre - projeto do produto ...........223 Quadro 63 - Decisões comuns à Perflex, Deca, Cecrisa e Tigre - teste e validação de

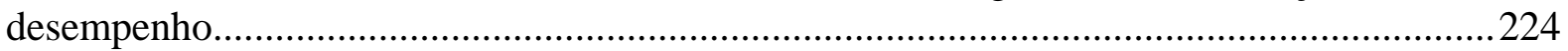

Quadro 64 - Decisões comuns à Perflex, Deca, Cecrisa e Tigre - ramp-up e lançamento ....226

Quadro 65 - Decisões comuns à Perflex, Deca, Cecrisa e Tigre - pós-desenvolvimento .......228 


\section{LISTA DE ILUSTRAÇÕES}

Ilustração 1 - Cadeia produtiva da construção civil.............................................................20

Ilustração 2- Planta da cadeia da construção ......................................................................21

Ilustração 3 - Tipos de projetos de desenvolvimento de produtos e/ou processos .................... 35

Ilustração 4 - Estrutura da estratégia de desenvolvimento........................................................54

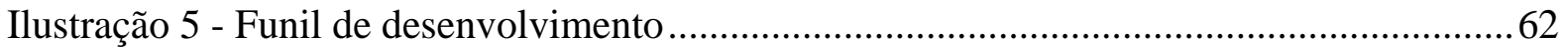

Ilustração 6 - Processo do stage-gate para empresas menores, com projetos de risco

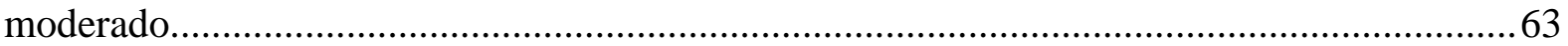

Ilustração 7 - Processo do stage-gate para empresas maiores, com projetos de alto risco......64

Ilustração 9 - Etapas de desenvolvimento de produtos Perflex ..............................................96

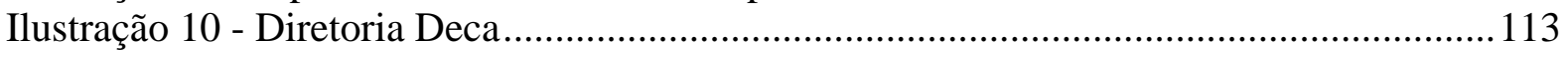

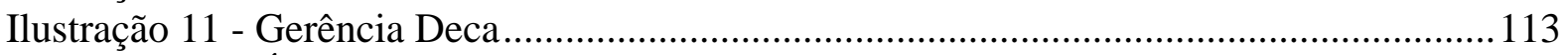

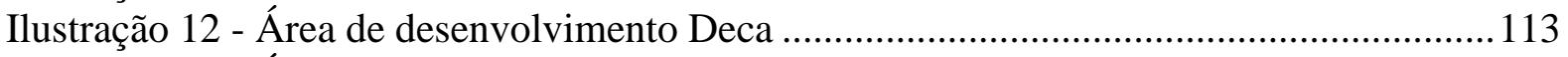

Ilustração 13 - Área de desenvolvimento Cecrisa.................................................................137

Ilustração 14 - Etapas do processo de GDP da Tigre...........................................................159 


\section{INTRODUÇÃO}

Shumpeter (1942) identificou o paradigma da “destruição criativa”, no qual a inovação é vista como um conjunto de novas funções que alteram os métodos de produção, criando novas formas de organização do trabalho e, que ao produzir novas mercadorias, possibilita a abertura de novos mercados através da criação de novos usos e consumos. Depois de mais de 50 anos a inovação é vital para a competitividade das empresas, resultado da velocidade do desenvolvimento tecnológico e do crescimento da competição, o que levou esta a ser uma das dimensões mais importantes, atualmente, no mundo dos negócios. Porém, Tidd et al (1999, p. 4) afirmam que a inovação não é garantia de sucesso, apesar de poder proporcionar à empresa vantagem competitiva e um posicionamento estratégico.

De acordo com Brown e Eisenhardt (1995), há uma vasta literatura sobre inovação, a qual se divide em duas vertentes de pesquisa, uma orientação econômica e outra organizacional. A primeira procura identificar as diferenças dos padrões de inovação nos países e nos setores industriais. A segunda é relacionada à pesquisa do desenvolvimento de novos produtos, analisando sua produção e gerenciamento, foco desta dissertação.

É fator essencial para o sucesso das empresas entender como funcionam as forças do ambiente de negócios e de sua competência em converter de forma habilidosa esse conhecimento em produtos e serviços que ofereçam valor superior aos consumidores. Empresas inovadoras, que utilizam a inovação para diferenciar seus produtos e serviços dos concorrentes, têm grandes vantagens sobre as outras. No entanto, a maior parte das novas tecnologias, quando transformadas em produto ou serviço, falha, e a grande parte de novos produtos e serviços não são sucessos comerciais. Por essa razão, a necessidade da utilização de diferentes formas de gerenciamento do conhecimento e das habilidades das pessoas envolvidas nas atividades chave da organização (TIDD et al, 1999).

Faz parte do ciclo da inovação a etapa de desenvolvimento de novos produtos, que vai da descoberta de um novo conhecimento até a sua transformação em um produto comercial. Inovação é, então, mais que simplesmente ter boas idéias, é o processo de desenvolvê-las e torná-las úteis. Para entender melhor o conceito de inovação é preciso conhecer a diferença 
que existe entre invenção e inovação. Garcia e Calantone (2002) apud Ferreira (2007) afirmam que uma

\begin{abstract}
[...] invenção não se torna uma inovação até a sua progressão pelas etapas de produção, atividades de marketing e a sua difusão no mercado. A "simples" solução de uma questão básica científica ou a invenção de um novo produto somente no nível de laboratório, para os autores, não traz nenhuma contribuição econômica direta para a empresa. Desta forma, a principal diferença entre invenção e inovação é que esta última traz um valor econômico, que é transmitido para outros além dos seus criadores.
\end{abstract}

O presente trabalho entende inovação como conhecimento em uso, o que está de acordo com o conceito acima citado.

Desenvolver um novo produto pode ser um grande desafio, particularmente quando a empresa procura ofertar produtos que atendam às “necessidades latentes” de seus clientes, as quais são bem difíceis de serem identificadas (CHUA, 2006). Essas são necessidades que o mercado ainda não demonstrou precisar, mas que as empresas devem ofertar antes mesmo de serem solicitadas.

Desenvolver novos produtos e inovar são questões centrais para empresas que estão inseridas em ambientes novos, altamente competitivos e turbulentos, mas também afetam indústrias maduras, que possuem produtos com ciclos de vida longos, tecnologia madura e demanda estável (CLARK; WHEELWRIGHT, 1993, p. 4). Novos produtos ajudam a conquistar novos mercados, como também a manter os já existentes.

Porém, a inovação traz consigo muita incerteza, o que exige que o processo seja cuidadosamente gerenciado e os experimentos muito bem projetados e controlados, minimizando assim a possibilidade de falhas e, caso estas não possam ser evitadas, proporcionando o aprendizado para projetos futuros. Tidd et al (1999, p. 32) e Clark e Wheelwright (1993, p. 3) complementam dizendo que a questão não é apenas inovar ou não, mas também como realizar esse processo extraordinariamente bem.

São inúmeras as técnicas e filosofias de desenvolvimento que auxiliam todo esse processo: integração de equipes de projeto, utilização de tecnologia de informação como suporte, técnicas de melhoria de qualidade, engenharia simultânea, dentre diversas outras. Diante de tantas técnicas são necessárias tomadas de decisões para o melhor andamento de um 
determinado projeto, desde as características funcionais e qualidade que o produto deverá ter, a questões relacionadas com a logística e os canais de distribuição que serão utilizados.

Administrar o processo de desenvolvimento de um novo produto requer conhecimentos multidisciplinares, além de um ambiente rico em informações de todas as naturezas, de forma a minimizar os riscos envolvidos. Clark e Wheelwright (1993, p. 7) apresentam alguns desafios para a gestão da inovação (Quadro 1).

\section{Quadro 1 - Desafios da gestão da inovação competitiva}

\begin{tabular}{|c|c|c|}
\hline Competência Necessária & Situação do Mercado & Implicações \\
\hline Rapidez e pró-atividade. & $\begin{array}{l}\text { Intensa concorrência; mudança nas } \\
\text { preferências dos consumidores e } \\
\text { mudança rápida na tecnologia. }\end{array}$ & $\begin{array}{l}\text { Prazos mais curtos de } \\
\text { desenvolvimento; produtos mais } \\
\text { focados. }\end{array}$ \\
\hline $\begin{array}{l}\text { Alta produtividade no } \\
\text { desenvolvimento. }\end{array}$ & $\begin{array}{l}\text { Variedade crescente de produto; } \\
\text { consumidores conscientes e } \\
\text { sofisticados; diversidade } \\
\text { tecnológica. }\end{array}$ & $\begin{array}{c}\text { Aperfeiçoamento dos recursos } \\
\text { críticos; aumento do número de } \\
\text { projetos bem-sucedidos } \\
\text { desenvolvidos por engenheiros. }\end{array}$ \\
\hline $\begin{array}{l}\text { Produtos com distinção e } \\
\text { integridade. }\end{array}$ & $\begin{array}{l}\text { Consumidores exigentes; } \\
\text { concorrência intensa; mercados } \\
\text { apinhados. }\end{array}$ & $\begin{array}{l}\text { Criatividade combinada com } \\
\text { qualidade total do produto; } \\
\text { consumidores integrados com } \\
\text { processos de desenvolvimento } \\
\text { multifuncionais. }\end{array}$ \\
\hline
\end{tabular}

FONTE: CLARK; WHEELWRIGHT; 1993, p. 7.

É necessário que as empresas integrem rapidez, eficiência e qualidade, pessoas capacitadas, processos bem desenvolvidos e ajustados, com um cuidado especial com a variável tempo, e uma forte e capacitada liderança. A intensa competitividade entre as empresas somada aos consumidores mais conscientes exige que os produtos surpreendam e impressionem seu mercado. Por essa razão, cada vez mais se aumenta o número de pesquisas com o intuito de identificarem práticas mais bem-sucedidas para determinados mercados ou produtos, mas deve-se lembrar que não existe uma melhor forma de organizar e gerenciar um projeto, cada tecnologia, cada mercado, cada empresa exige diferentes estruturas e processos organizacionais (TIDD et al, 1999).

A capacidade de inovar de uma empresa depende, portanto, da sua habilidade em gerenciar bem o seu desenvolvimento. Com isso, a empresa conseguirá abrir novos mercados, atrair novos consumidores e construir novas capacidades. Clark e Wheelwright (1993, p. 8) afirmam que o desenvolvimento de um produto bem-sucedido dá à empresa orgulho e confiança, melhorando assim os relacionamentos internos e externos. 
Apesar da vasta literatura existente, ainda há um número incipiente de pesquisas sobre GDP em indústrias de materiais de construção - IMC, objeto de estudo desta dissertação.

\subsection{Problema de pesquisa e objetivo do estudo}

Smith e Reinertsen (1998) afirmam que não existe uma melhor prática para gerir o desenvolvimento de um produto, mas sim práticas que, em determinados contextos, com a finalidade de alcançar objetivos específicos, podem ser mais adequadas e levarão a um resultado mais promissor que outras. Com isso, o objetivo deste estudo é identificar a estrutura, as práticas e as técnicas de GDP utilizadas na IMC, com o intuito de identificar o grau de formalização do processo nesse setor. Por se constituir em pesquisa inicial no setor em questão, não será possível analisar as práticas mais adequadas para este, mas sim responder à seguinte pergunta de pesquisa:

“Como é realizado o processo de gestão do desenvolvimento de um novo produto na indústria de materiais de construção?”

Os objetivos específicos desta pesquisa podem ser resumidos nos seguintes itens:

- identificar o grau de formalização da GDP na IMC;

- identificar as etapas da GDP na IMC;

- identificar convergências e divergências entre os casos práticos e a literatura levantada;

- identificar características da GDP peculiares à IMC.

\subsection{Relevância do estudo}

O aumento da competitividade, o avanço tecnológico e a conseqüente mudança do comportamento do consumidor, que vêm ocorrendo desde a década de 80, têm tornado cada vez mais importante a busca por parte das empresas por vantagens competitivas sustentáveis. Por essa razão, é preciso que as organizações encontrem formas de se superar, de surpreender seu mercado consumidor e seus concorrentes, ofertando novos e diferentes produtos, com 
rapidez, qualidade e eficiência. Torna-se, portanto, fundamental conhecer os fatores que contribuem para o sucesso da inovação do produto.

Nesse sentido, diversos estudos empíricos vêm sendo desenvolvidos. Apesar da vasta literatura existente sobre a GDP, ainda existe uma lacuna no que diz respeito a esse tema na IMC. Até há algum tempo, essa indústria ainda era pouco valorizada, devido ao baixo volume de investimentos dessas empresas no desenvolvimento de seu setor. Contudo, essa realidade tem mudado, tanto pela exigência de um mercado mais consciente, quanto pela necessidade das próprias empresas de se atualizarem.

É um setor de enorme peso econômico e com poucos ou quase nenhum trabalhos acadêmicos, o qual respondeu por 2,1\% do PIB em 2004 (ABRAMAT; FGV PROJETOS, 2007a). Segundo a Associação Brasileira da Indústria de Materiais de Construção - Abramat, e Fundação Getúlio Vargas Projetos - FGV Projetos (2007a), a receita líquida com produtos e serviços desse setor para a construção somou R\$ 75,5 bilhões em 2004.

O presente estudo servirá de base inicial para futuras pesquisas, de forma a identificar as práticas de GDP realizadas atualmente por empresas de referência no setor. Isso proporcionará o avanço de novos conhecimentos, tanto sobre a GDP, como também para a IMC.

A seguir será apresentada a abordagem de pesquisa desta dissertação.

\subsection{Abordagem da pesquisa}

O presente trabalho se constituirá de pesquisa qualitativa e exploratória, buscando identificar hipóteses e variáveis, por meio da geração de mais conhecimento sobre o tema ou problema em perspectiva. Esta dissertação está dividida em duas etapas. A primeira envolve a pesquisa de dados secundários e busca levantar um arcabouço teórico sobre o tema gestão do desenvolvimento de novos produtos, como também um levantamento sobre a indústria de materiais de construção. Com isso, procura-se embasar a segunda parte do trabalho, que compreende a pesquisa de campo, que será realizada pelo método do estudo de caso. 
A primeira parte desta dissertação refere-se ao levantamento do referencial teórico, e a segunda, aos aspectos metodológicos da pesquisa de campo. O referencial teórico, primeiro passo da pesquisa exploratória, divide-se em duas partes: o segmento da Indústria de Materiais de Construção, e a Gestão do Desenvolvimento de Novos Produtos. A análise de dados e as considerações finais se sucederão. 


\section{O SEgmento da INdÚstria de MATERIAIS de CONSTRUÇÃo}

Inicialmente serão apresentadas algumas características da IC, seguida de sua cadeia produtiva, segundo a União Nacional da Construção - UNC, e FGV (2006), proporcionando uma visão mais ampla do setor e o posicionamento da IMC nessa estrutura. Com isso, será possível melhor caracterizar a IMC, objeto de estudo desta dissertação.

\subsection{Indústria da construção}

Segundo Dalcul (1994), a IC é considerada um dos mais importantes setores industriais, por ser responsável pelas atividades de vários outros setores. Possui diversas classes de produtos, abrange desde a atividade de construção de grandes obras ou de hidrelétricas, denominada construção pesada, à de edificações. Trata-se, por isso, de difícil caracterização econômica e, conseqüentemente, causadora de imponderáveis obstáculos quando submetida à análise, além da escassa informação sistematizada.

Antes de iniciar com a caracterização do setor, vale ressaltar que o presente trabalho irá focar nos insumos necessários para a construção de edifícios, ou seja, a produção de prédios residenciais e comerciais. Por essa razão, será feita a caracterização da indústria da construção, excluindo-se maiores discussões sobre a indústria da construção pesada.

Esse setor difere bastante da indústria de transformação, tendo como diferença chave seu produto: fixo, imóvel e feito especificamente para cada consumidor (SOUZA, 2004; DULAIMI, 2005; DALCUL, 1994). Outra diferença é que a decisão do consumidor de comprar o produto na construção é baseada no conceito do produto final e não no produto em si. Em tese, isso deveria proporcionar que o produto fosse desenvolvido de acordo com as expectativas do consumidor, todavia não é o que acontece na prática (DULAIMI, 2005).

Pavitt (1984) apresenta uma classificação para o setor da IC, porém direcionada para a construção de habitações, que parece ser bastante adequada para caracterização da indústria da construção de edificações. O autor denomina as empresas desse setor como "empresas 



com um P\&D interno fraco e pouco investimento em vantagens tecnológicas, as quais são mais procuradas quando desejam a redução de custos. Direcionam seus investimentos no desenvolvimento de habilidades profissionais, projetos, marca e propaganda. Conforme tal classificação, a maior parte das inovações nesse setor é proveniente dos seus fornecedores de equipamentos e materiais, e, em alguns casos, de pesquisas financiadas e/ou realizadas por grandes clientes e pelo governo. A inovação no processo produtivo também ocorre por meio da aquisição de processos desenvolvidos por outras empresas.

Porém, consoante Agopyan (1999), a construção no Brasil não é pior que a desenvolvida em outros países e, nesse sentido, ressalta três aspectos fundamentais para industrialização do setor: a mão-de-obra, que em geral é pouco qualificada ou até mesmo sem qualificação; os materiais e os componentes, que devem ser especificados e comprados por profissionais e não por leigos; e os equipamentos, que devem auxiliar o trabalhador no melhor desenvolvimento de seu trabalho. Na realidade, possui baixo grau de modernização, abriga a maior faixa de mão-de-obra desqualificada do país e possui alto índice de desperdício e perdas. (DA CAMARA; BERGAMASCO, 2002; 2005; LINO, 2005).

Diante disso, como tentativa de caracterização da IC, pode-se, resumidamente, dizer que esta se distingue pela: baixa produtividade; precária organização da produção; incipiente base técnica e imprevisibilidades de tempos e custos. Essas características atualmente ainda estão bem presentes na IC, porém as iniciativas pela mudança dessa realidade são inúmeras. Segundo Dalcul (1994)

\footnotetext{
As empresas de construção civil lutam, incessantemente, para que seu processo produtivo se torne menos complexo e para diminuir os atrasos na execução de obras, desperdícios de materiais e principalmente, o índice de rotatividade aliado à falta de qualificação da mão-de-obra.
}

A partir de pesquisa realizada no setor da indústria da construção do Rio Grande do Sul, Dacul constatou que, para melhorar a qualidade e aumentar a produtividade, as empresas devem identificar inovações tecnológicas que possam ajudar no seu desenvolvimento quanto a equipamentos, processos, serviços e a organização do trabalho em geral.

\footnotetext{
1 "Supplier dominated."
} 
Agopyan (2005, p. 67) afirma que com o fim da Segunda Grande Guerra, a construção civil começou a evoluir, saindo de processos construtivos com forte embasamento empírico e dependentes de mão-de-obra com perfil artesanal e com poucas opções de materiais e componentes, para uma “indústria moderna, ágil e competente”. Foi então na década de 60 que a construção civil passou a investir em pesquisa e desenvolvimento.

Devido às características próprias da IC, as teorias modernas da qualidade tiveram que ser adaptadas para este setor. O conceito de qualidade deixou de ser uma simples verificação final do produto ou sistema e a sua confrontação com o especificado, para uma adequação às exigências dos usuários (AGOPYAN, 2005; ROCHA LIMA, [1997]). Essa mudança proporcionou a ampliação das opções para construir, com a introdução de novos materiais, componentes e sistemas. O setor foi bastante criativo e desenvolveu o conceito de qualidade evolutiva, com etapas prévias para se obter a certificação mais completa.

Essa idéia foi adotada no país pelo Programa QUALIHAB ${ }^{2}$, do CDHU de São Paulo, e pelo Programa Brasileiro de Qualidade e Produtividade do Habitat - PBQP-H, ampliando consideravelmente o número de produtos e empresas certificadas (AGOPYAN, 2005, p. 74). Segundo Souza (2004, p. 203), o PBQP-H foi o grande indutor da competitividade e qualidade no setor da construção no Brasil. Como conseqüência desse processo de transformações no cenário econômico, houve um desenvolvimento integrado de toda a cadeia produtiva (SILVA, 2005). Os diversos segmentos da IC se organizaram melhor, a interação da cadeia produtiva teve que ser implementada e aperfeiçoada, e a relação com os usuários/clientes melhorou sensivelmente.

A adesão ao PBQP-H, por exemplo, prevê uma capacitação gradativa nos diversos níveis de qualidade envolvendo uma lista de serviços e materiais a serem controlados, sendo necessária uma consultoria, especializada no setor de qualidade, para executá-la. A certificação dessas empresas, após a capacitação, deve ser feita por organismo credenciado ao PBQP-H.

No sentido documental a normalização melhorou, porém o grande problema é sua aplicação, fiscalização e monitoramento (CARDOSO, 2005). Há exigências legais, mas a manutenção de todo esse processo só será possível com a conscientização do consumidor, das

\footnotetext{
${ }^{2}$ Programa da Qualidade da Construção Habitacional (CDHU, 2007).
} 
universidades, da associação (ambiente organizacional) e das empresas. Outro entrave para as empresas construtoras é a qualidade dos materiais de construção disponíveis no mercado brasileiro.

Passa-se então a perceber que a inovação tecnológica na construção civil não depende somente de fatores intrínsecos aos canteiros, mas também à melhoria do ambiente de negócios e à união dos elos que compõem a cadeia produtiva. Para isso seria necessário melhorar esse ambiente no qual atuam os construtores e trabalhar para a integração racionalizada da cadeia produtiva da IC, pois não é possível pensar na melhoria da qualidade de obras avaliando, de forma isolada, apenas os fabricantes de materiais, os projetistas ou os construtores.

Um exemplo dessa integração entre os elos da cadeia produtiva da construção é a Comunidade da Construção, movimento nacional dos Sinduscons de 17 pólos $^{3}$ e a Associação Brasileira de Cimento Portland - ABCP (ABCP, 2008). A Comunidade da Construção é um movimento lançado pela ABCP em 2002 que “[...] integram cerca de 200 construtoras, 15 instituições de ensino, cerca de 20 entidades representativas de construtores, engenheiros e arquitetos, além de diversas indústrias e entidades de formação profissional e empresarial” (ABCP, 2008).

Um fato que acompanha esse processo de evolução dos conceitos da IC é a conscientização de que os clientes podem auxiliar nesse processo de desenvolvimento do setor, fazendo com que as empresas percebam sua importância e passem a proporcionar qualidade superior e serviços melhores para satisfazer suas necessidades e expectativas. Segundo Dulaimi (2005), este fato está bastante presente na IC britânica, porém é algo que deve ser levado em consideração pelo setor de todo o mundo, devido às características peculiares do produto dessa indústria.

Consoante Miozzo e Ivory (2000), a IC britânica tem adotado novas práticas de gerenciamento, mudanças no projeto e novas tecnologias relacionadas com materiais, equipamentos e componentes. No Brasil, essas mudanças iniciaram a partir dos anos 90 que, por meio de profundas transformações no perfil de investimentos estatais e privados na

\footnotetext{
${ }^{3}$ Bauru, Belo Horizonte, Brasília, Campinas, Curitiba, Florianópolis, Fortaleza, Goiânia, Natal, Porto Alegre, Recife, Ribeirão Preto, Rio de Janeiro, Salvador, Uberlândia e Vitória.
} 
construção civil, um novo desafio foi traçado: a evolução tecnológica associada aos processos de gestão da qualidade e desenvolvimento integrado das cadeias produtivas (SOUZA, 2004, p. 202). Isso levou a uma industrialização e normalização do setor.

Agopyan (2005, p. 78) complementa que toda a cadeia produtiva está aperfeiçoando sua gestão. As empresas inserem a inovação tecnológica cada vez mais em suas estratégias competitivas, tendo a indústria de materiais e componentes como uma das principais fontes de desenvolvimento de novas tecnologias (MARTINS, 2002). Uma empresa que tem buscado evoluir, orientando-se para a descoberta de novos mercados, produtos e negócios, é a Tigre. Boechat (2007) afirma que “[...] A partir de 2008, a companhia pretende ser uma das líderes do mercado de acessórios sanitários plásticos voltados para as classes C, D e E. [...] finaliza o desenvolvimento de uma nova marca, específica para essa linha de produtos”.

O item a seguir apresentará a cadeia produtiva da construção.

\subsection{Cadeia produtiva da construção}

Entende-se por cadeia produtiva como o conjunto de atividades, que se articulam progressivamente desde os insumos básicos até o produto final, incluindo distribuição e comercialização, constituindo-se em elos de uma corrente. Os elos que compõem a cadeia produtiva da construção, de acordo com a UNC e a FGV (2006), são os citados a seguir (Ilustração 1): segmentos da indústria que produzem os materiais de construção; segmentos do comércio atacadista e varejista; atividades de prestação de serviços - técnico-profissionais, financeiros, comercialização e locação de imóveis e seguros; indústria da construção. 
Comércio de materiais de construção

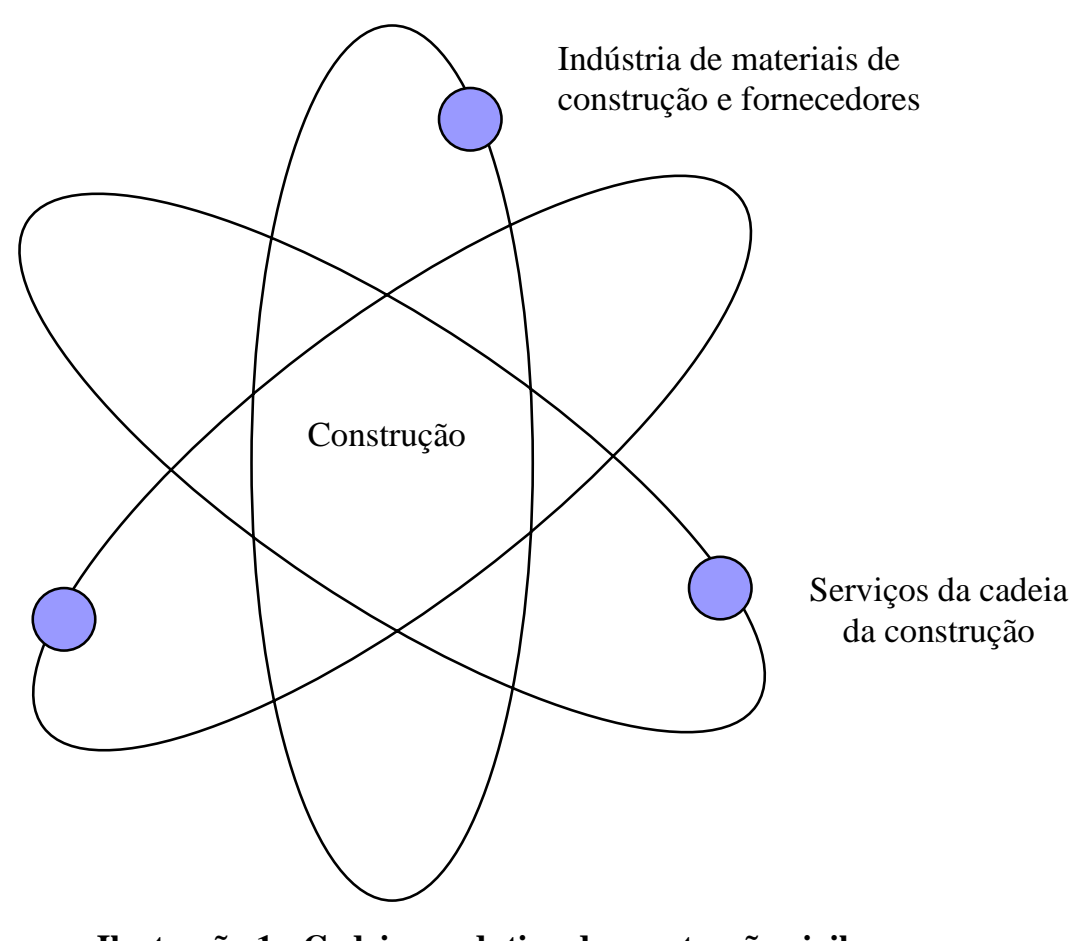

Ilustração 1 - Cadeia produtiva da construção civil FONTE: UNC; FGV, 2006, p. 28.

A partir da Ilustração 1 é possível conhecer os elos, porém, observando-se a Ilustração 2, consegue-se extrair uma visão mais ampla de toda a cadeia, de modo a identificar exatamente onde a indústria de materiais de construção está posicionada. As matérias-primas percorrem caminhos diferentes, aonde vão sendo transformadas e montadas. Existe um complexo processo de produção presente nesta estrutura (ABRAMAT; FGV PROJETOS, 2007a, p. 6).

\footnotetext{
Para construir uma casa ou um edifício, as empresas investem seu capital para empreender o negócio, contratam mão-de-obra e adquirem materiais e serviços que são transformados e montados na obra. Assim, o trabalho de construção adiciona valor aos materiais e serviços, os quais são provenientes de outras empresas. Enquanto consumidores, lidamos com agentes financeiros e de venda na negociação do imóvel, cada qual ofertando um serviço que agrega valor a este imóvel.
}

Cada material utilizado dentro desse complexo processo de construção de edifícios possui sua própria cadeia produtiva, como apresentado na Ilustração 2. Como é o caso, por exemplo, dos materiais elétricos que primeiramente passam pela etapa de extração do cobre, siderurgia, depois são transformados em materiais elétricos. Igualmente, todos os outros envolvem várias etapas de transformação. 


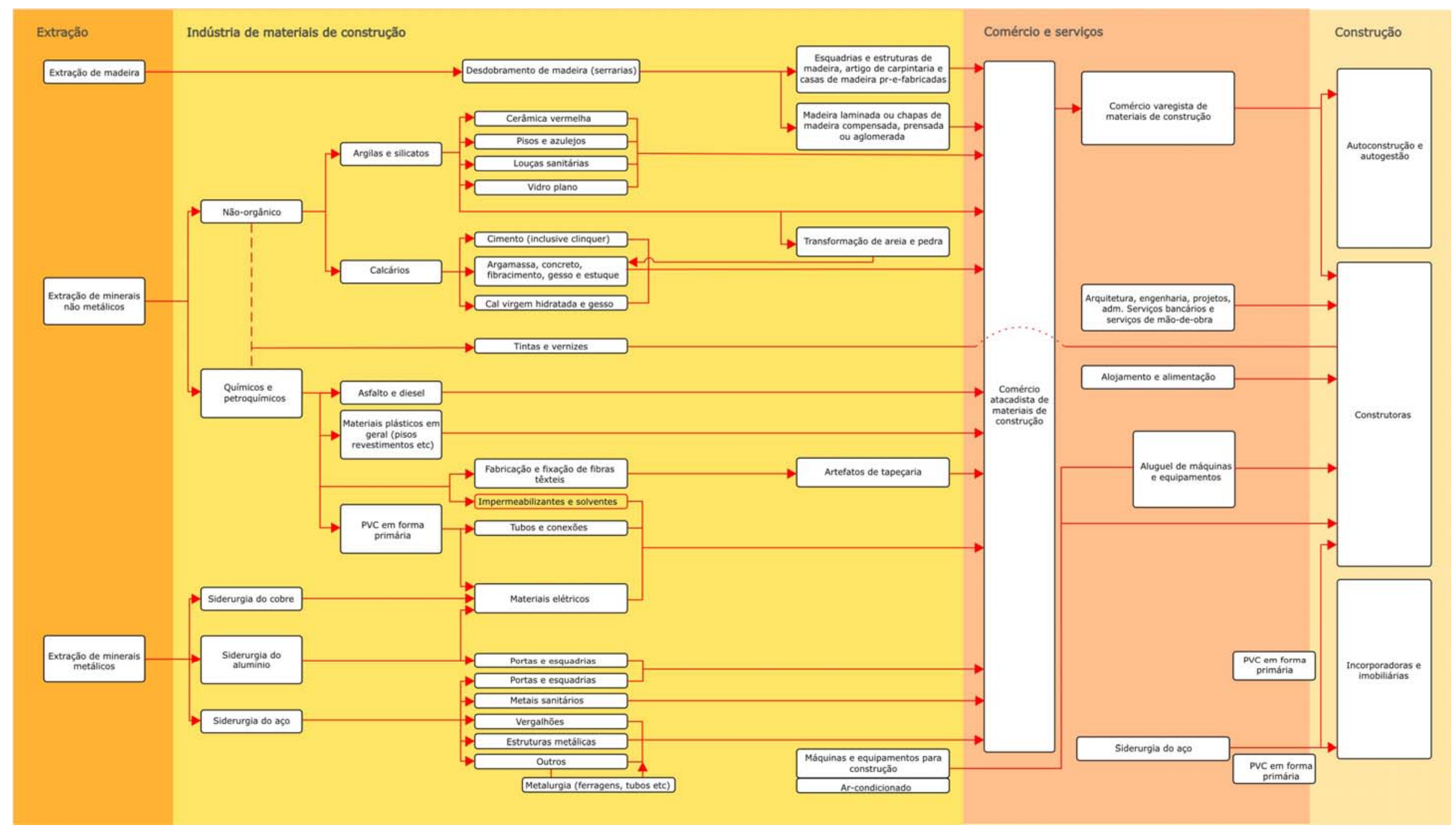

Ilustração 2- Planta da cadeia da construção FONTE: ABRAMAT; FGV PROJETOS, 2007a, p. 11. 
A Abramat e a FGV Projetos (2007b) afirmam que toda a cadeia produtiva da construção iniciou o ano com expectativas positivas, conseqüência da expansão do crédito imobiliário e do anúncio do Programa de Aceleração do Crescimento (PAC), do governo federal, conforme faturamento anual da IMC, que vem aumentando a cada ano, mesmo com a elevação média dos preços dos materiais de construção. As vendas do comércio varejista caminham no mesmo ritmo da indústria de materiais. Em janeiro de 2006, o faturamento nominal foi de R\$ 5.332,55 bilhões, subindo para R\$ 6.382,73 bilhões em junho de 2007. O Quadro 2 apresenta dados referentes ao valor adicionado - $\mathrm{VA}^{4}$ de toda a cadeia da construção.

Quadro 2 - Valor adicionado da cadeia produtiva da IC

\begin{tabular}{|c|c|c|}
\hline CADEIA PRODUTIVA & VA & \% DO VA DA CADEIA \\
\hline $\begin{array}{c}\text { Construção } \\
\text { (R\$ bilhões) }\end{array}$ & 60,1 \\
\hline $\begin{array}{c}\text { Indústria de materiais de } \\
\text { construção }\end{array}$ & $84.868,0$ & 24,7 \\
\hline $\begin{array}{c}\text { Fornecedores da indústria de } \\
\text { materiais }\end{array}$ & $34.810,3$ & 6,4 \\
\hline $\begin{array}{c}\text { Serviços da cadeia de construção } \\
\text { Comércio de materiais de } \\
\text { construção } \\
\text { TOTAL }\end{array}$ & $9.008,8$ & 3,6 \\
\hline
\end{tabular}

FONTE: ABRAMAT; FGV PROJETOS; 2007a, p. 17.

O percentual de toda a cadeia produtiva da construção no PIB é de 8,47\%. A indústria de materiais de construção respondeu por 2,1\% do PIB em 2004, enquanto a indústria da construção propriamente dita produziu $5,1 \%$ da riqueza nacional (ABRAMAT; FGV PROJETOS, 2007a).

Outro grande número da cadeia é o de pessoas ocupadas em todo o setor da construção, o qual vem registrando taxas de crescimento expressivas (Quadro 3). Associado a isso, tem-se um alto número de pessoas na informalidade (aproximadamente 50\% dos trabalhadores) e, por conseguinte, uma baixa produtividade da mão-de-obra.

\footnotetext{
4 Valor adicionado "equivale à soma dos lucros e dos salários e juros pagos pela empresa fabricante" (DICIONÁRIO AURÉLIO, 1999), ou seja, quanto a entidade (setor) contribuiu para a formação do PIB do país.
} 


\begin{tabular}{|l|c|c|c|}
\multicolumn{4}{|c|}{ Quadro 3 - Emprego na IMC e IC } \\
\begin{tabular}{|c|c|c|c|}
\hline \multirow{2}{*}{ ANO } & MÊS & \multicolumn{2}{|c|}{ EMPREGO } \\
& & IMC & IC \\
$\mathbf{2 0 0 6}$ & Janeiro & 585.029 & 1.474 .031 \\
$\mathbf{2 0 0 7}$ & Maio & 622.858 & 1.642 .220 \\
& Junho & 625.183 & - \\
\hline
\end{tabular}
\end{tabular}

FONTE: ABRAMAT; FGV PROJETOS, 2007b.

É importante ressaltar também que a dimensão do ônus dos impostos sobre a cadeia da construção se caracteriza ainda como um fator que afeta a competitividade do setor, refletindo sobre seu potencial de crescimento. A cadeia da construção recolheu $R$ \$31,8 bilhões em tributos em 2004, sendo R \$ 17,3 bilhões pagos pela indústria da construção e R\$ 14,5 bilhões pela indústria de materiais de construção e os demais segmentos da cadeia (ABRAMAT; FGV PROJETOS, 2007b).

Diante desses dados, percebe-se a importância do setor, refletindo também seu crescimento nos últimos meses. O item a seguir contém as principais características referentes à IMC, relatando sua evolução no passar dos anos.

\subsection{Indústria de materiais de construção}

A partir da Ilustração 2, é possível observar que há diferentes formas de se abordar uma cadeia produtiva de materiais de construção, como, por exemplo, colocando em seu centro o agente sob cuja coordenação o processo de produção do bem final ocorre. Dessa forma, a indústria de materiais é composta por oito cadeias de produção (ABRAMAT; FGV PROJETOS, 2007a): madeiras; argilas e silicatos; calcários; materiais químicos e petroquímicos; siderurgia; metalurgia de não-ferrosos; materiais elétricos; e máquinas e equipamentos.

Outra classificação é feita por Cardoso et al (2002), segmentando-a conforme a natureza das operações que geram no canteiro de obras e também pelo grau de serviços acoplados ao seu fornecimento:

- Materiais básicos - são todos aqueles que geram atividades de conformação e não possuem serviços acoplados ao seu fornecimento. Ex.: aglomerantes (cimento, cal), agregados (areia, pedra britada), tijolos, blocos, madeira, etc.; 
- $\quad$ Componentes - geram operações de associação e/ou montagem e podem ter algum grau de serviços incorporados ao seu fornecimento. Ex.: esquadrias, componentes de instalações elétricas e hidráulicas, etc.;

- $\quad$ Elementos e subsistemas - geram, predominantemente, operações de montagem, com alto grau de serviços acoplados. Ex.: Kits de instalações, banheiro pronto, fachadas pré-moldadas, etc.

Segundo Abramat e FGV Projetos (2007a), a receita líquida com produtos e serviços da indústria de materiais e equipamentos para a construção somou R\$ 75,5 bilhões em 2004. Tendo os seguintes segmentos como os principais: siderurgia (12,3\%); cimento (11,3\%); produtos cerâmicos (8\%); produtos de concreto, cimento e fibrocimento (6,3\%); e máquinas e equipamentos para a construção (6\%). Somente a indústria de materiais de construção teve receitas líquidas de R \$67,3 bilhões em 2004. Os segmentos com produtividade média mais elevada são aqueles mais capital-intensivos: siderurgia, cimento, produção de ferro-gusa e ferro-liga e a metalurgia de metais não-ferrosos (alumínio e cobre), os quais contrastam com a produtividade mais reduzida da fabricação de produtos cerâmicos e desdobramento de madeira, por exemplo.

O Quadro 4 apresenta o valor adicionado e o pessoal ocupado na IMC, em cada subsetor, conforme Abramat e FGV Projetos (2007a).

Quadro 4 - Valor adicionado e pessoal ocupado na IMC, 2004

\begin{tabular}{|c|c|c|}
\hline SEGMENTOS & VA (R\$ milhão) & $\begin{array}{l}\text { PESSOAL } \\
\text { OCUPADO }\end{array}$ \\
\hline Indústrias extrativas & $1.511,2$ & 44.667 \\
\hline Extração de pedra, areia e argila & $1.511,2$ & 44.667 \\
\hline Indústrias de transformação & 33.299,1 & 551.400 \\
\hline Desdobramento de madeira & 552,2 & 21.840 \\
\hline $\begin{array}{l}\text { Fabricação de produtos de madeira, cortiça e material trançado - } \\
\text { exceto móveis }\end{array}$ & $1.385,7$ & 37.551 \\
\hline Fabricação de tintas, vernizes, esmaltes, lacas e afins & $1.270,2$ & 14.030 \\
\hline Fabricação de produtos de material plástico & 909,6 & 20.141 \\
\hline Fabricação de vidro e de produtos do vidro & 800,3 & 8.484 \\
\hline Fabricação de cimento & $5.172,8$ & 16.266 \\
\hline $\begin{array}{l}\text { Fabricação de artefatos de concreto, cimento, fibrocimento, gesso e } \\
\text { estuque }\end{array}$ & $1.669,8$ & 63.632 \\
\hline Fabricação de produtos cerâmicos & $3.067,1$ & 123.309 \\
\hline $\begin{array}{l}\text { Aparelhamento de pedras e fab. de cal e de outros produtos de } \\
\text { minerais não-metálicos }\end{array}$ & $1.568,1$ & 33.555 \\
\hline Produção de ferro-gusa e de ferro-liga & $1.088,1$ & 5.226 \\
\hline Siderurgia & $4.688,1$ & 13.269 \\
\hline
\end{tabular}




\begin{tabular}{|l|c|c|}
\hline Fabricação de tubos - exceto em siderúrgicas & 601,8 & 5.828 \\
\hline Metalurgia de metais não-ferrosos & $1.290,1$ & 6521 \\
\hline Fabricação de estruturas metálicas e obras de caldeiraria pesada & $1.609,6$ & 65.662 \\
\hline $\begin{array}{l}\text { Fabricação de tanques, caldeiras e reservatórios metálicos } \\
\text { Fabricação de artigos de cutelaria, de serralheria e ferramentas } \\
\text { manuais }\end{array}$ & 127,7 & 2.682 \\
\hline $\begin{array}{l}\text { Fabricação de produtos diversos de metal } \\
\text { Fabricação de motores, bombas, compressores e equipamentos de } \\
\text { transmissão }\end{array}$ & 569,3 & 11.244 \\
\hline $\begin{array}{l}\text { Fabricação de máquinas e equipamentos de uso geral } \\
\text { Fabricação de máquinas e equipamentos de usos na extração } \\
\text { mineral e construção }\end{array}$ & 792,2 & 16.859 \\
\hline $\begin{array}{l}\text { Fabricação de equipamentos para distribuição e controle de energia } \\
\text { elétrica }\end{array}$ & $\mathbf{8 7 5 , 8}$ & 9.875 \\
\hline $\begin{array}{l}\text { Fabricação de fios, cabos e condutores elétricos isolados } \\
\text { Total - Materiais e equipamentos de construção }\end{array}$ & $1.676,6$ & 16.690 \\
\hline Indústria de materiais de construção & 952,8 & 21.577 \\
\hline
\end{tabular}

FONTE: ABRAMAT; FGV PROJETOS, 2007a, p. 19.

Em 2007, houve uma geração de quase 30 mil novos postos de trabalho em média, registrando um crescimento de 5\% em relação a 2006 (ABRAMAT; FGV PROJETOS, 2008). Destes, 11,8 mil foram do segmento de fabricação de estruturas metálicas, 7,9 mil da fabricação de artefatos de cimento e fibrocimento e 5,6 mil da fabricação de produtos cerâmicos (Quadro 5). A maioria foi criada nas regiões Sudeste e Sul do país, com destaque para São Paulo, Minas Gerais e Paraná (Quadro 6).

Quadro 5 - Segmentos que liberaram a geração de emprego em 2007
\begin{tabular}{|l|r|}
\multicolumn{1}{|c|}{ Segmentos da indústria de materiais } & $\begin{array}{c}\text { Empregos } \\
\text { gerados }\end{array}$ \\
\hline Produtos de madeira, cortiça e material trançado & -2.135 \\
\hline Desdobramento de madeira & -1.530 \\
\hline Produção de ferro-gusa e de ferro-liga & 213 \\
\hline $\begin{array}{l}\text { Motores, bombas, compressores e equip. de } \\
\text { transmissão }\end{array}$ & 425 \\
\hline Cimento & 471 \\
\hline Metais não-ferrosos & 496 \\
\hline Tanques, caldeiras e reservatórios metálicos & 500 \\
\hline Artigos de serralheria e de ferramentas manuais & 647 \\
\hline Siderurgia & 819 \\
\hline Vidro e produtos de vidro & 836 \\
\hline Tubos de ferro e aço & 873 \\
\hline Tintas, vernizes, esmaltes e lacas & 1.048 \\
\hline Produtos diversos de metal & 2.006 \\
\hline Aparelhamento de pedras e fabricação de cal & 2.064 \\
\hline Máquinas e equipamentos de uso geral & 2.442 \\
\hline Máquinas e equipamentos de uso na construção & 2.458 \\
\hline Produtos de plástico & 2.683 \\
\hline Fios, cabos e condutores elétricos isolados & 2.709 \\
\hline Extração de pedra, areia e argila & 2.884 \\
\hline Equipamentos para distribuição de energia elétrica & 2.987 \\
\hline
\end{tabular}




\begin{tabular}{|l|r|}
\hline Produtos cerâmicos & 5.551 \\
\hline Artefatos de concreto, cimento, fibrocimento e gesso & 7.927 \\
\hline Estruturas metálicas & 11.833 \\
\hline
\end{tabular}

FONTE: ABRAMAT; FGV PROJETOS, 2008, p. 2.

Quadro 6 - Geração de empregos por estados em 2007

\begin{tabular}{|l|r|}
\hline \multicolumn{1}{|c|}{ Estados do Brasil } & $\begin{array}{c}\text { Empregos } \\
\text { gerados }\end{array}$ \\
\hline Amazonas & -151 \\
\hline Acre & -56 \\
\hline Alagoas & -45 \\
\hline Sergipe & -15 \\
\hline Amapá & -1 \\
\hline Roraima & 1 \\
\hline Distrito Federal & 44 \\
\hline Tocantins & 85 \\
\hline Mato Grosso do Sul & 106 \\
\hline Piauí & 160 \\
\hline Rondônia & 194 \\
\hline Paraíba & 274 \\
\hline Pernambuco & 358 \\
\hline Rio Grande do Norte & 361 \\
\hline Pará & 521 \\
\hline Maranhão & 533 \\
\hline Bahia & 662 \\
\hline Goiás & 714 \\
\hline Ceará & 733 \\
\hline Mato Grosso & 820 \\
\hline Espírito Santo & 1.234 \\
\hline Santa Catarina & 1.303 \\
\hline Rio Grande do Sul & 1.976 \\
\hline Rio de Janeiro & 2.104 \\
\hline Paraná & 2.226 \\
\hline Minas Gerais & 6.080 \\
\hline São Paulo & 9.533 \\
\hline ONTE: ABRAMAT; FGV PROJETOS & p. 2 \\
\hline
\end{tabular}

FONTE: ABRAMAT; FGV PROJETOS, 2008, p. 2.

Note-se que as diferenças entre os setores são bastante atenuantes, o que leva Garcia et al (1997) ressaltarem a falta de organização do setor e a grande quantidade de materiais com características bastante divergentes. No entanto, as empresas em geral têm cada vez mais se destacado no desenvolvimento de novas tecnologias e na sua transferência para empresas construtoras (MARTINS, 2002). Essas indústrias têm iniciado um processo de readequação de suas estruturas, procurando estabelecer e seguir normas técnicas, que regulamentem e padronizem seus produtos.

Um fenômeno de destaque é o processo de redução de cópias de produtos estrangeiros com a finalidade de incrementar o design próprio, aumentando o número de mão-de-obra qualificada, o que, conseqüentemente, eleva a produtividade, a modernização da gestão 
empresarial e a gestão baseada na inovação através do emprego de técnicas organizacionais avançadas. Ainda são poucas as indústrias conscientes desse novo cenário, visto que para isso é preciso que sejam realizadas mais pesquisas no setor, com o intuito de agregar conhecimento e apresentar práticas de sucesso para serem replicadas, testadas e aperfeiçoadas.

Veja-se o caso da alvenaria que, para a realização de ensaios técnicos dos produtos é necessária a construção de um protótipo em escala real em alvenaria estrutural. Nesse sentido, foi aberta uma nova linha de pesquisa no Núcleo de Ensino e Pesquisa da Alvenaria Estrutural - NEPAE ${ }^{5}$, cujo objetivo é representar o modelo real através de um molde em tamanho reduzido que apresente similaridade no comportamento estrutural (CAMACHO, 2005, p. 44). Dessa forma, tem se efetivado parcerias com empresas para apoio técnico, otimização de produtos e procedimentos, além do desenvolvimento de pesquisas em conjunto.

As empresas da IMC são produtoras de bens de capital, de produção e de consumo, trabalhando sob condições de competitividade mais amplas, pois se constituem por um conjunto de outras indústrias distribuídas pelos vários setores da economia, fornecedoras de insumos para a indústria de processos e seus clientes finais. De acordo com Pavitt (1984), se caracterizam como um setor de produção intensiva, onde o mercado é bastante sensível às mudanças de preço. Pavitt (1984) complementa que são os grandes clientes dessas empresas que realizam os testes de seus produtos e suas facilidades, como também desenvolvem recursos para a utilização de equipamentos especializados.

Dalcul (1994) indica que a indústria de materiais e componentes de construção passou por alterações impulsionadas tanto pela diversidade de materiais e componentes produzidos, quanto pela tecnologia utilizada nesse setor. No entanto, esse impulso ocorreu, no princípio, de uma forma não direcionada para a racionalização em si, mas no sentido de cobrir as necessidades quantitativas que se impuseram naquele momento.

\footnotetext{
${ }^{5}$ O NEPAE foi fundado em junho de 2000 por um grupo de professores e alunos que trabalhavam na linha de pesquisa 'alvenaria estrutural' no programa de pós-graduação em engenharia civil da UNESP, Universidade Estadual Paulista “Júlio de Mesquita Filho” (NEPAE, 2006).
} 
Atualmente, as empresas líderes têm procurado se adequar às normas técnicas, reduzir a cópia de produtos estrangeiros em favor do desenvolvimento de design próprio, treinar e elevar a qualificação da mão-de-obra como instrumento de elevação de produtividade e modernizar a gestão empresarial e a gestão da qualidade através do emprego de técnicas organizacionais avançadas. Porém, ainda existe um baixo grau de conscientização dessas empresas (GARCIA et al, 1997).

Essa indústria, como foi observado, é bastante diversificada, o que coloca o Brasil em vantagem no panorama internacional. A aplicação da ciência e da engenharia dos materiais para o estudo de materiais de construção civil foi um grande passo do setor, segundo Agopyan (2005, p. 76), permitindo uma melhor compreensão do comportamento dos materiais empregados. Foi possível, com isso, melhorar as características e propriedades de diversos materiais já existentes, desenvolver novos materiais, bem como aplicá-los nas obras de maneira mais correta, podendo assim reduzir problemas e acelerar os trabalhos. Os estudos avançaram muito nesse segmento, e ao visitar um protótipo num laboratório de desenvolvimento, pode-se prever que o seu progresso continuará sendo intenso.

Martins (2002) assevera que as indústrias de materiais e componentes têm se destacado no desenvolvimento de novas tecnologias e assumem um importante papel no processo de transferência de uma nova tecnologia para as empresas construtoras. O mesmo autor complementa dizendo que uma forte tendência do momento é que o setor deverá dar garantia do desempenho do produto aplicado na obra e não apenas a garantia do produto na embalagem, ou seja, a realização de testes nos canteiros de obras.

Em função dessa perspectiva atual, as empresas estão cada vez mais se aprimorando através de estratégias inovadoras, programas de qualidade total, certificações ISO, reengenharia, investimentos em tecnologia e, também, concentrando suas ações em atender melhor às exigências dos seus clientes, buscando atingir padrões mundiais (MARTINS, 2002). A normalização, segundo a ABNT (2006), é uma “atividade que estabelece, em relação a problemas existentes ou potenciais, prescrições destinadas à utilização comum e repetitiva com vistas à obtenção do grau ótimo de ordem em um dado contexto”.

Isso tem exigido das empresas verdadeiras redefinições de sua cadeia de valores, visando atingir vantagens competitivas, em longo prazo, no mercado. Apesar das estratégias das 
empresas líderes, ainda existe baixo grau de conscientização das empresas quanto à necessidade de: produzir em conformidade com as normas técnicas; reduzir a cópia de produtos estrangeiros em favor do desenvolvimento de design próprio; treinar e elevar a qualificação da mão-de-obra como instrumento de elevação de produtividade; modernizar a gestão empresarial e a gestão da qualidade através do emprego de técnicas organizacionais avançadas; e utilizar indicadores gerenciais e de competitividade (MARTINS, 2002).

No tocante ao desperdício de materiais, a IMC procurou inovar, no sentido desenvolver produtos mais fáceis de manusear. Entretanto, recentemente surgiu o conceito de sustentabilidade na construção, afetando toda a cadeia produtiva. A preocupação com o desenvolvimento de produtos sustentáveis surgiu tanto por exigências governamentais, e ambientais, como também por parte do mercado consumidor. Isso é observado por Coelho (2007, p. 82), quando indica que no momento da escolha de qual material utilizar em uma construção, leva-se em consideração desde a estética à preocupação com, por exemplo, o consumo de água.

A sustentabilidade hoje é um tema bastante discutido e que merece atenção especial da IMC, já que a atividade que mais consome matérias-primas é a IC. "Estima-se que 50\% dos recursos materiais extraídos da natureza estão relacionados à atividade de construção, e mais de 50\% da produção de resíduos provêm do setor da construção” (TORGAL; JALALI, 2007). São diversos os estudos que apresentam soluções para a IC e IMC. Alguns indicam que o ideal seria a incorporação, pela IMC, de resíduos de outras indústrias, como também aumentar a vida útil do produto.

Torgal e Jalali (2007) asseguram que "Materiais produzidos a partir de resíduos, com elevado nível de reciclagem, mais duráveis, que incorporem menos energia ou que sejam escolhidos mediante uma análise do seu ciclo de vida, constituem soluções que contribuem para uma construção sustentável”. Exemplos de produtos que incorporam o conceito de desenvolvimento sustentável são a torneira automática, que é 20\% mais econômica que a convencional; a torneira eletrônica, 40\%; e a válvula de descarga automática, que reduz em $50 \%$ o valor da conta de água (COELHO, p. 82, 2007). 


\subsection{Mercado e relações de mercado}

Segundo Kotler (2000), a grande maioria dos fabricantes não vende os seus produtos diretamente aos consumidores finais. Para se chegar até ele existem diversos intermediários realizando diferentes funções, o que constitui o canal de distribuição da empresa fabricante. “As mercadorias volumosas, como materiais de construção, precisam de canais que reduzam a distância de embarque e manuseio no transporte do produtor ao consumidor” (PROENÇA, 2007).

Como já foi abordado anteriormente, esse segmento possui um elevado grau de informalidade que está assaz relacionado à informalidade do próprio núcleo da cadeia. Conforme Proença (2007), isso se deve ao fato de a demanda, principalmente pelos segmentos informais da construção de obras de reparos e manutenção e autoconstrução, partir de pequenos depósitos de bairros, alguns localizados em favelas, ou de áreas rurais mais afastadas.

A maior parte da demanda por materiais de construção é comercializada por empresas atacadistas e varejistas, e o restante é atendido diretamente pelas próprias indústrias. A procura por materiais para as obras informais acontece, em sua maioria, junto ao comércio varejista especializado, enquanto que as construtoras formais dirigem-se ao comércio atacadista ou diretamente às indústrias (ABRAMAT; FGV PROJETOS, 2007a, p.8).

A Anamaco, Associação Nacional dos Comerciantes de Material de Construção, juntamente com o Ibope Solution, realizou uma pesquisa, em 2006, que traça o perfil do varejo de materiais de construção do Brasil, o qual conta com cerca de 105 mil lojas. Do total, estimase que $52 \%$ estejam na região Sudeste; $80 \%$ têm até $1.000 \mathrm{~m}^{2}$ de área, portanto, sejam de pequeno porte; 77\% das empresas têm apenas uma loja; 68\% comercializam até 5.000 itens e 59\% têm, no máximo, dez funcionários (ANAMACO, 2006).

Consoante Moriconi et al (2006, apud PROENÇA, 2007), o cenário competitivo atual no varejo de materiais de construção é o seguinte:

- $43 \%$ das lojas de material de construção têm como principal categoria de produtos vendidos os materiais básicos (cal, cimento, madeira, aço e areia). 
- O processo de reestruturação do varejo da construção civil, com um movimento de fusões e aquisições, foi acelerado com a entrada dos grupos franceses Leroy Merlin e Castorama.

- As lojas e redes de pequeno e médio porte estão formando redes associativas, para sobreviverem à acirrada concorrência. Com isso, aumentam o poder de negociação com os fornecedores, e dividem as despesas com treinamento e publicidade.

- Alguns problemas que atingem o varejo de material de construção são os altos níveis de estoque, rupturas nas gôndolas e mix de produtos inadequados ao perfil dos consumidores.

- $70 \%$ das vendas no mercado de materiais de construção são realizadas com algum tipo de financiamento (crediário ou cartão).

O setor está se movimentando e procurando cada vez mais aprimorar-se, em busca de um melhor relacionamento com o cliente final.

No item a seguir será apresentada a revisão da literatura feita sobre o tema central desta dissertação, Gestão do Desenvolvimento de Novos Produtos. 


\section{Gestão do Desenvolvimento de Novos Produtos}

\subsection{Projetos de desenvolvimento de novos produtos}

Como apontado por Clark e Wheelwright (1993), a inovação é caracterizada pela mudança tecnológica, em produtos ou em processos. Essas mudanças, dependendo do grau de "novidade”, podem gerar melhorias incrementais (que proporcionam uma alteração pequena nos produtos e processos) ou mudanças radicais (que transformam a maneira de se pensar sobre o uso dos produtos ou processos). A IMC é uma das grandes propulsoras de inovação na IC, devido à grande quantidade de novos produtos que são gerados, e a maior parte são proporcionados pelos fornecedores de equipamentos e matéria-prima.

Baseados nessa classificação, Clark e Wheelwright (1993, p. 104) identificam quatro tipos de projetos de desenvolvimento de produtos e processos: incrementais ou derivativos; plataforma ou próxima geração; radicais ou breakthroughs; e pesquisa e desenvolvimento avançado, como apresentado na Ilustração 3.

- Projetos incrementais ou derivativos - são projetos que melhoram a performance de algumas dimensões do produto, selecionados anteriormente, com a finalidade de atender às necessidades dos diversos segmentos do mercado. São também chamados de projetos de sustentação, pois, por requererem menos recursos, são bastante utilizados para prolongar o ciclo de vida dos produtos.

- Projetos radicais ou breakthroughs - envolvem mudanças significativas no projeto do produto e/ou do processo de produção. Quando bem-sucedido, podem criar uma nova categoria ou família de produtos. Como é o caso do sistema “Light Steel Framing”, proposta de construção, há muito usada nos Estados Unidos, mas nova para o Brasil (JARDIM; CAMPOS, 2005). Alia rapidez com o diferencial competitivo técnico, mercadológico e de negócios.

- Projetos de plataforma ou próxima geração - é a geração de novos “sistemas” de soluções para consumidores, envolvendo mudanças significativas tanto no processo produtivo, quanto no produto, ou mesmo em ambos, mas sem a introdução de novas 
tecnologias ou materiais. Normalmente possuem ciclos de vida longos, devido ao fato de sofrerem modificações incrementais, mantendo-se uma arquitetura básica, que caracteriza a plataforma ${ }^{6}$ ou a linha de produtos $^{7}$. Um exemplo de projeto modular para o desenvolvimento de plataformas é o da indústria automobilística, em que variações de modelo podem ser obtidas para um mesmo chassi, bem como modificações de natureza estética e de conforto em um mesmo modelo (ROZENFELD et al, 2006, p. 263).

- Projetos de desenvolvimento avançado, também denominado Pesquisa e Desenvolvimento - P\&D, são realizados por um grupo de trabalho específico da empresa direcionado para a realização deste tipo de projeto. Tendo como objetivo criar conhecimento, know-how e know-why, os quais possam ser aplicados em projetos específicos de desenvolvimento. Recentemente foi lançado pela empresa Emmeti um sistema de aquecimento de piso que deixa o ambiente com a temperatura desejada, liga e desliga sozinho quando o local está aquecido, permite programação a distância por computador ou celular, dentre outras facilidades.

\footnotetext{
${ }^{6}$ Plataforma, segundo Halman et al (2003, p. 150), não é nem um produto individual, nem a família de produtos, mas a base comum de todos os produtos que pertencem à mesma família de produtos.

${ }^{7}$ Família de produto é a "coleção" de produtos que compartilham as mesmas características (HALMAN et al, 2003, p. 150).
} 


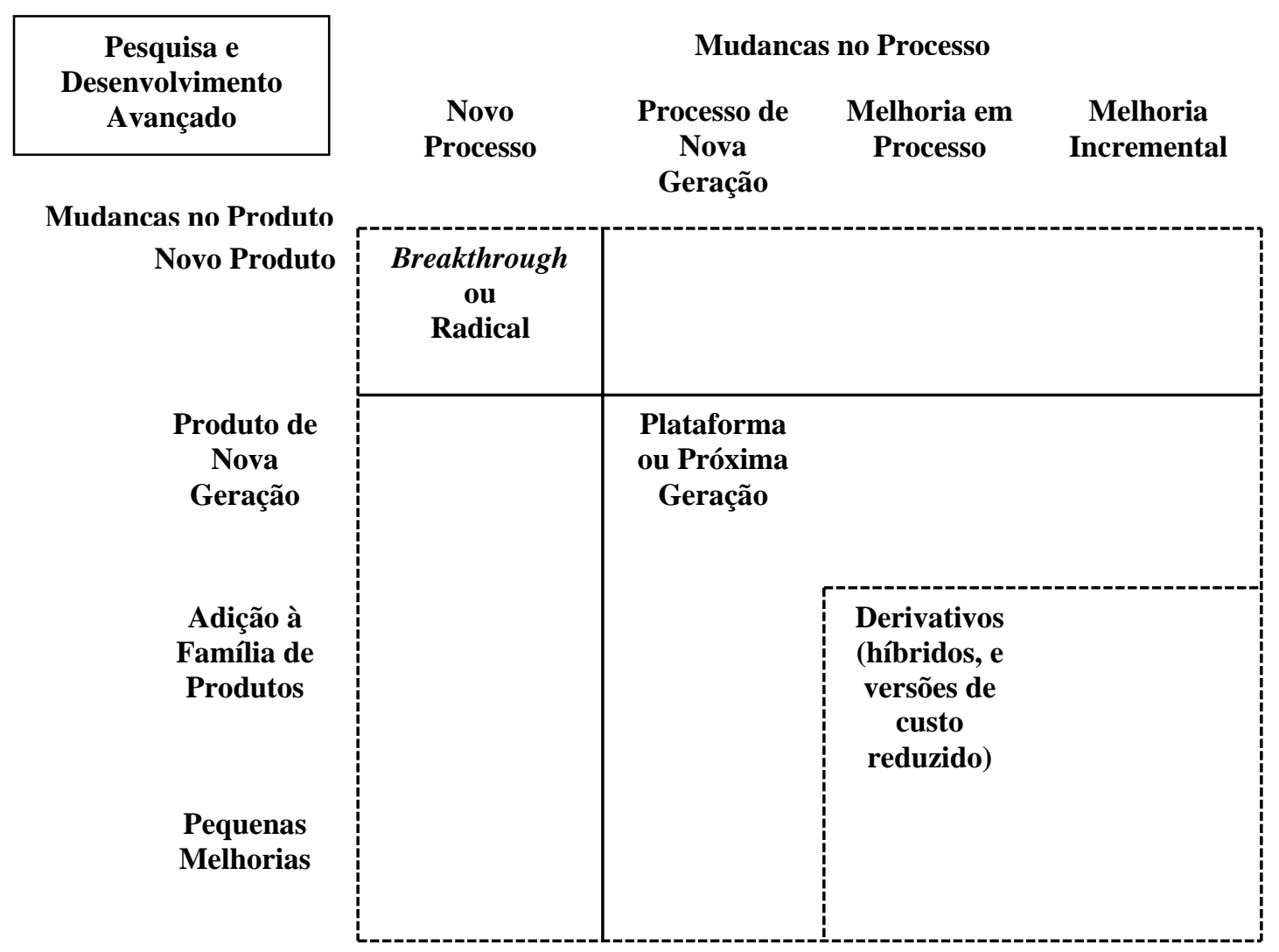

Ilustração 3 - Tipos de projetos de desenvolvimento de produtos e/ou processos FONTE: CLARK; WHEELWRIGHT; 1993, p. 104.

Dentre os tipos de projetos de desenvolvimento indicados por Clark e Wheelwright (1993), Sanderson e Uzumeri (1995, p. 770) indicam que a categoria dos produtos derivativos é muito ampla, por essa razão, os autores subdividiram-na em inovações incrementais e topológicas. A identificação dessas duas categorias foi feita a partir de um estudo realizado pelos autores na empresa Sony, com o caso do walkman e sua família de produtos.

As inovações incrementais caracterizam-se pelas modificações internas, por exemplo, nos circuitos eletrônicos de um walkman, por essa razão são mais difíceis de serem copiadas. Enquanto que nos projetos topológicos as modificações ocorrem nas características externas do produto, adaptando-o aos estilos de vida de cada mercado, dando-lhe funcionalidade através do design. É também denominada de “inovação via design”, segundo Verganti (2007, p. 68). Na IMC, as modificações feitas no design de metais sanitários constituem-se como uma inovação topológica, pois existem diversos tipos de torneiras, com designs diferenciados e, por isso, direcionados para diversos públicos, conforme suas necessidades. 
Essas mudanças podem ser feitas com custos reduzidos e baixo risco. Conforme Sanderson e Uzumeri (1995, p. 771), as empresas devem ser cuidadosas ao utilizarem esse tipo de projeto de desenvolvimento, pois ao acelerarem a freqüência das mudanças topológicas no produto, podem levar a uma "agitação disfuncional do produto" ${ }^{8}$, resultando na necessidade de outros tipos de projeto, que não sejam nem incrementais, nem topológicos.

Para o desenvolvimento de projetos topológicos é necessário que a empresa mantenha uma forte relação com seu mercado consumidor, de forma a ofertar produtos que superem as expectativas de seus clientes. Diante disso, Sanderson e Uzumeri (1995, p. 775) apresentam duas categorias das fontes de mudanças dos projetos incrementais e topológicos: "mudanças guiadas pelos canais e mudanças guiadas pelo modo de vida” ${ }^{9}$. A primeira refere-se ao uso do marketing e da área de vendas para acompanhar as necessidades dos canais de suas principais regiões, por meio de contatos com os canais de distribuição, de surveys realizadas com os consumidores, reuniões com o setor de vendas, dentre outras formas de se manter próximo às reações do mercado consumidor. A segunda baseia-se na maneira de viver de cada consumidor, modificando a cor, o formato, a disposição das funções, caso tenha, no produto, o tamanho. Dessa forma, podem-se atingir diferentes consumidores, com custo e risco reduzido.

Vale ressaltar que esses projetos podem ser desenvolvidos internamente ou pela terceirização da área de P\&D para um estúdio de criação, como é o caso da empresa $\operatorname{IDEO}^{10}$, que desenvolve idéias baseadas no que o público quer, por meio de observações, entrevistas, conversas informais e dados arquivados de projetos anteriores, denominada memória organizacional (HARGADON; SUTTON, 1997).

Toda empresa deve preocupar-se com sua carteira de projetos, para que consiga alocar seus recursos de forma otimizada e consciente, almejando a competitividade a curto, médio e longo prazo. Sanderson e Uzumeri (1995, p. 779) concluem em sua pesquisa que há uma nova forma de vantagem competitiva para as empresas denominada "a habilidade da empresa em gerenciar a evolução de sua família de produtos”11.

\footnotetext{
8 "Dysfunctional 'product churning'."

9 "Channel-driven changes; lifestyle-driven changes."

${ }^{10}$ A IDEO é uma empresa que cria novos conceitos, ou mesmo produtos físicos, por meio de combinações de idéias que antes pareciam sem conexão (HARGADON; SUTTON, 1997, p. 716).

11 "[...] firm's skill at managing the evolution of its product families."
} 
A seguir será apresentado, conforme literatura utilizada na presente pesquisa, como se constitui o gerenciamento desses projetos de desenvolvimento de novos produtos dentro das empresas.

\subsection{Gestão de projetos de desenvolvimento de novos produtos}

Inovação é mais que simplesmente ter boas idéias, é o processo de desenvolvê-las e torná-las úteis. Faz-se muita confusão de inovação com invenção, porém a última é apenas o primeiro passo de um longo processo de transformar uma boa idéia em algo efetivo. Isso exige a existência de um processo muito bem estruturado, possibilitando que a empresa consiga aumentar o retorno do investimento realizado, maiores margens de lucro, expansão do volume de vendas, aumento do valor agregado do produto, redução dos custos e aumento da produtividade. Sem falar dos benefícios de liderança do mercado, de melhor utilização das informações, de renovação e crescimento da organização, ou seja, da melhoria das habilidades da empresa.

Atualmente, desenvolver novos produtos é o grande diferencial no ambiente competitivo das empresas, tendo como prioridade o encurtamento dos prazos de desenvolvimento e lançamento de produtos. Essa necessidade não é limitada a indústrias de alta tecnologia, com gastos significativos em $\mathrm{P} \& \mathrm{D}$, ou onde novos produtos tenham tradicionalmente representado a maior participação nas vendas anuais (SOBRAL, 2003, p. 1). É uma realidade presente em diversas indústrias como da construção civil, de materiais de construção, dentre outras. A Tigre aposta neste ano em um novo segmento, influenciada pelo anunciado boom imobiliário para a classe média baixa e afirma que será uma das líderes do mercado de acessórios sanitários plásticos voltados para esse mercado (BOECHAT, 2007).

Clark e Wheelwright (1993) asseveram que há uma crescente preocupação na melhoria da organização dos processos de gestão de desenvolvimento de novos produtos e processos por parte das empresas. Rozenfeld et al (2006) afirmam que poucas pessoas dentro da empresa possuem uma visão do todo, e os gerentes de projeto, que teoricamente deveriam ter essa visão, não conseguem administrar os conflitos, muitas vezes, se perdendo na abrangência do projeto, o que reforça a necessidade de uma visão unificada do processo. Essa realidade 
acarreta problemas e ineficiências no processo de desenvolvimento de produtos, dificultando a comunicação e integração entre os profissionais e as áreas envolvidas.

Esse panorama pode ser facilmente observado em setores intensos em tecnologia, como informática e telefonia celular, bem como em setores mais tradicionais, como o automobilístico. No entanto, setores como o da IC e da IMC, que somente há pouco tempo conscientizaram-se da importância da regulamentação e normalização de suas atividades, possuem pouca documentação que descreva e padronize o gerenciamento de projetos. Foi somente no ano de 1994, após a estabilização da moeda, que a IC lançou mão de técnicas de gestão da construção (SOUZA, 2004). Essa atitude refletiu-se nos procedimentos de gestão das empresas projetistas, de consultoria e produtores de materiais e componentes. Inseriramse pouco tempo depois os modelos de Gestão da Qualidade. Com isso, há poucos estudos que analisem o processo de GDP desses setores.

A seguir serão apresentados alguns conceitos da GDP, e posteriormente serão indicadas etapas levantadas na literatura que compõem o processo de desenvolvimento, como também as principais decisões e estratégias que as empresas utilizam para gerir todo esse complexo processo.

\subsubsection{Conceituação}

$\mathrm{Na}$ vasta literatura existente, é senso comum o conceito de GDP, o qual diz que é a transformação de uma oportunidade, técnica ou de mercado, em um produto disponível para aquisição (KAMINSKI, 2000; KRISHNAN; ULRICH, 2001; BROWN; EISENHARDT, 1995; CLARK; WHEELWRIGHT, 1993). Embora simples no conceito, na verdade, é um processo complexo, que deve ser executado cuidadosamente.

Segundo Kaminski (2000), a GDP é um conjunto de atividades que envolve quase todos os departamentos da empresa e apresenta como objetivo a transformação de necessidades de mercado em produtos ou serviços economicamente viáveis, ou seja, vai desde o projeto do produto até a sua avaliação pelo consumidor. Já Rozenfeld et al (2006, p. 3) acreditam que o processo de desenvolver produtos consiste 
[...] em um conjunto de atividades por meio das quais se busca, a partir das necessidades do mercado e das possibilidades e restrições tecnológicas, e considerando as estratégias competitivas e de produto da empresa, chegar às especificações de projeto de um produto e de seu processo de produção, para que a manufatura seja capaz de produzi-lo.

É, então, por meio desse processo que a empresa pode criar novos produtos mais competitivos num menor espaço de tempo, com o intuito de ofertar produtos que consigam se manter nessa constante evolução do mercado (ROZENFELD et al, 2006).

A seguir serão apresentadas as diferentes perspectivas de estudo que existem dentro do tema GDP, direcionando a área que será pesquisada nesta dissertação.

\subsubsection{Diferentes perspectivas}

Krishnan e Ulrich (2001) fizeram uma revisão bibliográfica sobre as diversas áreas de estudo da GDP e a partir desta vasta literatura montaram um quadro comparativo com quatro perspectivas comuns existentes nas áreas de projeto e desenvolvimento: marketing, organizações, engenharia e administração da produção. Isso se deve ao fato da GDP caracterizar-se por ser um processo interdisciplinar, depender da aplicação de conhecimentos provindos de diversas disciplinas; e ser interfuncional, ou seja, todas as áreas da empresa estão envolvidas em maior ou menor grau, cada uma com modelos referenciais próprios.

A perspectiva organizacional está focada no estudo de fatores determinantes para o sucesso dos projetos (BROWN; EISENHARDT, 1995). A literatura pertinente à área de marketing e engenharia é bem extensa, geralmente direcionada em pesquisas de marketing, através de surveys, e na engenharia do produto. Por fim, a perspectiva da administração da produção, ainda não muito explorada, estuda a tomada de decisão para dentro dos projetos de desenvolvimento de produtos.

Quadro 7 - Comparação das perspectivas das comunidades acadêmicas de marketing, organizações, engenharia de projeto e administração da produção

\begin{tabular}{|c|c|c|c|c|}
\hline & Marketing & Organizações & $\begin{array}{l}\text { Engenharia de } \\
\text { Projeto }\end{array}$ & $\begin{array}{l}\text { Administração da } \\
\text { Produção }\end{array}$ \\
\hline $\begin{array}{l}\text { Perspectiva do } \\
\text { produto }\end{array}$ & $\begin{array}{l}\text { Um produto é um } \\
\text { conjunto de } \\
\text { atributos. }\end{array}$ & $\begin{array}{l}\text { Um produto é um } \\
\text { artefato resultante } \\
\text { de um processo } \\
\text { organizacional. }\end{array}$ & $\begin{array}{l}\text { Um produto é uma } \\
\text { montagem } \\
\text { complexa de } \\
\text { componentes } \\
\text { interconectados. }\end{array}$ & $\begin{array}{l}\text { Um produto é uma } \\
\text { seqüência de } \\
\text { desenvolvimento } \\
\text { e/ou passos do } \\
\text { processo de } \\
\text { produção. }\end{array}$ \\
\hline Métricas Típicas & “Adequado ao & "Sucesso do & "Forma e função" & "Eficiência”" \\
\hline
\end{tabular}




\begin{tabular}{|c|c|c|c|c|}
\hline de desempenho & $\begin{array}{c}\text { mercado" } \\
\text { Participação de } \\
\text { mercado. } \\
\text { Utilidade para o } \\
\text { consumidor } \\
\text { (Algumas vezes } \\
\text { lucros) }\end{array}$ & projeto” & $\begin{array}{l}\text { Desempenho } \\
\text { técnico. } \\
\text { Capacidade de } \\
\text { inovar. } \\
\text { (Algumas vezes } \\
\text { custos diretos) }\end{array}$ & $\begin{array}{c}\text { Custo total. } \\
\text { Nível de serviço. } \\
\text { Tempo de } \\
\text { desenvolvimento. } \\
\text { Utilização da } \\
\text { capacidade } \\
\text { produtiva. }\end{array}$ \\
\hline $\begin{array}{l}\text { Paradigma de } \\
\text { representação } \\
\text { dominante }\end{array}$ & $\begin{array}{c}\text { Utilidade para o } \\
\text { cliente como uma } \\
\text { função dos atributos } \\
\text { do produto. }\end{array}$ & $\begin{array}{c}\text { Sem paradigma } \\
\text { dominante. } \\
\text { Rede organizacional } \\
\text { é usada algumas } \\
\text { vezes. }\end{array}$ & $\begin{array}{c}\text { Modelos } \\
\text { geométricos. } \\
\text { Modelos } \\
\text { paramétricos de } \\
\text { desempenho } \\
\text { técnico. }\end{array}$ & $\begin{array}{l}\text { Diagrama de fluxo } \\
\text { do processo. } \\
\text { Modelos } \\
\text { paramétricos de } \\
\text { desempenho do } \\
\text { processo. }\end{array}$ \\
\hline $\begin{array}{l}\text { Exemplos de } \\
\text { variáveis de } \\
\text { decisão }\end{array}$ & $\begin{array}{c}\text { Níveis de atributos } \\
\text { de produto. } \\
\text { Preço. }\end{array}$ & $\begin{array}{l}\text { Estrutura da equipe } \\
\text { de desenvolvimento } \\
\text { de produto. } \\
\text { Incentivos. }\end{array}$ & $\begin{array}{c}\text { Tamanho do } \\
\text { produto, forma, } \\
\text { configuração, } \\
\text { função, dimensões. }\end{array}$ & $\begin{array}{c}\text { Seqüência e } \\
\text { cronograma do } \\
\text { processo de } \\
\text { desenvolvimento, } \\
\text { ponto de } \\
\text { diferenciação no } \\
\text { processo de } \\
\text { produção. }\end{array}$ \\
\hline $\begin{array}{c}\text { Fatores críticos } \\
\text { de sucesso }\end{array}$ & $\begin{array}{l}\text { Posicionamento do } \\
\text { produto e preço. } \\
\text { Coletar e entender } \\
\text { necessidades dos } \\
\text { clientes. }\end{array}$ & $\begin{array}{c}\text { Alinhamento } \\
\text { organizacional. } \\
\text { Características da } \\
\text { equipe. }\end{array}$ & $\begin{array}{l}\text { Conceito e } \\
\text { configuração } \\
\text { criativa. } \\
\text { Otimização de } \\
\text { desempenho. }\end{array}$ & $\begin{array}{c}\text { Seleção de material } \\
\text { e fornecedores. } \\
\text { Projeto da seqüência } \\
\text { de produção. } \\
\text { Administração do } \\
\text { projeto. }\end{array}$ \\
\hline
\end{tabular}

FONTE: KRISHNAN; ULRICH; 2001, p. 3.

Conforme o Quadro 7, pode-se perceber as sutis diferenças existentes entre as quatro áreas e como estão interligadas, o que torna possível a identificação das principais decisões que uma empresa pode tomar durante o desenvolvimento de um novo produto.

A partir do levantamento realizado por Krishnan e Ulrich (2001), foram também identificadas diferenças significativas existentes entre os artigos, seja na metodologia para análise das empresas, seja no processo de desenvolvimento dos produtos. Mesmo com a grande dificuldade de definição de uma teoria comum a todas as empresas, autores como Clark e Wheelwright (1993), Kaminski (2000), além de Krishnan e Ulrich (2001), dentre outros, encararam o desafio e definiram etapas que auxiliam no processo da GDP.

Porém, a principal contribuição do trabalho realizado por Krishnan e Ulrich (2001) foi a identificação das principais decisões tomadas, intencionalmente ou por acaso, durante as etapas da GDP. Os autores dividem a pesquisa em duas linhas. A primeira, já bem explorada, repleta de excelentes artigos de revisão, está direcionada para a importância de variáveis ambientais e contextuais, como o índice de crescimento do mercado, o ambiente competitivo 
e o nível de suporte do top-management. A segunda, foco da pesquisa realizada pelos autores, retrata o processo de tomada de decisão no desenvolvimento de produtos.

Diferentes empresas tomarão diferentes decisões, mas todas seguirão o mesmo pensamento, a mesma lista de pontos relacionados com o processo de GDP, como conceito do produto, arquitetura, configuração, distribuição, prazos, dentre outros. O processo que envolve decisões genéricas comuns entre diferentes projetos é denominado perspectiva da decisão e, devido a não envolver a parte final da decisão, ou seja, qual caminho a empresa deverá seguir, pode ser utilizado para diferentes setores empresariais.

Krishnan e Ulrich (2001) organizaram as decisões de desenvolvimento de produtos em duas categorias: a primeira constitui-se em decisões tomadas no contexto de um só projeto, porém somente quando desenvolvido; a segunda engloba as decisões tomadas quando a empresa define o contexto organizacional e planeja o projeto de desenvolvimento. Ambas serão indicadas a seguir. No tópico “etapas do projeto” serão apresentadas etapas da GDP conforme dois autores, e posteriormente serão estabelecidas as etapas que o presente estudo adotará, seguidas das principais decisões a serem tomadas.

Em seguida, nas “decisões de planejamento” serão apresentadas as principais estratégias, como organizar e planejar a GDP, indicando também as principais decisões durante esse processo, o qual Rozenfeld et al (2006) definem como “a macrofase do prédesenvolvimento”. Após o efetivo lançamento do produto no mercado existem atividades que devem ser desenvolvidas para a continuidade do ciclo de vida do produto, denominada macrofase do pós-desenvolvimento (ROZENFELD et al, 2006), que será tratada também no tópico “decisões de planejamento”.

\subsubsection{Etapas do projeto}

Diversos estudos indicam passos que auxiliam na GDP, apresentando formas de gerir melhor o tempo, os recursos, como organizar as pessoas e as informações, dentre outros pontos relevantes para esse processo (CLARK; WHEELWRIGHT, 1993; ROZENFELD et al, 2006; KRISHNAN; ULRICH, 2001). No entanto, somente um pequeno número de empresas consegue transformar as informações coletadas em produtos potenciais. 
Conforme Krishnan e Ulrich (2001), existem diferenças significativas, tanto na metodologia utilizada pelas empresas nos seus projetos de desenvolvimento, quanto na forma em que esses processos são executados. E complementam indicando que essas diferenças não existem somente entre empresas, mas entre projetos dentro da mesma empresa. Isso demonstra a dificuldade de definição de uma melhor forma, ou mesmo de uma teoria para desenvolver novos produtos.

Krishnan e Ulrich (2001) fizeram um levantamento de uma vasta literatura existente sobre a GDP, resultando em aproximadamente 200 artigos na pesquisa final. Nesta, eles identificaram etapas geradas a partir de decisões relacionadas, no entanto, não se referem à ordem temporal do processo de desenvolvimento. Por essa razão, o presente estudo, que tem como objetivo conhecer o processo de GDP na IMC, adotou as etapas de Krishnan e Ulrich (2001), no sentido de auxiliar esta pesquisa quanto à organização das informações sobre a IMC. Do ponto de vista metodológico, Krishnan e Ulrich (2001) deram ênfase nos aspectos considerados interessantes para a pesquisa, contudo não enfatizaram o projeto do sistema, como poderá ser observado na descrição das etapas.

As etapas da GDP, segundo Krishnan e Ulrich (2001), são:

- Desenvolvimento do conceito.

- Projeto da cadeia de suprimentos.

- Desenvolvimento do produto.

- Teste e validação de desempenho.

- Ramp-up e lançamento.

A separação em estágios é bem didática e auxilia na identificação da interdependência de cada fase, no entanto, na prática o processo ocorre simultaneamente e de forma mais interativa, auxiliando na redução do tempo e dos custos de desenvolvimento.

É importante ressaltar que cada etapa de um projeto possui um ou mais produtos resultantes da atividade desenvolvida, denominadas saídas ${ }^{12}$, como também resultados de trabalhos específicos, projetados com o objetivo de estabelecer um controle gerencial (VALERI, 1996). Os produtos de cada etapa e as próprias etapas compõem uma seqüência lógica, criada para

\footnotetext{
${ }^{12}$ Deliverables.
} 
assegurar uma adequada definição do produto do projeto. Conforme Valeri (2000), a conclusão de uma etapa é, geralmente, marcada pela revisão das principais saídas e pela avaliação do desempenho do projeto, com a finalidade de determinar a sua continuidade ou não.

\subsubsection{Desenvolvimento do conceito}

Smith e Reinertsen (1998) denominam essa fase de "fase inicial nebulosa”"13, pois a incerteza, presente nessas fases iniciais é alta, principalmente para inovações radicais, que têm a descontinuidade como característica principal. A interação entre diferentes departamentos nessas fases iniciais é problemática e, com o intuito de melhorar essas interações, procura-se realizá-las por meio de processos formais, porém existe uma grande discussão sobre formalizar ou não essas etapas (SMITH; REINERTSEN, 1998).

A especificação é o ponto de partida do produto, e todas as fases seguintes dependerão dessas orientações iniciais. Devem ser muito bem definidas, pois, conforme Smith e Reinertsen (1998, p. 100), “quaisquer características e nuances, adicionadas posteriormente às especificações, podem parecer inocentes, mas talvez adicionem complexidade e, conseqüentemente, mais tempo ao ciclo”. Claro que, em alguns casos, pequenos acréscimos podem não causar grandes atrasos, mas o melhor é não arriscar.

No entanto, a grande dificuldade relativa a essa fase é definir essas especificações, pois não há um parâmetro que direcione o caminho para os projetistas e, além disso, algumas das informações que devem nela constar não ficam disponíveis até que o projeto inicie. Isso motiva a necessidade de serem combinados conhecimentos de engenharia, materiais, marketing, produção e outros. Esses especialistas devem fornecer dados à especificação e procurar alcançar uma solução mutuamente satisfatória (SMITH; REINERTSEN, 1998).

Outro ponto relevante para o sucesso dessa fase é que todos os envolvidos no projeto compreendam quem é o cliente e quais necessidades deverão ser satisfeitas. Apesar de ser essencial, não é facilmente alcançada. Consoante Smith e Reinertsen (1998, p. 106), uma

\footnotetext{
13 “Fuzzy front end."
} 
definição sólida contém o perfil do cliente, a necessidade do produto e orienta o time nas respostas para as perguntas que não foram claramente respondidas pela especificação.

Para a melhoria da fase de desenvolvimento do conceito, a empresa pode incluir clientes no processo (VON HIPPEL, 1986; THOMKE; VON HIPPEL, 2002; SMITH; REINERTSEN, 1998; COOPER et al, 2002a). Von Hippel (1986) os denomina de “usuários líderes”14, e correspondem àqueles cujas necessidades atuais se tornarão as do mercado em alguns meses ou anos, servindo como um meio para "prever” o futuro. No entanto, deve-se ter um processo apropriado para sua seleção, no sentido de procurar identificar os líderes inovadores, pois são os mais exigentes e conscientes das falhas de soluções que estão atualmente no mercado (SMITH; REINERTSEN, 1998; COOPER et al, 2002a; THOMKE; VON HIPPEL, 2002).

Slaughter (1991) complementa o conceito ao indicar que, além dos clientes diretos, não podem ser esquecidos os consumidores finais. Para ele, vários problemas podem aparecer durante a aplicação e o uso do produto, facilitando assim a ídentificação de algum possível problema, como também novas necessidades para a conseqüente melhoria do produto.

Uma ferramenta utilizada para auxiliar no processo de escutar a "voz do cliente” é o Quality Function Deployment - QFD (GRIFFIN; HAUSER; 1993). Caracteriza-se como um processo que requer a participação de um time multifuncional, no qual, por meio da utilização de matrizes, identifica as necessidades reais dos consumidores com dados provenientes das áreas de projeto, produção e entrega de serviços. Outra ferramenta é a pesquisa etnográfica, onde os pesquisadores passam um determinado tempo com o consumidor, observando suas atividades diárias, como utiliza o produto, podendo assim identificar os problemas e dificuldades no seu uso (COOPER et al, 2002a).

É nessa fase, então, que é definido o escopo detalhado do produto, levantando-se questões como tecnologias disponíveis e necessárias; padrões/normas, patentes e legislação relacionada ao produto; produtos concorrentes e similares; serviços que serão ofertados durante o ciclo de vida do produto; necessidades e requisitos dos clientes; requisitos do produto; objetivos ou metas que o produto deve atender; e outras informações adicionais que a empresa acredita serem relevantes (ROZENFELD et al, 2006, p. 213).

14 "Lead users." 
Algumas das principais decisões na etapa de desenvolvimento do conceito do produto estão listadas abaixo (KRISHNAN; ULRICH, 2001):

- Quais os valores alvo dos atributos do produto, incluindo preço?

- Qual o conceito central do produto?

- Qual a arquitetura do produto?

- Quais variações do produto serão oferecidas?

- Quais componentes serão compartilhados entre as variações do produto?

- Qual será a forma física e o projeto industrial do produto?

Os atributos do produto, conforme Krishnan e Ulrich (2001, p. 6), são as necessidades dos consumidores somadas às especificações do produto. Sendo o primeiro os atributos indicados pelos próprios consumidores, e o segundo as características da engenharia ou as métricas de performance técnica do produto.

Na visão de Backman et al (2007), o conceito do produto pode basear-se em diferentes inputs: na technology-driven concept, ou seja, nas melhorias tecnológicas da empresa, desde funções de segurança a novos componentes, menos problemático, pois pode ser bem calculado e avaliado; service concept, bastante integrado com o desenvolvimento tecnológico; design-driven concept, relacionado com o visual do produto, como escolha do material e formato do produto; value-driven concept, baseado nos valores centrais da empresa; e customer-and market-driven concept, ligado a um determinado nicho do mercado ou a alguma oportunidade de negócio. Não existe um tipo de conceito para cada processo, cada um possui um contexto, conseqüentemente, deve procurar formas diferentes de criar um impacto no mercado.

Conforme Agopyan (2007) ${ }^{15}$, o ponto central da IMC é o customer-and market-driven concept. Essa afirmação indica que os novos materiais de construção são desenvolvidos levando-se em consideração informações provenientes do mercado, de seus clientes e consumidores. No entanto, atualmente um dos pontos que estão sendo considerados na definição dos conceitos dos novos produtos na IMC é o desenvolvimento sustentável. Destarte, a maior parte das inovações atuais desse setor carrega consigo conceitos de

\footnotetext{
${ }^{15}$ Afirmação do Prof. Dr. Vahan Agopyan, no ato da qualificação desta dissertação.
} 
sustentabilidade, caso da empresa Lorenzetti ${ }^{16}$, a qual definiu para sua nova carteira de produtos as seguintes especificações: segmento de baixa renda, banhos quentes e economizadores de água (ABRAMAT, 2008).

Diferentes tipos de conceitos podem ser utilizados num mesmo processo de GDP, porém os novos produtos devem sempre proporcionar valor para seu consumidor-alvo, pois este, ao efetuar uma aquisição, procura obter um conjunto de benefícios que atenda às suas necessidades e expectativas. De acordo com Maidique e Zirger (1990), esse valor pode ser medido de diversas maneiras: através da superioridade da performance técnica; baixos custos, com conseqüente redução do preço; características únicas àquele produto; e qualidade superior à dos concorrentes.

Com a definição do conceito central do produto a ser desenvolvida, a empresa terá condições de escolher a melhor idéia. Outro ponto de decisão é a arquitetura do produto, "esquema pelo qual os elementos funcionais do produto são arranjados em partes físicas e como essas partes interagem” (ROZENFELD et al, 2006, p. 239). Isso ajuda na definição de quais componentes serão compartilhados dentre as variações do produto, que deverão ser balanceadas de acordo com a heterogeneidade das preferências dos consumidores e a padronização do projeto e da produção. Por fim, a definição de sua forma física e de seu projeto industrial, que são essenciais para as discussões sobre o conceito do produto.

A linha tradicional de seleção de conceito indica que as características do produto devem ser congeladas antes de se iniciar o seu projeto (ROZENFELD et al, 2006, p. 44), mas, de acordo com Bacon et al (1994) apud Krishnan e Ulrich (2001), congelar especificações de um produto em um mercado dinâmico é uma meta impossível de ser alcançada. Srinivasan et al (1997) acrescentam que pode ser bem melhor coletar múltiplas opções de conceitos e selecionar a melhor em etapas finais do processo. Cada empresa deve procurar adotar a forma que seja mais adequada à sua realidade.

Em resumo, as atividades do time nesta etapa relacionam-se com: a busca por produtos concorrentes ou similares; o processo de criação de soluções, direcionado pelas necessidades, requisitos e especificações do projeto; a representação das soluções por meio de esquemas,

\footnotetext{
${ }^{16}$ A Lorenzetti é uma empresa de capital 100\% nacional e a maior fabricante de duchas e chuveiros elétricos do
} Brasil. 
croquis e desenhos (manuais ou computacionais); e ainda com a seleção de soluções para o problema de projeto, feita com o auxílio de ferramentas que facilitam o encontro das necessidades e requisitos previamente definidos (ROZENFELD et al, 2006, p. 236).

Essa fase exige uma intensa geração de idéias, proveniente dos diversos setores envolvidos no processo. Todos os especialistas devem interagir para compartilhar informações e alcançar uma solução mutuamente satisfatória. Uma das grandes preocupações na GDP é com a redução dos seus custos, o cuidado é necessário, contanto que não prejudique o processo de criação da empresa. "E uma especificação mal executada pode não só atrasar o início, como prolongar todo o ciclo de desenvolvimento” (SMITH; REINERTSEN, 1998, p. 99).

\subsubsection{Projeto da cadeia de suprimentos}

As atividades da fase de projeto da cadeia de suprimentos envolvem o fluxo interno e externo de materiais. Nessa etapa serão selecionados os fornecedores, como também os projetos dos sistemas de produção e distribuição. De acordo com Krishnan e Ulrich (2001), algumas das decisões referentes a essa fase são as listadas a seguir:

- Quais componentes serão projetados e quais serão selecionados? E quem os projetará?

- Quem produzirá os componentes e quem montará o produto?

- Qual a configuração da cadeia física de suprimentos, incluindo o local onde será feita a junção dos componentes?

- Qual o tipo de processo que será utilizado para montagem?

- Quem desenvolverá e fornecerá o processo tecnológico e os equipamentos?

Para a construção do modelo do produto, na etapa seguinte, devem ser definidos os componentes que serão projetados internamente e os que serão projetados fora da empresa, caso exista essa opção, como também quem produzirá e onde será feita a junção desses componentes. A etapa de projetar a cadeia de suprimento envolve também a definição da propriedade intelectual e dos serviços da empresa.

A cadeia física de suprimentos deve ser bem definida, levando-se em consideração os custos diretos de produção e os custos entre fornecimento e demanda. Com posse desses dados, 
questões como “fazer ou comprar pronto" ${ }^{17}$, poderão ser decididas, indicando-se quem projetará e quem produzirá tais suprimentos para que a cadeia seja configurada. Possíveis fornecedores também devem ser lembrados, tanto os das tecnologias envolvidas no processo, quanto dos equipamentos necessários, para que dessa forma seja possível identificar o que a empresa precisará adquirir para o desenvolvimento do projeto, podendo assim definir os custos envolvidos.

Um exemplo de como planejar e preparar-se para o desenvolvimento de um novo produto é apresentado por Clark e Wheelwright (p. 209, 1993). O caso é de uma IMC que decide desenvolver uma nova linha de produtos e, dentre os fatores considerados para análise de seu planejamento, estavam a sua cadeia de suprimentos; o espaço necessário para a produção, se precisaria ou não de uma nova planta; novos mercados; mudanças na linha de produção; pensou-se também na necessidade de antecipação ao giro do mercado da construção; e a possibilidade de realizar-se algum financiamento.

\subsubsection{Projeto do produto}

Essa é a etapa de detalhamento do projeto do produto, que se constitui na especificação dos parâmetros do projeto, a relação entre componentes do produto, incluindo seleção de material e de processo e projeto das ferramentas e equipamentos necessários para o desenvolvimento dos novos produtos. Rozenfeld et al (2006, p. 297) indicam que é nessa etapa que serão feitos os desenhos finais com tolerâncias, os planos de processo, os projetos de embalagem e o material de suporte do produto.

O projeto da embalagem envolve a avaliação da distribuição do produto, incluindo transporte e entrega, a definição das formas e sinalizações das embalagens, projeção da embalagem e planejamento do processo de embalagem. E as tarefas da atividade de criação do material de suporte do produto são a criação do manual de operação, do material de treinamento e do manual de descontinuidade do produto (ROZENFELD et al, 2006, p. 377).

As questões que Krishnan e Ulrich (2001) indicam que se referem à esta etapa são:

- Quais são os valores dos parâmetros dos projetos chave?

17 "Make or buy." 
- Qual a configuração dos componentes e a relação de montagem entre eles?

- Qual é o projeto detalhado dos componentes, incluindo a seleção dos materiais e do processo?

A projeção tem a finalidade de auxiliar na definição dos valores finais dos parâmetros do projeto, enquanto otimiza as características de performance desejada. É necessário que todos os parâmetros estejam bem definidos nesse momento, os componentes desenvolvidos ou adquiridos, suas relações estabelecidas, com todos os recursos necessários para sua realização. Feito isso, inicia-se a prototipagem.

\subsubsection{Teste e validação de desempenho}

Enquanto as decisões do projeto estão sendo refinadas, o projeto é prototipado para validação, em relação a funcionamento, tamanho e fabricação. O processo de prototipagem pode ser feito seqüencialmente ou paralelamente, isso implica em diferentes custos, benefícios e tempo. A empresa pode procurar definir qual a melhor estratégia levando em consideração o custo do protótipo e o custo de reprojetar. São diversas as tecnologias existentes que auxiliam o processo de prototipagem, o que proporciona a identificação de processos mais adequados para cada circunstância. São também listados todos os materiais necessários para o projeto e toda a documentação de controle para a produção deste.

Clark e Wheelwright (1993) acrescentam a essa fase a realização de um teste em pequena escala do projeto, com a construção de modelos, e em alguns casos, é feita ainda a discussão deste com clientes potenciais. A simulação do processo de fabricação tem como objetivo antecipar possíveis problemas das operações, com a possibilidade de aperfeiçoar o processo (ROZENFELD et al, 2006, p. 335).

De acordo com Krishnan e Ulrich (2001), alguns dos questionamentos que devem ser feitos nessa etapa são:

- Qual é o plano de prototipagem?

- Quais tecnologias devem ser utilizadas na prototipagem?

Percebe-se com isso que a construção do protótipo tem como finalidade criar e refinar idéias. Pontos que são levados em consideração nos protótipos são: custo; tempo; capacidade, ou 
quantos experimentos podem ser produzidos em quanto tempo; aprendizado; e representatividade ou fidelidade do protótipo (THOMKE, 2001a, p. 68).

Testes com protótipos é uma estratégia muito empregada no processo de desenvolvimento, essencial para guiar a gerência na GDP, pois possibilita o melhor conhecimento do progresso do projeto, identifica pontos que não foram solucionados, ajuda a focar nos recursos, auxiliam a responder questões sobre reações de consumidores, projeto industrial, durabilidade, encaixe e finalização, e custos de produção (CLARK; WHEELWRIGHT, 1993). Dessa forma, contribuem para a identificação de oportunidades, o aprendizado da organização, e a formação de novas capacidades. Esses testes podem acontecer em laboratórios internos, como também em campo. Algumas empresas costumam realizar os testes em lugares movimentados, com a finalidade de avaliar com maior rapidez características técnicas dos produtos.

Além de todos esses benefícios, ajuda ainda na solução de problemas, testa a comunicação entre os membros do projeto e auxilia também na resolução de conflitos. Com um produto físico em mãos a empresa pode fazer diversos testes, os engenheiros podem estudar os fatores críticos de funcionalidade do produto; o marketing pode testar e explorar as necessidades e reações dos consumidores; e a produção pode determinar qual será a real estrutura para a produção em larga escala (CLARK; WHEELWRIGHT, 1993).

Rozenfeld et al (2006) dizem que a produção piloto faz parte da fase de preparação da produção, incluindo as atividades de definição dos processos de produção e manutenção, ou seja, a complementação de todas as atividades relacionadas com a cadeia de suprimentos interna da empresa já esboçadas na etapa anterior.

A empresa deve escolher o processo de protótipo baseada no tipo de produto e nos objetivos do projeto. Clark e Wheelwright (1993) apresentam três modelos de construção de protótipos combinados com o tipo de projeto que a empresa está desenvolvendo. O primeiro modelo, uma rápida resposta para a engenharia, é mais indicado para projetos breakthrough, que tenham o intuito de desenvolver inovação técnica. O segundo modelo, sistema de solução integrado (periódico), mais aplicado em projetos de plataforma, para desenvolver nova arquitetura. E o terceiro modelo, replicação da produção cedo, leva em consideração a 
possibilidade de produzir o custo e a confiabilidade, sendo mais indicado para projetos incrementais. Não importa o tipo de projeto, sempre haverá práticas e características, como qualidade, tempo, eficiência no uso de materiais e processos, que contribuirão para uma performance superior.

Outra decisão é a forma como esses protótipos serão construídos. Thomke (1998) indica duas formas de se construir protótipos, são elas: simulação virtual e prototipagem rápida. A primeira refere-se ao protótipo feito com programas de computação, como o Computer-Aided Design - CAD, o qual possibilita a geração de um maior número de testes, em diferentes situações, reduzindo o tempo de prototipagem. Já a prototipagem rápida corresponde à experimentação real. De acordo com Clark e Wheelwright (1993), há uma outra forma de se fazer experimentações, que é por meio da construção de protótipos de papelão ou argila.

O que mais motiva as empresas a adotarem ferramentas de simulação virtual é a possibilidade da redução do tempo e do custo de desenvolvimento de seus projetos (THOMKE, 2001b; BECKER et al, 2005). Srinivasan et al (1997) dizem que o custo de construção de protótipos virtuais é consideravelmente menor que dos protótipos físicos, além de permitir que se teste vários conceitos numa mesma pesquisa. No entanto, segundo Becker et al (2005), existem muitas outras vantagens ao se adotar esse tipo de ferramenta, algumas delas são: modifica a natureza do processo de solução de problemas; melhoram a qualidade do projeto, devido às informações a serem disponibilizadas nas fases iniciais do projeto; e proporciona coordenação e integração, facilitando assim a comunicação entre as diversas áreas da empresa

Thomke (2001b) atenta para o cuidado que se deve ter ao adotarem-se ferramentas de simulação virtual, pois o uso dessas tecnologias exigem um alinhamento com a estratégia de posicionamento do produto, como também uma reestruturação da cultura da empresa e de suas rotinas, o que também é reforçado por Becker et al (2005).

Para melhorar esse processo, Thomke (2001a, p. 69) diz que as empresas devem procurar falhar com mais freqüência e no início do projeto, pois assim evitarão erros maiores, para isso deve combinar grande quantidade de informações com técnicas de experimentação novas, como também as tradicionais. Falhas não podem ser confundidas com erros, esses produzem pouca informação nova e útil e não possuem valor. 
Deve-se atentar para o fato de que a prototipagem pode ser inserida nas fases inicias do projeto, que, de acordo com Srinivasan et al (1997), possibilita o desenvolvimento de várias alternativas de conceitos viáveis, deixando a escolha do melhor projeto para mais adiante no processo.

Gann (1994, p. 204) afirma a dificuldade que existe na realização de testes com novos materiais e componentes, pois é difícil e caro simular os efeitos do tempo no material que é desenvolvido para durar, por exemplo, 60 anos. Isso acaba gerando a necessidade de altos custos de prototipagem.

\subsubsection{Ramp-up e lançamento}

Essa etapa é influenciada diretamente por todas as decisões tomadas durante o projeto do produto. Na fase final do projeto, Krishnan e Ulrich (2001) indicam que a empresa deve fazer os seguintes questionamentos:

- Qual é o plano de teste de mercado e lançamento?

- Qual é o plano para o ramp-up da produção?

É nesse momento que a empresa deve decidir qual o nível em que será realizado o teste do produto no mercado, como também a seqüência para a introdução dos produtos no mercado. O tempo para o lançamento do produto leva em discussão diversos fatores, como quando o concorrente entrará ou entrou no mercado, e a finalização do desenvolvimento do projeto, o qual na maioria das vezes não é cumprido. Por essa razão, a empresa deve ser cuidadosa ao anunciar a data ou período de lançamento do produto, pois isso pode ser um ponto bastante negativo para ela, mesmo antes de colocar o produto no mercado.

O lançamento envolve o desenho dos processos de venda e distribuição, atendimento ao cliente e assistência técnica e as campanhas de marketing, ou seja, as atividades relacionadas com a colocação do produto no mercado (ROZENFELD et al, 2006, p. 416). O time de desenvolvimento é dissolvido ao fim desta fase, no entanto, Rozenfeld et al (2006) sugerem que seja deixado um núcleo à disposição, para conduzir as fases de acompanhamento do produto e sua descontinuidade. 
De acordo com Smith e Reinertsen (1998), ser o primeiro a lançar um novo produto no mercado, antecipando seus concorrentes, pode aumentar a participação no mercado, possibilitando uma maior margem de lucro. No entanto, afirmam que isso não assegura a viabilidade da empresa.

No tópico seguinte serão apresentadas todas as decisões que fazem parte da organização dos projetos de desenvolvimento, presentes na literatura estudada. Estão divididas em estratégia e planejamento do produto; organização e desenvolvimento do produto; e gerenciamento do produto.

\subsubsection{Decisões para organização de projetos de desenvolvimento}

Uma empresa pode não possuir somente um projeto, mas uma infinidade de projetos, por essa razão torna-se necessária a organização de todos os fatores que envolvem um projeto. É preciso também que o ambiente seja estruturado para preparar-se para o desenvolvimento deste. Nesse tópico serão tratadas decisões referentes ao planejamento de como desenvolver um projeto: estratégia e planejamento do produto; organização do desenvolvimento do produto; e gerência do projeto.

\subsubsection{Estratégia e planejamento do produto}

Existem diversas atividades que devem ser realizadas antes de iniciar o desenvolvimento do projeto, que servirão como base para o processo (CLARK; WHEELWRIGHT, 1993). Rozenfeld et al (2006, p. 52) denominam essa etapa de pré-desenvolvimento, indicando que esta deve garantir que “[...] o direcionamento estratégico, as idéias de todos os atores internos e externos envolvidos com os produtos, e as oportunidades e restrições sejam sistematicamente mapeados e transformados em um conjunto de projetos bem definidos”. No entanto, nessa etapa também serão tratadas questões sobre a aprendizagem que houve com o projeto, que se referem à etapa de pós-desenvolvimento, segundo Rozenfeld et al (2006).

Krishnan e Ulrich (2001) indicam que as seguintes decisões são algumas das que fazem parte dessa etapa de planejamento:

- Qual é a estratégia de mercado e de produto para maximizar a probabilidade de sucesso?

- Quais as oportunidades do portfólio de produtos que serão ofertadas? 
- Qual o tempo para o desenvolvimento do projeto do produto?

- Quais componentes serão compartilhados entre as plataformas de produtos?

- Quais tecnologias serão empregadas no produto?

A estratégia deve ter uma "estrutura"18 clara, bem definida e bem difundida entre todos na empresa. Diante disso, os autores desenvolveram uma estrutura que serve de base para a compreensão das etapas para o desenvolvimento de um projeto, como apresentado na Ilustração 2.

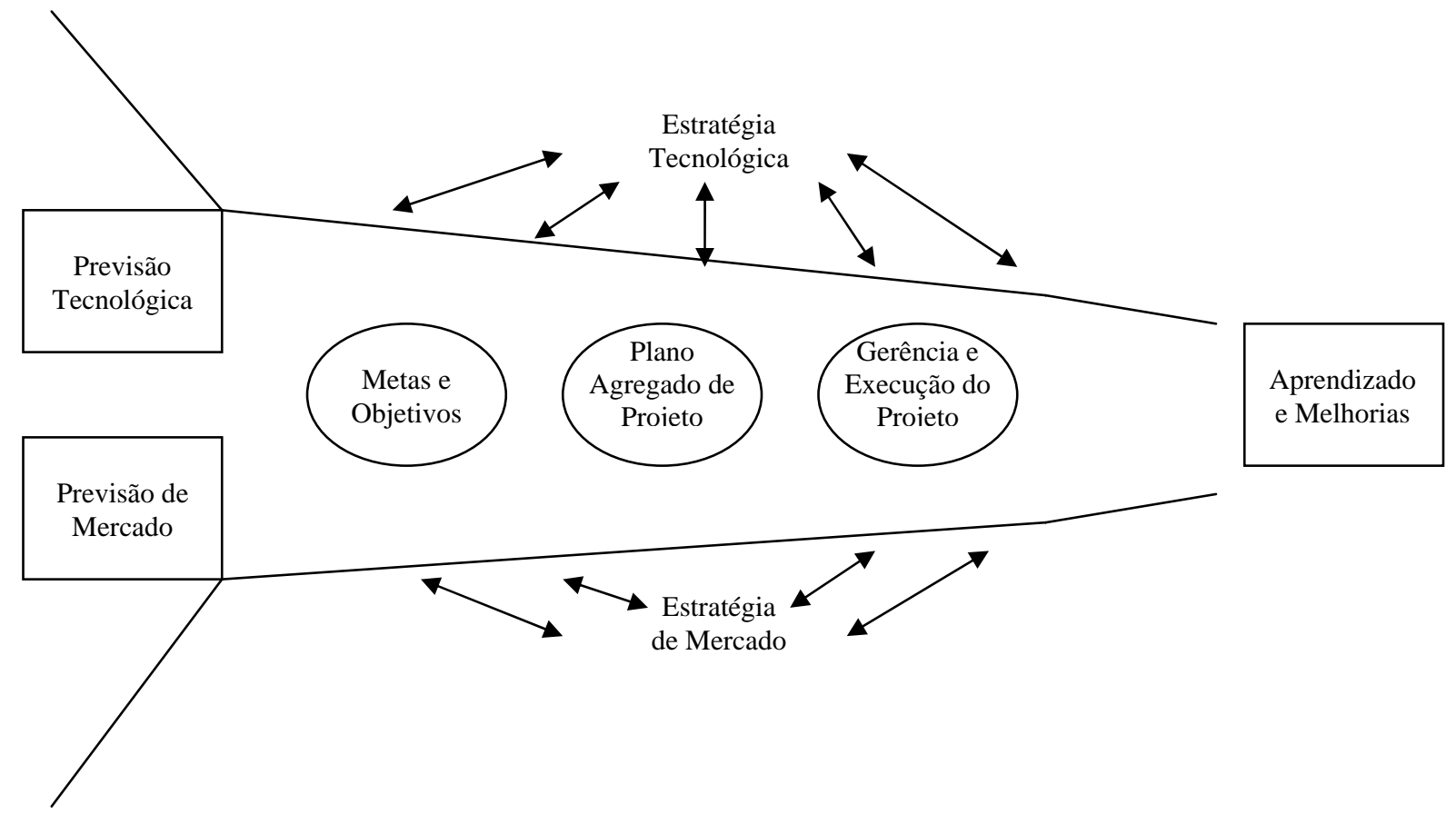

Ilustração 4 - Estrutura da estratégia de desenvolvimento FONTE: CLARK; WHEELWRIGHT, 1993, p. 90.

A partir da estrutura acima são extraídas as etapas que constituem a estratégia de desenvolvimento. Primeiro são feitas as previsões tecnológicas e de mercado, baseado nisso são definidas as metas e os objetivos do desenvolvimento. Com essas informações em mãos é elaborado o Plano Agregado de Projeto e, por fim, é colocado em prática o projeto de desenvolvimento. Ao fim de cada projeto deve ser realizada uma avaliação para identificação de possíveis aprendizados e melhorias para projetos futuros.

A estratégia tecnológica do projeto deve estabelecer explicitamente as tecnologias necessárias, definindo o Know-how e o Know-why, para obter a vantagem competitiva; focar

18 “Framework." 
em tecnologias onde a empresa pretende ter vantagem competitiva, utilizando tecnologias padrões; estabelecer a fonte, externa e interna; e estabelecer o tempo para capacitação e maturação da tecnologia e freqüência (incremental ou em grandes saltos) das implementações (CLARK; WHEELWRIGHT, 1993).

Enquanto que a estratégia de mercado deve conter as decisões sobre os produtos que serão oferecidos; o público-alvo; a forma como serão disponibilizados; define número, tempo e taxa de mudança da plataforma; e define número, tempo, freqüência e relações de produtos diferenciados (CLARK; WHEELWRIGHT, 1993). O maior benefício que se tem com uma estratégia efetiva é a integração que será proporcionada entre o planejamento e a estratégia geral da empresa com a seleção e desenvolvimento dos projetos mais específicos.

Em seguida, alinhado às estratégias anteriormente definidas, desenvolvem-se os objetivos e metas que a empresa pretende alcançar com o projeto. Antes de se iniciar o seu desenvolvimento, é elaborado o plano agregado de projetos, o qual é realizado com o único intuito de garantir que eles estejam caminhando para o alcance dos objetivos e metas estabelecidos, e construindo uma capacidade organizacional necessária para o seu sucesso constante.

Esse plano tem como finalidade ajudar a definir prioridades, no momento da escolha do portfólio de projetos da empresa. Ajuda na decisão de quais projetos serão escolhidos, quando iniciarão e quando serão concluídos, quais recursos serão alocados por qual período de tempo, e como esses projetos irão contribuir, conjuntamente, para a estratégia da empresa. Com esse plano a empresa conseguirá saber qual a capacidade que terá que disponibilizar para desenvolver habilidades nas pessoas e na organização como um todo.

Uma forma de compilar todas as informações necessárias para a tomada de decisão dos gerentes e diretores de uma determinada empresa é por meio dos mapas funcionais (CLARK; WHEELWRIGHT, 1993). Estes auxiliam na mobilização das informações, capacidades e habilidades da organização, levando a uma unificação das diferentes linguagens dentro de uma empresa, facilitando assim a comunicação entre as funções e a integração estratégica de todas as áreas em uma única finalidade. 
A etapa final é a de aprendizagem, a qual tem como objetivo melhorar as capacidades envolvidas no processo de desenvolvimento de um produto e o próprio processo. Construir capacidade para desenvolver novos produtos e processos eficientemente requer determinação, persistência, e atenção cuidadosa. Porém, para conseguir essa melhoria é preciso aprender a aprender com as experiências passadas de desenvolvimento.

Essa aprendizagem pode surgir tanto dos problemas, erros e dificuldades, como também dos acertos. Identificar e entender esses problemas é apenas parte da solução. A organização deve também determinar a mudança que será feita para melhorar o processo. A aprendizagem em grupo é bastante difícil de ser alcançada e, para que esta ocorra, é necessário que haja inicialmente a aprendizagem individual.

Diversas ferramentas podem ser utilizadas para auxiliar o processo de aprendizagem sobre desenvolvimento de projetos, mas para o sucesso deste é preciso que a empresa tenha comprometimento e saiba trabalhar em equipe. Dessa forma, as empresas conseguirão realizar seus projetos com rapidez, eficiência e qualidade superior.

\subsubsection{Organização do desenvolvimento do produto}

Organizar o desenvolvimento do produto significa discutir sobre qual será o sistema social e o ambiente necessário para o desenvolvimento de um projeto. As decisões envolvem a definição do time do projeto, dos incentivos e formas de recompensa, e dos investimentos para aumentar a produtividade das ferramentas e dos processos para o desenvolvimento do produto.

Mais detalhadamente, Krishnan e Ulrich (2001) indicam algumas decisões para esta etapa:

- Como o time será selecionado?

- Como será o arranjo físico do time do projeto e onde serão alocados?

- Será utilizado algum projeto funcional ou estrutura matricial?

- Qual tipo de processo de desenvolvimento será empregado (stage-gate...)?

- Como será medida a performance do projeto?

- Quais investimentos em infra-estrutura, ferramentas e treinamento serão necessários? 
Brown e Eisenhardt (1995) citam três aspectos relacionados aos times que exercem influência no desempenho do processo de desenvolvimento de produtos: a composição da equipe, o processo de trabalho e a organização do trabalho. Por essa razão a definição do time de desenvolvimento deve ser cuidadosa e trazer áreas e funções estratégicas para o sucesso do projeto. Conforme Rozenfeld et al (2006, p. 49), o time pode ser composto por membros da diretoria, gerente funcional, responsável pela engenharia, gerente de projetos, especialistas e parceiros, distribuídos pelas áreas de marketing, vendas, tecnologia, produção e finanças (COOPER et al, 2002b). Estes podem ser alocados em uma área comum, ou cada um em seu setor de trabalho, apenas reunindo-se nos momentos indicados no planejamento do projeto.

Segundo Von Hippel (1986) e Slaughter (1991), os clientes diretos e os consumidores finais também podem ser incluídos no processo, como já foi dito anteriormente. No entanto, devese ter cuidado para a inovação não se tornar um processo baseado na imitação, como também reduzir a criatividade da equipe interna de desenvolvimento. Isso pode acontecer devido ao fato de os consumidores terem idéias relacionadas com os produtos que já conhecem e não sugerirem alguma modificação mais radical.

Uma ferramenta utilizada para auxiliar na definição do time responsável pelo desenvolvimento de cada projeto é o plano agregado de projetos, que indica quais os recursos existentes na empresa, quais deverão ser adquiridos ou desenvolvidos, para que dessa forma possam alocá-los da melhor maneira, conforme suas capacidades e habilidades.

Além da definição do time de desenvolvimento, a empresa deve decidir a estrutura organizacional em que estes estarão inseridos. As diferentes estruturas organizacionais podem ser mais ou menos adequadas, dependendo das características da empresa e de seus produtos (ROZENFELD et al, 2006, p. 49). A organização das atividades de desenvolvimento de um produto se refere à maneira como os indivíduos estão trabalhando, individualmente ou em grupos, formal ou informalmente. 
Clark e Wheelwright (1993) apresentam quatro estruturas associadas ao papel da liderança em projetos: "estrutura do time funcional; estrutura do time 'peso leve'; estrutura do time ‘peso pesado'; e estrutura do time autônomo”19.

- Estrutura do time funcional - organização funcional tradicional encontrada em grandes e maduras empresas. A relação entre os componentes do time acontece primeiro entre aqueles que realizam funções similares (ROZENFELD et al, 2006, p. 26). A estrutura funcional é a forma tradicional de se organizar o desenvolvimento por disciplinas funcionais, e os engenheiros são bem especializados. Ninguém tem total responsabilidade por todo o produto.

- Estrutura do time 'peso leve' - da mesma forma como acontece no modelo anterior, as pessoas que compõem o time se encontram fisicamente nas suas áreas funcionais, mas cada função designa uma pessoa para representar no comitê de coordenação do projeto. O gerente do projeto é ‘peso leve’, por ser de um nível médio dentro da empresa, que apesar de ter um considerável conhecimento específico, tem pouca influência na organização. Porém, os recursos-chave ainda ficam sob o controle do gerente funcional. Uma organização que passa de funcional para 'peso leve' tem uma melhora na comunicação e coordenação das atividades. Rozenfeld et al (2006, p. 27) classificam essa estrutura como uma subdivisão da estrutura matricial.

- Estrutura do time 'peso pesado' - o gerente do projeto tem acesso direto e responsabilidade pelo trabalho de todos os envolvidos no projeto. Eles são os gerentes seniores da organização. Em algumas organizações se encontram no mesmo nível dos gerentes funcionais. Acontece muito pouco na prática, mas demonstra ter potencial para diversos tipos de organizações. Conforme Rozenfeld et al (2006, p. 27), essa estrutura também é uma subdivisão da estrutura matricial.

- Estrutura do time autônomo ou por projeto - pessoas de funções diferentes são alocadas conjuntamente em um time de projeto. O líder do projeto tem total controle sobre os recursos de todos os grupos funcionais. A esse time é permitido que criem suas práticas organizacionais. Nesse caso, a responsabilidade pelo projeto é do time.

\footnotetext{
19 "Functional team structure; lightweight team structure; heavyweight team structure; autonomous team structure.”
} 
O peso do time não está somente ligado à estrutura e ao mecanismo usado, mas às atitudes e comportamentos das pessoas que o compõem. Empresas que tentam criar times 'peso pesado' sem fazerem profundas mudanças terão maiores problemas no futuro. A partir de um levantamento da literatura existente sobre casos de sucesso e fracasso realizada por Kleinknecht et al (2003), observou-se que a estrutura matricial é a preferida atualmente pelas empresas, pois facilita a integração entre os membros do time e o controle do projeto.

Diante de tantas decisões, um problema pode ocorrer quando o time de desenvolvimento encontra um gap entre o plano do projeto e as necessidades dos consumidores. A pergunta que deve ser feita é: o que é necessário ser feito no nível operacional do projeto para que o plano seja seguido, sem perder o foco nas necessidades do mercado consumidor? É nesse momento que a empresa deve analisar o que será necessário para a efetivação do projeto e o que ela possui naquele momento. A partir daí, devem ser indicados quais os investimentos que serão necessários em infra-estrutura, ferramentas e treinamento. Ferramentas que auxiliam nessa etapa são QFD, plano agregado de projeto, mapas funcionais e Design For Manufacturability - DFM ${ }^{20}$.

Como parte da etapa de organização do desenvolvimento do produto a empresa deve definir qual processo de desenvolvimento adotará em seus projetos. As abordagens que serão apresentadas são: abordagem tradicional de desenvolvimento; engenharia simultânea; funil de desenvolvimento; e stage-gate.

\section{- Abordagem tradicional de desenvolvimento}

A abordagem tradicional de desenvolvimento é a de total separação entre a fase do conceito e a implementação, que só começa quando as especificações estiverem todas congeladas. Iansiti (1995) afirma que em ambientes onde o nível de competição é previsível essa abordagem demonstra ter bastante potencial. No entanto, em ambientes turbulentos, os times lidam com níveis maiores de incertezas nos primeiros estágios do desenvolvimento, onde se tem somente uma idéia sobre as principais características ou atributos que os consumidores desejam para o produto. Conseguir tempo adicional para estudar o mercado e obter

\footnotetext{
${ }^{20}$ DFM é uma ferramenta utilizada com o intuito de trazer questões relacionadas com a capacidade de produção para etapas iniciais do projeto (ROZENFELD et al, 2006).
} 
informações mais apuradas sobre os consumidores podem fazer a diferença entre o sucesso e o fracasso, para assim responder às incertezas técnicas e de mercado. (CLARK; WHEELWRIGHT, 1993; IANSITI, 1995).

\section{- Engenharia simultânea}

Possibilita a melhoria da gestão das informações através da integração das funções e da sobreposição de algumas etapas do desenvolvimento, tornando assim o processo mais rápido e eficiente no que diz respeito à produtividade dos recursos e redução do número de retrabalhos. Por essa razão, tem sido apontada como uma técnica de gestão de projetos capaz de apresentar resultados bastante favoráveis em relação a melhorias na qualidade do produto, na produtividade do processo e na diminuição do time to market.

Camargo Júnior (2003) diz que o grande objetivo na utilização da engenharia simultânea é o de "encontrar mais cedo eventuais problemas ou conflitos, para mais cedo também solucionálos, economizando tempo e recursos com futuras análises e tarefas que teriam que ser refeitas”. Como é o caso da empresa 'Lehrer McGovern Bovis', da indústria da construção civil, que constrói utilizando técnicas de engenharia simultânea. E afirma que conseguiu melhorar a entrega conforme as exigências de seus consumidores, como também a construção mais rápida e a baixos custos (CLARK; WHEELWRIGHT, 1993, p. 508).

Contudo, só a implementação da engenharia simultânea parece não ser suficiente na condução de projetos sob níveis intensos de incertezas tecnológicas e/ou de mercado (EISENHARDT; TABRIZI, 1995). A partir de uma pesquisa junto a 36 empresas de competição global no ramo de hardwares, os autores Eisenhardt e Tabrizi (1995) descobriram ser a engenharia simultânea a técnica predominante para aceleração da GDP. Identificaram também que empresas sob maiores incertezas, como as de impressoras e computadores pessoais, utilizavam um mix de técnicas de criação de flexibilidade através da introdução de pontos de decisão e reavaliação ao longo do processo.

\section{- Funil de desenvolvimento}

A ferramenta que Clark e Wheelwright (1993) indicam para seleção de projetos é o funil de desenvolvimento (Ilustração 5). Permite compreender os efeitos das estratégias tecnológicas e 
mercadológicas sobre a discussão das metas e operacionalização do processo de forma a se obter uma convergência do tipo de produto/processo a serem desenvolvidos. O funil simboliza, para estes autores, a conjunção das estratégias tecnológicas e de mercado com seu plano de metas e objetivos, além do plano agregado que, quando analisados em conjunto, estabelecem uma linha estratégica de atuação e execução de médio e longo prazos para o desenvolvimento de novos produtos para a empresa. Os autores apresentam três modelos de funis:

- O primeiro é o modelo centrado nas idéias do $\mathrm{P} \& \mathrm{D}$, mais utilizado por grandes empresas com foco em tecnologia intensiva. Uma desvantagem desse modelo é que inúmeras idéias surgirão, mas poucas serão produtos de sucesso.

- O segundo é mais utilizado por pequenas empresas, onde na maioria das vezes tem-se uma grande idéia que é transformada em um produto de sucesso. É chamada de estratégia "todos os ovos na mesma sacola”, pois leva em consideração todos os fatores críticos do processo. Empresas menores têm a vantagem de ter clareza e foco no projeto. Já grandes empresas que utilizam este modelo têm como desvantagem ter que fazer diversas correções no decorrer do desenvolvimento; ter pouco sucesso na introdução do produto no mercado; e, nesse caso, cria uma reputação de empresa conservadora e não mais inovadora. Isso ocorre devido à complexidade de levar em consideração todos os fatores críticos do processo para análise das melhores opções de projeto, e ao aumento de custos. Dessa forma, dificulta a possibilidade de realizar projetos competitivos.

- O último modelo é o “inovador e focado”, uma combinação entre os dois modelos citados anteriormente. A melhor forma de se desenvolver um funil, o qual proporcionará produtos competitivos e efetivos. 


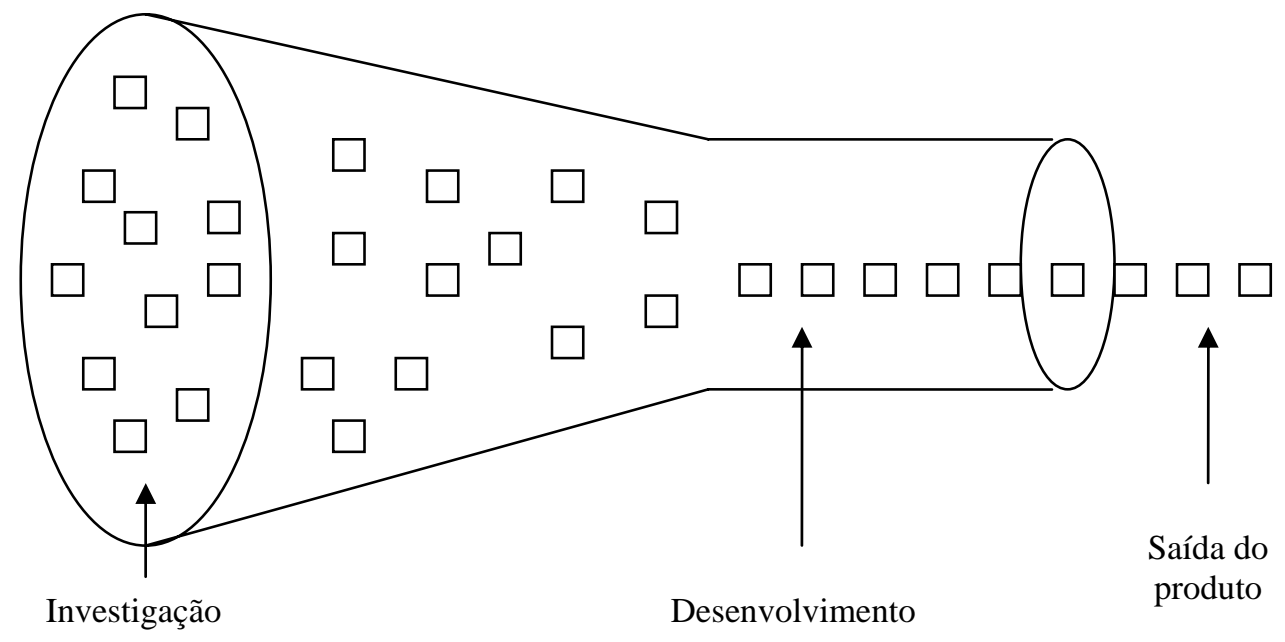

Ilustração 5 - Funil de desenvolvimento

FONTE: CLARK; WHEELWRIGHT, 1993, p. 294.

Como pode observar-se, o funil é composto por três etapas. Primeiramente, a empresa deve expandir o máximo possível sua "boca”, com conhecimentos e informações, gerando um maior número de projetos. Depois se devem afunilar as opções, focando nas oportunidades mais atrativas, tecnológicas, na estratégia da empresa e nas necessidades financeiras. E por último, confirmar as informações dos projetos selecionados.

\section{- Stage-gate}

O foco principal desse modelo é um processo sistemático de decisão, que garante não apenas o desempenho e a qualidade do desenvolvimento, mas permite que a escolha pelo novo projeto leve em consideração o andamento de todos os projetos e as mudanças do ambiente. O processo se inicia com uma idéia e finaliza com o lançamento de um novo produto, sendo dividido em atividades (estágios ${ }^{21}$ ) e pontos de decisão (portas ${ }^{22}$ ), como pode ser observado nas Ilustrações 6 e 7.

Com o passar do tempo, o processo do stage-gate tem sido aperfeiçoado, fazendo com que os pontos de decisões (portas) ficassem mais rígidos, portanto, mais seletivos. Estudos mais recentes integram esse processo ao gerenciamento do portfólio de produtos, com a finalidade de definir o melhor mix de projetos, balanceá-los e maximizar o seu valor (COOPER et al, 2002b).

\footnotetext{
21 "Stages"

22 "Gates"
} 
É nos estágios que o time de desenvolvimento busca as informações necessárias para o avanço do projeto e são nas portas que se tomam as decisões de continuar ou não. Cada estágio significa:

- Estágio 1 - Escopo - é feito o escopo do produto, onde são coletadas informações sobre as características técnicas e de mercado do projeto.

- Estágio 2 - Construção do business plan - as características técnicas e de mercado são todas coletadas e inseridas no business plan, sendo dividido em três partes: definição do produto e do projeto; justificativa do projeto e plano do projeto.

- Estágio 3 - Desenvolvimento - o business plan é concretizado. As atividades do plano do desenvolvimento acontecem, a produção é mapeada, o plano de marketing e de lançamento são elaborados, como também o plano de testes.

- Estágio 4 - Teste e Validação - momento em que é validado todo o projeto: produto, processo de produção, aceitação do consumidor, e os custos do projeto.

- Estágio 5 - Lançamento - o início da produção e da comercialização do produto.

Essas etapas não serão realizadas da mesma forma em todos os projetos. Quando estes pertencerem a empresas menores e o projeto for de risco moderado, pode ser aplicado conforme a Ilustração 6. Caso o projeto seja de alto risco, devem ser aplicadas todas as atividades e pontos de decisão, conforme Ilustração 7.



Ilustração 6 - Processo do stage-gate para empresas menores, com projetos de risco moderado FONTE: COOPER et al; 2002b, p. 45. 


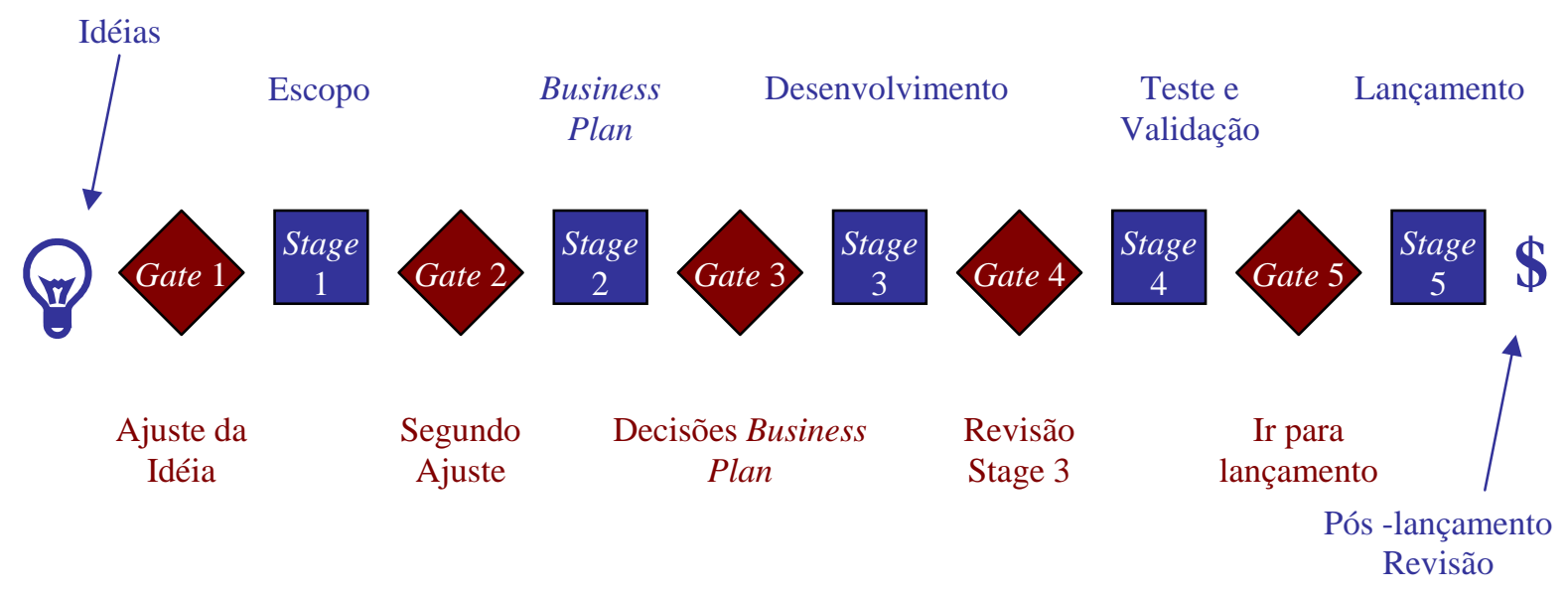

Ilustração 7 - Processo do stage-gate para empresas maiores, com projetos de alto risco FONTE: COOPER et al; 2002b, p. 45.

\subsubsection{Gerenciamento do projeto}

Quando se fala em gerenciar um projeto pensa-se logo em decisões relacionadas com os objetivos de desenvolvimento, tempo planejado, seqüência de desenvolvimento das atividades, os principais marcos e protótipos do projeto, mecanismos de coordenação entre os membros do time, e tudo que estiver relacionado com o monitoramento e controle do projeto. O monitoramento e controle antes, durante ou após o desenvolvimento do projeto.

Diante disso, Krishnan e Ulrich (2001) indicam as seguintes perguntas para guiar esta fase:

- Como o projeto será monitorado e controlado?

- Qual é a relação de prioridade dos objetivos do desenvolvimento?

- Qual o tempo planejado e a seqüência das atividades do processo de desenvolvimento?

- Quais os mecanismos de comunicação que serão utilizados entre os membros do time?

- Quais os principais marcos do projeto e os protótipos planejados?

Como foi apresentado anteriormente, existem diversas técnicas para organizar o processo de desenvolvimento, como o funil, o stage-gate, engenharia simultânea, dentre outras. Adotando corretamente essas técnicas, é possível se escolher bons projetos, definir um mix de produtos adequados aos recursos da empresa, reduzir o tempo de desenvolvimento, produzir com qualidade e, acima de tudo, monitorar e controlar os projetos. Clark e Wheelwright (1993) indicam que o processo deve ser formalmente monitorado durante todo o ciclo de vida do produto, por meio de um suporte efetivo da gerência. 
Esse monitoramento acontecerá por meio dos planejamentos elaborados. Baseado nesses planos, o time poderá definir qual o tempo ideal para cada etapa, qual a seqüência de atividades que serão realizadas num determinado projeto, os marcos e os protótipos planejados necessários. Conforme Krishnan e Ulrich (2001), para definir as prioridades de desenvolvimento, o tempo e a seqüência das atividades do processo, as empresas lançam mão de técnicas como Program Evaluation and Review Technique - PERT e CPM, bastante utilizadas na IC. A PERT é uma "análise de rede orientada a evento que estima a duração total do projeto, considerando as incertezas” (ROZENFELD et al, 2006, p. 538).

Vale salientar para o fato de que estabelecer um tempo de desenvolvimento muito severo pode prejudicar a conversão das idéias em produtos comerciáveis (CHANDY et al, 2006). Outro ponto relevante para a transformação de idéias em produtos comerciáveis é em relação aos projetos descartados. Muitas empresas têm dificuldade de eliminar projetos que já tenham sido aprovados, muitas vezes por serem projetos solicitados por fortes clientes, acreditando que se não realizá-los os perderão (COOPER et al, 2002b).

A maior dificuldade, porém, está na inexistência de ferramentas que auxiliem o descarte de projetos fracos, com pouca probabilidade de sucesso. Cooper et al (2002b) realizaram um estudo e identificaram que a grande maioria das empresas não possuíam nenhum critério de priorização de objetivos de desenvolvimento. Os autores acrescentam que a elaboração de um check list para cada marco auxiliará na escolha do melhor projeto, e que para prepará-los devem-se levar em consideração três pontos: ser de fácil uso; utilizar informações disponíveis; e diferenciar bons e maus projetos.

A comunicação atua nesse processo como fator fundamental para a efetivação do projeto. $\mathrm{O}$ desenvolvimento rápido e eficiente de um novo produto e processo dependem largamente da capacidade de se atingir a integração entre as funções na hora certa e de modo efetivo. Para se atingir a integração interfuncional, deve-se mudar não só as próprias funções (o que se faz), mas também o momento (quando se faz) e o modo de se exercer as funções (como se faz). Contudo, nem todos os desenvolvimentos de projetos requerem alto grau de integração interfuncional. 
Um fator crítico no desenvolvimento de um projeto é o grau de integração entre as diversas áreas envolvidas na GDP. Clark e Wheelwright (1993, p. 457) consideram a integração multifuncional fundamental para uma performance superior do desenvolvimento, no que diz respeito às dimensões de custo, tempo e qualidade. A integração multifuncional deve acontecer de forma que os departamentos colaborem entre si, com qualidade, e direcionando seus esforços para as demandas do ambiente empresarial.

O nível de integração requerido entre os departamentos pode variar de acordo com o momento em que o processo da GDP se encontra. Nas fases iniciais é preciso uma maior integração entre o marketing e o $P \& D$, enquanto que nas últimas fases o $P \& D$ deve estar mais integrado com a produção (FRISHAMMAR, 2005). Um outro fator que influencia no grau de integração é o tipo do produto e o tipo de inovação (FRISHAMMAR, 2005).

Frishammar (2005) diz que a integração é composta por duas dimensões: interação - inclui reuniões, teleconferência planejada, memorandos, e todo o fluxo de documentação padronizada; e colaboração - representando a informação menos estruturada, as relações afetivas entre os departamentos. Clark e Wheelwright (1993) complemetam essa classificação apresentando dois extremos de como ocorre a comunicação, baseada em quatro critérios de análise: riqueza, freqüência, direção e tempo.

De um lado encontra-se a comunicação realizada com menos freqüência; feita por meio de documentos; vinda de um único sentido, ou seja, um monólogo; e tardia. Do outro lado temse a comunicação mais rica, realizada cara a cara com a utilização de modelos gráficos, que facilitam a interação; mais freqüente; ocorre nos dois sentidos, ou seja, um diálogo; e acontece nas fases iniciais do projeto.

A importância da efetiva comunicação dentro dos times multifuncionais de cada projeto é clara, porém deve-se ser cuidadoso com o excesso de reuniões, ou seja, de interação. Como também se houver muita colaboração, os funcionários poderão ter problemas com regras, sendo necessárias mudanças no clima e na cultura organizacionais. A interação é necessária, mas não suficiente, enquanto que a colaboração faz a diferença no sucesso ou fracasso do produto (FRISHAMMAR, 2005). 
Brown e Eisenhardt (1995) afirmam que o sucesso da GDP é resultado de um cuidadoso planejamento aliado a um produto superior, este direcionado para um mercado atrativo, com a ajuda de um time multifuncional sob a coordenação de um senior management. Brown e Eisenhardt (1995) e Griffin (1997) ressaltam a importância do gerenciamento, afirmando que a atuação do gerente, o envolvimento e o compromisso da alta administração com o processo afetam o seu desempenho, no que se refere à qualidade, rapidez e produtividade.

Uma grande preocupação das empresas é que seus concorrentes copiem com facilidade seus diferenciais. As empresas podem utilizar diferentes métodos para se apropriar dos benefícios da atividade que desenvolve, pode se diferenciar de seus concorrentes mantendo em segredo o seu processo produtivo, ou pode proteger seu produto devido às suas características, outras podem lançar mão da proteção através das patentes. No entanto, a dificuldade da imitação ocorre em decorrência do conhecimento e das habilidades técnicas demandadas para o desenvolvimento de um determinado produto e/ou processo de uma empresa inovadora (PAVITT, 1984).

Diante de tantos planejamentos, controles, estratégias e ferramentas, parece certo o sucesso do projeto, no entanto, de acordo com Clark e Wheelwright (1993, p. 84), existem alguns problemas que nos levam a fazer correções no projeto, pois, na maioria das vezes, o que é planejado não acontece. Esses problemas ocorrem, uma vez que os gerentes não fazem planejamentos com antecedência, dessa forma não disponibilizam os recursos necessários para o desenvolvimento do projeto. Planejar é primordial para que os projetos e seus objetivos sejam definidos com clareza e riqueza de informações. E, por fim, os gerentes não podem falhar no momento de integrar o projeto que está sendo desenvolvido com as estratégias da empresa.

Diante de tantas técnicas a certeza de um excelente desenvolvimento parece certa, mas como saber se realmente o projeto está sendo bem desenvolvido? A performance do projeto é medida por meio do que foi planejado e do que efetivamente aconteceu. Conforme Clark e Wheelwright (1993) e Clark e Fujimoto (1991), são utilizadas três dimensões para avaliar a performance de projetos de desenvolvimento: tempo para colocar o produto no mercado (time-to-market), produtividade e qualidade do projeto. Estes devem ser otimizados para capacitar uma empresa na sua habilidade de atrair e satisfazer seus clientes, aumentando a competitividade de seus produtos. Estes três parâmetros desempenham um papel particular no 
melhoramento global do desempenho e competitividade no desenvolvimento de produtos. Para se obter um balanceamento otimizado do produto desenvolvido, as empresas devem buscar a excelência integrada nos três parâmetros.

A estrutura de uma estratégia deve ser bem desenvolvida e segura e não como é encontrada em diversas empresas, as quais apenas possuem um plano para tecnologia, outro para marketing e depois os transformam no projeto de execução. Todo processo de planejamento, de definição da estratégia deve ser feito primeiro definindo os objetivos e sempre trocando informações para que as estratégias de cada setor sejam desenvolvidas com direcionamento para a estratégia geral da empresa.

Clark e Wheelwright (1993, p. 16) indicam que bons projetos devem ter:

- objetivos claros e partilhados por todos; solução dos conflitos no início;

- antecipação ativa das necessidades dos futuros clientes;

- continuidade de ofertas;

- foco firme nos prazos;

- $\quad$ solução criativa de problemas;

- $\quad$ visão sistêmica do conceito do projeto;

- teste e validação antes da preparação do ferramental e da produção comercial;

- ampla competência nas funções críticas;

- solução integrada de problemas;

- responsabilidade na equipe;

- liderança forte e responsabilidades bem atribuídas.

A seguir serão discutidos os aspectos metodológicos da pesquisa de campo do presente trabalho. 


\section{Aspectos Metodológicos da Pesquisa}

Esta seção destina-se a apresentar os aspectos da pesquisa de campo, considerando a metodologia, a coleta de dados, a análise de dados e o relatório de pesquisa.

\subsection{Método geral da pesquisa}

Pesquisa, segundo Gil (2007, p. 17), é um “procedimento racional e sistemático que tem como objetivo proporcionar respostas aos problemas que são propostos”. A pesquisa é realizada por meio de conhecimentos disponíveis e da utilização de métodos, técnicas e outros procedimentos científicos.

Uma classificação bastante ampla para os métodos de investigação é o quantitativo e o qualitativo (RICHARDSON, 1999; GODOY, 1995a). Enquanto que no método quantitativo o pesquisador irá preocupar-se com a medição objetiva e a quantificação dos resultados, no qualitativo, serão obtidos dados descritivos sobre pessoas, lugares e processos, diante do contato direto do pesquisador com a situação estudada. Godoy (1995a, p. 62) indica que com o desenvolvimento do método qualitativo surgiu uma "grande diversidade de métodos de trabalho, estilos de análise e a apresentação de resultados e diferentes considerações quanto aos sujeitos”.

O presente trabalho se constituirá de pesquisa qualitativa, por essa razão serão apresentadas as características básicas desse tipo de pesquisa (GODOY, 1995a, p.62):

- o ambiente natural é a fonte direta dos dados e o pesquisador é o instrumento fundamental;

- é descritiva;

- $\quad$ procura-se compreender o fenômeno a partir da perspectiva dos participantes;

- não partem de hipóteses estabelecidas a priori.

Outra classificação, baseada nos objetivos gerais do estudo, é em pesquisas (GIL, 2007, p. 41): exploratórias; descritivas; e explicativas. A primeira tem a finalidade de aprofundar o 
conhecimento sobre um determinado problema, para torná-lo mais explícito ou para a construção de hipóteses. A segunda procura descrever as características de um fenômeno ou população pré-determinada, como também, a relação entre variáveis. E por fim, a pesquisa explicativa preocupa-se em identificar as relações de causa e efeito entre as variáveis estudadas.

Devido ao presente estudo não possuir hipóteses claramente definidas e ter pouco conhecimento sobre o tema no ambiente que será pesquisado, a melhor pesquisa que se aplica é a exploratória. O que é confirmado por Cooper e Schindler (2003), os quais afirmam que quando um pesquisador procura o entendimento sobre a natureza geral de um problema, o tipo de pesquisa mais adequado é a exploratória.

Nesta, não há uma estrutura rígida, os métodos são flexíveis, não estruturados e qualitativos (GIL, 1995). É um tipo de pesquisa que visa prover o pesquisador de maior conhecimento sobre o tema ou problema de pesquisa em perspectiva. Por se caracterizar como um estudo inicial, o pesquisador busca identificar hipóteses e variáveis, as quais servirão para comprovação em estudos futuros, por meio de um dos dois primeiros tipos de pesquisa citados. Apesar do valor óbvio da pesquisa exploratória, os pesquisadores dão menos atenção à exploração do que deveriam, pois há fortes pressões por respostas rápidas (COOPER; SCHINDLER, 2003, p. 131).

Dessa forma, esta pesquisa pode ser classificada como uma pesquisa qualitativa, já que não lançará mão de técnicas estatísticas; e exploratória, uma vez que se caracteriza por ser pesquisa inicial que tem como objetivo aprofundar o conhecimento sobre a gestão do desenvolvimento de novos produtos na IMC. Existe um conhecimento prévio, mas sobre outros setores industriais, com grandes diferenças do que será pesquisado.

\subsubsection{Dados secundários - levantamento bibliográfico e documental}

Cooper e Schindler (2003, p. 132) afirmam que o primeiro passo a ser dado em um estudo exploratório é buscar literatura secundária, esta essencial para o entendimento da situação estudada e para o bom desenvolvimento do problema pesquisado. Yin (2005) acrescenta que o levantamento de campo só deve ser iniciado após o entendimento da teoria do que está sendo estudado. 
Diante disso, foi desenvolvida para esta dissertação uma pesquisa bibliográfica e documental sobre os temas relevantes ao trabalho, GDP e IMC. A pesquisa bibliográfica coloca o pesquisador em contato com o que já se produziu a respeito do seu tema de pesquisa, tornando-se imprescindível para qualquer pesquisa científica. Apesar da semelhança que existe entre a pesquisa documental e a bibliográfica, há uma diferença fundamental entre elas, a natureza das fontes, onde na pesquisa documental são utilizados materiais que não receberam ainda um tratamento analítico, ou que ainda podem ser reelaborados de acordo com os objetivos da pesquisa (GIL, 2007, p. 46).

\subsubsection{Dados primários}

Como já foi dito anteriormente, os métodos, na pesquisa exploratória, são muito flexíveis, não estruturados e qualitativos, fazendo com que o pesquisador comece seu estudo sem préconcepções sobre aquilo que será encontrado. A pesquisa exploratória constitui-se pela primeira aproximação com o tema, visando conhecer os fatos e fenômenos relacionados a

este. É realizada através de entrevistas com profissionais da área, visitas a instituições e empresas em geral e, dentre as formas mais utilizadas, estão a pesquisa bibliográfica e o estudo de caso (GIL, 2007, p. 41). Já Godoy (1995b, p. 21) divide os possíveis métodos de pesquisa exploratória em documental, estudo de caso e etnográfica.

Uma outra classificação é a de Krishnan e Ulrich (2001), os quais apresentam duas abordagens metodológicas de pesquisa, na área de administração de operações. A primeira é a abordagem empírica composta por estudos de caso, levantamento e análise de dados por meio de questionários, entrevistas ou fontes secundárias, utilizadas para descrever e explicar fenômenos relacionados com o desenvolvimento de produtos e processos nas organizações. A segunda abordagem é a elaboração de um sistema de apoio à decisão em desenvolvimento de produtos. O objetivo desta abordagem é construir ferramentas que os executivos de desenvolvimento de produtos podem utilizar para melhorar o desempenho do seu sistema de inovação.

O estudo de caso é, portanto, um dos métodos mais indicados para pesquisas em fase exploratória, e será adotado neste estudo. Esse tipo de pesquisa é definido por Yin (2005) como uma forma de se fazer pesquisa social empírica com a investigação de um fenômeno 
atual dentro de seu contexto de vida real, onde as fronteiras entre o fenômeno e o contexto não são claramente definidas e na situação em que múltiplas fontes de evidência são usadas.

\subsection{Método da pesquisa de campo}

Segundo Yin (2005, p. 32), "um estudo de caso é uma investigação empírica que investiga um fenômeno contemporâneo dentro de seu contexto de vida real, especialmente quando os limites entre o fenômeno e o contexto não estão claramente definidos”. É um estudo profundo e exaustivo, que permite o detalhamento do conhecimento (GIL, 2007; GODOY, 1995b).

O estudo de caso caracteriza-se por ser uma estratégia, do método de pesquisa, única, utilizado quando há muitas variáveis a serem consideradas, sendo que nem sempre todas são conhecidas pelo pesquisador. Dessa forma, para que a pesquisa seja realizada efetivamente, o estudo de caso deve se basear em fontes de evidência variadas, de onde serão levantados os dados que convergirão para a resposta da pergunta da pesquisa. Isso só será possível se o pesquisador possuir conhecimento prévio da teoria do tema estudado, possibilitando assim o desenvolvimento de proposições de pesquisa. Nesse sentido, o estudo de caso é mais que apenas uma técnica de coleta de campo, ou de planejamento de pesquisa, é uma estratégia de pesquisa abrangente.

Conforme Yin (2005, p. 23), existem três condições que indicam a adequação do estudo de caso como ferramenta de pesquisa: a) o tipo de questão-problema; b) o controle que o pesquisador possui sobre o comportamento dos eventos e c) o foco contemporâneo, em oposição ao histórico. O estudo de caso é, então, adequado para pesquisas que possuem perguntas como “por que” e “como”, as quais são mais explanatórias; em que não há controle do pesquisador sobre o comportamento dos eventos; e onde o foco é em eventos contemporâneos, e não análises históricas (YIN, 2005, p. 19).

As três características acima citadas encontram-se presentes no estudo que se pretende realizar. Vale ressaltar que não há uma estratégia de pesquisa melhor ou pior que outra, no entanto, é preciso buscar a mais adequada à pergunta e às condições de pesquisa. 
A presente pesquisa possui a pergunta do tipo "como" (Como é realizado o processo de gestão do desenvolvimento de um novo produto na indústria de materiais de construção?). O objetivo da pesquisa é compreender um fenômeno complexo, mas não estabelecer relações de causa e efeito. Apesar da utilização do levantamento para coleta de dados primários parecer viável para este estudo, não se aplica, pois muitas variáveis, pertinentes à questão-problema, podem ser omitidas. A questão-problema proposta é ampla e exige entendimento profundo, por isso a opção pelo estudo de caso, que preserva as características holísticas e significativas da vida real (YIN, 2005, p. 21).

No entanto, existem algumas desvantagens na adoção da estratégia do estudo de caso. Uma das principais é a impossibilidade de generalização dos resultados obtidos, o que não coincide com o pensamento de Yin (2005, p. 29), quando indica que os estudos de caso podem sim ser generalizados, porém não da mesma forma que a generalização estatística feita por meio de estudos amostrais.

A generalização adequada para estudos de caso é a analítica, na qual o pesquisador procura generalizar um conjunto particular de resultados a uma teoria mais ampla (YIN, 2005, p. 58). Porém, para que essa generalização ocorra é preciso que o pesquisador tenha clara a teoria sobre o assunto pesquisado, podendo identificar as semelhanças dos casos e dos resultados obtidos. Para que seja feita, é preciso realizar a repetição do estudo em um segundo ou terceiro caso com características semelhantes que justifiquem, com base na teoria levantada, resultados semelhantes. Caso os resultados de fato se assemelhem, poderão ser generalizados sem a necessidade de mais replicações (YIN, 2005, p. 59).

Esta pesquisa exploratória, no entanto, não tem a pretensão de trazer resultados generalizáveis. O que se busca aqui é levantar um primeiro entendimento sobre o tema, que possibilite a compreensão das variáveis relacionadas para a possível realização de pesquisas futuras, como por exemplo, uma pesquisa explicativa.

\subsubsection{Tipos de estudos de caso}

Yin (2005, p. 40) sugere que uma pesquisa, que lance mão do método do estudo de caso, deve levar em consideração duas dimensões: o número de casos que compõem o estudo (caso 
único ou casos múltiplos) e o foco de análise (uma ou várias unidades de análise). Dessas duas dimensões surgem quatro tipos de estudo de caso (Quadro 8).

\begin{tabular}{|c|c|c|}
\hline \multicolumn{3}{|c|}{ Quadro 8 - Tipos básicos de projetos para estudo de caso } \\
\hline $\begin{array}{c}\text { Holístico } \\
\text { (unidade única de análise) }\end{array}$ & Projeto de caso único & Projeto de casos múltiplos \\
$\begin{array}{c}\text { Incorporado } \\
\text { (unidades múltiplas de } \\
\text { análise) }\end{array}$ & Tipo 1 & Tipo 3 \\
\hline
\end{tabular}

FONTE: YIN, 2001, p. 61.

Quanto à quantidade de casos, pode ser única, quando se dedica a pesquisar apenas um caso; ou múltipla, quando trabalha com mais de um caso. O pesquisador deve optar pelo caso único em situações que representam: a) todos os aspectos de uma teoria bem formulada; b) um caso raro, extremo ou único; e c) uma oportunidade única para o pesquisador. Caso não se configure em nenhuma dessas condições, o estudo de casos múltiplos é o mais adequado.

O estudo de casos múltiplos deve ser realizado por meio da lógica de replicação e não da amostragem. A seleção dos casos estudados deve ser feita por meio da expectativa de resultado de cada caso. Os casos selecionados devem prever resultados semelhantes (definido como replicação literal), ou resultados contrastantes por razões previsíveis (definido como replicação teórica). Ou seja, é preciso que o pesquisador tenha clara a teoria sobre o assunto estudado de modo que possa selecionar casos que tragam resultados semelhantes (replicação literal), ou possa identificar quais fatores podem ser responsáveis por alterações nos resultados dos casos (replicação teórica). Independente da opção de replicação, os estudos de casos múltiplos vêm sendo amplamente utilizados, pois são em geral encarados como mais robustos e convincentes do que estudos de caso único.

Quanto à unidade de análise, o estudo de caso pode ser holístico ou incorporado. Um estudo de caso é incorporado quando subdivide o caso estudado em unidades menores, que são analisadas separadamente e formam, ao final, um conjunto. Um estudo de caso é holístico, quando não são feitas subdivisões e o caso é analisado de forma geral (YIN, 2005, p.61-75).

Em relação à unidade de análise, um estudo de caso holístico deve ser utilizado apenas quando não é possível identificar subunidades dentro do caso estudado, e/ou quando o 
próprio estudo de caso tenha natureza holística. No entanto, ao se optar por trabalhar com estudo de caso incorporado, é preciso atenção para que ao final não se tenha um conjunto de análises desvinculadas e que não sejam capazes de formar uma pesquisa única.

Assim, a pesquisa aqui proposta pretende trabalhar com o estudo de caso múltiplo incorporado. Optou-se por trabalhar com múltiplos casos, pois não foram encontrados casos que fossem por si só decisivos, raros, ou reveladores. Dessa forma, a estratégia de múltiplos casos se mostra mais interessante por possibilitar a confrontação de quatro diferentes casos, classificados conforme critérios pré-estabelecidos, os quais serão citados no tópico seguinte. O que se espera é encontrar resultados semelhantes (replicação literal).

O estudo foi dividido em duas unidades de análise: nível de gerência da carteira de projetos e nível de gerência de projetos individuais. A análise destas duas subunidades pretende dar uma visão geral do processo de gestão do desenvolvimento de novos produtos na indústria de materiais de construção, podendo assim responder à questão e aos objetivos da pesquisa. Os critérios para escolha dos casos serão indicados no tópico a seguir.

\subsubsection{Protocolo para execução da pesquisa}

Com a finalidade de proporcionar maior confiabilidade à pesquisa, Yin (2001) destaca a importância do uso do protocolo para o estudo de caso, especialmente em múltiplos casos. Yin (2005, p. 92) comenta sobre o protocolo,

Um protocolo para o estudo de caso é mais do que um instrumento. O protocolo contém o instrumento, mas também contém os procedimentos e as regras gerais que deveriam ser seguidas ao se utilizar o instrumento. É desejável se possuir um protocolo para o estudo de caso em qualquer circunstância, mas é essencial se você estiver utilizando um projeto de casos múltiplos.

Segundo o autor, o protocolo deve conter as seguintes seções:

a) visão geral do projeto, que deve incluir os objetivos, questões do estudo de caso e leituras necessárias sobre o tópico em análise;

b) procedimentos de campo, incluindo fontes gerais de informações sobre o caso e procedimento previamente determinados para coleta dos dados; 
c) questões do estudo de caso, considerando as questões específicas apresentadas no instrumento de coleta dos dados, tabelas para arranjo dos dados e fontes potenciais de informação para a resposta de cada questão;

d) guia para o relatório do estudo de caso, incluindo resumo e especificação de informações bibliográficas e outras documentações.

Os procedimentos de campo do protocolo devem enfatizar:

a) obtenção de acesso a organizações ou a entrevistados-chave;

b) ter em mãos todo o material necessário para a realização da pesquisa de campo;

c) definir uma agenda clara das atividades de coleta de dados;

d) estar preparado para acontecimentos inesperados, como impossibilidade de o entrevistado atender o pesquisador, demora em assunto sem maior importância, etc.

O protocolo deve servir como guia, dando flexibilidade ao pesquisador para considerar novos aspectos e insights. Com base no que foi dito, foi elaborado um protocolo (Apêndice 2) dessa dissertação, do qual faz parte o instrumento de coleta de dados (Apêndices 3 e 4).

É preciso também definir o nível das fontes de informações. Yin (2005, p. 98) apresenta dois níveis possíveis de fontes de dados: o indivíduo e a organização, que devem ser selecionados de acordo com os objetivos do estudo. Esta relação é apresentada na Ilustração 8.

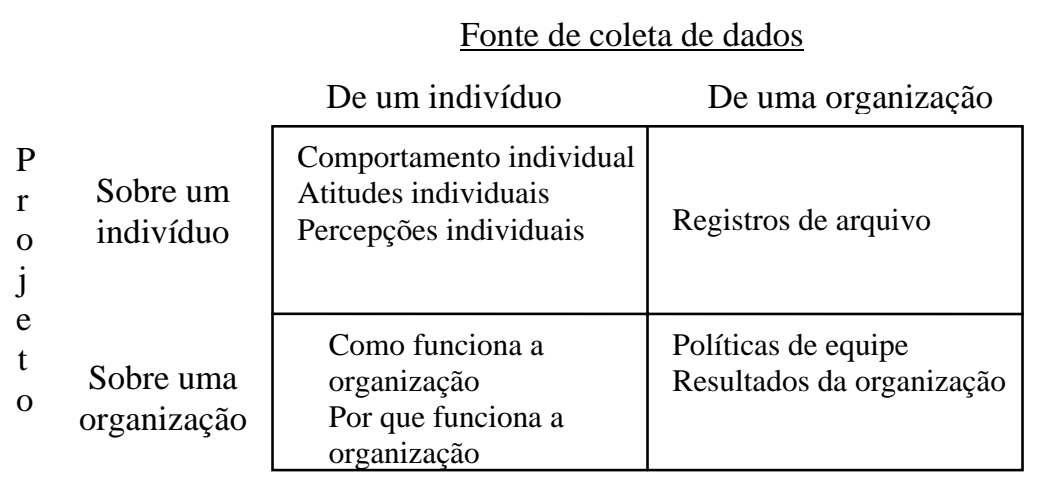

Ilustração 8 - Níveis de fontes de coleta de dados FONTE: YIN, 2001, p. 98.

\author{
Conclusões \\ do estudo \\ Se o estudo de \\ caso for um \\ indivíduo \\ Se o estudo de \\ caso for uma \\ organização
}

Como o estudo de caso aqui proposto pretende estudar a organização e seus processos, e não os indivíduos que compõem a organização, as fontes de dados utilizadas foram do indivíduo e da organização. 


\subsubsection{Casos pesquisados}

Estudaram-se neste trabalho múltiplos casos de empresas de um mesmo setor, IMC, com a finalidade de identificar como ocorre o processo de gestão do desenvolvimento de novos produtos na indústria de materiais de construção. Buscaram-se encontrar resultados semelhantes (replicação literal) nos quatro casos estudados.

O setor escolhido foi o da IMC, por ser este um dos setores que possuem pouca pesquisa nesse tema e está em processo de desenvolvimento crescente. Para definição do setor a ser pesquisado, alguns especialistas da área foram ouvidos, a saber:

- representante da Abramat;

- três professores da Escola Politécnica da Universidade de São Paulo;

- diretores de duas lojas de materiais de construção, no Estado de São Paulo e Ceará.

Segundo informações fornecidas por estes especialistas, o segmento da IMC tem crescido cada vez mais, procurando inserir no mercado produtos inovadores e diferenciados. Por este motivo, tem aperfeiçoado seus processos de desenvolvimento de novos produtos. Apesar do tema da pesquisa já ter sido bastante explorado em outros setores industriais, este ainda se encontra em fase inicial neste setor.

Conforme Eisenhardt (1989), a seleção de uma população apropriada controla variações estranhas e ajuda a definir os limites de generalização do caso. Os casos podem ser escolhidos para replicar um caso anterior ou estender a teoria existente, ou podem também ser escolhidos para preencher a teoria existente com casos ainda não abordados ou pouco estudados, que é a situação desta pesquisa.

Para definição da população susceptível a participar do estudo, são propostos os seguintes critérios:

- Indústrias de materiais de construção. 
- Empresas que ganharam o primeiro lugar, como melhores indústrias de materiais de construção, no $16^{\circ}$ Prêmio Anamaco ${ }^{23}$, e que tenham sido indicadas, tanto pelas pequenas e médias empresas, como pelos grandes clientes, em, no mínimo, três das 52 categorias existentes (Anexo B).

As empresas selecionadas, mediante os critérios acima indicados foram:

- Lorenzetti - se destaca nos segmentos de disjuntores residenciais; duchas, chuveiros e torneiras elétricas; e aquecedores de passagem a gás.

- Deca - indicada para os segmentos de metais sanitários economizadores; metais sanitários não economizadores; e sistemas de descarga.

- Tigre - destaque nos segmentos de tubos de PVC para água fria; conexões de PVC para água fria; e tubos e conexões para água quente.

A Deca ganhou, além dos prêmios em cada uma das categorias citadas acima, o prêmio de melhor inovação tecnológica de 2007. Enquanto a Lorenzetti foi, também, premiada em 2006 e 2007 como melhores lançamentos e, em 2006, como melhor inovação tecnológica.

Foram enviados para os contatos em cada empresa uma carta de apresentação que objetivava apresentar o estudo realizado e convidá-las para participar deste estudo. O modelo de carta de apresentação enviado consta dos Apêndices (Apêndice 5 - Carta de apresentação). No entanto, após contato direto com tais empresas, por meio de telefonemas e e-mails, somente a Deca e a Tigre decidiram participar da pesquisa.

De forma a acrescentar mais uma empresa ao estudo, a banca de qualificação desta dissertação indicou alguns novos nomes, mantendo o perfil das empresas selecionadas anteriormente, como: Quartzolit Weber, Celite e Cecrisa. Apenas as duas últimas aceitaram participar da pesquisa, porém após a realização da primeira entrevista na Celite, percebeu-se que esta possuía diversas limitações na disponibilização de informações essenciais para a análise final da pesquisa, e por essa razão foi excluída do estudo.

\footnotetext{
${ }^{23}$ O Prêmio Anamaco é realizado através de uma Pesquisa Anamaco com parceria com o IBOPE Solution. Esta levantou, este ano, junto a 1.432 lojistas de todo o país, as melhores indústrias do setor de Material de Construção. Foram pesquisados 52 segmentos (Anexo B), além de veículos de carga, melhores inovações tecnológicas e produtos do ano, em duas categorias distintas: pulverização (lojistas de pequeno e médio porte) e grandes clientes (138 grandes lojistas - home centers e lojas de material de construção de grande porte (REVISTA ANAMACO, 2006).
} 
A quarta empresa que fez parte desta pesquisa foi a Perflex. Inicialmente havia sido selecionada apenas para validação do questionário, no entanto as informações coletadas foram tão ricas, que se resolveu inseri-la na análise final desta dissertação. Portanto, as empresas que fizeram parte desta pesquisa foram: Perflex, Deca, Cecrisa e Tigre.

Dessa forma, a amostra da pesquisa é não-probabilística por conveniência, onde a seleção inicial da amostragem é de responsabilidade do entrevistador, de acordo com Cooper e Schindler (2003, p. 152). Apesar deste tipo de amostra ser menos dispendiosa, e proporcionar rapidez e conveniência, pode haver um possível viés de seleção. Independente desta possibilidade, a amostra não é representativa, logo, não é indicada para pesquisas que sejam predominantemente descritivas ou causais. A opção por este tipo de amostra foi feita em função da dificuldade existente em conseguir empresas que tenham interesse e disponibilidade para participar da pesquisa, e que possuam processos de GDP formalizados.

Vale destacar que as quatro empresas estudadas além de se direcionarem para a indústria da construção de edifícios, comerciais e residenciais, classificam-se em componentes, conforme categorização de Cardoso et al (2002).

\subsubsection{Instrumento de coleta de dados}

Com o objetivo de conseguir maior validade de construto, definida por Yin (2005, p. 56) como "medidas operacionais corretas sobre os conceitos que estão sob estudo", esta pesquisa contará com múltiplas fontes de dados. Assim, pretende-se minimizar os vieses que cada uma delas pode trazer e assegurar com maior grau de certeza a veracidade dos dados levantados.

Yin (2005, p. 109) afirma que o estudo de caso permite a utilização de seis fontes principais: documentação, registro em arquivos, entrevistas, observação direta, observação-participante e artefatos físicos. O autor destaca também que é importante que seja utilizada mais de uma fonte de evidência. Diante disso, a presente pesquisa utilizou como fonte principal a entrevista pessoal, considerada uma das mais importantes fontes de informação para um estudo de caso (YIN, 2005), a análise de documentos e a observação direta. 
De acordo com Brown e Eisenhardt (1995), na maior parte dos estudos em GDP os pesquisadores lançam mão de questionários ou entrevistas realizadas com pessoas bem posicionadas dentro da empresa. As entrevistas para a coleta de dados contemplaram dois tipos de públicos ou papéis (diretor ou gerente, time de projeto) a fim de possibilitar uma visão mais abrangente do processo da GDP.

O método de entrevista utilizado foi o não estruturado e não disfarçado. E a técnica foi a entrevista em profundidade, em que, segundo Gil (2007), não há estrutura rígida predefinida de perguntas e respostas. Esta técnica parece a mais adequada à natureza do estudo aqui proposto em que se busca levantar “insights” e descrever o fenômeno estudado.

A entrevista foi feita tendo por base um roteiro de perguntas abertas, focando aspectos prescritivos e descritivos do processo de gestão do desenvolvimento de novos produtos, conforme Apêndices 3 e 4. Tais entrevistas foram complementadas por e-mails e telefonemas, com o objetivo de esclarecer dúvidas e acrescentar detalhes necessários para um melhor entendimento do processo de GDP.

É importante ressaltar que a validação do instrumento de coleta de dados deve ser assegurada durante sua elaboração, verificando a compatibilidade dos objetivos específicos de pesquisa com os termos ou variáveis e os itens constantes nos instrumentos de coleta de dados. Os roteiros das entrevistas foram também pré-testados com o Gerente Industrial da empresa Perflex, a qual inicialmente não iria participar da pesquisa, porém, devido à riqueza das informações coletadas, foi inserida.

Além da entrevista, foram analisados alguns outros documentos: organograma da empresa; notícias e demais artigos publicados na mídia sobre a empresa e sua atuação; site da empresa na internet. Com o intuito de garantir a confiabilidade do estudo, todos os dados e informações coletados foram armazenados em um banco de dados para que estejam disponíveis para análise futura de quaisquer interessados.

\subsubsection{Respondentes}

As informações recebidas de cada uma das empresas se originaram de dois a três executivos em nível de diretoria ou gerência nas áreas de planejamento, engenharia, marketing, 
operações e P\&D em cada uma das empresas pesquisadas. Vale destacar que a possibilidade de distorção foi reduzida em determinados pontos da pesquisa, já que diferentes entrevistados falaram a respeito do mesmo assunto. Quando os assuntos não coincidiam, complementavamse.

Ao longo da coleta de dados, houve duas fases distintas, uma coleta a respeito do processo de gestão da carteira de projetos e outra se referindo a decisões mais específicas ao desenvolvimento de um projeto. Em seguida, complementaram-se as informações coletadas com uma série de e-mails e telefonemas. Ainda, todas as conversas foram gravadas e devidamente anotadas no exato momento da entrevista, assegurando o máximo de fidelidade aos relatos.

Na Perflex, a entrevista foi realizada inicialmente com o Gerente Industrial e depois com o Supervisor de Engenharia, também responsável pelo time de desenvolvimento. Nesta empresa foi possível confirmar e complementar informações obtidas em uma e outra entrevista. Não houve divergência de informações, e os contatos posteriores foram essenciais para complementações e esclarecimentos.

No caso da Deca, o contato foi feito com a Designer, responsável pela primeira etapa do processo de GDP, e também participante ativa do time, como também com o chefe da área de Planejamento. A designer foi quem respondeu aos dois questionários, sendo que as perguntas sobre as quais não tinha conhecimento foram complementadas pelo chefe da área de Planejamento. Diversos contatos foram feitos, por e-mail e telefonemas, para obtenção de conhecimentos (ou: dados) adicionais.

$\mathrm{Na}$ Cecrisa, primeiramente foi realizada uma entrevista com o diretor executivo e, posteriormente, com o gerente de produtos e marketing estratégico. Inicialmente, a entrevista iria ser realizada somente com o diretor executivo e, por essa razão aplicaram-se os dois questionários. Porém, durante sua transcrição, observou-se que alguns pontos mereciam um detalhamento maior de informações. Nesse momento foi realizada a entrevista com o gerente de produtos e marketing estratégico, onde foi possível confirmar diversas informações inicialmente obtidas e então complementar a pesquisa. 
Por fim, na Tigre os entrevistados foram o gerente de produtos e marketing, o gerente de P\&D e o coordenador de oportunidades, os quais se juntaram em uma sala de reunião, apresentaram um documento interno da empresa e depois abriram um espaço para discussões e complementações dos temas mais relevantes para a pesquisa e que não tinham sido ainda citados. A técnica foi bastante proveitosa, pois se conseguiu juntar duas áreas, marketing e $\mathrm{P} \& \mathrm{D}$, que se complementam em todo o processo, com dois representantes de níveis de gerência e um do nível técnico. As informações eram todas confirmadas na hora da entrevista, tanto pelos respondentes, quanto pelo documento que estava sendo apresentado no momento.

A seguir será apresentada a estratégia de análise dos dados utilizada na presente pesquisa.

\subsubsection{Estratégia de análise dos dados}

Uma vez coletados os dados, é preciso ter definido como serão feitas as análises para que se possa chegar à resposta da questão-problema da pesquisa. Yin (2005, p. 133-136) apresenta duas estratégias gerais de análise: baseando-se em proposições teóricas e desenvolvendo uma descrição do caso. A estratégia geral baseada em proposições teóricas é utilizada quando a teoria levantada sobre o assunto permite ao pesquisador levantar possíveis padrões de comportamento ou possíveis relações de causa e efeito entre as variáveis estudadas. Nesses casos, as proposições teóricas devem servir como guia de quais dados levantar e como analisá-los em conjunto.

Quando não existirem proposições teóricas anteriores à pesquisa de campo, a exemplo desta pesquisa, será utilizada a estratégia de descrição do caso. Esse tipo de estratégia de análise se aplica em situações casos em que o objetivo inicial é exatamente realizar uma descrição de algum fenômeno estudado, ou quando o que se busca não é a descrição do fenômeno, mas onde a análise da teoria não for suficiente para identificar relações causais entre as variáveis. Nesses casos, a abordagem descritiva pode auxiliar a identificação das relações de causa e efeito.

Como o objetivo deste estudo pode ser considerado prioritariamente descritivo, a estratégia geral de análise adotada foi o desenvolvimento da descrição do caso. Cada descrição individual tem a seguinte estrutura: 
- Caracterização da empresa:
o histórico
o tipo de produto
o segmentação do mercado

- Gestão do desenvolvimento de produtos:
o conceito
o estratégia e planejamento do produto
o organização do desenvolvimento do produto
o gerenciamento do projeto
o Etapas de desenvolvimento:
- desenvolvimento do conceito
- projeto da cadeia de suprimentos
- projeto do produto
- teste e validação de desempenho
- ramp-up e lançamento.

- Conclusão

No item gestão do desenvolvimento de produtos deve conter um primeiro quadro indicando as etapas e subetapas do processo de GDP da empresa em questão. Nos itens Estratégia e planejamento do produto, Organização do desenvolvimento do produto e Gerenciamento do projeto deve conter, em cada uma, um quadro, similar ao Quadro 9, mas com o acréscimo de uma coluna, à direita, que especifique as decisões tomadas por cada empresa. Serão utilizadas as decisões indicadas no Quadro 9 que fazem menção à cada um dos temas citados. O mesmo deve ser feito com o item Etapas do projeto, sendo que para cada uma das etapas haverá referência a cada linha do Quadro 10.

Quadro 9 - Decisões para organização de projetos de desenvolvimento

\begin{tabular}{|c|l|}
\hline $\begin{array}{c}\text { Organização do Projeto } \\
\text { de Desenvolvimento }\end{array}$ & \multicolumn{1}{|c|}{ Decisões para organização de projetos de desenvolvimento } \\
\hline & $\begin{array}{l}\text { - Estratégia de Mercado (KRISHNAN; ULRICH, 2001; CLARK; } \\
\text { WHEELWRIGHT, 1993) - produtos que serão ofertados, público-alvo e forma que } \\
\text { serão disponibilizados; número, tempo e taxa de mudança da plataforma; e define } \\
\text { número, tempo, freqüência e relações de produtos diferenciados; componentes } \\
\text { compartilhados entre as plataformas. }\end{array}$ \\
$\begin{array}{c}\text { Estratégia e } \\
\text { Planejamento do Produto }\end{array}$ & $\begin{array}{l}\text { Estratégia Tecnológica - tecnologia necessária; tecnologia que dê vantagem } \\
\text { competitiva; fonte externa e interna; tempo para capacitação; maturação da } \\
\text { tecnologia; e freqüência das implementações (KRISHNAN; ULRICH, 2001; } \\
\text { CLARK; WHEELWRIGHT, 1993). }\end{array}$ \\
\hline
\end{tabular}




\begin{tabular}{|c|l|}
\hline & - Plano Agregado de Projetos - prioridades; escolha do projeto e definição de \\
& quando começam e terminam; recursos disponíveis (CLARK; WHEELWRIGHT, \\
& 1993). \\
& - Aprendizados e melhorias para projetos futuros - melhoria das capacidades \\
envolvidas no processo e do próprio processo em si (CLARK; WHEELWRIGHT, \\
1993).
\end{tabular}

Quadro 10 - Decisões das etapas do processo de desenvolvimento

\begin{tabular}{|c|c|}
\hline $\begin{array}{c}\text { Etapas segundo } \\
\text { Krishnan e Ulrich (2001) }\end{array}$ & Decisões das etapas do processo de desenvolvimento \\
\hline $\begin{array}{l}\text { Desenvolvimento do } \\
\text { Conceito }\end{array}$ & $\begin{array}{l}\text { - Interação de todos os envolvidos no processo (SMITH; REINERTSEN, 1998). } \\
\text { - Clientes e consumidores finais - participação no processo de desenvolvimento; } \\
\text { utilização de ferramentas para conhecer as necessidades do mercado, como QFD } \\
\text { (GRIFFIN; HAUSER, 1993). } \\
\text { - Escopo detalhado do produto - tecnologias disponíveis e necessárias; normas; } \\
\text { patentes e legislação relacionada ao produto; identificar quem é o cliente, o } \\
\text { consumidor e suas necessidades; requisitos do produto; produtos concorrentes e } \\
\text { similares; serviços agregados ao produto; objetivos ou metas que o produto deve } \\
\text { atender; preço; e outras informações relevantes para a empresa (ROZENFELD et al, } \\
\text { 2006, p. 213; SMITH; REINERTSEN, 1998; VON HIPPEL, 1986; THOMKE; } \\
\text { VON HIPPEL, 2002; SMITH; REINERTSEN, 1998; COOPER et al, 2002a; } \\
\text { SLAUGHTER, 1991); congelamento das características em etapas iniciais ou finais } \\
\text { (ROZENFELD et al, 2006; BACON et al, 1994 apud KRISHNAN; ULRICH, } \\
\text { 2001); Conceito central - input - technology-driven concept; service concept; } \\
\text { design-driven concept; value-driven concept; customer- and market-driven concept } \\
\text { (BACKMAN et al, 2007). } \\
\text { - Arquitetura do produto, forma física e projeto industrial - desenho virtual ou } \\
\text { croqui (KRISHNAN; ULRICH, 2001). }\end{array}$ \\
\hline
\end{tabular}




\begin{tabular}{|c|c|}
\hline & $\begin{array}{l}\text { - Variações do produto - quais serão oferecidas, componentes compartilhados } \\
\text { entre as variações (KRISHNAN; ULRICH, 2001). }\end{array}$ \\
\hline $\begin{array}{l}\text { Projeto da Cadeia de } \\
\text { Suprimentos }\end{array}$ & $\begin{array}{l}\text { - Componentes - projetados internamente ou comprados prontos; quem projetará, } \\
\text { desenvolverá e produzirá (KRISHNAN; ULRICH, 2001). } \\
\text { - Cadeia física de suprimentos - configuração, incluindo o local de junção dos } \\
\text { componentes; seleção de fornecedores das tecnologias e equipamentos; sistema de } \\
\text { produção e distribuição; custos diretos de produção; custos entre fornecimento e } \\
\text { demanda (KRISHNAN; ULRICH, 2001). }\end{array}$ \\
\hline Projeto do Produto & $\begin{array}{l}\text { - Especificação dos parâmetros do projeto - projeto detalhado dos componentes; } \\
\text { relação entre os componentes do produto; seleção de material e de processo e } \\
\text { projeto das ferramentas e equipamentos; planos de processo; desenhos finais com } \\
\text { tolerâncias (ROZENFELD et al, 2006). } \\
\text { - Embalagem - avaliação da distribuição do produto, incluindo transporte e } \\
\text { entrega; definição das formas e sinalizações das embalagens dos produtos; projeção } \\
\text { da embalagem; planejamento do processo de embalagem (ROZENFELD et al, } \\
\text { 2006). } \\
\text { - Material de suporte do produto - criação do manual de operação do produto, do } \\
\text { material de treinamento e do manual de descontinuidade do produto (ROZENFELD } \\
\text { et al, 2006). }\end{array}$ \\
\hline $\begin{array}{l}\text { Teste e Validação de } \\
\text { Desempenho }\end{array}$ & $\begin{array}{l}\text { - Prototipagem para validação - em relação a funcionamento, tamanho e } \\
\text { fabricação (KRISHNAN; ULRICH, 2001); avalia reações dos consumidores, } \\
\text { projeto industrial, durabilidade, encaixe e finalização, e custos de produção } \\
\text { (ROZENFELD et al, 2006; CLARK; WHEELWRIGHT, 1993). } \\
\text { - Teste em pequena escala do projeto - produção piloto (CLARK; } \\
\text { WHEELWRIGHT, 1993); definição dos processos de produção e manutenção } \\
\text { (ROZENFELD et al, 2006). } \\
\text { - Tipo de protótipo - rápida resposta à engenharia, sistema de solução integrado } \\
\text { (periódico), ou replicação da produção cedo (CLARK; WHEELWRIGHT, 1993). } \\
\text { - Processo de construção dos protótipos - simulação virtual, prototipagem rápida } \\
\text { (experimentação real), e protótipos de papelão ou argila (CLARK; } \\
\text { WHEELWRIGHT, 1993; THOMKE, 1998; SRINIVASAN et al, 1997; BECKER et } \\
\text { al, 2005); seqüencial ou paralela; prototipagem em etapas iniciais do projeto } \\
\text { (SRINIVASAN et al, 1997). } \\
\text { - Benefícios do protótipo - contribuem para a identificação de oportunidades; } \\
\text { aprendizado da organização; formação de novas capacidades; testa a comunicação } \\
\text { entre os membros do projeto; auxilia na resolução de conflitos (CLARK; } \\
\text { WHEELWRIGHT, 1993). }\end{array}$ \\
\hline Ramp-up e Lançamento & $\begin{array}{l}\text { - Teste de mercado - nível de realização; seqüência de introdução dos produtos no } \\
\text { mercado (CLARK; WHEELWRIGHT, 1993). } \\
\text { - Lançamento - tempo para o lançamento do produto; como e quando o } \\
\text { concorrente entrará ou entrou no mercado; finalização do desenvolvimento do } \\
\text { projeto; desenho dos processos de venda e distribuição; atendimento do cliente e } \\
\text { assistência técnica; campanhas de marketing (ROZENFELD et al, 2006). } \\
\text { - Ramp-up - aumento da produção (CLARK; WHEELWRIGHT, 1993; } \\
\text { ROZENFELD et al, 2006). } \\
\text { - Ao fim cessa ou continua o acompanhamento do produto pelo time } \\
\text { (ROZENFELD et al, 2006). }\end{array}$ \\
\hline
\end{tabular}

Posteriormente, foi elaborado o Capítulo 6, onde é feita a apresentação comparada dos resultados obtidos a partir da análise individual. Sua estrutura foi a mesma utilizada na descrição dos casos individuais. No Capítulo 7 constam as análises conclusivas, onde foi aplicada a estratégia de construção da explanação, na qual a explanação final pode não ter sido inteiramente estipulada no começo do estudo, permitindo novas ilações baseadas nas 
evidências sob uma nova perspectiva, assemelhando-se ao processo de aprimoramento de um conjunto de idéias (YIN, 2005). 


\title{
5 DESCRIÇÃO DOS CASOS
}

\subsection{Perflex}

\subsubsection{Caracterização da empresa}

\subsubsection{Histórico}

A Perflex Metais foi fundada em 1979, iniciando suas atividades com a fabricação de flexíveis fornecidos somente para indústrias de metais sanitários. Com o tempo começou a investir na área produtiva, contratou mão-de-obra especializada, diversificou sua linha de produtos, estruturou a área comercial e desenvolveu as áreas administrativa e financeira. Caracteriza-se por ser uma empresa seguidora, que procura identificar no mercado os produtos que tenham vantagem competitiva e assim poder produzí-los. Por essa razão, não precisa de uma estrutura formal de GDP, mas de um mínimo de organização, como é o que acontece.

Atualmente está instalada em uma área de 20.000 m², com cerca de 250 funcionários, mais de 60 representantes comerciais e diversas atividades terceirizadas. Para que os dados financeiros da empresa fossem preservados, apenas se indicou o faturamento hoje em torno de $\mathrm{R} \$ 30$ a R\$ 60 milhões por ano.

A Perflex acredita que (PERFLEX, 2008),

\begin{abstract}
Graças à qualidade dos produtos e à parceria dos colaboradores, a Perflex consagrou-se no segmento de metais sanitários. Hoje ela é conhecida e respeitada em todo território nacional. Sempre atenta ao mercado e às exigências dos consumidores, procura oferecer os melhores serviços de assessoria nas áreas de produção, comercial, administrativa e financeira. É por isso que ela nunca pára de crescer.
\end{abstract}

\subsubsection{Tipo de produto}

Possui cerca de 630 produtos, tendo como principais os misturadores, torneiras, acessórios para banheiro, chuveiros, duchas manuais, duchas higiênicas, sifões, flexíveis, registros e válvulas. Anualmente são lançados aproximadamente 50 novos produtos, o que corresponde 
a duas linhas completas por ano. De acordo com a Perflex (2008), há 10 anos a empresa vem se dedicando a produtos com design e conceitos inspirados nas principais tendências mundiais.

Exporta para América do Sul, Central e do Norte, África e Europa. Pelo perfil de seus produtos é possível perceber a importância que a empresa dá para o consumidor final, ao justificar que é o próprio consumidor quem irá decidir qual produto comprar, dependendo do estilo de sua casa e, assim, do modelo de um determinado metal sanitário.

\subsubsection{Segmentação do mercado}

A Perflex procura ter um relacionamento próximo com seus clientes finais (Business to Consumer - B2C), isso se deve ao perfil do seu produto. O metal sanitário é um produto que não exige grandes recomendações técnicas para sua compra, assim o consumidor identifica a melhor opção para sua casa, por meio do design do produto. A proximidade com o cliente é fundamental para extrair oportunidades para sua carteira de produtos.

\subsubsection{Gestão do desenvolvimento dos produtos Perflex}

De acordo com o Gerente Industrial da Perflex (2007), esta área foi oficializada há apenas cinco anos. Anteriormente esta atividade já existia na empresa, mas em caráter informal. Nessa época, a alta administração idealizava o produto e envolvia outras áreas, como ferramentaria, usinagem e engenharia, para realização e teste dos protótipos. No entanto, mesmo sendo considerada, hoje, uma atividade formalizada dentro da empresa, não existe nenhum documento que descreva como deve acontecer o processo de desenvolvimento de um novo produto. Apesar dessa falta de formalização, adquiriu experiência com o tempo, o que proporcionou a identificação de etapas básicas para o desenvolvimento de seus projetos. $\mathrm{O}$ Quadro 11 indica as etapas e subetapas do processo de GDP da Perflex.

Quadro 11 - Etapas e subetapas do processo de GDP da Perflex

\begin{tabular}{|l|l|}
\hline \multicolumn{1}{|c|}{ Etapas } & \multicolumn{1}{c|}{ Subetapas } \\
\hline & $\begin{array}{l}\text { Identificação de Oportunidades } \\
\text { Identificação de Oportunidades e Seleção das Idéias } \\
\text { Ordenamento dos Projetos }\end{array}$ \\
\hline Planejamento do Produto & Elaboração do Cronograma \\
\hline Desenvolvimento do Conceito & Desenvolvimento do Conceito \\
\hline
\end{tabular}




\begin{tabular}{|c|c|}
\hline & Protótipo Virtual \\
\hline Engenharia do Produto e do Processo de Produção & $\begin{array}{l}\text { Protótipo em metal maciço } \\
\text { Teste no mercado } \\
\text { Produção das ferramentas e equipamentos } \\
\text { Lote piloto }\end{array}$ \\
\hline Avaliação do Projeto & $\begin{array}{l}\text { Avaliação da viabilidade técnica pela engenharia } \\
\text { Avaliação da viabilidade financeira pela área de } \\
\text { custos } \\
\text { Avaliação do marketing } \\
\text { Ficha técnica do produto }\end{array}$ \\
\hline Lançamento e Ramp-up & $\begin{array}{l}\text { Lançamento interno } \\
\text { Lançamento externo }\end{array}$ \\
\hline
\end{tabular}

Antes da discussão sobre as etapas e subetapas do processo, será apresentado como a Perflex, nas pessoas do Gerente Industrial e de um dos Supervisores de Engenharia, enxerga a GDP.

\subsubsection{Conceito}

Para a Perflex o processo contempla desde o entendimento da necessidade de um cliente, seja técnica ou estética, até a viabilização dessa necessidade, por meio da transformação das informações obtidas em um produto. Conforme o Gerente Industrial da empresa, é preciso primeiro criar um conceito, reproduzi-lo em caráter de projeto e, por fim, materializar esse desejo, sempre munidos de protótipos e testes no mercado para que tenham a certeza de que atenderam ou mesmo superaram as expectativas de seus consumidores. Um dos supervisores de engenharia complementa que também faz parte do processo de desenvolvimento de produtos o lançamento deste no mercado, sendo que a área responsável por essa etapa é a comercial, representada no time pelo Diretor da Perflex.

\subsubsection{Estratégia e planejamento do produto}

Em um primeiro momento é feito um planejamento estratégico que envolve os dois níveis mais altos da empresa: diretoria e gerência. Em seguida cada gerente, a partir do planejamento, distribui e detalha esse planejamento para sua área, mantendo-o sustentável ao longo do ano. Conforme o Gerente Industrial da Perflex, esse plano é reformulado bimestralmente, devido ao fato de estarem inseridos em um ambiente muito dinâmico.

Com o planejamento em mãos, o gerente industrial tem condições de definir os seus objetivos de desenvolvimento. São coletadas informações de três fontes para definição da nova carteira 
de produtos: pesquisa de mercado, elaborada pela área de marketing; tendências e moda do setor, observadas pelo Diretor da Perflex, nas feiras e eventos do setor; e análise dos projetos anteriores da empresa. Nas palavras do Gerente Industrial:

No segmento de metais sanitários a tendência começa na Europa, os líderes do mercado começam então a trazer a mesma tendência para o mercado nacional, a qual vai sendo repassada para todas as outras empresas. Anualmente nós vamos a feiras internacionais, principalmente na Europa, para absorver o desejo do consumidor.

Na Perflex (2008), percebe-se uma grande preocupação em inovar, indicando que nos últimos 10 anos a empresa tem se dedicado mais para o desenvolvimento de novos produtos, com design e conceitos inspirados nas principais tendências mundiais. Os produtos também são produzidos com conceitos de preservação ambiental, alcançados através de aprimoramentos tecnológicos voltados para a economia de água. Está tipificada como uma empresa seguidora, que tem o design, o mercado e a sustentabilidade como inputs para o desenvolvimento de seus novos produtos.

A partir desse levantamento, a empresa define em qual segmento deseja atuar e, com base nisso, planeja os produtos e identifica seus respectivos custos. A estratégia de mercado e a estratégia tecnológica são descritas conjuntamente. Definem quais produtos serão ofertados no ano, com o público-alvo; como também a tecnologia necessária, indicando a que proporcionará vantagem competitiva. O tempo necessário para gerir o desenvolvimento é também definido nessa etapa.

Com isso em mãos, avaliam a viabilidade dos projetos, com base nos dados coletados e nos recursos disponíveis para seu desenvolvimento. São definidos três projetos por ano, os quais são agrupados em linhas de produtos. Cada projeto cuida de uma linha, composta por 20 a 30 peças. Essas três linhas são itens totalmente novos para a empresa com diferencial no design, pois a sua funcionalidade geralmente é muito semelhante, salvo alguns casos específicos. Além disso, de acordo com os entrevistados, a grande solicitação do mercado é em modificações no design. Sendo que, a partir do momento em que são feitas inovações estéticas, design, ocorre a necessidade de serem feitos ajustes técnicos, que são mínimos na maioria das vezes. 
O portfólio de produtos que serão ofertados pela Perflex, devido a sua deficiência na identificação de oportunidades e a ausência de uma área de $\mathrm{P} \& \mathrm{D}$, possui um número pequeno de idéias, sem grandes inovações tecnológicas. Seu portfólio de produtos é formado, geralmente, por projetos topológicos, mudanças indicadas pela área de vendas e industrial, como também para ajustes ao estilo de vida do segmento que se direciona.

A empresa também possui projetos de melhoria contínua, onde são inseridas as pequenas modificações e ajustes que são feitos nos produtos. Essas alterações são provenientes da assistência técnica, produção, engenharia, qualidade, processo e custos. De acordo com o gerente industrial, para esse tipo de projeto existe uma grande preocupação com a redução de custos, para que se consiga disponibilizá-lo para classes mais baixas, mantendo-o por mais tempo em sua carteira ativa de projetos.

Vale ressaltar que, apesar da empresa já ter selecionado as três linhas que serão desenvolvidas no ano, elas podem ser abortadas em etapas seguintes. Caso a Perflex perceba que o projeto é inviável ou mesmo se, ao fazer o teste no mercado, notar que este não respondeu bem, o projeto será descontinuado. Isso pode acontecer até a etapa de avaliação do projeto. Selecionadas as três linhas que serão desenvolvidas, utilizam-se critérios para indicar qual projeto será desenvolvido primeiro. Basicamente, quem indica essa ordem é a área de marketing.

No que se refere aos aprendizados e melhorias para projetos futuros, a Perflex procura melhorar as capacidades envolvidas no processo e o próprio processo em si. Isso é feito através do preenchimento, por cada área, de uma ficha de avaliação do projeto. Além disso, a área de marketing se encarrega de coletar informações com os representantes comerciais e lojas para serem identificadas necessidades de alguma modificação na linha, coletando informações sobre aceitação do produto e volume de vendas. Com isso em mãos a empresa faz as melhorias necessárias, indicadas tanto pelas áreas internas da empresa, como pelo mercado consumidor, dando assim continuidade à vida útil do produto. Vale ressaltar que essas modificações são mais direcionadas ao produto e ao processo de produção, e não ao processo de desenvolvimento.

No Quadro 12 é apresentada, de forma resumida, a maneira que a Perflex desenvolve essa primeira fase do processo de GDP. 
Quadro 12 - Decisões Perflex - estratégia e planejamento do produto

\begin{tabular}{|c|c|c|}
\hline $\begin{array}{l}\text { Organização do } \\
\text { Projeto de } \\
\text { Desenvolvimento } \\
\end{array}$ & $\begin{array}{c}\text { Decisões para a organização de projetos de } \\
\text { desenvolvimento }\end{array}$ & Decisões Perflex \\
\hline $\begin{array}{c}\text { Estratégia e } \\
\text { Planejamento do } \\
\text { Produto }\end{array}$ & $\begin{array}{l}\text { - Estratégia de Mercado (KRISHNAN; ULRICH, } \\
\text { 2001; CLARK; WHEELWRIGHT, 1993) - produtos } \\
\text { que serão ofertados, público-alvo e forma que serão } \\
\text { disponibilizados; número, tempo e taxa de mudança } \\
\text { da plataforma; e define número, tempo, freqüência e } \\
\text { relações de produtos diferenciados; componentes } \\
\text { compartilhados entre as plataformas. } \\
\text { - Estratégia Tecnológica - tecnologia necessária; } \\
\text { tecnologia que dê vantagem competitiva; fonte } \\
\text { externa e interna; tempo para capacitação; maturação } \\
\text { da tecnologia; e freqüência das implementações } \\
\text { (KRISHNAN; ULRICH, 2001; CLARK; } \\
\text { WHEELWRIGHT, 1993). } \\
\text { - Plano Agregado de Projetos - prioridades; escolha } \\
\text { do projeto e definição de quando começam e } \\
\text { terminam; recursos disponíveis (CLARK; } \\
\text { WHEELWRIGHT, 1993). } \\
\text { - Aprendizados e melhorias para projetos futuros - } \\
\text { melhoria das capacidades envolvidas no processo e do } \\
\text { próprio processo em si (CLARK; WHEELWRIGHT, } \\
\text { 1993). }\end{array}$ & $\begin{array}{l}\text { - Estratégia de Mercado - } \\
\text { produtos que serão ofertados; } \\
\text { público-alvo. } \\
\text { - Estratégia Tecnológica - } \\
\text { tecnologia necessária; } \\
\text { tecnologia que dê vantagem } \\
\text { competitiva; tempo para } \\
\text { capacitação. } \\
\text { - Plano Agregado de } \\
\text { Projetos - prioridades; } \\
\text { escolha do projeto e definição } \\
\text { de quando começam e } \\
\text { terminam; recursos } \\
\text { disponíveis. } \\
\text { - Aprendizados e melhorias } \\
\text { para projetos futuros - } \\
\text { melhoria das capacidades } \\
\text { envolvidas no processo e o } \\
\text { próprio processo em si. }\end{array}$ \\
\hline
\end{tabular}

\subsubsection{Organização do desenvolvimento do produto}

Define-se nessa fase questões relacionadas ao time, estrutura de desenvolvimento, arranjo físico, investimentos, processo de desenvolvimento e desempenho. A Perflex possui apenas uma planta para a produção de seus produtos e, por essa razão, um centro de desenvolvimento de novos produtos. A área de desenvolvimento está sob a responsabilidade do gerente industrial da empresa, que por sua vez responde para o diretor e proprietário da empresa. Sem considerar o gerente industrial e o diretor, esta área é composta por sete pessoas, sendo: um supervisor de engenharia, o supervisor do projeto; um tecnólogo, quem realiza os testes laboratoriais dos produtos; três técnicos, os projetistas; e arquiteta, indica tendências do mercado. Os projetistas são os responsáveis pela elaboração dos protótipos virtuais do produto. Para realização desta pesquisa, foram entrevistados o gerente industrial da Perflex e um de seus supervisores de engenharia.

A organização das atividades do time é por projeto, ou seja, cada vez que se inicia um novo projeto, forma-se um time específico para tal, com pessoas fixas e também cargos e funções, que variam de projeto para projeto. Sua estrutura multifuncional é composta da parte fixa, 
que contém as seguintes funções: diretor, gerente industrial e arquiteta, e a variável vai de acordo com a necessidade de determinada função no projeto: supervisor de engenharia, tecnólogo e projetista. A participação da alta administração é bastante ativa, estando presente durante todo o processo de desenvolvimento de novos produtos. Isso se deve ao fato de a Perflex ser uma empresa pequena, onde há a possibilidade do acompanhamento, pelo diretor, de todas as suas atividades.

Dentre as áreas que compõem a empresa, marketing, vendas, tecnologia, produção e finanças fazem parte do time de desenvolvimento, cada um alocado em seu setor de trabalho, pois não existe uma área comum. Nenhuma das estruturas associadas ao papel da liderança, classificação de Clark e Wheelwright (1993), se aplica à Perflex. Nesta empresa a estrutura é funcional, onde um dos supervisores de engenharia é gerente de determinados projetos, e não possui poder para alterar o que foi inicialmente decidido pela alta administração, somente sob autorização do diretor, o qual participa ativamente de todo o processo. O supervisor de engenharia atua mais como um supervisor do projeto, tendo o diretor como o próprio gerente.

Na organização do desenvolvimento do produto deve-se procurar definir quais investimentos serão feitos com o novo projeto. Na Perflex podem ser em infra-estrutura, ferramentas e treinamentos necessários, o que vai de acordo com o que Clark e Wheelwright (1993) indicam. O processo de desenvolvimento da Perflex traz conceitos da abordagem tradicional de desenvolvimento, que, conforme Clark e Wheelwright (1993), o processo ocorre de forma seqüencial; e do stage-gate, que se apresenta na parada após cada etapa para análise dos resultados e aprovação, pela alta administração, para início da etapa seguinte. O funil de Clark e Wheelwright (1993) não é utilizado na empresa, pois o processo ocorre similar à um túnel, onde entra um produto, aperfeiçoam, produzem e lançam.

No Quadro 13 estão descritas, de forma resumida, todas as decisões para organização de projetos de desenvolvimento na Perflex, com base na literatura estudada.

Quadro 13 - Decisões Perflex - organização do desenvolvimento do produto

\begin{tabular}{|c|c|c|}
\hline $\begin{array}{c}\text { Organização do } \\
\text { Projeto de } \\
\text { Desenvolvimento }\end{array}$ & $\begin{array}{c}\text { Decisões para organização de projetos de } \\
\text { desenvolvimento }\end{array}$ & Decisões Perflex \\
\hline $\begin{array}{c}\text { Organização do } \\
\text { Desenvolvimento } \\
\text { do Produto }\end{array}$ & $\begin{array}{c}\text { - Time - membros da diretoria, gerente funcional, } \\
\text { responsável pela engenharia, gerente de projeto, } \\
\text { especialistas e parceiros (ROZENFELD } \text { et al, 2006); }\end{array}$ & $\begin{array}{l}\text { - Time - membros da diretoria, } \\
\text { gerente funcional, responsável } \\
\text { pela engenharia, especialistas; }\end{array}$ \\
\hline
\end{tabular}




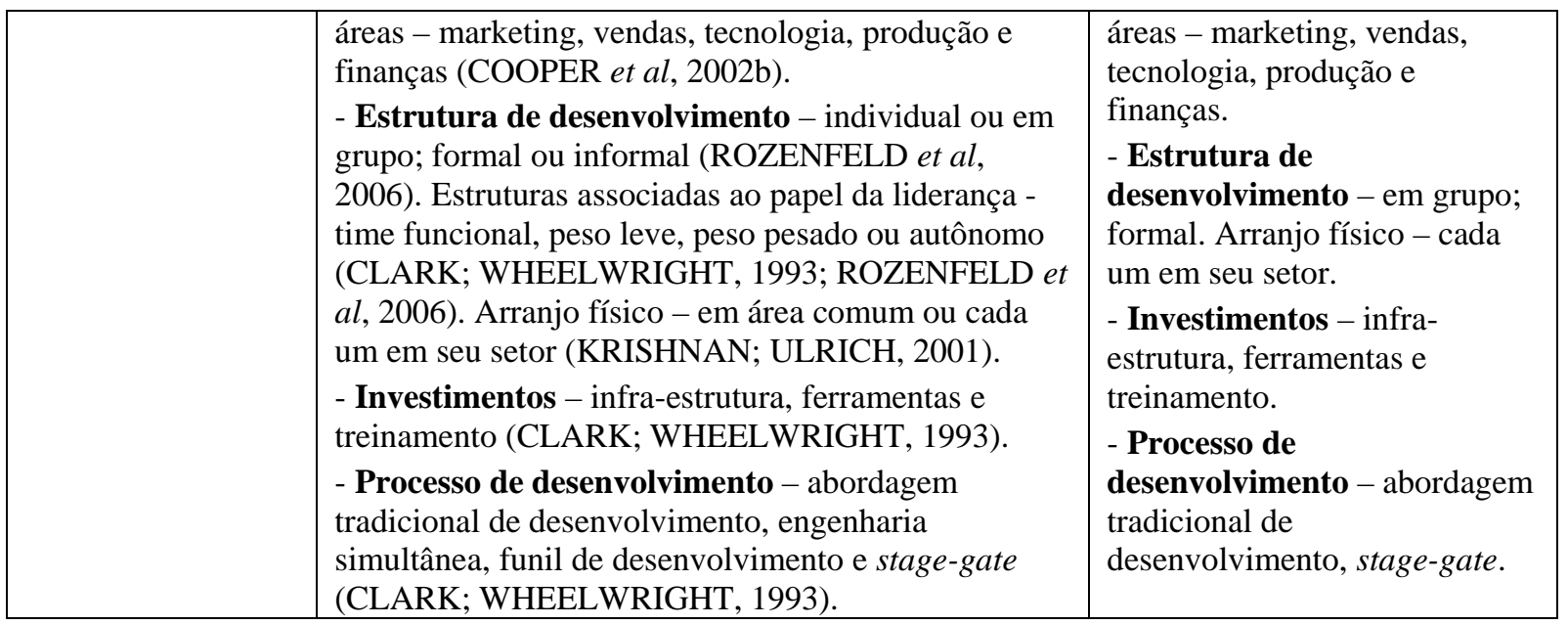

\subsubsection{Gerenciamento do projeto}

Definido o primeiro projeto elabora-se seu cronograma de acompanhamento, monitorado pelo gerente industrial e controlado efetivamente pelo supervisor de engenharia. Para sua elaboração conta-se também com a participação do diretor da empresa. Deve-se lembrar que essa etapa é iniciada com o segmento que o produto se direcionará e com os custos do projeto traçados e aprovados.

O cronograma de acompanhamento é composto pelas seguintes informações: objetivo; atividades; responsáveis; prazos; teste laboratorial e de mercado do produto; e ensaios na produção. No objetivo é definido o design do novo produto que, na maioria das vezes, é apresentado pelo diretor da empresa, um modelo virtual ou mesmo uma foto do produto desejado. No item atividades serão descritas todas as etapas que a Perflex precisará realizar para efetivação do projeto, indicando-se os responsáveis e os prazos. Nesse cronograma também estão presentes os momentos em que serão realizados os testes laboratoriais do produto, como também os testes no mercado e os ensaios na linha de produção.

Na Perflex, a prioridade de desenvolvimento de um produto é definida pelo marketing, que por sua vez se baseia nas necessidades do mercado e na percepção do diretor sobre o mercado consumidor. O tempo de desenvolvimento é fixado de acordo com as feiras, onde será exposta sua nova carteira de produtos, as quais ocorrem semestralmente. A definição dos marcos, protótipos e etapas do projeto são detalhados no cronograma, servindo para seu monitoramento e controle. 
A empresa citada não possui uma estrutura com critérios formais para descarte de projetos, isso poderá acontecer em qualquer momento do processo, desde que sejam explicadas, comprovadas e analisadas pela alta administração, as razões que motivam a descontinuação do projeto.

Outro ponto de decisão nessa fase é em relação à comunicação. A integração do time é multifuncional, como já foi apresentado anteriormente. Conforme Frishammar (2005), o time pode interagir e/ou colaborar entre si. No caso da Perflex, ocorrem as duas coisas de forma equilibrada, já que existem as reuniões formais e as conversas informais sobre os projetos. E, por fim, de acordo com Clark e Wheelwright (1993), a comunicação pode se dar de duas maneiras, monólogo ou diálogo. Na Perflex se caracteriza como diálogo e acontece nas fases iniciais do projeto. Por a empresa ser pequena, a comunicação não podia ser de outra forma, as discussões informais enriquecem e agilizam o tempo nas reuniões formais.

A forma em que será medido o desempenho do projeto também deve ser vista nessa etapa, no entanto a Perflex sempre analisa o desempenho da mesma maneira, não sendo um ponto de decisão. E, nesse caso, é medido levando-se em consideração o que foi planejado e comparando-se com o que efetivamente aconteceu, ocasião em que também é analisada a qualidade do projeto. O Quadro 14 apresenta as decisões para organização de projetos de desenvolvimento na Perflex, levando-se em consideração a literatura pesquisada.

Quadro 14 - Decisões Perflex - gerenciamento do projeto

\begin{tabular}{|c|c|c|}
\hline $\begin{array}{c}\text { Organização do } \\
\text { Projeto de } \\
\text { Desenvolvimento } \\
\end{array}$ & $\begin{array}{c}\text { Decisões para organização de projetos de } \\
\text { desenvolvimento }\end{array}$ & Decisões Perflex \\
\hline $\begin{array}{l}\text { Gerenciamento do } \\
\text { Projeto }\end{array}$ & $\begin{array}{l}\text { - Monitoramento e controle - através de planos, } \\
\text { formal, atuação do gerente e envolvimento e } \\
\text { compromisso da alta administração (BROWN; } \\
\text { EISENHARDT, 1995; CLARK; WHEELWRIGHT, } \\
\text { 1993; ROZENFELD et al, 2006; GRIFFIN, 1997). } \\
\text { - Priorização, tempo de desenvolvimento, seqüência } \\
\text { das atividades e marcos do projeto - planejamentos } \\
\text { com auxílio do PERT e CPM; cronograma } \\
\text { (KRISHNAN; ULRICH, 2001; ROZENFELD et al, } \\
\text { 2006). } \\
\text { - Descarte de projetos - critérios para descarte; check } \\
\text { list (COOPER et al, 2002b). } \\
\text { - Comunicação - integração funcional ou } \\
\text { multifuncional (CLARK; WHEELWRIGHT, 1993); } \\
\text { interação e/ou colaboração (FRISHAMMAR, 2005); e } \\
\text { monólogo ou diálogo, que acontece nas fases iniciais } \\
\text { do projeto (CLARK; WHEELWRIGHT, 1993). }\end{array}$ & $\begin{array}{l}\text { - Monitoramento e controle - } \\
\text { através de planos, formal, } \\
\text { atuação do gerente, e } \\
\text { envolvimento e compromisso da } \\
\text { alta administração. } \\
\text { - Priorização dos projetos, } \\
\text { tempo de desenvolvimento, } \\
\text { seqüência das atividades e } \\
\text { marcos do projeto - } \\
\text { cronograma. } \\
\text { - Descarte de projetos - critérios } \\
\text { para descarte. } \\
\text { - Comunicação - integração } \\
\text { multifuncional; interação e } \\
\text { colaboração; diálogo, que } \\
\text { acontece nas fases iniciais do } \\
\text { projeto. }\end{array}$ \\
\hline
\end{tabular}




\begin{tabular}{|l|l|l|}
\hline & $\begin{array}{l}\text { - Desempenho - qualidade do projeto, tempo para } \\
\text { colocar o produto no mercado e produtividade; } \\
\text { planejado x o que efetivamente aconteceu (CLARK; } \\
\text { WHEELWRIGHT, 1993; CLARK; FUJIMOTO; } \\
\text { 1991). }\end{array}$ & $\begin{array}{l}\text { - Desempenho - qualidade do } \\
\text { projeto; planejado x o que } \\
\text { efetivamente aconteceu. }\end{array}$ \\
\hline
\end{tabular}

\subsubsection{Etapas de desenvolvimento}

O processo de desenvolvimento de novos produtos na Perflex acontece em seis etapas (Ilustração 9). No entanto, as etapas iniciais de identificação de oportunidades e planejamento do produto já foram descritas nos itens anteriores, estando presentes nas fases de Estratégia e planejamento do produto, Organização do desenvolvimento do produto e Gerenciamento do projeto.



A descrição das etapas será feita com base na classificação apresentada por Krishnan e Ulrich (2001), que se subdivide em cinco etapas: desenvolvimento do conceito; projeto da cadeia de suprimentos; projeto do produto; teste e validação de desempenho; e ramp-up e lançamento. As etapas do processo da Perflex (Ilustração 9) foram alinhadas com as etapas de Krishnan e Ulrich (2001) como forma de análise (Quadro 15).

Quadro 15 - Quadro comparativo das etapas de Krishnan e Ulrich (2001) versus etapas Perflex

\begin{tabular}{|l|l|}
\hline \multicolumn{1}{|c|}{ Etapas segundo Krishnan e Ulrich (2001) } & \multicolumn{1}{c|}{ Etapas Perflex } \\
\hline Desenvolvimento do Conceito & Desenvolvimento do Conceito do Produto \\
\hline Projeto da Cadeia de Suprimentos & Engenharia do Produto e do Processo de Produção \\
\hline Projeto do Produto & Avaliação do Projeto \\
\hline Teste e Validação de Desempenho & Ramp-up e Lançamento \\
\hline Ramp-up e Lançamento & \\
\hline
\end{tabular}

\section{a) Desenvolvimento do conceito do produto}


Com o planejamento do produto feito e descrito no cronograma de acompanhamento, iniciase a etapa de desenvolvimento do conceito do produto. Nessa etapa será definido o conceito central, o escopo detalhado do produto, sua arquitetura, forma física e projeto industrial e variações do produto (ROZENFELD et al, 2006; BACKMAN et al, 2007; KRISHNAN; ULRICH, 2001). Deve ser identificado quem é o cliente, o consumidor e quais suas necessidades (SMITH; REINERTSEN, 1998; VON HIPPEL, 1986; THOMKE; VON HIPPEL, 2002; SMITH; REINERTSEN, 1998; COOPER et al, 2002a; SLAUGHTER, 1991), e sua participação no processo de desenvolvimento (GRIFFIN; HAUSER, 1993).

Na Perflex, a interação ocorre desde as etapas iniciais, entre todos os envolvidos no projeto em questão. No início, já pode ser identificado o cliente, o consumidor e suas necessidades, o que servirá de base para o desenvolvimento do conceito do produto. Seu conceito central parte do mercado, o que se encaixa na classificação de customer-and market-driven concept, conforme Backman et al (2007). O design do produto e a sustentabilidade são também fatores importantes na definição do conceito.

Apesar de o conceito ser proveniente do mercado consumidor, este participa apenas indiretamente do processo de desenvolvimento. Isso se dá por meio da área de marketing que realiza pesquisa de mercado, como também testes com o mercado alvo daquele determinado produto, no decorrer do processo. Outro conceito que está sendo fortemente utilizado pelas empresas do setor, e que é também utilizado na definição do conceito dos projetos na Perflex é o input sustentabilidade.

O projeto é entregue para o projetista selecionado para fazer parte deste time. Ele produzirá o primeiro protótipo virtual com auxílio de softwares, como o solid work e o solid can, os quais desenham a peça em 3D, possibilitando a realização de testes na parte técnica do produto, como: resistência, mecânica, tração e encaixe de folga. No entanto, todos esses recursos para testes virtuais somente serão utilizados na etapa seguinte. Com esse protótipo virtual será possível conhecer a arquitetura do produto, sua forma física e o projeto industrial, como também os componentes que serão compartilhados entre as variações do produto.

Nesse momento é definido o design inicial da nova linha, os componentes necessários, e suas relações, mas ainda nada definitivo. O projetista apresenta o protótipo virtual para o restante do time, que o aprovará conjuntamente para que assim possa ser iniciada a etapa seguinte. 
No Quadro 16 contém as decisões que a Perflex toma na etapa de desenvolvimento do conceito do produto.

Quadro 16 - Decisões Perflex - desenvolvimento do conceito

\begin{tabular}{|c|c|c|}
\hline $\begin{array}{c}\text { Etapa segundo } \\
\text { Krishnan e Ulrich } \\
(2001)\end{array}$ & Decisões das etapas do processo de desenvolvimento & Decisões Perflex \\
\hline $\begin{array}{l}\text { Desenvolvimento } \\
\text { do Conceito }\end{array}$ & $\begin{array}{l}\text { - Interação de todos os envolvidos no processo } \\
\text { (SMITH; REINERTSEN, 1998). } \\
\text { - Clientes e consumidores finais - participação no } \\
\text { processo de desenvolvimento; utilização de ferramentas } \\
\text { para conhecer as necessidades do mercado, como QFD } \\
\text { (GRIFFIN; HAUSER, 1993). } \\
\text { - Escopo detalhado do produto - tecnologias } \\
\text { disponíveis e necessárias; normas; patentes e legislação } \\
\text { relacionada ao produto; identificar quem é o cliente, o } \\
\text { consumidor e suas necessidades; requisitos do produto; } \\
\text { produtos concorrentes e similares; serviços agregados } \\
\text { ao produto; objetivos ou metas que o produto deve } \\
\text { atender; preço; e outras informações relevantes para a } \\
\text { empresa (ROZENFELD et al, 2006, p.213; SMITH; } \\
\text { REINERTSEN, 1998; VON HIPPEL, 1986; THOMKE; } \\
\text { VON HIPPEL, 2002; SMITH; REINERTSEN, 1998; } \\
\text { COOPER et al, 2002a; SLAUGHTER, 1991); } \\
\text { congelamento das características em etapas iniciais ou } \\
\text { finais (ROZENFELD et al, 2006; BACON et al, 1994 } \\
\text { apud KRISHNAN; ULRICH, 2001); Conceito central - } \\
\text { input - technology-driven concept; service concept; } \\
\text { design-driven concept; value-driven concept; customer- } \\
\text { and market-driven concept (BACKMAN et al, 2007). } \\
\text { - Arquitetura do produto, forma física e projeto } \\
\text { industrial - desenho virtual ou croqui (KRISHNAN; } \\
\text { ULRICH, 2001). } \\
\text { - Variações do produto - quais serão oferecidas, } \\
\text { componentes compartilhados entre as variações } \\
\text { (KRISHNAN; ULRICH, 2001). }\end{array}$ & $\begin{array}{l}\text { - Interação de todos os } \\
\text { envolvidos no processo. } \\
\text { - Clientes e consumidores } \\
\text { finais - utilização de } \\
\text { ferramentas para conhecer as } \\
\text { necessidades do mercado. } \\
\text { - Escopo detalhado do } \\
\text { produto - identificar quem é } \\
\text { o cliente, o consumidor e } \\
\text { quais suas necessidades; } \\
\text { requisitos do produto; } \\
\text { produtos concorrentes e } \\
\text { similares; objetivos ou metas } \\
\text { que o produto deve atender; } \\
\text { preço; congelamento das } \\
\text { características em etapas } \\
\text { finais. Conceito central - } \\
\text { customer- and market-driven } \\
\text { concept. } \\
\text { - Arquitetura do produto, } \\
\text { forma física e projeto } \\
\text { industrial - desenho virtual. } \\
\text { - Variações do produto - } \\
\text { quais serão, componentes } \\
\text { compartilhados entre as } \\
\text { variações. }\end{array}$ \\
\hline
\end{tabular}

\section{b) Projeto da cadeia de suprimentos}

Na Perflex o projeto da cadeia de suprimentos é feito paralelamente à etapa de projeto do produto, modificando assim a ordem apresentada por Krishnan e Ulrich (2001). Por essa razão, essa etapa será tratada no item seguinte, juntando as discussões sobre o projeto da cadeia de suprimentos com o projeto do produto. 


\section{c) Projeto do produto}

Na Perflex essa etapa, junto com a anterior, é denominada de engenharia do produto e do processo de produção, a qual se constitui na definição final do design do produto e de sua parte técnica. Na primeira parte dessa etapa é feito um protótipo em metal, maciço, para definição da estética do produto, design. Por ser um protótipo maciço, pode ser refeito quantas vezes forem necessárias, pois o material é reciclável, podendo ser derretido logo após sua análise. Para a produção desse protótipo é utilizada a área de ferramentaria, não havendo necessidade de se parar a linha produtiva para a produção de apenas uma peça de teste.

Aprovado pelo time, o protótipo é repassado para a área de marketing, com o intuito de realizar o teste do produto no mercado, pois acredita que inserindo o consumidor, mesmo que indiretamente no processo, conseguirá desenvolver um produto mais adequado às necessidades atuais do mercado. Para isso é selecionado um de seus revendedores, ou um representante comercial que irá analisar o produto e indicar possíveis modificações. Caso sejam necessárias, estas serão feitas e o teste de mercado será também refeito. Esse processo será repetido até que o protótipo seja aprovado pela área de marketing.

Com a aprovação da área de marketing é iniciado o processo de definição da parte técnica do produto. Nesse momento quem toma a frente do projeto é o supervisor de engenharia, que faz parte do time, mas sempre acompanhado pelo time. A engenharia irá desenvolver a parte interna do produto, identificando assim todos os componentes que serão necessários para o projeto, como também suas relações, indicando ainda os que serão produzidos internamente ou por terceiros. Alguns dos componentes que são feitos fora da empresa são: cromação, embalagem, componentes de plástico, guarnição, vedantes, dentre outros. A partir desse momento a empresa procura não mais modificar o projeto, somente se for algo que realmente prejudique o desempenho do produto no mercado.

Nessa fase, o time entrega o projeto detalhado para a engenharia, para que esta possa desenvolver todo o ferramental necessário para a produção das peças. Concluído o desenvolvimento de todos os equipamentos, a empresa produzirá um lote piloto de, em média 50 peças, para identificar possíveis adaptações nas máquinas ou na linha produtiva, como também a necessidade de treinamentos. Após a definição do design do produto, identificação 
dos componentes necessários e das possíveis adaptações nas máquinas, passa-se para a etapa seguinte.

Paralelamente são definidos os fornecedores das tecnologias e equipamentos necessários, como também a configuração da cadeia de suprimentos, incluindo o local de junção dos componentes. Os custos diretos de produção e os custos de fornecimento e demanda só serão identificados e analisados na etapa seguinte. Por fim, os serviços da empresa que estarão agregados ao produto final serão definidos no decorrer do processo, mas isso não é pensado pelo time, assim como o manual de operação do produto, que deve ser elaborado pela área de marketing da empresa, com indicações da engenharia.

O Quadro 17 apresenta as decisões referentes às etapas de Projeto da Cadeia de Suprimentos e Projeto do Produto da Perflex.

Quadro 17 - Decisões Perflex - projeto da cadeia de suprimentos e projeto do produto

\begin{tabular}{|c|c|c|}
\hline $\begin{array}{l}\text { Etapas segundo } \\
\text { Krishnan e Ulrich } \\
\qquad(2001)\end{array}$ & $\begin{array}{c}\text { Decisões das etapas do processo de } \\
\text { desenvolvimento }\end{array}$ & Decisões Perflex \\
\hline $\begin{array}{l}\text { Projeto da Cadeia } \\
\text { de Suprimentos }\end{array}$ & $\begin{array}{l}\text { - Componentes - projetados internamente ou } \\
\text { comprados prontos; quem projetará, desenvolverá e } \\
\text { produzirá (KRISHNAN; ULRICH, 2001). } \\
\text { - Cadeia física de suprimentos - configuração, } \\
\text { incluindo o local de junção dos componentes; seleção } \\
\text { de fornecedores das tecnologias e equipamentos; } \\
\text { sistema de produção e distribuição; custos diretos de } \\
\text { produção; custos entre fornecimento e demanda } \\
\text { (KRISHNAN; ULRICH, 2001). }\end{array}$ & $\begin{array}{l}\text { - Componentes - projetados } \\
\text { internamente ou comprados } \\
\text { prontos; quem projetará, } \\
\text { desenvolverá e produzirá. } \\
\text { - Cadeia física de suprimentos } \\
\text { - configuração, incluindo o } \\
\text { local de junção dos } \\
\text { componentes; seleção de } \\
\text { fornecedores das tecnologias e } \\
\text { equipamentos; sistema de } \\
\text { produção e distribuição; custos } \\
\text { diretos de produção; custos } \\
\text { entre fornecimento e demanda. }\end{array}$ \\
\hline Projeto do Produto & $\begin{array}{l}\text { - Especificação dos parâmetros do projeto - } \\
\text { projeto detalhado dos componentes; relação entre os } \\
\text { componentes do produto; seleção de material e de } \\
\text { processo e projeto das ferramentas e equipamentos; } \\
\text { planos de processo; desenhos finais com tolerâncias } \\
\text { (ROZENFELD et al, 2006). } \\
\text { - Embalagem - avaliação da distribuição do } \\
\text { produto, incluindo transporte e entrega; definição das } \\
\text { formas e sinalizações das embalagens dos produtos; } \\
\text { projeção da embalagem; planejamento do processo } \\
\text { de embalagem (ROZENFELD et al, 2006). } \\
\text { - Material de suporte do produto - criação do } \\
\text { manual de operação do produto, do material de } \\
\text { treinamento e do manual de descontinuidade do } \\
\text { produto (ROZENFELD et al, 2006). }\end{array}$ & $\begin{array}{l}\text { - Especificação dos } \\
\text { parâmetros do projeto - } \\
\text { projeto detalhado dos } \\
\text { componentes; relação entre os } \\
\text { componentes do produto; } \\
\text { seleção de material e de } \\
\text { processo e projeto das } \\
\text { ferramentas e equipamentos; } \\
\text { planos de processo; desenhos } \\
\text { finais com tolerâncias. } \\
\text { - Embalagem - projeção da } \\
\text { embalagem; planejamento do } \\
\text { processo de embalagem. }\end{array}$ \\
\hline
\end{tabular}




\section{d) Teste e validação de desempenho}

Na Perflex essa etapa é denominada de Avaliação do Projeto. Constitui-se na elaboração da ficha técnica do produto, onde serão detalhados todos os pontos necessários para a sua produção. Essa ficha é entregue para a engenharia e para a área de custos da empresa, as quais analisarão a viabilidade da nova linha e testarão os produtos para ver sua adequação aos padrões técnicos da empresa e às normas nacionais e internacionais, caso seja necessário. Com sua aprovação, é repassado mais uma vez para a área comercial, que dará a aprovação final, iniciando assim a sua produção.

Krishnan e Ulrich (2001) indicam que a produção piloto deve ser feita nessa etapa do processo, no entanto a Perflex faz o teste em pequena escala na etapa anterior. Outros pontos de decisão apresentados pela literatura estudada, como pode ser observado no Quadro 18, são questões relacionadas com o tipo do protótipo, o processo de construção dos protótipos e seus benefícios. Na Perflex, essas decisões não são tomadas nesta etapa, isso é definido no cronograma do projeto. Porém, é importante ressaltar como é feito na empresa em questão.

Nenhum dos tipos de protótipo, conforme classificação de Clark e Wheelwright (1993), aplicam-se à Perflex. No entanto, o protótipo é feito paralelamente ao processo, desde as etapas iniciais, e conta com a participação de todas as áreas necessárias para a sua elaboração. O processo de construção dos protótipos varia de acordo com a etapa em que se encontra o projeto, podendo ser virtual ou prototipagem rápida (experimentação real). Contribuem para a identificação de oportunidades, aprendizado da organização, testa a comunicação entre os membros do projeto e auxilia na resolução de conflitos.

Quadro 18 - Decisões Perflex - teste e validação de desempenho

\begin{tabular}{|c|l|l|}
\hline $\begin{array}{c}\text { Etapas segundo } \\
\text { Krishnan e Ulrich } \\
(2001)\end{array}$ & Decisões das etapas do processo de desenvolvimento & \multicolumn{1}{c|}{ Decisões Perflex } \\
\hline \multirow{2}{*}{$\begin{array}{c}\text { Teste e Validação } \\
\text { de Desempenho }\end{array}$} & $\begin{array}{l}\text { - Prototipagem para validação - em relação a } \\
\text { funcionamento, tamanho e fabricação (KRISHNAN; } \\
\text { ULRICH, 2001); avalia reações dos consumidores, } \\
\text { projeto industrial, durabilidade, encaixe e finalização, e } \\
\text { Custos de produção (ROZENFELD et al, 2006; }\end{array}$ & $\begin{array}{l}\text { - Prototipagem para } \\
\text { validação - em relação a } \\
\text { funcionamento, tamanho e } \\
\text { fabricação; avalia reações dos } \\
\text { consumidores, projeto } \\
\text { industrial, durabilidade, } \\
\text { encaixe e finalização e custos } \\
\text { de produção. }\end{array}$ \\
& $\begin{array}{l}\text { Teste em pequena escala do projeto - produção } \\
\text { piloto (CLARK; WHEELWRIGHT, 1993); definição } \\
\text { dos processos de produção e manutenção }\end{array}$ & \begin{tabular}{l} 
- Teste em pequena escala \\
\hline
\end{tabular} \\
\hline
\end{tabular}




\begin{tabular}{|l|l|l|}
\hline (ROZENFELD et al, 2006). & do projeto - produção piloto; \\
- Tipo de protótipo - rápida resposta à engenharia, & definição dos processos de \\
sistema de solução integrado (periódico), ou replicação & produção e manutenção. \\
da produção cedo (CLARK; WHEELWRIGHT, 1993). & - Processo de construção dos \\
protótipos - simulação & - Processo de construção dos protótipos - simulação \\
virtual, prototipagem rápida (experimentação real), e & virtual, prototipagem rápida; \\
protótipos de papelão ou argila (CLARK; & paralela; prototipagem em \\
EHEELWRIGHT, 1993; THOMKE, 1998; & etapiciais do projeto. \\
SRINIVASAN et al, 1997; BECKER et al, 2005); & - Benefícios do protótipo - \\
seqüencial ou paralela; prototipagem em etapas iniciais & contribuem para a \\
do projeto (SRINIVASAN et al, 1997). & identificação de \\
- Benefícios do protótipo - contribuem para a & oportunidades; aprendizado \\
da organização; testa a & comunicação entre os \\
identificação de oportunidades; aprendizado da & membros do projeto; auxilia \\
& organização; formação de novas capacidades; testa a \\
& comunicação entre os membros do projeto; auxilia na \\
& resolução de conflitos (CLARK; WHEELWRIGHT, \\
1993). & na resolução de conflitos. \\
\hline
\end{tabular}

\section{e) Ramp-up e lançamento}

A última etapa constitui-se no lançamento do produto, que deixa de ser responsabilidade do time e passa a ter apenas como responsável a área de marketing, tendo um representante do time, o diretor da Perflex, a alta administração da empresa. Paralelamente às etapas anteriores do processo, a área de marketing vai desenvolvendo as campanhas para lançamento da nova linha. Quando é iniciada a produção, todo o plano de lançamento está traçado e os materiais prontos para serem distribuídos. A divulgação inicia-se com a seleção de lojas específicas para lançar o produto, que varia de acordo com seu perfil. Nestas são deixados mostruários da nova linha de produtos, e aos poucos os pedidos começam a ser feitos. A área comercial vai repassando para a produção as coordenadas, indicando a quantidade de peças que devem ser produzidas.

O teste de mercado na Perflex é feito na etapa anterior. E o acompanhamento do produto pelo time só acontece até a etapa anterior, daí em diante é de total responsabilidade da área de marketing da empresa. As decisões tomadas pela Perflex na etapa de ramp-up e lançamento estão listadas, resumidamente, no Quadro 19.

Quadro 19 - Decisões Perflex - ramp-up e lançamento

\begin{tabular}{|c|l|l|}
\hline $\begin{array}{c}\text { Etapas segundo } \\
\text { Krishnan e Ulrich } \\
(2001)\end{array}$ & \multicolumn{1}{|c|}{ Decisões das etapas do processo de desenvolvimento } & \multicolumn{1}{c|}{ Decisões Perflex } \\
\hline $\begin{array}{c}\text { Ramp-up e } \\
\text { Lançamento }\end{array}$ & $\begin{array}{l}\text { - Teste de mercado - nível de realização; seqüência de } \\
\text { introdução dos produtos no mercado (CLARK; } \\
\text { WHEELWRIGHT, 1993). }\end{array}$ & $\begin{array}{l}\text { - Teste de mercado - nível } \\
\text { de realização. } \\
\text { - Lançamento - desenho dos }\end{array}$ \\
\hline
\end{tabular}




\begin{tabular}{|c|c|c|}
\hline & $\begin{array}{l}\text { - Lançamento - tempo para o lançamento do produto; } \\
\text { como e quando o concorrente entrará ou entrou no } \\
\text { mercado; finalização do desenvolvimento do projeto; } \\
\text { desenho dos processos de venda e distribuição; } \\
\text { atendimento do cliente e assistência técnica; campanhas } \\
\text { de marketing (ROZENFELD et al, 2006). } \\
\text { - Ramp-up - aumento da produção (CLARK; } \\
\text { WHEELWRIGHT, 1993; ROZENFELD et al, 2006). } \\
\text { - Ao fim cessa ou continua o acompanhamento do } \\
\text { produto pelo time (ROZENFELD et al, 2006). }\end{array}$ & $\begin{array}{l}\text { processos de venda e } \\
\text { distribuição; campanhas de } \\
\text { marketing. } \\
\text { - Ramp-up - aumento da } \\
\text { produção. } \\
\text { - Ao fim cessa o } \\
\text { acompanhamento do } \\
\text { produto pelo time. }\end{array}$ \\
\hline
\end{tabular}

\subsubsection{Conclusões}

A Perflex é uma empresa de pequeno porte, que atua no mercado há 29 anos, com uma carteira de produtos composta por 630 diferentes tipos de metais sanitários. Direcionada para o consumidor final, lança cerca de 50 novos produtos por ano. Destes, a maior parte são projetos topológicos, com mudanças indicadas pela área de vendas e industrial, e o restante é de melhoria contínua, proveniente da assistência técnica, produção, engenharia, qualidade, processo e custos. Dos 250 funcionários, sete compõem a área de desenvolvimento de produtos.

A empresa em questão possui um processo de desenvolvimento de novos produtos com método informal, em que o conhecimento está centralizado nas mãos de poucos e não está formalizado em nenhum documento. A partir da Ilustração 9, pode-se observar que ela possui um processo organizado, mas em se conhecendo o caso, nota-se que é apenas um instrumento de auxílio à inovação e não uma estrutura de gestão organizada e formalizada em si. Isso talvez se deva ao fato de essa área ter se organizado apenas há cinco anos, e por ser uma empresa seguidora e não líder de mercado, pois estas precisam ter uma estrutura formalizada, organizada e disseminada por toda a empresa, com a finalidade de transformá-la em um ambiente propício para a inovação.

Isso não quer dizer que a empresa não tenha um direcionamento para a inovação, mas ao desenvolverem um novo produto, baseiam-se sempre em lançamentos das líderes tanto de mercados nacionais, quanto internacionais. Cumpre ainda salientar que a inovação tratada na Perflex é nova para a empresa, mas não para o mercado. É o caso da definição da carteira de projetos de 2008, que, conforme o gerente industrial será composta por produtos direcionados para o mercado de baixa renda, pois a empresa observou que no ano passado as líderes de mercado passaram a direcionar sua produção para este segmento. 
Ainda sobre essa fase inicial de identificação de oportunidades, a empresa entrega praticamente toda a responsabilidade para o desenvolvimento de uma determinada linha na mão do diretor da empresa. É ele quem viaja para o exterior procurando identificar as novas tendências, representando a área de marketing, e analisa a carteira de produtos da empresa para que a diversifiquem. Existe a participação de alguns outros profissionais, principalmente da área de marketing, mas a decisão final é do diretor. Essa primeira definição das idéias é top down, ou seja, o diretor define, praticamente só, a nova carteira de projetos.

De acordo com Clark e Wheelwright (1993), essa estratégia é utilizada por pequenas empresas, que identificam um produto que pode dar certo, e o inserem no processo de desenvolvimento, para gerar um único produto similar ao inicialmente identificado. Característica de uma empresa seguidora. Observa-se que o conceito central do produto é definido, principalmente, de acordo com as necessidades do mercado, market-driven concept, mas também com inputs de design e sustentabilidade.

Isso acontece, pois a Perflex é uma empresa pequena, onde o diretor participa de todo o processo, acumulando funções, o que pode ser bom, pois assim ele tem uma visão global de tudo, auxiliando na maioria das decisões. Por outro lado, pode ser ruim, pois ele não tem uma visão detalhada de cada área, prejudicando a representação que faz, por exemplo, da área comercial no time de desenvolvimento. Essa possível falha no processo pode acarretar na escolha indevida de novos projetos, ou mesmo na exclusão de projetos de sucesso.

É dessa forma que a empresa define as três novas linhas de produtos. Estas são totalmente novas para a empresa, com diferencial no design, mas a partir do momento que são feitas inovações no design, gera-se a necessidade de serem feitos ajustes técnicos. A empresa também possui projetos de melhoria contínua provenientes da assistência técnica, produção, engenharia, qualidade, processo e custos. A priorização desses projetos é realizada pela área de marketing, indicando qual produto deverá ser produzido primeiro, conforme necessidades identificadas no mercado.

Grande parte de seus projetos são do tipo topológicos, onde as modificações são feitas com base em adequações dos produtos a um novo nicho. Uma vantagem na produção desse tipo de projeto é que pode ser feita com custos reduzidos e baixo risco. Conforme Sanderson e 
Uzumeri (1995), a empresa deve ser cuidadosa ao utilizar esse tipo de projeto, pois ao acelerar a freqüência das mudanças pode necessitar de projetos mais inovadores para aquecer seu mercado. A Perflex lança mão do tipo de projeto topológico que as mudanças são guiadas pelos canais, provenientes das áreas de marketing e vendas, e no caso desta empresa, também da assistência técnica, como também das mudanças guiadas pelo modo de vida, alterando detalhes no projeto que possam ser direcionados para diferentes nichos de mercado.

Todo esse processo é realizado pela área de desenvolvimento, tendo a gerência de um dos supervisores de engenharia, o qual possui poder de decisão limitado e encontra-se em um nível médio na empresa. A classificação da estrutura associada ao papel da liderança de Clark e Wheelwright (1993) não se aplica a este caso, pois o diretor encontra-se como participante ativo de todo o processo, não existindo assim distanciamento entre hierarquias, onde os gerentes são meros coordenadores do projeto. Esse gerenciamento é controlado por meio de um cronograma de acompanhamento, que lista as etapas do processo, indicando os marcos e protótipos que serão realizados durante todo o desenvolvimento.

Observa-se que a Perflex possui, em dois momentos muito importantes do processo, impedimentos para inovar. O primeiro, como foi apresentado, é a forma como procuram definir sua carteira de projetos, e o segundo é no momento em que a área de marketing indica se um determinado produto será ou não lançado, dependendo de como o mercado consumidor aceitou ou não esta nova linha.

Embora a Perflex realize uma avaliação final do produto, não a considera como parte do processo de desenvolvimento, é apenas uma forma que encontrou para manutenção do produto no mercado por mais tempo, para geração dos projetos topológicos. Os problemas enfrentados nesta e em outras fases seriam minimizados se a Perflex procedesse a uma revisão sistemática ao final dos projetos. Essa auditoria tem o objetivo de identificar e avaliar as causas-raízes dos elementos críticos do desenvolvimento e, além disso, recomendar modificações e incorporar o aprendizado para os próximos desenvolvimentos (CLARK; WHEELWRIGHT, 1993). 


\subsection{Deca}

\subsubsection{Caracterização da empresa}

\subsubsection{Histórico}

Em 1947, os engenheiros Olavo Edydio Setúbal e Renato Refinetti fundam a empresa “Artefactos de Metal Deca”, em São Paulo, para fabricar chaves, fechaduras e pequenas peças, por meio de um inédito sistema de fundição sob pressão, em um galpão de $210 \mathrm{~m}^{2}$. Após cinco anos, iniciou-se um processo de incorporação de empresas, sendo a primeira delas a Indústria Taiar S.A., a qual produzia metais sanitários. Alguns anos depois, incorporam a Válvula Hydra S.A., fabricante da válvula de descarga Hydra. E em 1968, foi a vez da Cia. Cerâmica Jundiaiense, fabricante de louças sanitárias.

Já em 1972, a Artefactos de Metal Deca foi incorporada pelo Grupo Duratex, controlado pelo Grupo Itaúsa - Investimentos Itaú S.A., uma das primeiras holdings puras brasileiras, de capital aberto. O conjunto de suas empresas a torna o $2^{\circ}$ maior grupo privado por volume de receitas. As empresas que compõem a holding Itaúsa são: área industrial - Duratex, Deca, Elekeiroz, Itautec; área imobiliária - Itaúsa Empreendimentos; área financeira - Banco Itaú, Banco Itaú - BBA; área cultural e responsabilidade socioambiental - Itaú sustentabilidade, Instituto Itaú Cultural, Itaú Numismática, Programa Itaú Social.

Em 1980, foi inaugurada a segunda fábrica de Cerâmica Sanitária em Jundiaí-SP, e um ano depois, a Duratex comprou sua terceira Unidade em São Leopoldo-RS, possuidora do sistema shanks na produção de louças. Em 1989, ampliou e modernizou sua fábrica de metais em São Paulo e construiu uma segunda Unidade. Atualmente, possui cinco unidades fabris, quatro no Brasil e uma na Argentina (CATÁLOGO DE PRODUTOS DECA, 2007). As fábricas do Brasil são: Metais São Paulo, localizada em Água Branca, zona oeste de São Paulo; Metais Jundiaí, Distrito Industrial de Jundiaí, a 60 km da capital paulista; Cerâmica Jundiaí, Distrito Industrial de Jundiaí; Cerâmica São Leopoldo, Rio Grande do Sul. A Duratex atingiu uma receita líquida de R 1.671 milhões, superior em 12\% ao valor de 2006 (ITAÚSA, 2008).

"Focada na fabricação de louças e metais sanitários, a Deca é líder regional e investe continuamente no desenvolvimento de novos produtos incluindo economizadores de água e 
produtos com design inovador” (CATÁLOGO DE PRODUTOS DECA, 2007). De acordo com Holofote Comunicação (2007)

Hoje, a Deca é líder brasileira no mercado de metais sanitários, além de ocupar posição de destaque no mercado de louças, contribuindo excepcionalmente no fornecimento de materiais de acabamento para a construção civil no País, e disputando o mercado exterior, no qual inúmeros de seus produtos concorrem com os melhores fabricantes do mundo.

Emprega, aproximadamente, três mil funcionários e fabrica três milhões de louças sanitárias e 11,5 milhões de metais sanitários por ano (HOLOFOTE COMUNICAÇÃO, 2007). Possui certificação ISO 9001/2000, tem um portfólio de mais de 1.200 itens de louças sanitárias e mais de 5.000 itens de metais sanitários e exporta para mais de 34 países (CATÁLOGO DE PRODUTOS DECA, 2007), com destaque para África do Sul, Portugal, Inglaterra e EUA (HOLOFOTE COMUNICAÇÃO, 2007).

A contribuição econômica do segmento de metais sanitários, de acordo com o Sindicato da Indústria de Artefatos de Metais Não Ferrosos do Estado de São Paulo - Siamfesp, foi de US\$ 1,1 bilhões no valor da produção, e US\$ 408 milhões em impostos arrecadados. Existem no Brasil, atualmente, cerca de 100 fabricantes de metais sanitários, dos quais a maior parte é composta por fabricantes de pequeno porte (SIAMFESP, 2008).

A Deca é o fabricante nacional que possui a mais completa linha de metais sanitários. Devido à grande variedade de produtos, esta empresa possui concorrentes diversos conforme o tipo de produto e o segmento de atuação. No segmento de produtos básicos, seus principais concorrentes são a Docol, Mipel e Fabrimar, no mercado nacional, e Meber, que atua principalmente na Região Sul do Brasil, além de alguns produtos importados (ENFOQUE, 2008).

O segmento de torneiras e registros de uso geral é o mais informal e competitivo do mercado. A Deca estima que este segmento represente $25 \%$ do volume de peças vendidas ao ano no mercado. A Deca atua, ainda, no segmento de banheiros médio/competitivo e luxo e tem como principais participantes Docol e Fabrimar. Os concorrentes, entretanto, não possuem a variedade de produtos da Deca e não investem de maneira tão intensa em ações de marketing para seus produtos como a Deca (ENFOQUE, 2008). 
Devido a seu forte foco no design, a Deca tem conquistado prêmios importantes, como o "IF Design Award”, um dos principais prêmios internacionais do segmento. Como também tem conquistado continuamente o prêmio nacional, "Museu da casa Brasileira”, bastante reconhecido pelo setor.

\subsubsection{Tipo de produto}

A Deca produz atualmente louças e metais sanitários; acessórios e monocomandos para banheiro; duchas e desviadores; chuveiros de teto e de parede; misturador externo; e válvulas de descarga. Como também produz torneiras e outros acessórios para cozinha. Outros produtos, definidos como básicos, são os registros de pressão; registros de gaveta; registros brutos; válvula de esfera; torneira bóia; sifões; válvula de escoamento; e complementos. A empresa também desenvolve produtos para a área de serviço e para uso profissional, dentre eles existem as linhas Decalux; Decamatic; Decamatic eco; Hydra pro; Deca hotel; e linha conforto, as quais serão apresentadas a seguir com o intuito de se entender os conceitos que são incorporados aos produtos Deca.

Em 2007 lançou cerca de 90 novos produtos, com destaques para a linha Max, voltada para o segmento econômico, e válvulas de descarga com controle de vazão - Nova Hydra alinhadas ao conceito de economia de água. A partir dessa filosofia foram fabricadas as linhas Decalux, Decamatic, Decamatic Eco, e as linhas ecológicas, as quais têm como princípio a economia de água e energia elétrica acompanhados de "requinte e elegância” (CATÁLOGO DE PRODUTOS DECA, 2007).

A linha Decalux possui o sistema elétrico ou bateria, sendo acionada automaticamente por sensor, com um potencial econômico de até $75 \%$ para as torneiras e de até $80 \%$ para as válvulas de mictório em relação a produtos convencionais. Além da economia, proporciona higiene e conforto para seus usuários. A linha Decamatic e Decamatic eco são acionadas através de um leve toque e possuem fechamento automático, com potencial econômico de até $55 \%$ para as torneiras e de até $80 \%$ para os mictórios se comparados a produtos convencionais. Ambas as linhas são compostas por dispositivos economizadores trazendo, além da economia, “conforto com tecnologia de ponta aos usuários” (CATÁLOGO DE PRODUTOS DECA, 2007). 
A empresa possui um showroom em São Paulo-SP para exposição de seus produtos, como também para atendimento personalizado ao consumidor final e aos profissionais da área.

\subsubsection{Segmentação do mercado}

Conforme a descrição dos produtos e das linhas, percebe-se o direcionamento da empresa para o consumidor final, pois é ele quem decide, nesse tipo de produto, qual irá comprar, mesmo que seja influenciado por outras pessoas. Com isso, conclui-se que a segmentação de mercado da empresa é B2C. De acordo com Hutt (2002, p. 35), uma empresa voltada para o mercado irá revelar duas características importantes: “a percepção de mercado e a ligação com o cliente”. A percepção de mercado demonstra o quanto a empresa está preparada para perceber continuamente as mudanças em seu mercado, enquanto que a capacidade de ligação com o cliente está relacionada com a competência desta em desenvolver, criar e gerenciar uma relação mais próxima com o cliente.

Através dos produtos Deca é possível perceber essa procura pela proximidade com o cliente, uma das razões é devido a sua preocupação com o design do produto. E uma das formas que a empresa encontrou para gerenciar essa proximidade foi através de um processo de gestão de desenvolvimento de novos produtos, como se verá a seguir.

\subsubsection{Gestão do desenvolvimento dos produtos Deca}

De acordo com a designer da Deca, a área de desenvolvimento de produtos evoluiu muito nos últimos anos. Antigamente o processo era feito de forma seqüencial, sem haver comunicação entre as áreas, o que tornava o processo lento e demorado. Com o tempo a estrutura foi aperfeiçoada. Aproximadamente 15 anos atrás, a Deca começou a trabalhar com a engenharia integrada, onde a área Engenharia de Produto começou a “conversar” com a área Engenharia Industrial, que por sua vez começou a “conversar” com os processistas da Fábrica, e assim em diante, o que proporcionou a melhoria da comunicação e a redução do tempo de desenvolvimento.

Na seqüência, partiu-se para a engenharia simultânea, onde todos os envolvidos com o projeto trabalham juntos desde sua fase inicial, são eles: engenharia, áreas de processo, equipe de embalagem e área de marketing. Com essas mudanças a comunicação ficou muito 
mais eficiente, o tempo de desenvolvimento foi reduzido consideravelmente de três anos para um tempo médio de oito a dez meses. Com isso, houve também a diminuição do índice de abortamento de projetos inacabados. O Quadro 20 indica as etapas e subetapas do processo de GDP da Deca.

Quadro 20 - Etapas e subetapas do processo de GDP da Deca

\begin{tabular}{|l|l|}
\hline \multicolumn{1}{|c|}{ Etapas } & \multicolumn{1}{c|}{ Subetapas } \\
\hline \multirow{2}{*}{ Identificação de Oportunidades e Seleção das Idéias } & $\begin{array}{l}\text { Identificação de Oportunidades } \\
\text { Seleção de Oportunidades } \\
\text { Elaboração do briefing } \\
\text { Elaboração da previsão de investimento } \\
\text { Ordenamento dos Projetos }\end{array}$ \\
\hline Desenvolvimento do Conceito & $\begin{array}{l}\text { Protótipo virtual } \\
\text { Protótipo em isopor }\end{array}$ \\
\hline Planejamento do Produto & Ficha técnica do produto \\
\hline Engenharia do Produto & $\begin{array}{l}\text { Início das reuniões de pré-viabilidade } \\
\text { Protótipo em metal }\end{array}$ \\
\hline \multirow{2}{*}{ Engenharia do Processo } & $\begin{array}{l}\text { Produção das peças e ferramentas necessárias } \\
\text { Try-out do processo } \\
\text { Testes dos produtos em laboratório } \\
\text { Ramp-up e Lançamento }\end{array}$ \\
\hline
\end{tabular}

Antes de entrar na discussão sobre as etapas e subetapas do processo, será apresentado como a Deca, de acordo com a designer da empresa, enxerga a GDP.

\subsubsection{Conceito}

De acordo com a Designer, o processo começa na identificação de uma oportunidade de mercado, seja ela uma inovação ou apenas uma melhoria contínua, até a sua transformação em um produto final e sua colocação no mercado. Para isso, a empresa lança mão de técnicas de GDP atuais, como a engenharia simultânea e os times multifuncionais, almejando o desenvolvimento de produtos de sucesso.

\subsubsection{Estratégia e planejamento do produto}

Todo o processo se inicia com a identificação das oportunidades no mercado para o ano que se iniciará. Para isso são elaboradas as previsões tecnológicas e de mercado, baseadas na estratégia geral da empresa, que serão utilizadas para traçar as metas e objetivos de desenvolvimento. 
As fontes de informações para a definição da nova carteira de produtos são provenientes da própria visão de mercado da empresa, a partir de uma avaliação dos produtos que possuem e da opinião de arquitetos e decoradores. A empresa obtém também diversas informações em seu showroom no Estado de São Paulo, em visita a feiras na Europa e nos EUA, com a exposição de seus produtos em feiras do setor, e pesquisas feitas pela engenharia e pela área de marketing da empresa. Ao identificarem-se as oportunidades, é elaborada a estratégia de mercado, que contém informações sobre os produtos que serão ofertados, público-alvo e componentes compartilhados entre as plataformas.

A estratégia tecnológica será traçada com base na estratégia de mercado, indicando a tecnologia que será necessária, e a que dará vantagem competitiva. Dessa primeira parte o resultado será um acervo de idéias disponível e organizado, as quais serão manipuladas pela área de marketing da Deca, quem terá a função de definir a carteira de projetos para o ano. Os projetos podem ser de melhoria contínua ou inovação, dependerá da carteira de projetos existente na empresa, desenvolvidos internamente no laboratório, ou provenientes de aquisições de máquinas e equipamentos. Os projetos de inovação podem trazer algo novo no design, ou na parte técnica do produto. Os projetos de melhoria contínua nascem de produtos que já estão no mercado, isso ocorre quando se verifica que: o produto poderia ter melhor performance; se mudar o processo de fabricação se gastará menos matéria-prima; alguns componentes podem ser padronizados; há a necessidade de adequação a alguma alteração na norma técnica do produto; etc.

Para definição da carteira de novos produtos a área de marketing procura mesclar projetos de inovação e melhoria contínua, com base nos anos anteriores, nas previsões e na estratégia da empresa. Também se levam em consideração os recursos necessários e por quanto tempo serão utilizados. 
No que se refere aos aprendizados e melhorias para projetos futuros, a Deca procura melhorar as capacidades envolvidas no processo e o próprio processo em si, mas tudo feito informalmente. Não existe um documento ou uma estrutura fixa e formal para identificação e registro dos aprendizados e melhorias para os próximos projetos, somente documentos que registram problemas técnicos no produto, gerando assim novos projetos.

No Quadro 21 é apresentada de forma resumida a maneira que a Deca desenvolve essa primeira fase do processo de GDP.

\begin{tabular}{|c|c|c|}
\hline \multicolumn{3}{|c|}{ Quadro 21 - Decisões Deca - estratégia e planejamento do produto } \\
\hline $\begin{array}{l}\text { Organização do } \\
\text { Projeto de } \\
\text { Desenvolvimento }\end{array}$ & $\begin{array}{c}\text { Decisões para organização de projetos de } \\
\text { desenvolvimento }\end{array}$ & Decisões Deca \\
\hline $\begin{array}{c}\text { Estratégia e } \\
\text { Planejamento do } \\
\text { Produto }\end{array}$ & $\begin{array}{l}\text { - Estratégia de Mercado (KRISHNAN; ULRICH, } \\
\text { 2001; CLARK; WHEELWRIGHT, 1993) - produtos } \\
\text { que serão ofertados, público-alvo e forma como serão } \\
\text { disponibilizados; número, tempo e taxa de mudança da } \\
\text { plataforma; e define número, tempo, freqüência e } \\
\text { relações de produtos diferenciados; componentes } \\
\text { compartilhados entre as plataformas. } \\
\text { - Estratégia Tecnológica - tecnologia necessária; } \\
\text { tecnologia que dê vantagem competitiva; fonte externa } \\
\text { e interna; tempo para capacitação; maturação da } \\
\text { tecnologia; e freqüência das implementações } \\
\text { (KRISHNAN; ULRICH, 2001; CLARK; } \\
\text { WHEELWRIGHT, 1993). } \\
\text { - Plano Agregado de Projetos.- prioridades; escolha } \\
\text { do projeto e definição de quando começam e } \\
\text { terminam; recursos disponíveis (CLARK; } \\
\text { WHEELWRIGHT, 1993). } \\
\text { - Aprendizados e melhorias para projetos futuros - } \\
\text { melhoria das capacidades envolvidas no processo e do } \\
\text { próprio processo em si (CLARK; WHEELWRIGHT, } \\
\text { 1993). }\end{array}$ & $\begin{array}{l}\text { - Estratégia de Mercado - } \\
\text { produtos que serão ofertados; } \\
\text { público-alvo. } \\
\text { - Estratégia Tecnológica - } \\
\text { tecnologia necessária; } \\
\text { tecnologia que dê vantagem } \\
\text { competitiva. } \\
\text { - Plano Agregado de } \\
\text { Projetos - prioridades; } \\
\text { escolha do projeto e definição } \\
\text { de quando começam e } \\
\text { terminam; recursos } \\
\text { disponíveis. } \\
\text { - Aprendizados e melhorias } \\
\text { para projetos futuros - } \\
\text { melhoria das capacidades } \\
\text { envolvidas no processo e do } \\
\text { próprio processo em si. }\end{array}$ \\
\hline
\end{tabular}

\subsubsection{Organização do desenvolvimento do produto}

A empresa divide-se em quatro diretorias (Ilustração 10): Diretoria Comercial; Diretoria de Exportação; Diretoria Industrial; Diretoria de Desenvolvimento e Marketing. 




A diretoria de desenvolvimento e marketing subdivide-se em três gerências: gerente de marketing, que trata do marketing operacional e mercadológico; gerente da assistência técnica e apoio operacional; e gerente de desenvolvimento de produto (Ilustração 11). Sob responsabilidade do gerente de desenvolvimento de produto, está o setor de desenvolvimento de novos produtos, formada por quatro áreas (Ilustração 12): planejamento, controla todos os projetos que estão sendo desenvolvidos na área junto com a fábrica; engenharia, projeta os novos produtos e realiza pesquisas de novas idéias - P\&D; produto, coordena os projetistas e a área de prototipagem; laboratório, testa os produtos em desenvolvimento e os produtos que vão entrar em linha. E por fim, a designer, que responde para os quatro chefes de área, e é responsável pelas etapas iniciais de todo o processo, como será visto na descrição do processo de desenvolvimento Deca.

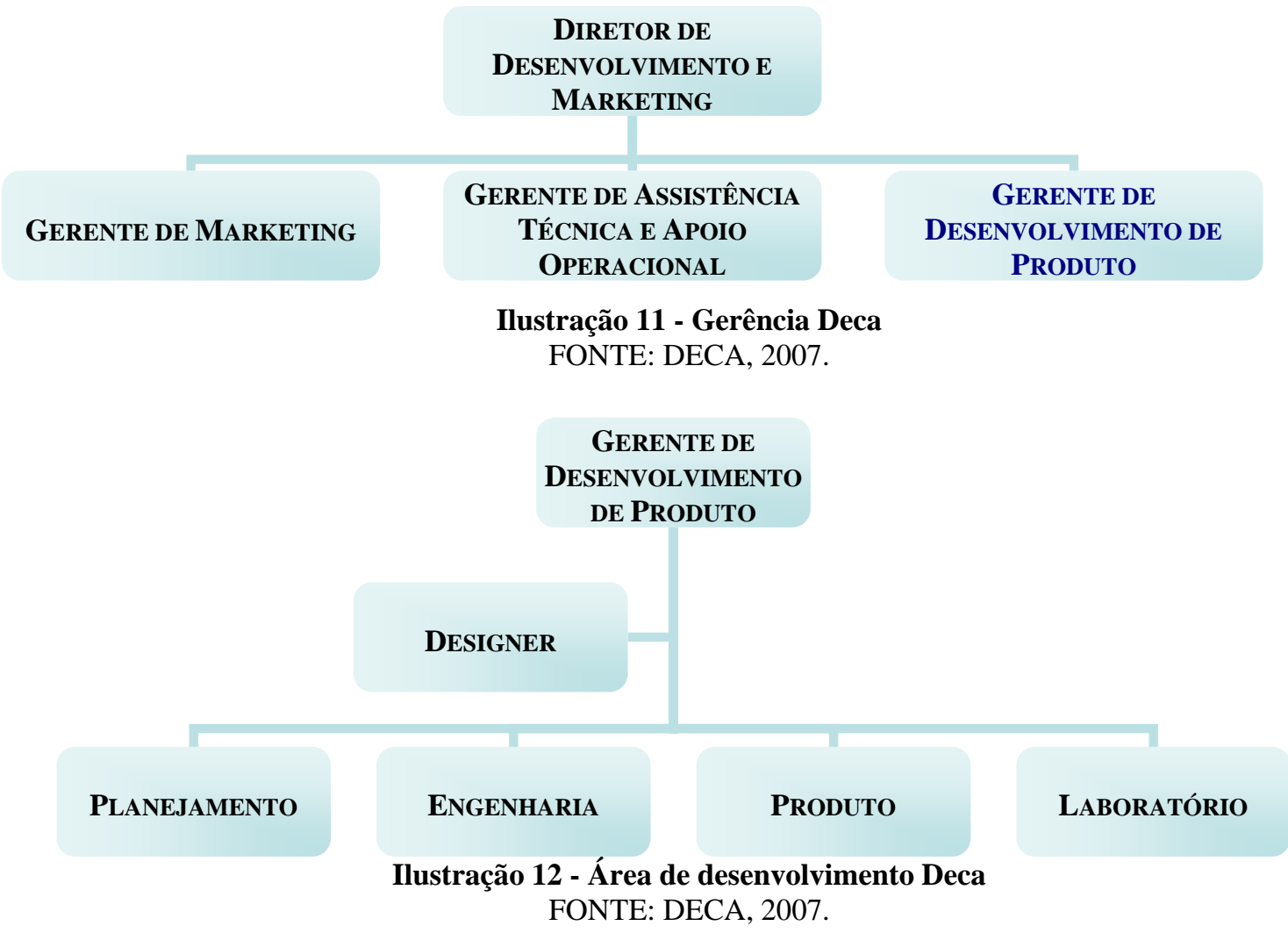


A Deca possui dois centros de desenvolvimento de novos produtos, um direcionado para o desenvolvimento de metais sanitários e o outro de louças sanitárias. As decisões são centralizadas nos centros específicos, e acompanhadas e validadas pelo comitê, formado pelos diretores da empresa e os gerentes de área de GDP. O processo que será descrito foi extraído da planta de metais sanitários. A área de desenvolvimento desta planta é formada por 60 pessoas, entre chefes de área, engenheiros, projetistas, designer, técnicos, modeladores, torneiros, fresadores, etc.

O arranjo físico do time de desenvolvimento é por projeto que está sendo desenvolvido. Existem pessoas fixas em cada projeto, como também cargos e funções que variam de projeto para projeto, alocados em uma área comum, o que proporciona e facilita a comunicação entre os membros do time. A estrutura funcional, formal e em grupo é composta da seguinte forma: designer, engenheiro, projetista e planejador. No que se refere à classificação da estrutura associada ao papel da liderança (CLARK; WHEELWRIGHT, 1993), nenhuma das opções se ajusta à Deca, pois além das distâncias hierárquicas serem pequenas, não existe uma área própria para o desenvolvimento de um determinado produto, os encontros entre os envolvidos no processo acontecem informalmente e nas reuniões. O gerente do projeto é de um nível médio, com pouca influência na organização, e toda e qualquer decisão relevante será acompanhada e tomada de perto pela alta administração.

Todas as áreas da fábrica envolvidas no projeto o acompanham desde suas primeiras fases, iniciando na etapa seguinte à de desenvolvimento do conceito. A alta administração também examina todos os projetos em andamento por meio das reuniões mensais do comitê. Os entrevistados foram a designer e o chefe da área de planejamento.

Na organização do desenvolvimento do produto deve-se procurar definir quais investimentos serão feitos com o novo projeto. Na Deca identificaram-se infra-estrutura, ferramentas e treinamentos necessários, o que vai de acordo com o que Clark e Wheelwright (1993) indicam.

O processo de desenvolvimento de produtos na Deca ocorre similar ao stage-gate, tendo os protótipos como portões de passagem para o estágio seguinte. A designer indica que com a estrutura atual foi possível a definição de metas e objetivos de desenvolvimento mais 
desafiadores. Essa estrutura é utilizada tanto quando a idéia é gerada pelo marketing da empresa, como quando partir da área de P\&D. A estrutura também será a mesma para o desenvolvimento de produtos de exportação, em que muitas vezes apenas se fazem ajustes em produtos desenvolvidos para o mercado brasileiro, sendo apenas uma inovação incremental.

O processo de desenvolvimento dos projetos de inovação ocorre similar a um túnel e não a um funil, pois eles inserem uma idéia e trabalham em cima dela para gerar um produto inovador. Nos outros casos, melhorias contínuas, já se tem um produto, o qual é aperfeiçoado e modificado.

O Quadro 22 apresenta as decisões que se referem à fase de organização do desenvolvimento do produto na Deca.

Quadro 22 - Decisões Deca - organização do desenvolvimento do produto

\begin{tabular}{|c|c|c|}
\hline $\begin{array}{l}\text { Organização do } \\
\text { Projeto de } \\
\text { Desenvolvimento } \\
\end{array}$ & $\begin{array}{c}\text { Decisões para organização de projetos de } \\
\text { desenvolvimento }\end{array}$ & Decisões Deca \\
\hline $\begin{array}{c}\text { Organização do } \\
\text { Desenvolvimento do } \\
\text { Produto }\end{array}$ & $\begin{array}{l}\text { - Time - membros da diretoria, gerente funcional, } \\
\text { responsável pela engenharia, gerente de projeto, } \\
\text { especialistas e parceiros (ROZENFELD et al, 2006); } \\
\text { áreas - marketing, vendas, tecnologia, produção e } \\
\text { finanças (COOPER et al, 2002b). } \\
\text { - Estrutura de desenvolvimento - individual ou em } \\
\text { grupo; formal ou informal (ROZENFELD et al, 2006). } \\
\text { Estruturas associadas ao papel da liderança - time } \\
\text { funcional, peso leve, peso pesado ou autônomo } \\
\text { (CLARK; WHEELWRIGHT, 1993; ROZENFELD et } \\
\text { al, 2006). Arranjo físico - em área comum ou cada um } \\
\text { em seu setor (KRISHNAN; ULRICH, 2001). } \\
\text { - Investimentos - infra-estrutura, ferramentas e } \\
\text { treinamento (CLARK; WHEELWRIGHT, 1993). } \\
\text { - Processo de desenvolvimento - abordagem } \\
\text { tradicional de desenvolvimento, engenharia } \\
\text { simultânea, funil de desenvolvimento, e stage-gate } \\
\text { (CLARK; WHEELWRIGHT, 1993). }\end{array}$ & $\begin{array}{l}\text { - Time - membros da } \\
\text { diretoria, gerente funcional, } \\
\text { responsável pela engenharia, } \\
\text { gerente de projeto, } \\
\text { especialistas. Áreas - } \\
\text { marketing, tecnologia, } \\
\text { produção e finanças. } \\
\text { - Estrutura de } \\
\text { desenvolvimento - em grupo; } \\
\text { formal. Arranjo físico - em } \\
\text { área comum. } \\
\text { - Investimentos - infra- } \\
\text { estrutura, ferramentas e } \\
\text { treinamento. } \\
\text { - Processo de } \\
\text { desenvolvimento - } \\
\text { engenharia simultânea e stage- } \\
\text { gate. }\end{array}$ \\
\hline
\end{tabular}

\subsubsection{Gerenciamento do projeto}

É elaborado no início dessa fase o briefing, que contém os dados sobre cada projeto que será desenvolvido, quantidade de peças que serão vendidas, custo variável individual meta - cvi meta e o segmento que os projetos se direcionarão. Toda a carteira de novos produtos deve trazer conceitos de sustentabilidade, uso racional de água, padrão ABNT, design inovador, devem ser tecnologicamente novos, como também seguir tendências mundiais. 
Vale ressaltar que no briefing, na maioria das vezes, não é indicado o produto que será desenvolvido, mas somente características deste, como, por exemplo, se é uma inovação ou melhoria contínua, ou ainda, se é direcionado para o segmento de luxo ou o segmento médio. Sabe-se também qual será a utilidade desse produto. O produto em si não terá variações, mas será composta uma linha que terá características de design similares.

Outro ponto relevante é que todo projeto que nasce na empresa, seja ele de melhoria contínua ou inovação, passa por marcos pré-definidos, onde se lançam mão de critérios que auxiliam na seleção e avaliação de projetos. Dois desses critérios utilizados na seleção de idéias são: viabilidade financeira e possibilidade de alcance do cvi meta.

Por essa razão, nem todos os projetos que são indicados no briefing são desenvolvidos. Muita coisa morre ainda no design, ou mesmo na engenharia. O mais raro de acontecer é o abortamento do projeto em etapas finais. Conforme relato da Deca, isso acontece devido ao fato de se ter uma equipe multidisciplinar, com o envolvimento, desde suas fases iniciais, de todas as áreas necessárias para desenvolver o projeto, e de marcos bem definidos para o descarte de projetos.

Após elaboração do briefing, cada área da empresa prepara uma previsão de investimento, indicando a verba necessária para desenvolvimento dos projetos indicados. Com a autorização da diretoria da empresa, define-se a carteira de projetos para o ano, onde são utilizados para cada tipo de projeto critérios de priorização que indiquem a ordem de desenvolvimento desta.

Os projetos de melhoria contínua são priorizados pelo ganho, ou seja, a ordem de desenvolvimento desse tipo de projeto é do que tiver maior possibilidade de retorno financeiro para o de menor retorno. Enquanto que os projetos de inovação são priorizados pelo mercado, ou seja, o marketing indica quando o mercado está preparado para recebê-lo.

O briefing do primeiro projeto é então entregue para o chefe da área de engenharia, que elaborará a ficha técnica do produto, com a finalidade de organizar o gerenciamento do projeto. Essa fase na Deca é denominada de Planejamento do Produto. Paralelamente, o 
briefing será também entregue à designer, no entanto isso faz parte da primeira etapa do processo de GDP da Deca, desenvolvimento do conceito do produto.

A estrutura inicial da ficha técnica deve conter os seguintes elementos: nome do produto (linha); projetista responsável; descrição; objetivos; paradigma; referências normativas; segmento; dados gerais; quantidade de novos componentes; metas de lançamento, que, conforme a empresa, sempre são bastante rigorosas. Vale ressaltar, que nesse momento não será possível preencher todos os itens citados, mas deve-se obter o máximo de informações possíveis e estas aos poucos serão complementadas e detalhadas.

Com o protótipo virtual e em isopor feitos pela designer, o chefe da área de planejamento poderá indicar na ficha quais componentes compõem cada produto, indicando os que serão produzidos internamente e os que serão comprados prontos. Além de fazerem um levantamento de todos os produtos similares presentes na carteira de produtos da empresa, como também produtos concorrentes.

Como foi dito, a ficha técnica vai sendo aperfeiçoada e detalhada aos poucos, somente após a definição final do produto é que será concluída. A passagem da segunda etapa, Planejamento do Produto, para a terceira, Engenharia do Produto, constitui-se como um dos marcos presentes no processo, onde serão analisadas as características do projeto para indicar se este será descontinuado. Aprovado, inicia-se a etapa de engenharia do produto.

O chefe da área de engenharia fará o controle do projeto apenas até a primeira reunião do time, logo após quem assumirá será o projetista. Esse controle é feito através de planos que contêm todos os projetos ativos na empresa, indicando os recursos que estão sendo alocados para cada projeto. Nesse plano também são indicados o tempo de desenvolvimento do projeto, com a seqüência das atividades e os marcos, como ainda os momentos em que serão realizadas as reuniões com o time e com a alta administração.

Outro ponto de decisão nessa fase é em relação à comunicação. A integração do time é multifuncional, como já foi apresentado anteriormente. Conforme Frishammar (2005), o time pode interagir e/ou colaborar entre si. No caso da Deca, ocorrem as duas coisas de forma equilibrada, uma vez que existem as reuniões formais e as conversas informais sobre os 
projetos, além da estrutura da empresa, permitindo que todos sejam alocados em uma área comum, de modo a proporcionar facilidade na comunicação entre os membros do time.

E por fim, de acordo com Clark e Wheelwright (1993), a comunicação pode acontecer de duas maneiras, através de monólogo ou diálogo. Na Deca se caracteriza como diálogo, e acontece nas fases iniciais do projeto. O Quadro 23 apresenta as decisões para organização de projetos de desenvolvimento na Deca, levando em consideração a literatura pesquisada.

Após o desenvolvimento, como forma de conhecer a performance do projeto, a Deca procura comparar o que ficou planejado no briefing e na ficha técnica com o que efetivamente aconteceu, porém não é uma atividade formalizada. No entanto, mede a performance do produto no mercado, por meio das metas de vendas, a qual é subdividida entre os vendedores da empresa. Através dessas metas é que a área comercial conseguirá avaliar qual região está vendendo mais, como foi a evolução das vendas, identificando assim se o vendedor teve ou não giro, servindo de base para identificar possíveis problemas do produto em um determinado mercado, abrindo portas para um projeto de melhoria contínua.

Quadro 23 - Decisões Deca - gerenciamento do projeto

\begin{tabular}{|c|c|c|}
\hline $\begin{array}{c}\text { Organização do } \\
\text { Projeto de } \\
\text { Desenvolvimento }\end{array}$ & $\begin{array}{c}\text { Decisões para organização de projetos de } \\
\text { desenvolvimento }\end{array}$ & Decisões Deca \\
\hline $\begin{array}{l}\text { Gerenciamento do } \\
\text { Projeto }\end{array}$ & $\begin{array}{l}\text { - Monitoramento e controle - através de planos, } \\
\text { formal, atuação do gerente e envolvimento e } \\
\text { compromisso da alta administração (BROWN; } \\
\text { EISENHARDT, 1995; CLARK; WHEELWRIGHT, } \\
\text { 1993; ROZENFELD et al, 2006; GRIFFIN, 1997). } \\
\text { - Priorização dos projetos, tempo de } \\
\text { desenvolvimento, seqüência das atividades e } \\
\text { marcos do projeto - planejamentos com auxílio do } \\
\text { PERT e CPM; cronograma (KRISHNAN; ULRICH, } \\
\text { 2001; ROZENFELD et al, 2006). } \\
\text { - Descarte de projetos - critérios para descarte; check } \\
\text { list (COOPER et al, 2002b). } \\
\text { - Comunicação - integração funcional ou } \\
\text { multifuncional (CLARK; WHEELWRIGHT, 1993); } \\
\text { interação e/ou colaboração (FRISHAMMAR, 2005); e } \\
\text { monólogo ou diálogo, que acontece nas fases iniciais } \\
\text { do projeto (CLARK; WHEELWRIGHT, 1993). } \\
\text { - Desempenho - qualidade do projeto, tempo para } \\
\text { colocar o produto no mercado e produtividade; } \\
\text { planejado x o que efetivamente aconteceu (CLARK; } \\
\text { WHEELWRIGHT, 1993; CLARK; FUJIMOTO, } \\
\text { 1991). }\end{array}$ & $\begin{array}{l}\text { - Monitoramento e controle } \\
\text { - através de planos, formal, } \\
\text { atuação do gerente e } \\
\text { envolvimento da alta } \\
\text { administração. } \\
\text { - Priorização dos projetos, } \\
\text { tempo de desenvolvimento, } \\
\text { seqüência das atividades e } \\
\text { marcos do projeto - } \\
\text { planejamento; cronograma. } \\
\text { - Descarte de projetos - } \\
\text { critérios para descarte. } \\
\text { - Comunicação - integração } \\
\text { multifuncional; interação e } \\
\text { colaboração; diálogo, que } \\
\text { acontece nas fases iniciais do } \\
\text { projeto. } \\
\text { - Desempenho - qualidade do } \\
\text { projeto; planejado x o que } \\
\text { efetivamente aconteceu. }\end{array}$ \\
\hline
\end{tabular}




\subsubsection{Etapas de desenvolvimento}

Neste item serão apresentadas as etapas do processo de desenvolvimento de novos produtos na empresa Deca, que se subdivide em seis etapas (Quadro 20). O Quadro 24 faz uma comparação entre as etapas indicadas por Krishnan e Ulrich (2001) com as etapas para a GDP na Deca.

Quadro 24 - Quadro comparativo etapas de Krishnan e Ulrich (2001) versus etapas Deca
\begin{tabular}{|c|c|}
\hline $\begin{array}{c}\text { Etapas segundo Krishnan e Ulrich } \\
\text { (2001) }\end{array}$ & Etapas Deca \\
\hline Desenvolvimento do Conceito & $\begin{array}{c}\text { Desenvolvimento do Conceito } \\
\text { Planejamento do Produto }\end{array}$ \\
\hline Projeto da Cadeia de Suprimentos & Engenharia do Produto \\
\hline Projeto do Produto & Engenharia do Processo \\
\hline Teste e Validação de Desempenho & Ramp-up e Lançamento \\
\hline Ramp-up e Lançamento &
\end{tabular}

\section{a) Desenvolvimento do conceito do produto}

A primeira etapa do processo de GDP da Deca inicia-se com a entrega do briefing do primeiro projeto para a designer, pessoa responsável pela tradução dessas informações, conforme ordem de prioridade de projetos já definida. Esta decodificará as informações desenvolvendo a forma física de toda a linha. Para isso é feito um croqui, com auxílio de ferramentas virtuais, no caso o corel draw. Em determinados projetos poderá ser auxiliada por algum projetista, para tirar dúvidas técnicas. Esse projeto, desenvolvido em programas de projeção, é, ainda nesta etapa, levado para a área de prototipagem interna da empresa, para o desenvolvimento do primeiro protótipo de isopor, feito em um modelador. A designer só repassará o projeto para a etapa seguinte quando acreditar que o protótipo está o mais próximo possível do conceito definido pela área de marketing. Por isso, pode haver necessidade de se fazer mais de um protótipo.

Ao chegar nessa etapa, o projeto já possui certo detalhamento, mas com o croqui e o protótipo é possível descrever na ficha técnica do produto, questões como: tecnologias disponíveis e necessárias, necessidades e requisitos dos clientes, requisitos do produto, produtos concorrentes e similares, serviços agregados ao produto, objetivos ou metas que o produto deve atender, preço, variações do produto, como também os componentes que serão 
compartilhados entre os produtos da linha, ou de linhas diferentes. Esse detalhamento foi possível, devido à utilização de ferramentas para coleta de informações sobre os clientes e consumidores. Para definição dessas especificações são trazidos também conceitos de sustentabilidade.

É importante observar que a Deca até esse momento não lançou mão dos conhecimentos de todos os envolvidos no processo, pois é somente ao fim dessa etapa e da etapa de planejamento do produto que é definido o time do projeto em questão. A interação de todos os envolvidos só acontecerá na etapa três - Engenharia do Produto. No Quadro 25 são indicadas as decisões que a Deca toma na etapa de Desenvolvimento do Conceito do Produto.

Quadro 25 - Decisões Deca - desenvolvimento do conceito

\begin{tabular}{|c|c|c|}
\hline $\begin{array}{c}\text { Etapas segundo } \\
\text { Krishnan e Ulrich } \\
(2001)\end{array}$ & $\begin{array}{c}\text { Decisões das etapas do processo de } \\
\text { desenvolvimento }\end{array}$ & Decisões Deca \\
\hline $\begin{array}{l}\text { Desenvolvimento } \\
\text { do Conceito }\end{array}$ & $\begin{array}{l}\text { - Interação de todos os envolvidos no processo } \\
\text { (SMITH; REINERTSEN, 1998). } \\
\text { - Clientes e consumidores finais - participação no } \\
\text { processo de desenvolvimento; utilização de } \\
\text { ferramentas para conhecer as necessidades do } \\
\text { mercado, como QFD (GRIFFIN; HAUSER, 1993). } \\
\text { - Escopo detalhado do produto - tecnologias } \\
\text { disponíveis e necessárias; normas; patentes e } \\
\text { legislação relacionada ao produto; identificar quem é } \\
\text { o cliente, o consumidor e suas necessidades; } \\
\text { requisitos do produto; produtos concorrentes e } \\
\text { similares; serviços agregados ao produto; objetivos ou } \\
\text { metas que o produto deve atender; preço; e outras } \\
\text { informações relevantes para a empresa } \\
\text { (ROZENFELD et al, 2006, p.213; SMITH; } \\
\text { REINERTSEN, 1998; VON HIPPEL, 1986; } \\
\text { THOMKE; VON HIPPEL, 2002; SMITH; } \\
\text { REINERTSEN, 1998; COOPER et al, 2002a; } \\
\text { SLAUGHTER, 1991); congelamento das } \\
\text { características em etapas iniciais ou finais } \\
\text { (ROZENFELD et al, 2006; BACON et al, 1994 apud } \\
\text { KRISHNAN; ULRICH, 2001); Conceito central - } \\
\text { input - technology-driven concept; service concept; } \\
\text { design-driven concept; value-driven concept; } \\
\text { customer- and market-driven concept (BACKMAN et } \\
\text { al, 2007). } \\
\text { - Arquitetura do produto, forma física e projeto } \\
\text { industrial - desenho virtual ou croqui (KRISHNAN; } \\
\text { ULRICH, 2001). } \\
\text { - Variações do produto - quais serão oferecidas, } \\
\text { componentes compartilhados entre as variações } \\
\text { (KRISHNAN; ULRICH, 2001). }\end{array}$ & $\begin{array}{l}\text { - Clientes e consumidores } \\
\text { finais - utilização de } \\
\text { ferramentas para conhecer as } \\
\text { necessidades dos } \\
\text { consumidores. } \\
\text { - Escopo detalhado do } \\
\text { produto - tecnologias } \\
\text { disponíveis e necessárias, } \\
\text { identificar quem é o cliente, o } \\
\text { consumidor e suas } \\
\text { necessidades, requisitos do } \\
\text { produto, produtos } \\
\text { concorrentes e similares, } \\
\text { serviços agregados ao } \\
\text { produto, objetivos ou metas } \\
\text { que o produto deve atender, } \\
\text { preço, congelamentos das } \\
\text { características em etapas } \\
\text { finais. Conceito central - } \\
\text { customer- and market-driven } \\
\text { concept. } \\
\text { - Arquitetura do produto, } \\
\text { forma física e projeto } \\
\text { industrial - croqui. } \\
\text { - Variações do produto - } \\
\text { quais serão oferecidas, } \\
\text { componentes compartilhados } \\
\text { entre as variações. }\end{array}$ \\
\hline
\end{tabular}




\section{b) Projeto da cadeia de suprimentos}

Na Deca, o projeto da cadeia de suprimentos é feito somente na etapa de projeto do produto, modificando assim a ordem apresentada por Krishnan e Ulrich (2001). Por essa razão, essa etapa será tratada no item seguinte, juntando as discussões sobre o projeto da cadeia de suprimentos com o projeto do produto.

\section{c) Projeto do produto}

A etapa de projeto do produto será tratada junto com a etapa de projeto da cadeia de suprimentos. Essas duas etapas do processo de GDP de Krishnan e Ulrich (2001) englobarão a etapa de engenharia do produto da Deca e parte da etapa de engenharia do processo.

A etapa de engenharia do produto inicia-se com a reunião de pré-viabilidade. Nesta são convocadas pessoas de todas as áreas que contribuirão e participarão do projeto, formando assim o time de desenvolvimento. Esse time, composto por pessoas estratégicas da empresa, tanto da área de desenvolvimento, como também da produção, irá detalhar o projeto. De acordo com a designer (2007), deve-se chamar até mesmo a pessoa responsável pela embalagem, para saber qual será o seu custo, material a ser utilizado, tamanho, folhetos de instalação que têm que ser feitos. E a área comercial também já começa a trabalhar, os vendedores já sabem que haverá um produto novo, e o merchandising logo saberá como vai apresentar esse produto para o mercado na loja.

É nessa etapa que se definem a configuração dos componentes e suas relações, tudo feito pelo projetista responsável. O detalhamento do projeto se constituirá da seguinte forma: são levadas às reuniões de pré-viabilidade protótipos do projeto, e a partir deles são analisados seus componentes, a relação entre eles, quais componentes novos serão necessários, quais serão desenvolvidos dentro da empresa e quais adquiridos, a tecnologia necessária, e possíveis treinamentos do pessoal da linha de produção para manuseio dos novos equipamentos e para a produção dos novos componentes.

Durante o processo serão feitos diversos protótipos até se chegar a um protótipo de isopor ideal. Feito isso, será elaborado um protótipo em metal, onde serão feitos ajustes, caso seja 
necessário, caso contrário, será levado para a reunião do comitê, a qual é composta por todos os diretores da Deca e pelos gerentes de engenharia de produto das duas empresas que desenvolvem as peças, uma de metais e a outra de louças sanitárias.

Na reunião será feita a análise do projeto para sua validação, por isso ela é vista como um marco no projeto, pois, caso não esteja adequado ao interesse da Empresa, o projeto será abortado. São levados para as reuniões do comitê somente os projetos que se encontram nos pontos de passagem para a etapa seguinte ou que estejam com problemas e precisem de autorização para se efetuar alguma modificação, aquisição e mudanças.

Apesar da possibilidade disso acontecer, a empresa indica que é uma situação praticamente rara, devido ao acompanhamento mensal dos projetos pelo comitê, o que inclui a presença dos diretores de todas as áreas da empresa: do alinhamento do projeto com o briefing inicialmente elaborado pela área de marketing, como também da presença, nas reuniões de previabilidade, de todas as áreas estratégicas para o desenvolvimento de produtos.

Vale ressaltar que a empresa possui tecnologia própria para o desenvolvimento de seus protótipos na área de modelagem e prototipagem, até mesmo para os protótipos em metal, tornando assim o processo mais ágil, já que não terá que enviar seu pessoal ou seus projetos para outros locais para o desenvolvimento do protótipo. E também não precisará disponibilizar a linha de produção para o desenvolvimento de um protótipo em metal, o qual pode ser feito diversas vezes até se chegar ao produto ideal.

Com o projeto aprovado pelo comitê, sua ficha técnica e os protótipos serão repassados para a engenharia, iniciando-se assim a quarta etapa do projeto. A partir desse momento, fim da etapa de engenharia do produto, este não será mais modificado. A etapa de engenharia do processo inicia-se com o recebimento do projeto detalhado na ficha técnica pela engenharia, para que possam: produzir as peças e ferramentas necessárias para o projeto; adquirir novos equipamentos e tecnologias; e realizar os treinamentos na linha de produção para manuseio das novas ferramentas, peças, equipamentos e tecnologias.

Nem sempre todos os componentes serão produzidos dentro da empresa. Nesse caso, eles serão adquiridos pelo setor de compras, mesmo assim o projetista deve projetar o componente e entregá-lo à empresa contratada. A cada nova compra, o setor responsável realiza uma 
avaliação dos fornecedores do mercado daquele componente específico para realizar a melhor negociação. A empresa contratada deverá enviar um lote do produto para uma bateria de testes, que será realizada no laboratório interno da Deca. Esses testes acontecem paralelamente à etapa de engenharia.

Selecionados os fornecedores, a empresa definirá a configuração da cadeia física de suprimentos, indicando o local onde será feita a junção dos componentes. É também nessa etapa que a Deca define e planeja o processo de embalagem de seus novos produtos, e cria o manual de operação. O Quadro 26 detalha as decisões tomadas pela Deca na etapa de projeto do produto e projeto da cadeia física de suprimentos.

Quadro 26 - Decisões Deca - projeto da cadeia de suprimentos e projeto do produto

\begin{tabular}{|c|c|c|}
\hline $\begin{array}{c}\text { Etapas segundo } \\
\text { Krishnan e Ulrich } \\
\text { (2001) }\end{array}$ & $\begin{array}{c}\text { Decisões das etapas do processo de } \\
\text { desenvolvimento }\end{array}$ & Decisões Deca \\
\hline $\begin{array}{l}\text { Projeto da Cadeia de } \\
\text { Suprimentos }\end{array}$ & $\begin{array}{l}\text { - Componentes - projetados internamente ou } \\
\text { comprados prontos; quem projetará, } \\
\text { desenvolverá e produzirá (KRISHNAN; } \\
\text { ULRICH, 2001). } \\
\text { - Cadeia física de suprimentos - } \\
\text { configuração, incluindo o local de junção dos } \\
\text { componentes; seleção de fornecedores das } \\
\text { tecnologias e equipamentos; sistema de } \\
\text { produção e distribuição; custos diretos de } \\
\text { produção; custos entre fornecimento e } \\
\text { demanda (KRISHNAN; ULRICH, 2001). }\end{array}$ & $\begin{array}{l}\text { - Componentes - projetados } \\
\text { internamente ou comprados prontos; } \\
\text { quem projetará; desenvolverá e } \\
\text { produzirá. } \\
\text { - Cadeia física de suprimentos - } \\
\text { configuração, incluindo o local de } \\
\text { junção dos componentes; seleção de } \\
\text { fornecedores das tecnologias e } \\
\text { equipamentos; sistema de produção e } \\
\text { distribuição; custos diretos de produção; } \\
\text { custos entre fornecimento e demanda. }\end{array}$ \\
\hline Projeto do Produto & $\begin{array}{l}\text { - Especificação dos parâmetros do projeto } \\
\text { - projeto detalhado dos componentes; relação } \\
\text { entre os componentes do produto; seleção de } \\
\text { material e de processo e projeto das } \\
\text { ferramentas e equipamentos; planos de } \\
\text { processo; desenhos finais com tolerâncias } \\
\text { (ROZENFELD et al, 2006). } \\
\text { - Embalagem - avaliação da distribuição do } \\
\text { produto, incluindo transporte e entrega; } \\
\text { definição das formas e sinalizações das } \\
\text { embalagens dos produtos; projeção da } \\
\text { embalagem; planejamento do processo de } \\
\text { embalagem (ROZENFELD et al, 2006). } \\
\text { - Material de suporte do produto - criação } \\
\text { do manual de operação do produto, do } \\
\text { material de treinamento e do manual de } \\
\text { descontinuidade do produto (ROZENFELD } \\
\text { et al, 2006). }\end{array}$ & $\begin{array}{l}\text { - Especificação dos parâmetros do } \\
\text { projeto - projeto detalhado dos } \\
\text { componentes; relação entre os } \\
\text { componentes do produto; seleção de } \\
\text { material e de processo e projeto das } \\
\text { ferramentas e equipamentos; planos de } \\
\text { processo; desenhos finais com } \\
\text { tolerâncias. } \\
\text { - Embalagem - avaliação da } \\
\text { distribuição do produto, incluindo } \\
\text { transporte e entrega; definição das } \\
\text { formas e sinalizações das embalagens } \\
\text { dos produtos; projeção da embalagem; } \\
\text { planejamento do processo de } \\
\text { embalagem. }\end{array}$ \\
\hline
\end{tabular}




\section{d) Teste e validação de desempenho}

Nessa etapa, de acordo com Krishnan e Ulrich (2001), a empresa deve procurar decidir questões relacionadas à prototipagem do produto e a realização de um teste em pequena escala do projeto. Na Deca isso é feito no fim da etapa de engenharia do processo, quando todos os equipamentos e novas tecnologias estão adquiridos. O try-out, ou seja, o processo de implantação com acompanhamento dos primeiros lotes produzidos é feito nesse momento, pelo fato de ser a primeira vez que a linha de produção está lidando com os novos produtos, equipamentos, tecnologias, etc. Por essa razão, dos produtos que saem dessa produção inicial selecionam-se, de forma aleatória, três a quatro peças de cada item novo para serem testadas pelo laboratório interno da empresa.

Além disso, esses lotes serão utilizados para realizar o teste de campo, para verificação das características técnicas. A empresa insere os produtos dentro da própria fábrica ou mesmo na casa dos funcionários, como também em restaurantes nas estradas, pois devido ao grande giro de pessoas nesses locais, é possível realizar vários testes em menor espaço de tempo. Todos devem atender às normas da ABNT, por isso a preocupação com testes. Devem funcionar 150.000 vezes, ficando assim em ciclo antes de ser lançado no mercado. Também é avaliado o custo da produção.

Outro ponto de decisão apresentado na literatura estudada, como pode ser observado no Quadro 27, são questões relacionadas com o tipo do protótipo, o processo de construção dos protótipos e seus benefícios. Na Deca, essas decisões não são feitas nessa etapa, isso é definido no briefing do projeto. Porém, é importante ressaltar como é feito na Deca. A classificação de Clark e Wheelwright (1993) do tipo de protótipo não se aplica à Deca, pois esta é feita paralelamente a todo o processo, podendo ser virtual, prototipagem rápida (experimentação real), e protótipos em isopor, o que dependerá da etapa em que o projeto se encontra. Ocorre paralelamente ao processo, desde as etapas iniciais, contribuindo assim para a identificação de oportunidades, no aprendizado da organização, na formação de novas capacidades, testa a comunicação entre os membros do projeto e auxilia na resolução de conflitos. 
Quadro 27 - Decisões Deca - teste e validação de desempenho

\begin{tabular}{|c|c|c|}
\hline $\begin{array}{c}\text { Etapas segundo } \\
\text { Krishnan e Ulrich } \\
\text { (2001) }\end{array}$ & Decisões das etapas do processo de desenvolvimento & Decisões Deca \\
\hline $\begin{array}{c}\text { Teste e Validação } \\
\text { de Desempenho }\end{array}$ & $\begin{array}{l}\text { - Prototipagem para validação - em relação a } \\
\text { funcionamento, tamanho e fabricação (KRISHNAN; } \\
\text { ULRICH, 2001); avalia reações dos consumidores, } \\
\text { projeto industrial, durabilidade, encaixe e finalização, e } \\
\text { custos de produção (ROZENFELD et al, 2006; } \\
\text { CLARK; WHEELWRIGHT, 1993). } \\
\text { - Teste em pequena escala do projeto - produção } \\
\text { piloto (CLARK; WHEELWRIGHT, 1993); definição } \\
\text { dos processos de produção e manutenção } \\
\text { (ROZENFELD et al, 2006). } \\
\text { - Tipo de protótipo - rápida resposta à engenharia, } \\
\text { sistema de solução integrado (periódico), ou replicação } \\
\text { da produção cedo (CLARK; WHEELWRIGHT, 1993). } \\
\text { - Processo de construção dos protótipos - simulação } \\
\text { virtual, prototipagem rápida (experimentação real), e } \\
\text { protótipos de papelão ou argila (CLARK; } \\
\text { WHEELWRIGHT, 1993; THOMKE, 1998; } \\
\text { SRINIVASAN et al, 1997; BECKER et al, 2005); } \\
\text { seqüencial ou paralela; prototipagem em etapas iniciais } \\
\text { do projeto (SRINIVASAN et al, 1997). } \\
\text { - Benefícios do protótipo - contribuem para a } \\
\text { identificação de oportunidades; aprendizado da } \\
\text { organização; formação de novas capacidades; testa a } \\
\text { comunicação entre os membros do projeto; auxilia na } \\
\text { resoluçãa de conflitos (CLARK; WHEELWRIGHT, } \\
\text { 1993). }\end{array}$ & $\begin{array}{l}\text { - Prototipagem para } \\
\text { validação - em relação a } \\
\text { funcionamento, tamanho e } \\
\text { fabricação; avalia reações dos } \\
\text { consumidores, projeto } \\
\text { industrial, durabilidade, } \\
\text { encaixe e finalização, e custos } \\
\text { de produção. } \\
\text { - Teste em pequena escala } \\
\text { do projeto - produção piloto; } \\
\text { definição dos processos de } \\
\text { produção e manutenção. } \\
\text { - Processo de construção de } \\
\text { protótipos - simulação } \\
\text { virtual, prototipagem rápida e } \\
\text { protótipos de isopor; paralela; } \\
\text { prototipagem em etapas } \\
\text { iniciais do projeto. } \\
\text { - Benefícios do protótipo - } \\
\text { contribuem para a } \\
\text { identificação de } \\
\text { oportunidades; aprendizado } \\
\text { da organização; formação de } \\
\text { novas capacidades; testa a } \\
\text { comunicação entre os } \\
\text { membros do projeto; auxilia } \\
\text { na resolução de conflitos. }\end{array}$ \\
\hline
\end{tabular}

\section{e) Ramp-up e lançamento}

A última etapa constitui-se no lançamento do produto. Inicialmente é divulgado o lançamento para todos os colaboradores da Deca, em especial para os vendedores, através de uma Instrução Administrativa - IA. Apesar de todos já estarem cientes da existência do produto, essa IA é enviada com a finalidade de sedimentar e passar maiores detalhes sobre o produto, como: preço, tamanho, vantagens, novas tecnologias, e locais de venda.

Após sua divulgação interna, é feita a divulgação externa da nova linha de produtos, desde a formação do time, que a área comercial trabalha paralelamente com a função de desenvolver o merchandising, até desenhar o processo de distribuição dos novos produtos, definir como será a exposição no ponto de venda, dentre outros pontos de decisão que envolvem a divulgação do novo produto. 
Algumas vezes é possível coincidir o lançamento do produto com feiras e eventos do setor, porém, caso isso não aconteça, a empresa parte para a divulgação em seu maior mercado, o Estado de São Paulo. Para facilitar o processo de distribuição dos novos produtos, a empresa possui classificações para suas revendas, selecionando grupos específicos de lojas para começarem a venda dos novos produtos. Alguns vão direto para todos os pontos de venda, outros para os home centers, isso vai depender do que foi planejado pela área comercial, que se baseia no perfil do produto e no segmento para o qual está direcionado.

Aos poucos, sob indicação da área comercial, a produção vai aumentando e, conseqüentemente, dando margens para ampliação dos locais de oferta dos produtos. O Quadro 28 apresenta de forma resumida as decisões tomadas pela Deca na etapa de ramp-up e lançamento.

Quadro 28 - Decisões Deca - ramp-up e lançamento

\begin{tabular}{|c|c|c|}
\hline $\begin{array}{c}\text { Etapas segundo } \\
\text { Krishnan e Ulrich } \\
\text { (2001) }\end{array}$ & $\begin{array}{c}\text { Decisões das etapas do processo de } \\
\text { desenvolvimento }\end{array}$ & Decisões Deca \\
\hline $\begin{array}{l}\text { Ramp-up e } \\
\text { Lançamento }\end{array}$ & $\begin{array}{l}\text { - Teste de mercado - nível de realização; } \\
\text { seqüência de introdução dos produtos no } \\
\text { mercado (CLARK; WHEELWRIGHT, 1993). } \\
\text { - Lançamento - tempo para o lançamento do } \\
\text { produto; como e quando o concorrente entrará } \\
\text { ou entrou no mercado; finalização do } \\
\text { desenvolvimento do projeto; desenho dos } \\
\text { processos de venda e distribuição; atendimento } \\
\text { do cliente e assistência técnica; campanhas de } \\
\text { marketing (ROZENFELD et al, 2006). } \\
\text { - Ramp-up - aumento da produção (CLARK; } \\
\text { WHEELWRIGHT, 1993; ROZENFELD et al, } \\
\text { 2006). } \\
\text { - Ao fim, cessa ou continua o } \\
\text { acompanhamento do produto pelo time } \\
\text { (ROZENFELD et al, 2006). }\end{array}$ & $\begin{array}{l}\text { - Teste de mercado - seqüência de } \\
\text { introdução dos produtos no mercado. } \\
\text { - Lançamento - tempo para o } \\
\text { lançamento do produto; como e } \\
\text { quando o concorrente entrará ou } \\
\text { entrou no mercado; desenho dos } \\
\text { processos de venda e distribuição; } \\
\text { atendimento do cliente e assistência } \\
\text { técnica; campanhas de marketing. } \\
\text { - Ramp-up - aumento da produção. } \\
\text { - Ao fim, cessa o acompanhamento } \\
\text { do produto pelo time. }\end{array}$ \\
\hline
\end{tabular}

\subsubsection{Conclusões}

A Deca é fabricante nacional, empresa líder no segmento em que atua, e possui a mais completa linha de metais sanitários (ENFOQUE, 2008). Há 61 anos no mercado, com 3.000 funcionários, e uma área de desenvolvimento composta por 60 pessoas, tem uma carteira de produtos com cerca de 6.200 metais e louças sanitárias. Direciona suas atenções para o consumidor final, pois entende que seu produto é um conjunto de atributos, tendo como paradigma a utilidade para o cliente como uma função das características do produto. Seus 
novos produtos são novos não somente para a empresa, mas também para o mercado, com diferenciação no design e na tecnologia. Dividem-se em topológicos, incrementais e radicais. No entanto, devido ao perfil do seu produto, a grande maioria é do tipo topológico, pois com pequenas alterações, por exemplo, em um detalhe de estilo, é ofertado para diferentes nichos de mercado.

O processo de desenvolvimento de novos produtos na Deca possui alguns pontos que merecem ser destacados. Além de formalizado dentro da empresa, acontece de forma bastante interativa, envolvendo a participação de todas as pessoas necessárias para o desenvolvimento do projeto, desde a direção da empresa até a área de produção industrial, como também a área comercial. Essa característica multifuncional proporciona benefícios à Deca, como por exemplo, o desenvolvimento de projetos realmente possíveis de serem produzidos, de forma a evitar dificuldades técnicas em fases finais, possibilitando assim uma redução de abortamentos de projetos em andamento. De acordo com a empresa, quanto menos abortarem projetos, melhor, pois isso indicará que estão selecionando idéias promissoras. Isso, no entanto, gera um processo mais em forma de túnel, que de um funil de desenvolvimento de Clark e Wheelwright (1993).

O processo de desenvolvimento dos projetos de inovação ocorre similar a um túnel e não à um funil, pois eles inserem uma idéia e trabalham em cima desta para gerar um produto inovador. Nos outros casos, melhorias contínuas, já se tem um produto, o qual é aperfeiçoado e modificado.

É importante ressaltar que a interação entre os participantes do time só acontece a partir da segunda etapa do desenvolvimento. A Deca afirma que essa estrutura funciona muito bem, não prejudicando o projeto, indicando que inicialmente a designer idealiza o projeto de forma a organizar as primeiras possíveis características do produto, para que assim seja possível saber quais os conhecimentos que realmente serão necessários.

A participação da área comercial no time de desenvolvimento é de extrema importância para que sejam definidas estratégias de divulgação e distribuição dos produtos, adequadas às características da nova linha. Por essa razão a empresa insere essa área no seu processo. Além desse benefício, a empresa acredita que, com o acompanhamento constante do 
desenvolvimento, é possível a definição de formas de divulgação diferentes, baseadas nas dificuldades e nas motivações do desenvolvimento dos produtos.

A Deca acredita que não há necessidade de inserir o consumidor em seu processo de desenvolvimento, pois está diretamente ligada à área de marketing e de assistência técnica, que por sua vez relacionam-se com o mercado. A área de marketing fornece informações do mercado consumidor, e prepara o merchandising da empresa. E a área de Assistência Técnica lida com os problemas técnicos dos produtos, coletando ricas informações para os projetos de melhoria contínua, como também de inovação.

A área de marketing identifica as oportunidades no mercado, buscando idéias das mais diversas formas. E também define quando um produto deve ou não ser produzido, e quando pode ou não ser lançado, mesmo quando é uma inovação técnica do produto desenvolvida no laboratório interno da empresa. Deve-se ter cuidado com essa “dominação” do marketing, pois este se baseia nas necessidades do mercado, e nem sempre o mercado sabe o que realmente se precisa. Muitas vezes, é necessária a criação de novas necessidades e desejos desses consumidores, geralmente atrelado a um produto inovador, desenvolvido pela área de engenharia.

Com uma área de desenvolvimento que interage formal e informalmente, um time com estrutura multifuncional e técnicas como a engenharia simultânea, o stage-gate e protótipos que acompanham o processo desde a etapa de desenvolvimento do conceito do produto, a Deca conseguiu reduzir o tempo de desenvolvimento e o número de projetos abortados.

E, por fim, a Deca não procura identificar e analisar as falhas que ocorrem nos projetos. Existe um aperfeiçoamento que acontece informalmente durante o desenvolvimento de determinado projeto, no entanto não há registros, ou mesmo reuniões para discutir formas para melhorar esse processo. Apesar de haver medição da performance do produto no mercado, isso não traz benefício para o processo, somente para a manutenção do produto no mercado, como também para a utilização dessas informações, pela área de marketing, em projetos futuros. 


\subsection{Cecrisa}

\subsubsection{Caracterização da empresa}

\subsubsection{Histórico}

A Cecrisa S.A. é uma companhia aberta que produz e comercializa porcellanatos e revestimentos cerâmicos com as marcas PORTINARI e CECRISA. Originou-se na década de 40, quando o empresário Diomício Freitas iniciou atividades no setor extrativo de carvão mineral, na bacia carbonífera de Santa Catarina. A empresa Cerâmica Criciúma S.A. foi construída em 08 de junho de 1966, por iniciativa do empresário catarinense Manoel Dilor de Freitas, filho de Diomício Freitas. Os primeiros azulejos saíram da linha de produção em 11 de abril de 1971. Desde então a empresa vem seguindo com seu arrojado programa de expansão.

A empresa afirma que "Inovação e pioneirismo sempre foram fatores marcantes na vida da Cecrisa”. Isso pode ser constatado ao longo de sua história. Desde 1972, tem comprovado essa afirmação, como, por exemplo, foi pioneira: na produção de revestimentos de parede decorados, de pisos monoqueima em fornos a rolo sem placas, e de revestimentos de parede com técnica monoporosa; na utilização de fornalhas de leito fluidizado, de secadores a rolo e de escolha eletrônica e de CAD no desenvolvimento de produtos. Foi ainda a primeira empresa no Brasil a produzir Porcellanatos Esmaltados e em grandes formatos, como também a primeira no setor cerâmico, nas Américas, a receber Certificação pela Norma ISO 9000.

Seu perfil inovador e desafiador também pode ser identificado através das diversas aquisições que ocorreram durante toda sua história, começando em 1974 com a aquisição da Unidade Industrial Incocesa em Tubarão-SC, seguida por diversas outras: Unidade Industrial Cesaca em Criciúma-SC, Portinari em Criciúma-SC, Cemisa em Santa Luzia-MG, Klace no Rio de Janeiro- RJ e Brilho em São Paulo-SP. Além da construção da Unidade Industrial Cemina em Anápolis-GO e Portinari em Criciúma-SC.

Foi então em 1990, que Manoel Dilor de Freitas, diante de toda a expansão vivida nos últimos anos, conduziu o processo de profissionalização da empresa, passando a família a integrar o Conselho de Administração. Atualmente, possui gestão profissionalizada, constituída pelo Conselho de Administração da Cecrisa, cujo presidente é o empresário João 
Paulo Borges de Freitas, e sua Diretoria Executiva é presidida por Rogério Gustavo Arns Sampaio, um dos entrevistados para a realização desta pesquisa.

A empresa hoje é líder em seu segmento, Indústria e Comércio de Revestimentos Cerâmicos. Conforme a Anfacer (2003), atualmente existem 94 empresas nesse setor, 117 plantas industriais em 17 estados, as quais em conjunto empregam 23 mil pessoas e possuem uma produção total de 607,9 m²/ano. A Cecrisa possui o maior portfólio de porcellanatos do mercado nacional, o que lhe gerou um faturamento bruto anual de R\$ 497.601 mil em 2007. É integrada por regionais de vendas instaladas nas principais cidades e capitais do País. Exporta para mais de 50 países, em cinco continentes.

Conta com 5 unidades industriais, com parque fabril modernizado, utilizando tecnologia de ponta na produção de revestimento cerâmico e porcellanato, com capacidade produtiva de $40.140 \mathrm{~m}^{2}$ /ano, contando com 2.199 colaboradores (CECRISA, 2008). São elas: Portinari, em Criciúma-SC; Eldorado, em Criciúma-SC; Cemisa, Santa Luzia-MG; Cemina, Anápolis-GO; e Incocesa, em Tubarão-SC.

O faturamento da Cecrisa tem em sua composição menos de $20 \%$ de produtos massificados e, em média, 45\% de porcelanatos. Em 2007, a empresa investiu 2,2\% da receita líquida em inovação. De acordo com o seu Diretor Executivo, o percentual do faturamento anual com novos produtos foi:

\footnotetext{
Se considerarmos o faturamento das coleções lançadas nos últimos dois anos como lançamentos, teremos $15 \%$ da receita total como resposta. Se considerarmos que há coleções pétreas como as das cores básicas e coleções clássicas que não têm perspectivas de descontinuação fora da base de cálculo, o valor sobe de $15 \%$ para $25 \%$.
}

A Cecrisa tem como intenção estratégica ser líder em lucratividade e reconhecida por: “[...] agregar permanentemente valor aos seus clientes; usar a inovação como vantagem competitiva; e desenvolver seus profissionais” (CECRISA, 2008). É com essa estratégia que vem alcançando diversos prêmios, como consta em sua Revista Jornal do Cliente (CECRISA, 2008):

[...] está presente nos anuários publicados pelo jornal Gazeta Mercantil e pela Revista Expressão, onde é apontada em seus rankings como uma das melhores empresas do Brasil em seu segmento. O Balanço Anual 2007 da Gazeta Mercantil está comemorando 31 anos de existência, e traz nessa edição 10 mil empresas dos setores da indústria, comércio, serviços e agronegócios. A Cecrisa 
está em $1^{\circ}$ lugar na classe Cerâmicas, Porcelanas e Louças. Esta publicação apresenta a análise de dados dos balanços das empresas em atuação no Brasil, com o respaldo de critérios elaborados pelo Ibmec São Paulo - escola de economia e negócios conceituada internacionalmente. No Anuário Expressão 2007, onde são publicadas as 300 maiores empresas do Sul, a Cecrisa aparece no ranking como a maior empresa do setor cerâmico, maior em vendas, e maior em crescimento de vendas. No ranking geral, ocupa a posição número 64. O Anuário Expressão está em sua $14^{a}$ edição, e é elaborado pela Fundação Getúlio Vargas. A empresa também está entre as Melhores \& Maiores empresas do país, da Revista Exame, e as 1000 maiores, ranking do Anuário Valor 1000, do Jornal Valor Econômico, sendo a primeira entre as indústrias cerâmicas.

A Cecrisa é uma empresa ambientalmente responsável, que utiliza técnicas e equipamentos necessários ao tratamento dos resíduos, efluentes e emissões provenientes das suas áreas de produção, ao mesmo tempo em que investe na conscientização ambiental dos seus profissionais. Em todas as cinco unidades industriais possui as seguintes ações: programa de reciclagem; controle seletivo dos resíduos sólidos; estação de tratamento de efluentes; lavadores de gases dos atomizadores; e reciclagem das quebras do processo industrial. Como forma de aperfeiçoamento do seu sistema de gestão, a empresa encontra-se no processo de implantação da ISO 14001 (conformidade na gestão ambiental) em todas as suas unidades industriais.

O prêmio “As melhores da Dinheiro”, da Revista IstoÉ Dinheiro, como a Melhor Empresa em Responsabilidade Social e Meio Ambiente do Setor de Material de Construção e Decoração, “mostra que os caminhos escolhidos são sustentáveis social e ambientalmente”. (CECRISA, 2008).

\subsubsection{Tipo de produto}

A Cecrisa possui 73 coleções, termo utilizado pela empresa para indicar as linhas de produtos, e 1.200 acessórios, ou peças especiais. Em 2007, foram lançadas 11 novas coleções, as quais contêm 272 produtos, distribuídos em de fundo e de acessórios. Dentre os principais estão: porcellanato, pisos, azulejos e revestimentos de fachadas.

Conforme o Diretor Executivo da empresa (CECRISA, 2008), a Portinari consolidou, no ano de 2007, sua posição de liderança em inovação e design no setor cerâmico nacional. Ele acredita que isso se deve a diversos fatores. Um deles foi o lançamento na Revestir de algumas coleções, tais como a Connection e a Stellar de Pietra Portinari. A grande complexidade tecnológica desta última coleção citada faz com que seja produzida em todo o mundo apenas pela Portinari e pela empresa italiana Graniti Fiandre. Essa liderança também 
se deve à ousada campanha publicitária que associa, de forma direta e original, o design cerâmico com moda de vestir através das consagradas top models brasileiras Gianne Albertoni, Mariana Weickert e Ana Cláudia Michels, que fazem sucesso tanto na indústria da construção quanto na da moda.

Para exposição de todo o seu portfólio de produtos, ou melhor, de todas as suas coleções, a Cecrisa conta com showrooms corporativos em três lugares do Brasil - Criciúma, Florianópolis e São Paulo.

\subsubsection{Segmentação do mercado}

Conforme a descrição dos produtos e das linhas, percebe-se o direcionamento da empresa para o consumidor final, pois é ele quem decide, nesse tipo de produto, qual irá comprar, mesmo que seja influenciado por outras pessoas. Com isso, conclui-se que a segmentação de mercado da empresa é B2C. De acordo com Hutt (2002, p. 35), uma empresa voltada para o mercado irá revelar duas características importantes: “a percepção de mercado e a ligação com o cliente”. A percepção de mercado demonstra o quanto a empresa está preparada para perceber continuamente as mudanças em seu mercado, ao passo que a capacidade de ligação com o cliente está relacionada com a competência desta em desenvolver, criar e gerenciar uma relação mais próxima com o cliente.

Através dos produtos Cecrisa é possível perceber essa procura pela proximidade com o cliente. Por isso a sua preocupação com o design do produto. E uma das formas que a empresa encontrou para gerenciar essa proximidade foi através de um processo de gestão de desenvolvimento de novos produtos, como será visto a seguir.

\subsubsection{Gestão do desenvolvimento de produtos Cecrisa}

A estrutura de desenvolvimento na empresa existe há mais de 20 anos. A procura pela mudança é constante, daí que em 1998, a empresa firmou uma parceria com fornecedores internacionais para a realização de testes na produção de seus novos produtos; e em 2002, houve um grande investimento nessa área, que foi a contratação de consultores internacionais em design. O Quadro 29 apresenta as etapas e subetapas do processo de GDP da Cecrisa. 
Quadro 29 - Etapas e subetapas do processo de GDP da Cecrisa

\begin{tabular}{|l|l|}
\hline \multicolumn{1}{|c|}{ Etapas } & \multicolumn{1}{c|}{ Subetapas } \\
\hline Levantamento e Seleção de Idéias & $\begin{array}{l}\text { Identificação de oportunidades } \\
\text { Seleção das idéias } \\
\text { Elaboração do cronograma dos projetos } \\
\text { Reunião de lançamento para seleção dos projetos }\end{array}$ \\
\hline Elaboração do Anteprojeto & $\begin{array}{l}\text { Elaboração do anteprojeto } \\
\text { Concepção gráfica do produto } \\
\text { Reunião 2 - análise alta administração }\end{array}$ \\
\hline Desenvolvimento do Produto e Mix Promocional & $\begin{array}{l}\text { Prototipagem simulada em processo produtivo do } \\
\text { laboratório } \\
\text { Modelo do mix promocional } \\
\text { Reunião 3 - análise alta administração }\end{array}$ \\
\hline Realização de Semi-industriais e Confecção de & $\begin{array}{l}\text { Produção piloto } \\
\text { Mix promocional impresso } \\
\text { Material Promocional }\end{array}$ \\
\hline Lançamento das Coleções & $\begin{array}{l}\text { Lançamento interno } \\
\text { Lançamento externo }\end{array}$ \\
\hline Verificação da Eficácia do Lançamento & Avaliação do lançamento \\
\hline Acompanhamento dos Resultados Comerciais & Avaliação das vendas \\
\hline
\end{tabular}

\subsubsection{Conceito}

A Cecrisa entende que a Gestão do Desenvolvimento de Produtos - GDP, vai desde a identificação do que o mercado quer ou nem mesmo pensou em ter, criando dessa forma o desejo de comprá-lo, por ser um produto de moda, que tem o design como determinante na decisão de compra. Porém, não se esquece da tecnologia, seja a partir de uma matéria-prima diferente, ou da aplicação de uma tecnologia já existente e já utilizada pela empresa, de uma maneira diferente, ou ainda uma tecnologia que esteja em alta no mercado, de modo a transformar todas essas informações em um conjunto que faça sentido, podendo a partir daí, gerar idéias para produtos futuros.

\subsubsection{Estratégia e planejamento do produto}

Todo o processo inicia com a identificação das oportunidades do mercado, após a última das três feiras mundiais mais importantes existentes do setor: Revestir, Covering e Cersaie. Para complementar essas informações, a empresa procura também identificar os gaps do mercado. A Cecrisa dispõe de três consultores, que observam o mercado. Um consultor italiano que busca tendências do Brasil e do mundo, através de visitas a uma série de feiras e eventos, no mundo do design, e não especificamente da cerâmica, mas também de móveis, roupas e 
eletrodomésticos. E ainda uma consultora de moda de roupas e outra com experiência em cerâmica, que também trazem manifestações da moda e do design no Brasil e no mundo.

De acordo com o Diretor Executivo da Cecrisa, os inputs de desenvolvimento desta empresa são: inovação própria por criação de nossos profissionais; inovação com inspiração em setores afins que estão mais “perto” da moda - tecidos, móveis, eletrodomésticos; inovação que vem de novas tecnologias de matérias-primas; inovações que vêm de novas tecnologias de equipamentos; e o Desenvolvimento reativo - reinterpretar o sucesso da grande concorrência internacional. As fontes de informações sobre o mercado são provenientes da própria visão de mercado da empresa, a partir de uma avaliação dos produtos que possuem, como também da opinião de arquitetos e decoradores.

A empresa obtém também diversas informações em seu showroom no Estado de São Paulo, em visita a feiras do setor na Europa e nos EUA, com exposição de seus produtos, e ainda através de pesquisas de mercado feitas pela área de marketing da empresa.

Vale ressaltar que a Cecrisa não procura muito informações provenientes de consumidores, arquitetos e construtoras, pois acredita que essas fontes não poderão lhe fornecer informações tão valiosas para desenvolver produtos totalmente novos e inovadores. A concepção da Cecrisa, de acordo com o seu diretor executivo, é que os consumidores finais ou intermediários conseguem enxergar melhorias nos produtos já existentes, mas não têm idéias para produtos inovadores. Por essa razão, quem mais influencia, tanto no design, quanto na tecnologia do produto, são os consultores, pois são eles que estão em contato com as grandes inovações tecnológicas da indústria de equipamentos e de matéria-prima, que, na visão do gerente de produtos e marketing estratégico, são um dos grandes propulsores de avanços na indústria cerâmica.

Com essas informações é possível desenhar as estratégias de mercado e tecnológica da Cecrisa. A estratégia de mercado é composta pelos produtos ofertados, público-alvo e forma que serão disponibilizados, define o número, tempo e relações de produtos diferenciados, e indica os componentes compartilhados entre as plataformas. E a estratégia tecnológica, traçada com base na estratégia de mercado, indica a tecnologia necessária e que dê vantagem competitiva, e ainda a sua fonte externa e interna. 
O consultor italiano, a consultora de moda de roupas e a consultora de cerâmica, juntamente com o gerente de produto e marketing estratégico, pessoal da área de marketing e da área de desenvolvimento de produtos, e o controller reúnem-se para analisar as novas idéias. Dessa reunião serão indicadas, em média, dez idéias. A primeira seleção de idéias é uma apresentação de slide indicando o que está acontecendo no mundo da cerâmica e nos outros setores observados, são descritas algumas idéias, sem forma definida, pois esta quem vai dar é o Anteprojeto. Por exemplo, está se usando muitas flores em roupas, daí começa-se a pensar em produtos com flores. Após a realização dessa reunião, o controller elabora o cronograma, levando em consideração os projetos selecionados. Este já possui uma estrutura fixa, que poderá ser modificada com o decorrer do processo.

Indicadas as dez idéias, faz-se a reunião de lançamento, que tem como participantes a diretoria, o gerente de produtos e marketing estratégico, o controller e os três consultores. Normalmente essas reuniões ocorrem duas vezes por ano, com a finalidade de atualizar as informações e aperfeiçoar os projetos identificados no início do ano. O critério de análise não se resume a identificar sua adequação a um dos dois pólos, mas também ao que a empresa estiver mais interessada no momento, tendo-se uma certa priorização para a inovação.

No entanto, caso a idéia ou o projeto sejam muito inovadores, não terão um retorno rápido, pois provavelmente no início precisará de um tempo para maturação, tendo a adesão apenas de um público formador de opinião. Como também, pode ter um projeto com grande possibilidade de venda, mas sem ser uma inovação muito relevante. Enfim, a idéia será aprovada tanto se estiver de acordo com os dois pólos, quanto só com um deles. Das, em média, dez idéias que haviam sido indicadas, poderão ser selecionadas, na Reunião de Lançamento, uma ou mesmo todas as idéias.

Dentre as três coleções que serão desenvolvidas no ano, é feito um balanceamento entre o número de projetos de posicionamento, nomenclatura utilizada para os projetos radicalmente novos, e os projetos com menor risco, com maior possibilidade de vender, de dar certo. A empresa prefere não trabalhar com as melhorias incrementais dos produtos, pois acredita na descontinuidade. Trata as melhorias de produtos como upgrades, caso da coleção canyon, que foi aperfeiçoada e assim gerou a coleção element (CECRISA, 2008). 
No que se refere aos aprendizados e melhorias para projetos futuros, a Cecrisa procura melhorar as capacidades envolvidas no processo e o próprio processo em si, mas tudo feito informalmente. Só há informações nos documentos que registram falhas técnicas e que a partir destas são gerados novos projetos. Não possui documentos, nem uma estrutura fixa para registro desses aprendizados. O Quadro 30 apresenta as decisões tomadas pela Cecrisa na fase de Estratégia e Planejamento do Produto.

Quadro 30 - Decisões Cecrisa - estratégia e planejamento do produto

\begin{tabular}{|c|c|c|}
\hline $\begin{array}{l}\text { Organização do } \\
\text { Projeto de } \\
\text { Desenvolvimento }\end{array}$ & $\begin{array}{c}\text { Decisões para organização de projetos de } \\
\text { desenvolvimento }\end{array}$ & Decisões Cecrisa \\
\hline $\begin{array}{c}\text { Estratégia e } \\
\text { Planejamento do } \\
\text { Produto }\end{array}$ & $\begin{array}{l}\text { - Estratégia de Mercado (KRISHNAN; } \\
\text { ULRICH, 2001; CLARK; WHEELWRIGHT, } \\
\text { 1993) - produtos que serão ofertados, público- } \\
\text { alvo e forma que serão disponibilizados; } \\
\text { número, tempo e taxa de mudança da } \\
\text { plataforma; e define número, tempo, freqüência } \\
\text { e relações de produtos diferenciados; } \\
\text { componentes compartilhados entre as } \\
\text { plataformas. } \\
\text { - Estratégia Tecnológica - tecnologia } \\
\text { necessária; tecnologia que dê vantagem } \\
\text { competitiva; fonte externa e interna; tempo para } \\
\text { capacitação; maturação da tecnologia; e } \\
\text { freqüência das implementações (KRISHNAN; } \\
\text { ULRICH, 2001; CLARK; WHEELWRIGHT, } \\
\text { 1993). } \\
\text { - Plano Agregado de Projetos - prioridades; } \\
\text { escolha do projeto e definição de quando } \\
\text { começam e terminam; recursos disponíveis } \\
\text { (CLARK; WHEELWRIGHT, 1993). } \\
\text { - Aprendizados e melhorias para projetos } \\
\text { futuros - melhoria das capacidades envolvidas } \\
\text { no processo e do próprio processo em si } \\
\text { (CLARK; WHEELWRIGHT, 1993). }\end{array}$ & $\begin{array}{l}\text { - Estratégia de Mercado - } \\
\text { produtos que serão ofertados, } \\
\text { público-alvo e forma que serão } \\
\text { disponibilizados; define número, } \\
\text { tempo, frequêencia e relações de } \\
\text { produtos diferenciados. } \\
\text { - Estratégia Tecnológica - } \\
\text { tecnologia necessária; tecnologia } \\
\text { que dê vantagem competitiva; } \\
\text { fonte externa e interna. } \\
\text { - Plano Agregado de Projetos - } \\
\text { prioridades; escolha do projeto e } \\
\text { definição de quando começam e } \\
\text { terminam; recursos disponíveis. } \\
\text { - Aprendizados e melhorias para } \\
\text { projetos futuros - melhoria das } \\
\text { capacidades envolvidas no } \\
\text { processo e do próprio processo em } \\
\text { si. }\end{array}$ \\
\hline
\end{tabular}

\subsubsection{Organização do desenvolvimento do produto}

A estrutura administrativa da Cecrisa é composta por um conselho de administração e uma diretoria executiva. O conselho de administração tem a seguinte formação: presidente; três vice-presidentes; e dois conselheiros. Enquanto a diretoria executiva possui: presidente; diretor de operações; diretor de relações com investidores; e diretor de vendas.

Na Ilustração 13 é feita a representação do organograma referente às áreas que estão envolvidas no processo de desenvolvimento de novos produtos. Como pode ser observado, o diretor de operações responde diretamente ao presidente, como também o gerente de produtos 
e marketing estratégico, o que os coloca no mesmo patamar. A coordenação geral dos projetos está sob a responsabilidade do gerente de produto e marketing estratégico. Ao diretor de operações cabe executar a Etapa 3 - Desenvolvimento do Produto, onde é feita a prototipagem do projeto.

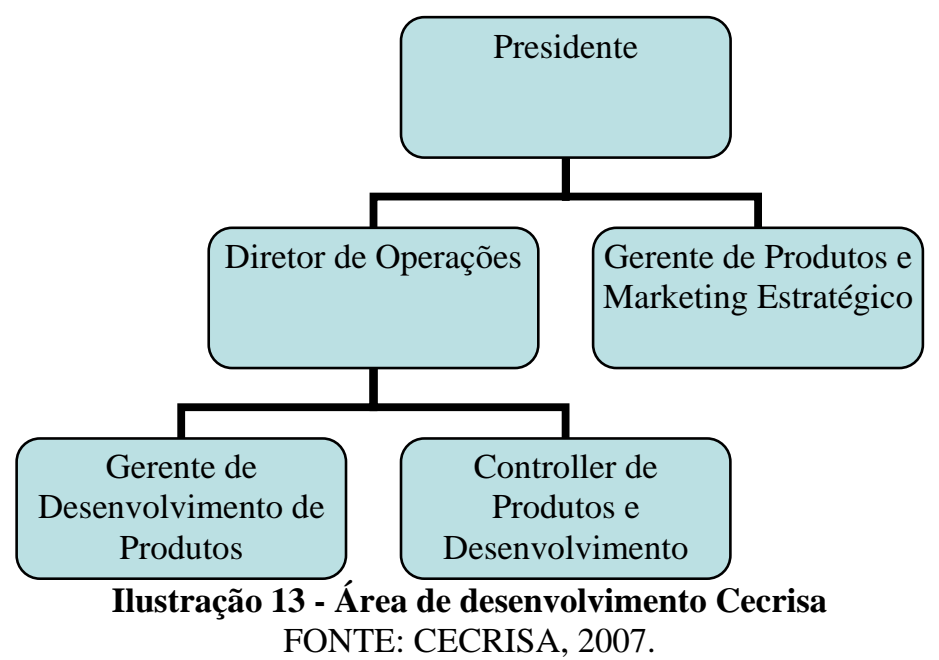

Abaixo do diretor de operações está o gerente de desenvolvimento de produtos, que entra na Etapa 3 - Desenvolvimento do Produto e Mix Promocional - do processo, cabendo-lhe executar a montagem do produto, realizar os testes em laboratório na linha de produção e produzir os protótipos. O responsável pelo controle efetivo do projeto é o controller de produtos e desenvolvimento, que tem a função de elaborar o cronograma, o qual deve interagir com diversas áreas, e fazer com que seja cumprido. Por ser responsável por cada projeto, torna-se o elo entre o gerente de produtos e marketing estratégico e o time de desenvolvimento. E, conforme este gerente, "Ele é o guardião do bom andamento das atividades”.

O controller faz com que etapas formais do processo sejam cumpridas, controla prazos e acompanha toda a carteira de projetos em desenvolvimento. No entanto, tem poder de decisão limitado, pode fazer as alterações necessárias para o andamento do projeto, desde que não altere os landmarks do anteprojeto. O time de desenvolvimento possui uma estrutura multifuncional, com funções fixas. Deve sempre ser composto pelas seguintes funções: controller; consultor italiano; consultora em moda e design; consultora em cerâmica; gerente de desenvolvimento de produto; gerente de produtos e marketing estratégico; e área de design. Sob responsabilidade de cada uma das funções citadas existem pessoas que auxiliam 
em todo o processo da produção, da engenharia, do laboratório, do marketing estratégico, trade-marketing, e das finanças.

Como pode ser observado, a estrutura de desenvolvimento de novos produtos na Cecrisa possui uma estrutura diferente, o que não permite sua classificação em funcional, peso leve, peso pesado ou autônomo. Isso se deve ao fato do controller ser o supervisor de todos os projetos e o elo entre cada projeto e a alta gerência. Possui responsabilidade limitada, como também não participa do desenvolvimento em si, mas apenas controla o andamento dos projetos. O controller se encontra no mesmo nível do gerente de desenvolvimento de produtos, como pode ser observado na Ilustração 13, e tem responsabilidade pelo trabalho de todos os envolvidos no projeto.

A estrutura de desenvolvimento na empresa existe há mais de 20 anos. A Cecrisa possui um centro de desenvolvimento de novos produtos para as cinco empresas, composto por 21 pessoas, dentre elas: designer italiano, consultora em moda e design, designers, interface controller - e envolvimento com fornecedores. Todos trabalham em uma área comum. O processo está sempre sendo aperfeiçoado. Em 1998, a empresa firmou uma parceria com fornecedores internacionais para a realização de testes na produção de seus novos produtos. Já em 2002, houve um grande investimento nessa área, que foi a contratação de consultores internacionais em design.

O processo de desenvolvimento engloba conceitos da engenharia simultânea, funil de desenvolvimento e stage-gate. A engenharia simultânea está presente, por exemplo, na etapa de Elaboração do Anteprojeto, quando paralelamente ao desenvolvimento do conceito do produto inicia-se a geração das primeiras idéias do mix promocional da nova coleção. Lançase mão do funil de desenvolvimento de Clark e Wheelwright (1993), com a finalidade de gerar um produto a partir de várias idéias, provenientes de diferentes fontes. E o stage-gate refere-se aos momentos em que o projeto é avaliado pela alta administração a fim de aproválo para a etapa seguinte.

Clark e Wheelwright (1993) afirmam que nessa fase do processo a empresa deve procurar decidir questões como infra-estrutura, ferramentas e treinamentos, e ainda como será medido o desempenho do projeto. No que se refere aos investimentos, nessa fase a Cecrisa já tem identificado quais projetos desenvolverá, e com isso poder analisar o que será necessário de 
aquisições e treinamentos, mas nada ainda muito concreto, pois essas informações serão complementadas e aperfeiçoadas na etapa de Elaboração do Anteprojeto.

O Quadro 31 apresenta as decisões que a Cecrisa toma na fase de Organização do Desenvolvimento do Produto.

Quadro 31 - Decisões Cecrisa - organização do desenvolvimento do projeto

\begin{tabular}{|c|c|c|}
\hline $\begin{array}{c}\text { Organização do } \\
\text { Projeto de } \\
\text { Desenvolvimento } \\
\end{array}$ & $\begin{array}{c}\text { Decisões para organização de projetos de } \\
\text { desenvolvimento }\end{array}$ & Decisões Cecrisa \\
\hline $\begin{array}{l}\text { Organização do } \\
\text { Desenvolvimento } \\
\text { do Produto }\end{array}$ & $\begin{array}{l}\text { - Time - membros da diretoria, gerente funcional, } \\
\text { responsável pela engenharia, gerente de projeto, } \\
\text { especialistas e parceiros (ROZENFELD et al, 2006); } \\
\text { áreas - marketing, vendas, tecnologia, produção e } \\
\text { finanças (COOPER et al, 2002b). } \\
\text { - Estrutura de desenvolvimento - individual ou em } \\
\text { grupo; formal ou informal (ROZENFELD et al, } \\
\text { 2006). Estruturas associadas ao papel da liderança - } \\
\text { time funcional, peso leve, peso pesado ou autônomo } \\
\text { (CLARK; WHEELWRIGHT, 1993; ROZENFELD et } \\
\text { al, 2006). Arranjo físico - em área comum ou cada } \\
\text { um em seu setor (KRISHNAN; ULRICH, 2001). } \\
\text { - Investimentos - infra-estrutura, ferramentas e } \\
\text { treinamento (CLARK; WHEELWRIGHT, 1993). } \\
\text { - Processo de desenvolvimento - abordagem } \\
\text { tradicional de desenvolvimento, engenharia } \\
\text { simultânea, funil de desenvolvimento e stage-gate } \\
\text { (CLARK; WHEELWRIGHT, 1993). }\end{array}$ & $\begin{array}{l}\text { - Time - membros da diretoria, } \\
\text { gerente funcional, responsável } \\
\text { pela engenharia, gerente de } \\
\text { projeto, especialistas; áreas - } \\
\text { marketing, vendas, tecnologia, } \\
\text { produção e finanças. } \\
\text { - Estrutura de } \\
\text { desenvolvimento - em grupo; } \\
\text { formal; Arranjo físico - em } \\
\text { área comum. } \\
\text { - Investimentos - infra- } \\
\text { estrutura, ferramentas e } \\
\text { treinamento. } \\
\text { - Processo de } \\
\text { desenvolvimento - engenharia } \\
\text { simultânea, funil de } \\
\text { desenvolvimento e stage-gate. }\end{array}$ \\
\hline
\end{tabular}

\subsubsection{Gerenciamento do projeto}

Todo o processo de GDP na Cecrisa é controlado através de mapas, cronogramas, que agregam todos os projetos, com a finalidade de organizá-los, baseando-se nos recursos disponíveis da empresa. Como já foi dito, esse controle é feito pelo controller, interface entre o time do projeto e o gerente de produtos e marketing estratégico.

A formalização do processo acontece por meio de etapas claras e bem definidas, como pode ser visto no item 5.3.2.5 - Etapas de Desenvolvimento. Conforme o Diretor Executivo da Cecrisa, a padronização é fundamental, e afirma que

[...] processos não engessam a estrutura, mas proporcionam organização. O processo é totalmente flexível. Existem processos formalizados para serem seguidos, mas caso haja, por alguma razão, a necessidade de se mudar a maneira como é realizado, será modificado. Os processos existem, mas não é por essa razão que a empresa ficará presa a essa estrutura. 
Existem três momentos durante o desenvolvimento de um produto que a diretoria se reúne com todas as áreas envolvidas em determinado projeto: reunião de lançamento - acontece na etapa 1 - levantamento e seleção de idéias; reunião dois, no fim da etapa 2 - elaboração do anteprojeto; reunião três, no fim da etapa 3 - desenvolvimento do produto e mix promocional; e reunião final, etapa 4 - realização de semi-industriais e confecção de material promocional.

Essas reuniões acontecem com a finalidade de analisar-se o projeto em conjunto com a diretoria. A avaliação, em cada uma das reuniões, é feita baseando-se em dois pólos: o grau de inovação da idéia, e se é vendável, sendo que em cada reunião será dada uma atenção maior a um determinado pólo. Caso o projeto não saia como o esperado, e não esteja adequado à estratégia da empresa, será abortado, independente do momento no qual se encontra.

A duração de todo o processo de desenvolvimento, normalmente, é de seis meses. Vale ressaltar que o prazo para lançamento dos produtos é estipulado pelas feiras do setor, ocasião em que serão apresentados para o mercado. Em um primeiro momento acontecem as feiras Revestir, no Brasil, e a Covering, nos Estados Unidos; no segundo semestre é realizada a feira Bologna, na Itália. Essas feiras tornaram-se o ponto de referência para o controller verificar os prazos de desenvolvimento, e para a empresa ter a consciência coletiva de que a hora de apresentar o novo produto aproxima-se.

Esse processo, conforme a Cecrisa, é bastante dinâmico, pois possui uma estrutura que proporciona e facilita a comunicação entre as pessoas, formal ou informalmente. Conforme Frishammar (2005), a comunicação pode ocorrer de duas formas: por meio da interação e da colaboração. Na Cecrisa são utilizadas as duas formas, já que uma complementa a outra. Outra classificação da comunicação, segundo Clark e Wheelwright (1993), é se há um monólogo ou diálogo entre os membros do time. No caso da Cecrisa, o diálogo acontece constantemente, desde as fases iniciais do projeto.

Nas duas etapas finais do processo de GDP da Cecrisa: Verificação da eficácia do lançamento e Acompanhamento dos resultados comerciais, é feita uma medição do desempenho do 
projeto. Após o lançamento da nova coleção, verifica-se sua eficácia, procurando identificar falhas no sistema, como por exemplo, se o material promocional chegou a toda a equipe de vendas, se as amostras chegaram aos pontos de vendas, se a equipe apresentou o material para os clientes, se os clientes fizeram a primeira compra, se gostaram, e se o pessoal de produção está produzindo os primeiros pedidos. Após alguns meses, analisam-se as vendas da nova coleção, para ver se a coleção teve sucesso ou não. Caso não tenha tido o sucesso esperado, analisam-se as causas e, se possível, consertam-se os erros. Entretanto, o gerente de produtos e marketing estratégico diz que na maioria das vezes há um bom desempenho e as vendas vão além das expectativas. De acordo com o diretor executivo da Cecrisa, os aprendizados não são registrados, mas aperfeiçoam o sistema, para que não se repitam.

O Quadro 32 apresenta as decisões que a Cecrisa toma durante o desenvolvimento de uma nova coleção.

Quadro 32 - Decisões Cecrisa - gerenciamento do projeto

\begin{tabular}{|c|c|c|}
\hline $\begin{array}{c}\text { Organização do } \\
\text { Projeto de } \\
\text { Desenvolvimento }\end{array}$ & $\begin{array}{c}\text { Decisões para organização de projetos de } \\
\text { desenvolvimento }\end{array}$ & Decisões Cecrisa \\
\hline $\begin{array}{l}\text { Gerenciamento do } \\
\text { Projeto }\end{array}$ & $\begin{array}{l}\text { - Monitoramento e controle - através de planos, } \\
\text { formal, atuação do gerente e envolvimento, e } \\
\text { compromisso da alta administração (BROWN; } \\
\text { EISENHARDT, 1995; CLARK; WHEELWRIGHT, } \\
\text { 1993; ROZENFELD et al, 2006; GRIFFIN, 1997). } \\
\text { - Priorização dos projetos, tempo de } \\
\text { desenvolvimento, seqüência das atividades, e } \\
\text { marcos do projeto - planejamentos com auxílio do } \\
\text { PERT e CPM; cronograma (KRISHNAN; ULRICH, } \\
\text { 2001; ROZENFELD et al, 2006). } \\
\text { - Descarte de projetos - critérios para descarte; } \\
\text { check list (COOPER et al, 2002b). } \\
\text { - Comunicação - integração funcional ou } \\
\text { multifuncional (CLARK; WHEELWRIGHT, 1993); } \\
\text { interação e/ou colaboração (FRISHAMMAR, } \\
\text { 2005); e monólogo ou diálogo, que acontece nas } \\
\text { fases iniciais do projeto (CLARK; } \\
\text { WHEELWRIGHT, 1993). } \\
\text { - Desempenho - qualidade do projeto, tempo para } \\
\text { colocar o produto no mercado e produtividade; } \\
\text { planejado x o que efetivamente aconteceu (CLARK; } \\
\text { WHEELWRIGHT, 1993; CLARK; FUJIMOTO, } \\
\text { 1991). }\end{array}$ & $\begin{array}{l}\text { - Monitoramento e controle - } \\
\text { através de planos, formal, } \\
\text { atuação do gerente e } \\
\text { envolvimento e compromisso da } \\
\text { alta administração. } \\
\text { - Priorização dos projetos, } \\
\text { tempo de desenvolvimento, } \\
\text { seqüência das atividades e } \\
\text { marcos do projeto - } \\
\text { planejamentos; cronograma. } \\
\text { - Descarte de projetos - } \\
\text { critérios para descarte. } \\
\text { - Comunicação - integração } \\
\text { multifuncional; interação e } \\
\text { colaboração; e diálogo, que } \\
\text { acontece nas fases iniciais do } \\
\text { projeto. } \\
\text { - Desempenho - qualidade do } \\
\text { projeto; planejado x o que } \\
\text { efetivamente aconteceu. }\end{array}$ \\
\hline
\end{tabular}




\subsubsection{Etapas de desenvolvimento}

O processo de GDP da Cecrisa se subdivide em sete etapas: Levantamento e Seleção de Idéias; Elaboração do Anteprojeto; Desenvolvimento do Produto e Mix Promocional; Realização de Semi-Industriais e Confecção de Material Promocional; Lançamento da Coleção; Verificação da Eficácia do Lançamento; Acompanhamento dos Resultados Comerciais. Nos itens anteriores, 5.3.2.2, 5.3.2.3 e 5.3.2.4 foram discutidas as etapas um, seis e sete. Neste serão apresentadas as outras, conforme Quadro 33, o qual faz uma comparação entre as etapas indicadas por Krishnan e Ulrich (2001) com as etapas da GDP na Cecrisa.

Quadro 33 - Quadro comparativo etapas de Krishnan e Ulrich (2001) versus etapas Cecrisa
\begin{tabular}{|c|c|}
\hline $\begin{array}{c}\text { Etapas segundo Krishnan e Ulrich } \\
\text { (2001) }\end{array}$ & Etapas Cecrisa \\
\hline Desenvolvimento do Conceito & Elaboração do Anteprojeto \\
\hline Projeto da Cadeia de Suprimentos & $\begin{array}{c}\text { Desenvolvimento do Produto e Mix } \\
\text { Promocional }\end{array}$ \\
\hline Projeto do Produto & $\begin{array}{c}\text { Realização de Semi-industriais e } \\
\text { Confeção de Material Promocional }\end{array}$ \\
\hline Teste e Validação de Desempenho & Lançamento das Coleções \\
\hline Ramp-up e Lançamento &
\end{tabular}

\section{a) Desenvolvimento do conceito do produto}

Essa etapa, Elaboração do Anteprojeto, inicia-se com a conceituação da coleção, criando além de questões comerciais, também simbólicas. “As idéias ganham corpo”, diz o gerente de produtos e marketing estratégico. A conceituação da coleção, conforme a Cecrisa (2008), constitui-se como uma operação tática, que tem como objetivo viabilizar as orientações estratégicas da empresa nas oportunidades do mercado. Complementa o gerente de produtos e marketing estratégico que, nessa etapa, é elaborada

[...] uma representação da coleção a ser desenvolvida e lançada, através de suas características gerais e atributos distintivos, expressando seu valor simbólico, sua funcionalidade, assinalando sua importância para o portfólio de produtos, os canais de distribuição a que se destina posicionando preços e volumes, e expondo sua inserção nas tendências em voga.

Para o aprimoramento do design, o processo de conceituação dos produtos tem como principal benefício posicionar a Cecrisa não como uma empresa seguidora, mas como uma empresa inovadora. Além disso, a Cecrisa adotou, a partir de 2003, algumas mudanças no seu modus operandus, que visam o aprimoramento do design de seus produtos. Um deles foi a contratação de um Consultor Italiano para essa área. Com ampla experiência no 
desenvolvimento de produtos em importantes empresas italianas, tem inserção no ambiente da indústria cerâmica italiana, conhece e acompanha os produtores de revestimentos de matérias primas e de equipamentos, bem como dos estúdios de design.

Todo o investimento nessa etapa deve-se ao fato da Cecrisa acreditar que é necessária uma dedicação especial no momento de descrever as características da nova idéia, proporcionando assim uma consistência nas informações. O gerente de produtos e marketing estratégico afirma que é o ponto chave do processo e aponta que é preciso ter um conceito forte que oriente todas as ações seguintes.

Na Cecrisa, o consultor dedica parte de seu tempo acompanhando as tendências da indústria cerâmica italiana, e outra parte permanece no Brasil, onde atua nas etapas iniciais do processo, com dedicação especial para a segunda e a terceira. Ele traz idéias de novos produtos apreendidas no ambiente cerâmico ou interpretadas de outros setores do design, apresenta e discute essas idéias, avalia sua importância, participa da seleção e elaboração de projetos e acompanha a sua execução. É por seu intermédio que a empresa estabelece relação com estúdios de design italianos, trazendo informações sobre equipamentos e matériasprimas.

Observa-se que o conceito central do produto é definido a partir dos seguintes inputs: tecnologia, serviço, projeto, valor e sustentabilidade. É interessante notar que a Cecrisa não procura obter muitas informações de seus consumidores, pois, como já foi dito acredita que não conseguirá ofertar produtos inovadores com esse input.

Conforme o gerente de produtos e marketing estratégico a elaboração do anteprojeto da nova coleção tem como objetivo "dar substância conceitual e mercadológica às novas linhas de produtos e integrar as várias ações a elas relacionadas. O desenvolvimento de produtos e do mix promocional tem como função realizar as definições do anteprojeto”. É composto pelos seguintes itens: conceituação geral da coleção, produto, mercado, preço, e mix promocional.

Conceituar a coleção significa "elaborar uma representação da linha através de suas características gerais e atributos distintivos, expressando seu valor simbólico, sua funcionalidade, assinalando sua importância para o portfólio de produtos, os canais de 
distribuição a que se destina, e expondo sua inserção nas tendências em voga” (CECRISA, 2008). A conceituação da linha deve conter os seguintes requisitos:

- Nome provisório da linha.

- Tema da linha - definir, descrever, documentar visualmente, fazer um breve histórico, demonstrar a relevância.

- Funcionalidade - indicar uso, distinguindo entre usos principais e secundários.

- Mercado-alvo - segmentar mercado, orientando a linha para subcanais específicos.

- Linguagem estética - definir estilo e caracterizá-lo através de seus atributos principais. Anexar imagens ilustrativas.

- Estilo de vida - flashs, imagens, insígnias do modo de vida relacionado à linha, como cenas da vida; cidade, país ou região emblemática; e usuário símbolo, indicando profissão, hobby, preferências por arte, alimentação, lazer, leitura, trajes, transporte, motivações, idade, ciclo de vida familiar.

- Palavras-chaves - associação de idéias que ajudam a objetivar as conotações que orbitam em torno da linha.

- Imagem ícone da linha - imagem em alta definição que represente o conceito da linha a ser utilizada em peças promocionais.

- Toque de MIDAS - adotar para a linha algo que a distingue de todas as demais. Pode ser uma inovação de envergadura ou apenas incremental, mas deve ser criada, assinalada, salvaguardada no processo de desenvolvimento e promovida no mercado.

- Testemunhos da inserção da linha nas tendências internacionais em voga. Afirmações pessoais que atestam a atualidade da linha, frases curtas e assinadas.

No item Produto devem ser indicadas as seguintes informações:

- Definir a estrutura de linha - elaborar a representação visual dos tipos e formatos que compõem uma linha, mostrando como eles se articulam entre si e oferecendo uma visão global da linha. Deve ser feita também a indicação textual dos formatos e a indicação do processo produtivo.

- Definir as características dos produtos:

o Características estéticas gerais, como cores, intensidade de brilho, relevos, bordas, sensação tátil, textura visual e destonalização; 
o Características estéticas dos complementos, procurando distinguir os complementos decorativos de complementos funcionais, e descrever o uso de materiais complementares à cerâmica;

o Características técnicas - especificar, dentre as características técnicas, aquelas que variam de produto para produto, salientando as que são fundamentais ao projeto;

o Novos formatos - indicar a dimensão comercial, dimensão de fabricação e número de peças por embalagem;

o Novo packing.

No item Mercado deve ser feita a sondagem do mercado para identificar o potencial da linha, indicando os canais e subcanais alvo. No item Preço devem ser analisados os produtos concorrentes, de modo que se possa definir um preço de venda para os produtos que compõem a linha. E, por último, o mix promocional, onde deve ser desenvolvido o anteprojeto do mix promocional, discriminando os instrumentos necessários e realizando seu esboço.

Os participantes dessa etapa são: gerente de produtos e marketing estratégico, gerente de desenvolvimento e, em determinados projetos, também pode haver a participação do gerente de trade-marketing, responsável pelo controle das vendas, dos revendedores, da organização dos showrooms da empresa, dentre outras atividades que estejam relacionadas com a parte de vendas da empresa. O responsável pela elaboração do Anteprojeto é o gerente de produtos e marketing estratégico, sendo que sua coordenação é função do gerente de desenvolvimento de produtos, do controller e dos dois consultores.

As especificações definidas nessa etapa podem e devem ser modificadas, para seu aperfeiçoamento, até a última etapa do processo de desenvolvimento. Essas especificações, que são definidas nas fases iniciais no projeto, não são fixas, são modificadas de acordo com as mudanças que forem identificadas no mercado, nas feiras, nas tendências (moda). Isso não acarreta nenhum problema, pelo contrário, proporciona a oferta de um produto muito bem ajustado com as necessidades e, principalmente, com a moda do momento. Sempre que são feitas mudanças, há uma repactuação do anteprojeto com todas as áreas envolvidas. 
Com o Anteprojeto pronto, os responsáveis por essa etapa voltam a apresentá-lo para a Diretoria na Reunião dois. Nessa reunião será avaliado o Anteprojeto que foi elaborado, levando-se em consideração os dois pólos de análise. Nesse momento a Cecrisa procura equilibrar a análise entre o grau de inovação, e se é vendável, levando em conta todas as informações coletadas até o momento.

O Quadro 34 apresenta as decisões que a Cecrisa toma ao desenvolver o conceito de suas coleções novas.

Quadro 34 - Decisões Cecrisa - desenvolvimento do conceito

\begin{tabular}{|c|c|c|}
\hline $\begin{array}{c}\text { Etapas segundo } \\
\text { Krishnan e Ulrich } \\
\text { (2001) }\end{array}$ & $\begin{array}{c}\text { Decisões das etapas do processo de } \\
\text { desenvolvimento }\end{array}$ & Decisões Cecrisa \\
\hline $\begin{array}{l}\text { Desenvolvimento } \\
\text { do Conceito }\end{array}$ & $\begin{array}{l}\text { - Interação de todos os envolvidos no processo } \\
\text { (SMITH; REINERTSEN, 1998). } \\
\text { - Clientes e consumidores finais - participação } \\
\text { no processo de desenvolvimento; utilização de } \\
\text { ferramentas para conhecer as necessidades do } \\
\text { mercado, como QFD (GRIFFIN; HAUSER, } \\
\text { 1993). } \\
\text { - Escopo detalhado do produto - tecnologias } \\
\text { disponíveis e necessárias; normas; patentes e } \\
\text { legislação relacionada ao produto; identificar } \\
\text { quem é o cliente, o consumidor e suas } \\
\text { necessidades; requisitos do produto; produtos } \\
\text { concorrentes e similares; serviços agregados ao } \\
\text { produto; objetivos ou metas que o produto deve } \\
\text { atender; preço; e outras informações relevantes } \\
\text { para a empresa (ROZENFELD et al, 2006, p.213; } \\
\text { SMITH; REINERTSEN, 1998; VON HIPPEL, } \\
\text { 1986; THOMKE; VON HIPPEL, 2002; SMITH; } \\
\text { REINERTSEN, 1998; COOPER et al, 2002a; } \\
\text { SLAUGHTER, 1991); congelamento das } \\
\text { características em etapas iniciais ou finais } \\
\text { (ROZENFLL et al, 2006; BACON et al, 1994 } \\
\text { apud KRISHNAN; ULRICH, 2001); Conceito } \\
\text { central - input - technology-driven concept; } \\
\text { service concept; design-driven concept; value- } \\
\text { driven concept; customer- and market-driven } \\
\text { concept (BACKMAN et al, 2007). } \\
\text { - Arquitetura do produto, forma física e } \\
\text { projeto industrial - desenho virtual ou croqui } \\
\text { (KRISHNAN; ULRICH, 2001). } \\
\text { - Variações do produto - quais serão oferecidas, } \\
\text { componentes compartilhados entre as variações } \\
\text { (KRISHNAN; ULRICH, 2001). }\end{array}$ & $\begin{array}{l}\text { - Interação de todos os envolvidos } \\
\text { no processo. } \\
\text { - Clientes e consumidores finais - } \\
\text { utilização de ferramentas para } \\
\text { conhecer essas necessidades. } \\
\text { - Escopo detalhado do produto - } \\
\text { tecnologias disponíveis e } \\
\text { necessárias; identificar quem é o } \\
\text { cliente, o consumidor e suas } \\
\text { necessidades; requisitos do } \\
\text { produto; produtos concorrentes e } \\
\text { similares; serviços agregados ao } \\
\text { produto; objetivos ou metas que o } \\
\text { produto deve atender; preço; e } \\
\text { outras informações relevantes para } \\
\text { a empresa; congelamento das } \\
\text { características em etapas finais. } \\
\text { Conceito central - input - } \\
\text { technology-driven concept; design- } \\
\text { driven concept; value-driven } \\
\text { concept; customer- and market- } \\
\text { driven concept. } \\
\text { - Arquitetura do produto, forma } \\
\text { física e projeto industrial - } \\
\text { desenho virtual. } \\
\text { - Variações do produto - quais } \\
\text { serão oferecidas, componentes } \\
\text { compartilhados entre as variações. }\end{array}$ \\
\hline
\end{tabular}




\section{b) Projeto da cadeia de suprimentos}

Na Cecrisa o projeto da cadeia de suprimentos é feito junto com a etapa de projeto do produto, modificando assim a estrutura apresentada por Krishnan e Ulrich (2001). Por essa razão, essa etapa será tratada no item seguinte, juntando as discussões sobre o projeto da cadeia de suprimentos com o projeto do produto.

\section{c) Projeto do produto}

Como foi dito anteriormente, a etapa de Projeto da Cadeia de Suprimentos acontece dentro da etapa de Projeto do Produto, sendo na Cecrisa denominada Desenvolvimento do Produto e Mix Promocional, na qual é feito o desdobramento do conceito do produto em especificação de projeto, seguida da concepção gráfica do produto e da prototipagem, junção dos elementos gráficos com as matérias-primas, tendo em vista as potencialidades do processo produtivo.

Conforme o gerente de marketing estratégico, a montagem do produto “dá corpo material ao conceito do produto, é a hora da verdade”. É a fase em que a idéia inicial pode ganhar amplitude ou perder importância, tudo dependerá do que foi estabelecido no Anteprojeto e o que realmente aconteceu ao se elaborar o protótipo. Sua relação com o design é, muitas vezes, operacionalmente determinante, proporcionando inovações nos produtos.

Nessa etapa é realizada a prototipagem em cerâmica do produto, simulando o processo produtivo no laboratório interno da empresa. Esses protótipos são concebidos com as matérias-primas definidas para o produto final, então já podem ser feitos os contatos com possíveis fornecedores. São eles que disponibilizam a matéria-prima para a realização dos testes, até que seja identificada a melhor opção. Quando necessário, identificam logo o local de junção dos componentes.

Outra alteração que foi feita no processo de desenvolvimento em 2003 foi nessa etapa. Contrataram-se serviços de estúdios internacionais, italianos, para a elaboração de algumas de suas coleções. A decisão surgiu da necessidade de serem realizados testes com a matériaprima e o processo produtivo, sem ter de parar a produção da empresa. Como esta possuía apenas sua estrutura industrial para a produção dessas coleções específicas, optou-se por enviar seus produtos, juntamente com o pessoal envolvido no projeto, para estúdios 
internacionais, onde é simulada a produção das peças. O gerente de produtos e marketing estratégico afirmou que, mesmo tendo de enviar seus produtos e um responsável para a Itália, esta foi a melhor opção.

Paralelamente à montagem dos produtos, o mix promocional da nova linha é produzido, já delineado na etapa anterior. Ao fim dessa etapa, o protótipo só foi produzido em laboratório, interno ou externo, e o mix promocional está elaborado, mas só foi produzido um modelo de todo o mix. A montagem do produto é responsabilidade da área de desenvolvimento de produtos, que responde para o diretor de operações. E a elaboração e execução do mix promocional é função da área de marketing estratégico, sendo que, ao ser lançado, é repassado para o trade-marketing.

Na terceira reunião os resultados finais são analisados pela diretoria, para avaliar se estão de acordo com o que havia sido delineado e apresentado inicialmente. Avalia-se se o projeto ficou a contento, ou mesmo se superou as expectativas, como também se houve alguma dificuldade técnica que tenha prejudicado o projeto inicial. Alguns projetos podem ser abortados nesse momento, nesse caso volta-se à etapa anterior para seu aperfeiçoamento. São utilizados também, para avaliação do projeto, os dois pólos de análise, o grau de inovação e se é vendável.

Em relação à embalagem, desde a etapa de desenvolvimento do conceito que a Cecrisa procura identificar a necessidade de algo diferente, analisando facilidades para a distribuição do produto, já que se caracteriza como de difícil manuseio, devido ao seu tamanho e peso. Na maioria das vezes, não é necessário nenhuma alteração, já que os tamanhos são padronizados.

No Quadro 35 contém as decisões tomadas pela Cecrisa nas etapas de Projeto da Cadeia de Suprimentos e Projeto do Produto.

Quadro 35 - Decisões Cecrisa - projeto da cadeia de suprimentos e projeto do produto

\begin{tabular}{|c|l|l|}
\hline $\begin{array}{c}\text { Etapas segundo } \\
\text { Krishnan e Ulrich } \\
\text { (1993) }\end{array}$ & \multicolumn{1}{|c|}{$\begin{array}{c}\text { Decisões das etapas do processo de } \\
\text { desenvolvimento }\end{array}$} & \multicolumn{1}{c|}{ Decisões Cecrisa } \\
\hline $\begin{array}{c}\text { Projeto da Cadeia } \\
\text { de Suprimentos }\end{array}$ & $\begin{array}{l}\text { - Componentes - projetados internamente ou } \\
\text { comprados prontos; quem projetará, desenvolverá } \\
\text { e produzirá (KRISHNAN; ULRICH, 2001). } \\
\text { - Cadeia física de suprimentos - configuração, } \\
\text { incluindo o local de junção dos componentes; }\end{array}$ & $\begin{array}{l}\text { - Componentes - projetados } \\
\text { internamente ou comprados } \\
\text { prontos; quem projetará, } \\
\text { desenvolverá e produzirá. } \\
\text { - Cadeia física de suprimentos - }\end{array}$ \\
\hline
\end{tabular}




\begin{tabular}{|c|c|c|}
\hline & $\begin{array}{l}\text { seleção de fornecedores das tecnologias e } \\
\text { equipamentos; sistema de produção e } \\
\text { distribuição; custos diretos de produção; custos } \\
\text { entre fornecimento e demanda (KRISHNAN; } \\
\text { ULRICH, 2001). }\end{array}$ & $\begin{array}{l}\text { configuração, incluindo o local de } \\
\text { junção dos componentes; seleção } \\
\text { de fornecedores das tecnologias e } \\
\text { equipamentos; sistema de produção } \\
\text { e distribuição; custos de produção; } \\
\text { custos entre fornecimento e } \\
\text { demanda. }\end{array}$ \\
\hline Projeto do Produto & $\begin{array}{l}\text { - Especificação dos parâmetros do projeto - } \\
\text { projeto detalhado dos componentes; relação entre } \\
\text { os componentes do produto; seleção de material e } \\
\text { de processo e projeto das ferramentas e } \\
\text { equipamentos; planos de processo; desenhos } \\
\text { finais com tolerâncias (ROZENFELD et al, } \\
\text { 2006). } \\
\text { - Embalagem - avaliação da distribuição do } \\
\text { produto, incluindo transporte e entrega; definição } \\
\text { das formas e sinalizações das embalagens dos } \\
\text { produtos; projeção da embalagem; planejamento } \\
\text { do processo de embalagem (ROZENFELD et al, } \\
\text { 2006). } \\
\text { - Material de suporte do produto - criação do } \\
\text { manual de operação do produto, do material de } \\
\text { treinamento e do manual de descontinuidade do } \\
\text { produto (ROZENFELD et al, 2006). }\end{array}$ & $\begin{array}{l}\text { - Especificação dos parâmetros } \\
\text { do projeto - projeto detalhado dos } \\
\text { componentes; relação entre os } \\
\text { componentes do produto; seleção } \\
\text { de material e de processo e projeto } \\
\text { das ferramentas e equipamentos; } \\
\text { planos de processo; desenhos finais } \\
\text { com tolerâncias. } \\
\text { - Embalagem - projeção da } \\
\text { embalagem; planejamento do } \\
\text { processo de embalagem. } \\
\text { - Material de suporte do produto } \\
\text { - do material de treinamento. }\end{array}$ \\
\hline
\end{tabular}

\section{d) Teste e validação de desempenho}

Krishnan e Ulrich (2001) inserem essa etapa no processo para desenvolvimento dos protótipos e realização do teste da linha de produção. Porém, na Cecrisa a prototipagem acontece durante todo o desenvolvimento do projeto, desde as etapas iniciais. E em relação ao teste da linha de produção, ocorreu na etapa anterior: Realização de Semi-industriais e Confecção de Material Promocional. Este último não é realizado na linha produtiva da empresa, mas em laboratório.

Nessa etapa, denominada Realização de Semi-industriais e Confecção de Material Promocional, a área de desenvolvimento juntamente com o pessoal da fábrica gera as primeiras peças dentro da linha de produção da empresa. São denominados de testes semiindustriais. Estas vão para estoque, e servirão de amostra para teste, para as lojas que venderão a nova coleção, showrooms. Serão também utilizados para que o pessoal de marketing tire fotos que irão compor os catálogos do mix promocional. Estes também já estão sendo produzidos, paralelamente a todo o processo. 
Como já foi dito, a prototipagem acompanha todo o processo, porém Krishnan e Ulrich (2001) indicam que podem ser tomadas algumas decisões relacionadas com o tipo do protótipo, o processo de construção dos protótipos e seus benefícios. Na Cecrisa, a classificação de Clark e Wheelwirght (1993) para o tipo de protótipo não se aplica. O processo de construção dos protótipos varia de acordo com a etapa em que se encontra o projeto, podendo ser virtual ou prototipagem rápida (experimentação real). Ocorre paralelamente ao processo, desde as etapas iniciais. Contribuem para a identificação de oportunidades, aprendizado da organização, testa a comunicação entre os membros do projeto e auxilia na resolução de conflitos.

Na Reunião Final, que reúne mais uma vez a Diretoria, o Gerente de Produtos e Marketing Estratégico, o Controller, o Gerente de Desenvolvimento de Produtos e os Consultores, é feita uma avaliação mais equilibrada entre os dois pólos. Levando-se em consideração tanto o grau de inovação da nova coleção, como também se é um produto vendável. O Quadro 36 apresenta as decisões que a Cecrisa toma na etapa de Teste e Validação de Desempenho.

Quadro 36 - Decisões Cecrisa - teste e validação de desempenho

\begin{tabular}{|c|c|c|}
\hline $\begin{array}{c}\text { Etapas segundo } \\
\text { Krishnan e Ulrich } \\
\text { (2001) }\end{array}$ & Decisões das etapas do processo de desenvolvimento & Decisões Cecrisa \\
\hline $\begin{array}{c}\text { Teste e Validação } \\
\text { de Desempenho }\end{array}$ & $\begin{array}{l}\text { - Prototipagem para validação - em relação a } \\
\text { funcionamento, tamanho e fabricação (KRISHNAN; } \\
\text { ULRICH, 2001); avalia reações dos consumidores, } \\
\text { projeto industrial, durabilidade, encaixe e finalização, e } \\
\text { custos de produção (ROZENFELD et al, 2006; } \\
\text { CLARK; WHEELWRIGHT, 1993). } \\
\text { - Teste em pequena escala do projeto - produção } \\
\text { piloto (CLARK; WHEELWRIGHT, 1993); definição } \\
\text { dos processos de produção e manutenção } \\
\text { (ROZENFELD et al, 2006). } \\
\text { - Tipo de protótipo - rápida resposta a engenharia, } \\
\text { sistema de solução integrado (periódico), ou replicação } \\
\text { da produção cedo (CLARK; WHEELWRIGHT, 1993). } \\
\text { - Processo de construção dos protótipos - simulação } \\
\text { virtual, prototipagem rápida (experimentação real), e } \\
\text { protótipos de papelão ou argila (CLARK; } \\
\text { WHEELWRIGHT, 1993; THOMKE, 1998; } \\
\text { SRINIVASAN et al, 1997; BECKER et al, 2005); } \\
\text { seqüencial ou paralela; prototipagem em etapas iniciais } \\
\text { do projeto (SRINIVASAN et al, 1997). } \\
\text { - Benefícios do protótipo - contribuem para a } \\
\text { identificação de oportunidades; aprendizado da } \\
\text { organização; formação de novas capacidades; testa a } \\
\text { comunicação entre os membros do projeto; auxilia na } \\
\text { resolução de conflitos (CLARK; WHEELWRIGHT, } \\
\text { 1993). }\end{array}$ & $\begin{array}{l}\text { - Prototipagem para } \\
\text { validação - em relação a } \\
\text { funcionamento, tamanho e } \\
\text { fabricação; projeto industrial, } \\
\text { durabilidade, encaixe e } \\
\text { finalização, e custos de } \\
\text { produção. } \\
\text { - Teste em pequena escala } \\
\text { do projeto - produção piloto; } \\
\text { definição dos processos de } \\
\text { produção e manutenção. } \\
\text { - Processo de construção dos } \\
\text { protótipos - simulação } \\
\text { virtual, prototipagem rápida } \\
\text { (experimentação real); } \\
\text { paralela; prototipagem em } \\
\text { etapas iniciais do projeto. } \\
\text { - Benefícios do protótipo - } \\
\text { contribuem para a } \\
\text { identificação de } \\
\text { oportunidades; aprendizado } \\
\text { da organização; formação de } \\
\text { novas capacidades; testa a } \\
\text { comunicação entre os } \\
\text { membros do projeto; auxilia } \\
\text { na resolução de conflitos. }\end{array}$ \\
\hline
\end{tabular}




\section{e) Ramp-up e lançamento}

Com tudo finalizado, tem início o lançamento interno e externo das novas coleções. Para o pessoal interno, as coleções podem ser apresentadas por meio de treinamentos, através de teleconferência, gravações de DVD's com um dos consultores ministrando uma palestra sobre a nova coleção, e também treinamentos feitos pelos consultores para arquitetos, donos de lojas, e todos aqueles que fazem parte do processo de compra final dos produtos da empresa, no Brasil. O lançamento externo começa com a apresentação da coleção nas feiras internacionais, Covery, Bologna e Revestir. Depois, todo o material é distribuído para os revendedores, para que o apresentem aos seus clientes. As áreas responsáveis são o marketing estratégico e o trade-marketing. Sendo que o lançamento interno só acontecerá após a realização das feiras que irão expor seus produtos. A Cecrisa acredita que a surpresa deve ser para todos, até mesmo para seus funcionários.

O plano de ramp-up acontece da seguinte forma: quando o produto é lançado, é feito um lote mínimo e o produto entra no status “ativo", o que o coloca dentro dos padrões de planejamento de produção da empresa, que é feito com o sistema Manugistics, um dos mais sofisticados do mundo devido a seus complexos e eficazes sistemas de previsão de demanda e seqüenciamento de produção. Dessa forma, o ramp-up se dá de acordo com o sucesso que o produto tem no mercado, de maneira a evitar a eventual formação de estoques não saudáveis.

O Quadro 37 apresenta as decisões tomadas pela Cecrisa na etapa de Ramp-up e Lançamento.

Quadro 37 - Decisões Cecrisa - ramp-up e lançamento

\begin{tabular}{|c|c|c|}
\hline $\begin{array}{c}\text { Etapas segundo } \\
\text { Clark e } \\
\text { Wheelwright } \\
\text { (1993) }\end{array}$ & $\begin{array}{c}\text { Decisões das etapas do processo de } \\
\text { desenvolvimento }\end{array}$ & Decisões Cecrisa \\
\hline $\begin{array}{l}\text { Ramp-up e } \\
\text { Lançamento }\end{array}$ & $\begin{array}{l}\text { - Teste de mercado - nível de realização; } \\
\text { seqüência de introdução dos produtos no mercado } \\
\text { (CLARK; WHEELWRIGHT, 1993). } \\
\text { - Lançamento - tempo para o lançamento do } \\
\text { produto; como e quando o concorrente entrará ou } \\
\text { entrou no mercado; finalização do } \\
\text { desenvolvimento do projeto; desenho dos } \\
\text { processos de venda e distribuição; atendimento } \\
\text { do cliente e assistência técnica; campanhas de } \\
\text { marketing (ROZENFELD et al, 2006). } \\
\text { - Ramp-up - aumento da produção (CLARK; } \\
\text { WHEELWRIGHT, 1993; ROZENFELD et al, } \\
\text { 2006). }\end{array}$ & $\begin{array}{l}\text { - Teste de mercado - seqüência de } \\
\text { introdução dos produtos no } \\
\text { mercado. } \\
\text { - Lançamento - tempo para o } \\
\text { lançamento do produto; como e } \\
\text { quando o concorrente entrará ou } \\
\text { entrou no mercado; desenho dos } \\
\text { processos de venda e distribuição; } \\
\text { atendimento do cliente e assistência } \\
\text { técnica; campanhas de marketing. } \\
\text { - Ramp-up - aumento da produção. } \\
\text { - Ao fim, cessa o } \\
\text { acompanhamento do produto }\end{array}$ \\
\hline
\end{tabular}




\begin{tabular}{|l|l|l|}
\hline & $\begin{array}{l}\text { - Ao fim cessa ou continua o acompanhamento } \\
\text { do produto pelo time (ROZENFELD } \text { et } \text { al, } \\
\text { 2006). }\end{array}$ & pelo time. \\
\hline
\end{tabular}

\subsubsection{Conclusões}

A Cecrisa é líder de mercado no segmento que atua, com uma história baseada em inovações em sua estrutura, processos e produtos. É uma empresa ambientalmente responsável, que utiliza técnicas e equipamentos necessários ao tratamento dos resíduos, efluentes e emissões provenientes das suas áreas de produção, ao mesmo tempo em que investe na conscientização ambiental dos seus profissionais. Direciona suas pesquisas para conhecer profundamente esse consumidor e suas necessidades.

Com aproximadamente 68 anos de atuação no mercado, possui uma carteira de produtos de 73 coleções mais 1.200 acessórios, lança anualmente 11 coleções, o que corresponde a 272 produtos, desenvolvidos por 21 pessoas componentes de um ambiente de 2.199 colaboradores.

Os inputs para o desenvolvimento desses novos produtos são: inovação própria por criação de nossos profissionais; inovação com inspiração em setores afins que estão mais "perto" da moda - tecidos, móveis, eletrodomésticos; inovação que vem de novas tecnologias de matérias-primas; inovações que vêm de novas tecnologias de equipamentos; e o desenvolvimento reativo - reinterpretar o sucesso da grande concorrência internacional. Observou-se que também são levados em consideração conceitos de sustentabilidade para gerar os novos produtos. Nessa etapa, a empresa procura abrir o máximo possível a 'boca’ do funil de desenvolvimento de Clark e Wheelwright (1993), buscando idéias das mais diversas fontes possíveis.

A definição dos projetos na Cecrisa passa por dois momentos de seleção. Primeiro, todas as idéias são apresentadas e discutidas em uma reunião composta pelos consultores, gerentes de produto e marketing estratégico, pelo pessoal da área de marketing e da área de desenvolvimento de produtos, e pelo controller. Dessa reunião selecionam-se dez idéias, que serão apresentadas para a diretoria, na qual se definirá o portfólio de novos produtos. É a partir do cronograma, dos recursos disponíveis, do grau de inovação e do retorno financeiro que os projetos serão selecionados e priorizados. A maioria de suas melhorias incrementais é 
topológica, baseada em suas duas fontes de informações, mercado e estilo de vida do consumidor. No entanto, há também uma forte presença de projetos radicais, desenvolvidos tanto internamente, como obtidos por meio da aquisição de novas máquinas e equipamentos.

A estrutura do time na Cecrisa é formal e em grupo. Dentro da classificação de Clark e Wheelwright (1993) e de Rozenfeld et al (2006), a Cecrisa não se encaixa em nenhuma das opções. O gerente do projeto tem acesso direto e responsabilidade pelo trabalho de todos os envolvidos no projeto, é responsável por todos os projetos que estão em andamento na empresa e se encontra no mesmo nível do gerente de desenvolvimento de produtos. Vale ressaltar que o controller tem pouca influência na organização.

A Cecrisa se destaca na elaboração do anteprojeto da nova coleção, o qual faz parte da etapa de desenvolvimento do conceito do produto. Tem como objetivo "dar substância conceitual e mercadológica às novas linhas de produtos e integrar as várias ações a elas relacionadas. É composto pelos seguintes itens: conceituação geral da coleção, produto, mercado, preço, e mix promocional.

Outro destaque do processo é a realização da prototipagem do produto, com a matéria-prima final e com o processo produtivo que será utilizado já na segunda etapa do processo. Isso só é possível, pois a empresa possui um laboratório interno completo, devido ao fato de seus fornecedores disponibilizarem suas novas tecnologias para a realização de testes produtivos.

Observou-se que não existe um plano de teste de mercado. A empresa nem sequer divulga para os outros profissionais, muito menos para os representantes, pois acredita que divulgando os lançamentos tiraria a surpresa da criação, da apresentação nas feiras, de toda a preparação para divulgar a novidade no mercado. Com isso em mente, a empresa prefere não inserir clientes, arquitetos, ou mesmo construtoras em seu processo de desenvolvimento, pois, como já foi mencionado, a Cecrisa acredita que não é a partir do contato direto com seus consumidores intermediários ou finais que conseguirá definir uma carteira de projetos que seja inovadora, de modo que, não é feito nenhum teste do projeto, este é apresentado em uma das três feiras mais importantes do setor, pronto para ser vendido. Muitas vezes, já existem produtos em estoque para serem vendidos de imediato. 
Por fim, é importante ressaltar a forma com que a Cecrisa realiza o lançamento interno do produto. Anteriormente dito, o lançamento é feito primeiro nas feiras do setor que a empresa participa. Depois, é feito o lançamento interno, por meio de treinamentos, que serão realizados através de teleconferência, gravações de DVD’s com um dos consultores ministrando uma palestra sobre a nova coleção, e também treinamentos realizados pelos consultores para arquitetos, donos de lojas, e todos aqueles que fazem parte do processo de compra final dos produtos da empresa, no Brasil.

\subsection{Tigre}

\subsubsection{Caracterização da empresa}

\subsubsection{Histórico}

Em 1941, o jovem empresário João Hansen Júnior adquire uma pequena fábrica de pentes, em Joinville, chamada Tigre. Ainda na década de 40, descobre uma nova matéria-prima, o plástico, que começa a ser utilizada na empresa para a produção de seus pentes, como também de vários novos produtos, dentre eles: copos, pratos, brinquedos e leques.

Após um longo período de estudos e testes com a nova matéria-prima, além da atualização tecnológica de seu parque industrial, João Hansen Júnior inicia a fabricação de tubos e conexões para instalações hidráulicas, utilizando como matéria-prima o Poly Vinil Chloryde PVC, ou Cloreto de Polivinila. O PVC é uma resina plástica dura, que foi utilizada pela Tigre para substituição dos materiais tradicionais, como os tubos galvanizados de ferro. Para conquistar o mercado, a Tigre lançou mão de diversas técnicas com a finalidade de uma maior aproximação com seu público-alvo, tendo sempre uma prática em mente: “ouvir o cliente, atender suas necessidades e expectativas” (TIGRE, 2007).

Em 1983, João Hansen Júnior passa a atuar como presidente do Conselho Administrativo e seu filho Carlos Roberto Hansen assume a presidência executiva da Tubos e Conexões Tigre. Em 1991, João Hansen afasta-se definitivamente dos negócios. Carlos Roberto, além de presidente executivo da Tigre, assume a presidência do Conselho de Administração. Em sua gestão procurou incorporar na empresa a descentralização das decisões, partindo da premissa 
de que uma idéia não deveria partir de uma só pessoa, mas de todos que trabalhavam na Tigre.

Após um longo processo de discussões, os diretores da empresa, assessorados por consultorias externas, elaboraram a nova estratégia da Tigre. Em 1994, quando a implantação do novo modelo de gestão e da estratégia de crescimento estava em sua primeira fase, Carlos Roberto morre em um acidente aéreo. Seu irmão, João Neto, assume a presidência e dá continuidade ao processo que havia sido iniciado. No entanto, em 1995, Amaury Olsen, antigo colaborador da empresa, é nomeado o primeiro presidente da diretoria executiva, que não fazia parte da família Hansen. Esse foi um momento de ruptura para a empresa, que deixou de ser uma empresa familiar para tornar-se "um grupo com alto grau de profissionalização” (TIGRE, 2007).

A área de P\&D da empresa foi reduzida a atividades de melhoria dos produtos existentes (manutenção) durante o período de 1994 até 1998. Os poucos lançamentos que aconteceram nesse período foram realizados através de empresas terceiras de $\mathrm{P} \& \mathrm{D}$. Na busca pelo crescimento, sustentado pela inovação a partir de 1999, a empresa inicia a reestruturação de P\&D, processo este que vai até 2002. Foram implantados na Tigre novos conceitos, como engenharia simultânea e times multidisciplinares. Uma das grandes modificações que fizeram parte desse processo foi a integração física das áreas de desenvolvimento, a engenharia de manufatura, a qualidade e o centro de desenvolvimento de moldes. A soma dessas áreas gerou a atual área de pesquisa, desenvolvimento e engenharia - PD\&E.

Toda essa reestruturação promoveu a melhoria na comunicação e uma maior agilidade no desenvolvimento de novos produtos. Após cinco anos lidando com essa nova estrutura, a Tigre acredita que já virou parte da cultura da empresa, "todos já internalizaram os conceitos e práticas implantados”, é o que diz o gerente de produtos e marketing. Isso é resultado de uma estratégia muito bem definida, tendo a inovação como ponto fundamental para o crescimento. O gerente de P\&D da Tigre afirma que "Inovar, fazer acontecer e acreditar que é possível”, é a grande bandeira da empresa.

A Tigre enxerga a inovação sob a ótica de quem está comprando, mas acredita que ela também é muito importante sob a ótica dos funcionários, o que, de acordo com ela, significa a melhor empresa para se trabalhar. Em 2002, a empresa foi eleita a segunda melhor empresa 
para se trabalhar no Brasil, e está no ranking das 150 há dez anos. Outro dado que reflete nesse conceito de inovação incorporado na empresa é o market share de 60\% do mercado brasileiro de tubos e conexões.

O que a empresa quer transmitir através desses conceitos é que a inovação deve ser vista como valor, ou seja, com a inovação é possível se manter na liderança. Hoje, conforme os entrevistados, a meta de crescimento da empresa está pautada em três pilares: novos produtos, novos negócios e novos mercados. Isso é alcançado por meio da oferta de linhas completas de produtos, identificando e antecipando-se às necessidades do cliente.

Atualmente, exporta para 35 países, conta com 5.200 funcionários e possui um faturamento de US\$ 1 bilhão. Além de líder da América Latina na fabricação de tubos, conexões e acessórios em PVC, lidera a fabricação de pincéis e de esquadrias em PVC no Brasil. Tem unidades fabris em Joinville (SC), Rio Claro (SP), Camaçari (BA), Castro (PR), Indaiatuba (SP) e Centros de Distribuição em Recife (PE) e Uruguai. Possui ainda unidades externas na Argentina, Chile, Paraguai, Estados Unidos, Equador, Peru, Colômbia e Bolívia.

Conforme o Portal Exame (2006 apud TIGRE, 2007), a Tigre

[...] tem a posição de número um entre as melhores do setor pelo segundo ano consecutivo. A receita, de 600 milhões de dólares, teve queda de $11 \%$, repetindo exatamente o mesmo desempenho do setor, mas a Tigre foi a segunda em rentabilidade, com retorno de 18,5\% sobre o investimento, a quarta em liderança do mercado e a quinta em investimento no imobilizado e em liquidez. Uma marca muito comemorada foi a geração de caixa, medida pelo Ebitda, que passou de 67 milhões de dólares em 2004 para 81 milhões de dólares.

\subsubsection{Tipo de produto}

A Tigre é uma empresa que procura inovar sempre, antecipando-se às necessidades do consumidor, desenvolvendo soluções que contribuam para melhorar os processos construtivos, garantindo a eficácia e a durabilidade dos sistemas. Indica que seu processo de inovação permeia todos os ambientes da organização, através de uma política de pesquisa e desenvolvimento centrada na oferta de soluções completas nos segmentos em que atua. Para isso, trabalha em parceria com universidades, instituições de pesquisa e fornecedores no Brasil e no exterior. 
Dessa forma, é possível oferecer uma linha extensa de produtos para a construção civil. Em 2005, foram lançados 279 novos produtos, ou, em média, cerca de um a cada dia útil. Com seu portfólio de mais de seis mil itens, possui soluções integrais em:

- Instalações prediais - sistemas completos para água fria e quente, esgoto, drenagem pluvial, energia e telecomunicações; acessórios sanitários; ferramentas para pintura; e portas, janelas e forros.

- Infra-estrutura - sistemas completos de adução e distribuição de água, coleta e condução de esgoto, drenagem pluvial, além de dutos de distribuição de linhas de telecomunicações, energia e gás natural.

- Irrigação - soluções para irrigação e drenagem agrícola através de sistemas fixos e portáteis que incorporam inovações tecnológicas voltadas para a economia de água e de energia, aumentando a produtividade do agronegócio e preservando o meio ambiente.

Essa estratégia proporcionou à empresa ocupar o $26^{\circ}$ lugar em número de patentes de empresas no Brasil, com a obtenção de, aproximadamente, 10 patentes por ano. Esse número justifica os $15 \%$ do faturamento da empresa dos lançamentos que houve nos últimos cinco anos. Como empresa privada, isso é bastante relevante, pois a cultura de patentes está muito mais presente nas universidades. Mais relevante ainda por ser uma empresa que faz parte de um setor tão conservador, a Indústria de Materiais de Construção, como afirma o Gerente de Produtos e Marketing.

\subsubsection{Segmentação do mercado}

Conforme a descrição dos produtos e das linhas, percebe-se o direcionamento da empresa para um consumidor intermediário. No momento da compra, a especificação e a influência de um especialista contam muito. Por essa razão, a Tigre considera o projetista, o engenheiro, o arquiteto e o instalador como atores fundamentais para esse processo. Tanto o Gerente de Produtos e Marketing, quanto o Gerente de P\&D afirmam que um dos grandes segredos da história de sucesso da Tigre foi investir no instalador. Ele é um dos grandes formadores de opinião. Com isso, observa-se que a segmentação de mercado da empresa é B2B. 
Todavia, nos últimos quatro anos tem desenvolvido práticas direcionadas também para o consumidor final. Diante disso, a Tigre hoje é uma empresa que se direciona para o consumidor intermediário e para o final.

\subsubsection{Gestão do desenvolvimento dos produtos Tigre}

Até o ano de 1994, a empresa possuía uma estrutura de desenvolvimento bastante organizada, no entanto, como já foi apresentado em seu histórico, nesse mesmo ano houve o falecimento do presidente da empresa, o que levou a uma reestruturação interna. E somente em 2002, é que retomaram a área de desenvolvimento, acompanhada de novos conceitos, de uma nova estrutura e de novos desafios.

Para coleta das informações referentes ao processo de GDP da Tigre foram entrevistados o Gerente de Produtos e Marketing, o Gerente de P\&D e o Coordenador de Oportunidades. O Quadro 38 indica as etapas e subetapas do processo de GDP da Tigre.

Quadro 38 - Etapas e subetapas do processo de GDP da Tigre

\begin{tabular}{|c|c|}
\hline Etapas & Subetapas \\
\hline Identificação de Oportunidades & $\begin{array}{l}\text { Identificação de Oportunidades } \\
\text { Relatórios Financeiros } \\
\text { Seleção dos Projetos pela Alta Administração }\end{array}$ \\
\hline Desenvolvimento do Conceito & $\begin{array}{l}\text { Projeto Conceitual } \\
\text { Protótipo Virtual } \\
\text { Projeto Preliminar } \\
\text { Protótipo Virtual } \\
\text { Logística } \\
\text { Projeto Detalhado } \\
\text { Avaliação do Projeto pela Alta Administração } \\
\text { Protótipo em gesso }\end{array}$ \\
\hline Try-out & $\begin{array}{l}\text { Try-out } \\
\text { Análise dos dados financeiros do projeto } \\
\text { Análise da comunicação interna e externa } \\
\text { Política Promocional }\end{array}$ \\
\hline Lançamento & $\begin{array}{l}\text { Lançamento interno } \\
\text { Lançamento externo } \\
\text { Ramp-up }\end{array}$ \\
\hline
\end{tabular}




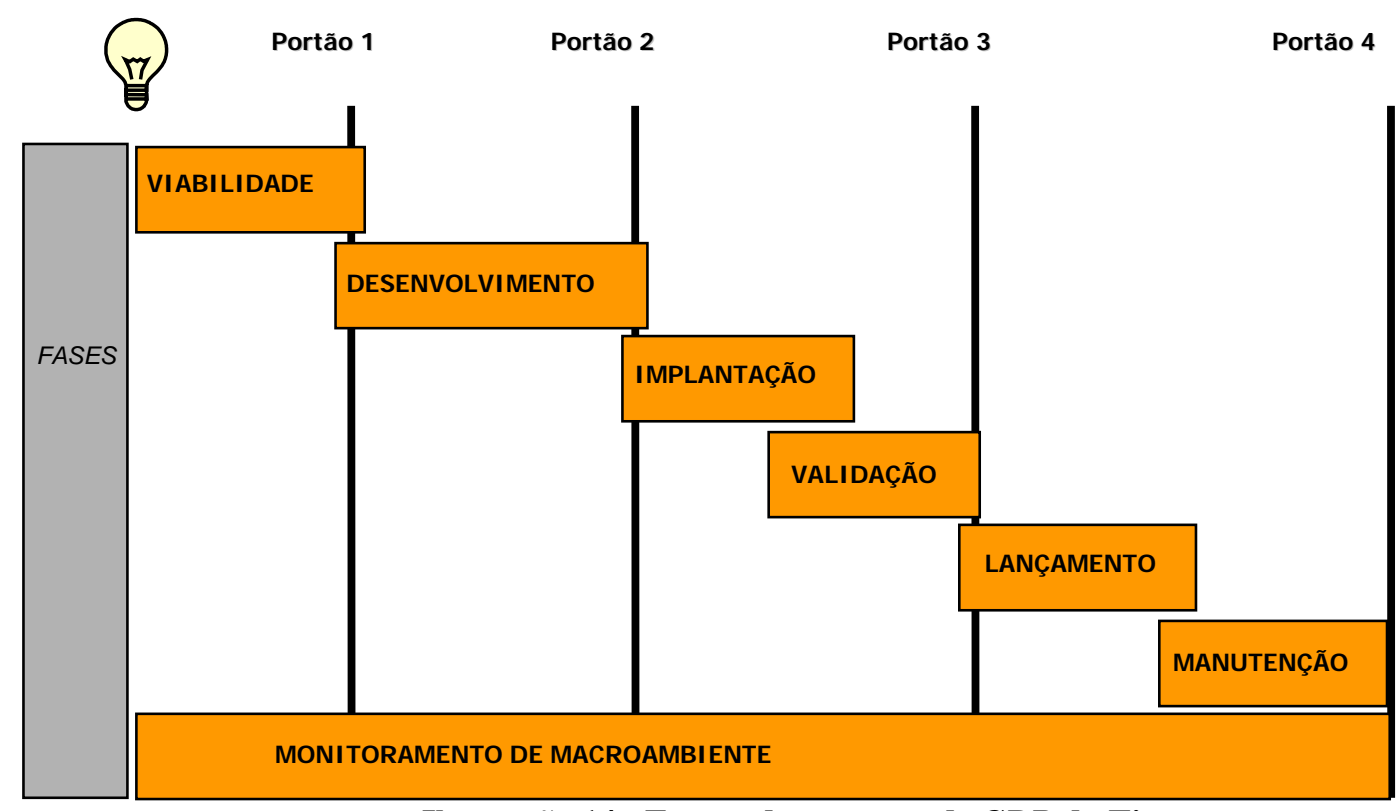

Ilustração 14 - Etapas do processo de GDP da Tigre

FONTE: TIGRE, 2008

Antes de entrar na discussão sobre as etapas e subetapas do processo, será apresentado como a Tigre, na visão dos entrevistados, enxerga a GDP.

\subsubsection{Conceito}

A inovação na Tigre se tornou mais presente nos últimos cinco anos, o que gerou mudanças na forma como a empresa enxerga o desenvolvimento de novos produtos. O gerente de $\mathrm{P} \& \mathrm{D}$ afirma que hoje a inovação na Tigre é tratada como estratégia de crescimento. Complementa dizendo que “A inovação está no sangue. Inovar, fazer acontecer e acreditar que é possível, é a nossa bandeira”. A GDP na Tigre, como pode ser observada na Ilustração 14, engloba desde a identificação da oportunidade até a colocação do produto no mercado e sua manutenção.

\subsubsection{Estratégia e planejamento do produto}

Durante muito tempo, a Tigre desenvolveu novos produtos pensando somente na complementação de suas linhas de produtos, o que fez com que hoje tenha o maior portfólio de produtos nos três negócios em que a empresa atua. No entanto, era um processo basicamente reativo, ou seja, deixava-se que as idéias chegassem, mas atualmente a empresa somou a essa estrutura uma visão mais proativa, de buscar idéias, ou melhor, oportunidades. A empresa deixou de trabalhar orientada a produto, para trabalhar orientada a mercado. 
Houve uma forte quebra de paradigmas, e essa mudança, conforme o gerente de $P \& D$, aconteceu há mais ou menos quatro anos.

Inicialmente a empresa identificou os seus clientes, de fato, e suas necessidades, e procurou agregar todas as novas propostas ao seu já existente programa de relacionamento. De acordo com o gerente de produtos e marketing, um dos grandes segredos da Tigre durante todos esses anos foi saber investir na pessoa certa, o formador de opinião, o “advogado” desse mercado, o instalador. Foi com esse pensamento que a empresa formou um consolidado programa de relacionamento com seus clientes, estipulando também metas bastante ousadas para o treinamento dessas pessoas. No entanto, com essa reestruturação a empresa percebeu a necessidade de investir mais no seu consumidor final.

Atualmente, existem diversas formas de se obter informações de todo o seu mercado, seja ele arquiteto, engenheiro, balconista, encanador, instalador, consumidor final, dentre outros. Possui espaço para sugestões, críticas, atualização do público-alvo com os lançamentos da empresa, os especificadores são inseridos no processo através da força de vendas, de visitas a construtoras e de palestras técnicas. O gerente de produtos e marketing indica que toda e qualquer interação com o mercado consumidor tem como finalidade conhecer suas necessidades.

A Tigre possui hoje um banco de dados, no qual essas pessoas recebem feedback, se relacionam com a Tigre, dando dicas, indicando necessidades, representando parcela do mercado que consome os produtos da empresa. A parte da empresa que é mais voltada a campo, por exemplo, vendedores, assistência técnica, que estão por todo o Brasil, tem um contato próximo com projetistas, engenheiros, arquitetos e instaladores. "Todo dia estamos treinando ou nos relacionando”, é o que diz o gerente de produtos e marketing. Esse relacionamento acontece por meio de palestras, cursos de uma semana, centros de aperfeiçoamento técnico, escolas em três plantas da empresa, dentre outros.

A citada empresa mapeou também seus principais geradores de inovação, buscando uma maior aproximação com as universidades, investindo em projetos de pesquisa, participando de feiras dentro e fora do Brasil, conhecendo melhor seus concorrentes. Também é feita uma vigilância tecnológica muito forte na análise de patentes. São diversas as técnicas utilizadas pela Tigre para manter-se cada vez mais próxima de seu mercado consumidor. 
Porém, além de todo esse programa de relacionamento, a Tigre somou ao seu processo de geração de idéias uma nova maneira de identificar essas oportunidades. A primeira etapa desse novo processo é a observação in loco. O pessoal da área de pesquisa vai ao local onde poderá fazer observações de uso e manuseio de produtos os quais esteja interessado em desenvolver, ou mesmo já tenha, para que possa identificar novas necessidades.

Em um de seus projetos a Tigre se inseriu, durante 40 horas, na casa de seus consumidores, e afirma que somente assim conseguiu identificar as reais necessidades desse público. Segundo a empresa, a própria dona de casa acabou dando uma aula de design, mostrando onde estava o erro de diversas peças, como estas poderiam tornar a vida dela mais prática, até mesmo o que faltava em determinados produtos. Após toda essa coleta de informações, o material foi analisado através de metodologias como focus group, post-it, mesas repletas de idéias e comparações com o que já existe no mercado, metodologia bastante similar à da IDEO, caso apresentado na literatura levantada. Definem-se três propostas e as levam para a etapa seguinte.

Essa é uma das maneiras, identificadas mais recentemente pela empresa, para se relacionar com o seu consumidor. Os entrevistados afirmam que atualmente o foco está na estruturação dessa etapa de captação de informações, principalmente com o consumidor final, uma vez que há tanto tempo dedicaram sua atenção para a obra e seu entorno. No entanto, afirmam que isso não será deixado de lado, apenas será acrescentado a essa etapa informações também provenientes do consumidor final, aumentando cada vez mais a boca do funil de desenvolvimento.

A intenção é fazer a open innovation, o portal de inovação, procurando com isso abrir um espaço para assuntos e discussões mais específicas, pois apesar de já possuir o “Tele-Tigre”, este não é direcionado para um tema, que esteja sendo pesquisado no momento na empresa.

A Tigre acredita já ter uma maturidade na gestão de projetos, por isso essa dedicação na reconfiguração dessa etapa do projeto, além de acreditar que ela é fundamental para o bom desempenho das etapas seguintes. “Aumentando a eficácia na captação da oportunidade, aumentaremos nosso sucesso em projetos”, é o que afirma o gerente de P\&D. Ao fim dessa 
etapa, a empresa possui uma lista de novas oportunidades, entrando assim no Portão 1 - P1. (Conforme ilustração 14).

No P1, antes de iniciar o desenvolvimento, são feitos todos os relatórios financeiros com o plano agregado dos projetos. Nesse momento é feita uma apresentação com dois slides dos dados financeiros, sem nenhuma alocação de recursos. O gerente de P\&D diz que de, em média, 80 projetos que são apresentados para a diretoria, somente pouco mais da metade são aprovados. E a partir dessa lista é que a área de desenvolvimento inicia todo o processo. Esses relatórios financeiros são elaborados com o auxílio de um ScoreCard (tomada de decisão), e apresentados pelos gerentes de negócios, de todo o Brasil, na reunião do Comitê Estratégico da Tigre. A análise financeira e a estratégia das oportunidades proporcionam uma análise mais apurada do potencial da idéia. As oportunidades viáveis por esta ótica continuam no processo.

Nessa reunião são apresentados dados quali e quantitativos dos projetos e mercado onde eles participarão para ajudar na tomada de decisão. Aprovado pela alta administração, o projeto passa para a etapa seguinte, Desenvolvimento do Conceito. Os projetos selecionados são ordenados com o auxílio dos seguintes critérios: quantitativos e qualitativos, margem de contribuição, tempo de retorno do investimento, potenciais estratégicos, grau de complexidade e inovação.

As mudanças dividem-se em incrementais, topológicas e radicais. As incrementais são mudanças técnicas, mas resultantes de algum ajuste. As topológicas caracterizam-se como adaptações feitas nos produtos para adequação a diferentes tipos de clientes. E as inovações radicais resultam tanto de pesquisas internas, como da aquisição de novas máquinas e equipamentos.

Todos os novos produtos da Tigre entram em “quarentena” na Assistência Técnica assim que são lançados. Isso significa que qualquer reclamação de campo que aconteça durante os primeiros três meses do produto no mercado serão atendidas pelo próprio engenheiro da assistência técnica interna da Tigre. Além disso, a empresa possui um profissional em cada cidade abastecida com produtos Tigre, a fim de ter pessoas treinadas e capacitadas para solucionar problemas que porventura aconteçam. Existe um universo com cerca de 100 
pessoas que fazem esse pós. Então, nesses casos de lançamentos de produtos novos, a Tigre faz questão de que o engenheiro vá ao local pessoalmente.

Algo relevante percebido pela empresa foi a importância dessa etapa acontecer antes da formação do estoque, pois caso sejam necessários ajustes, estes serão feitos sem grandes prejuízos. Essa é a forma que a Tigre encontrou para fazer melhorias nos seus produtos, logo após seu lançamento. Outros aprendizados são utilizados em produtos futuros, podendo ser a evolução do produto para uma nova linha.

No Quadro 39 é apresentada, de forma resumida, a maneira como a Tigre desenvolve essa primeira fase do processo de GDP.

Quadro 39- Decisão Tigre - estratégia e planejamento do produto

\begin{tabular}{|c|c|c|}
\hline $\begin{array}{l}\text { Organização do } \\
\text { Projeto de } \\
\text { Desenvolvimento }\end{array}$ & $\begin{array}{c}\text { Decisões para organização de projetos de } \\
\text { desenvolvimento }\end{array}$ & Decisões Tigre \\
\hline $\begin{array}{c}\text { Estratégia e } \\
\text { Planejamento do } \\
\text { Produto }\end{array}$ & $\begin{array}{l}\text { - Estratégia de Mercado (KRISHNAN; } \\
\text { ULRICH, 2001; CLARK; WHEELWRIGHT, } \\
\text { 1993) - produtos que serão ofertados, público- } \\
\text { alvo e forma que serão disponibilizados; número, } \\
\text { tempo e taxa de mudança da plataforma; e define } \\
\text { número, tempo, freqüëncia e relações de produtos } \\
\text { diferenciados; componentes compartilhados entre } \\
\text { as plataformas. } \\
\text { - Estratégia Tecnológica - tecnologia necessária; } \\
\text { tecnologia que dê vantagem competitiva; fonte } \\
\text { externa e interna; tempo para capacitação; } \\
\text { maturação da tecnologia; e freqüência das } \\
\text { implementações (KRISHNAN; ULRICH, 2001; } \\
\text { CLARK; WHEELWRIGHT, 1993). } \\
\text { - Plano Agregado de Projetos - prioridades; } \\
\text { escolha do projeto e definição de quando } \\
\text { começam e terminam; recursos disponíveis } \\
\text { (CLARK; WHEELWRIGHT, 1993). } \\
\text { - Aprendizados e melhorias para projetos } \\
\text { futuros - melhoria das capacidades envolvidas no } \\
\text { processo e do próprio processo em si (CLARK; } \\
\text { WHEELWRIGHT, 1993). }\end{array}$ & $\begin{array}{l}\text { - Estratégia de Mercado - } \\
\text { produtos que serão ofertados, } \\
\text { público-alvo e forma que serão } \\
\text { disponibilizados; define número, } \\
\text { tempo, freqüência e relações de } \\
\text { produtos diferenciados. } \\
\text { - Estratégia Tecnológica - } \\
\text { tecnologia necessária; tecnologia } \\
\text { que dê vantagem competitiva; } \\
\text { fonte externa e interna; tempo para } \\
\text { capacitação; maturação da } \\
\text { tecnologia. } \\
\text { - Plano Agregado de Projetos - } \\
\text { prioridades; escolha do projeto e } \\
\text { definição de quando começam e } \\
\text { terminam; recursos disponíveis. } \\
\text { - Aprendizados e melhorias para } \\
\text { projetos futuros - melhoria das } \\
\text { capacidades envolvidas no } \\
\text { processo e do próprio processo em } \\
\text { si. }\end{array}$ \\
\hline
\end{tabular}

\subsubsection{Organização do desenvolvimento do produto}

A empresa possui uma estrutura de P\&D com cerca de 100 pessoas. Todas estão alocadas na unidade industrial de Joinville. O piso de formação dessas pessoas é o nível técnico. Trata-se de uma equipe multidisciplinar, na qual se investe bastante em sua revitalização e 
oxigenação. A idéia de formar uma equipe multidisciplinar é a possibilidade da inexistência de uma linha divisória entre as áreas. Conforme Ganem e Santos (2006):

\begin{abstract}
Os novos produtos saem de idéias dessa equipe, mas boa parte dos trabalhos principalmente aqueles que envolvem mais pesquisa, é desenvolvida por meio de parcerias com universidades, em especial a Universidade Federal de Santa Catarina - UFSC, a Universidade de São Paulo USP, e a Universidade Federal do Rio de Janeiro - UFRJ. Cerca de 0,5\% do faturamento é aplicado em P\&D, o que no exercício de 2005 representou um investimento da ordem de $\mathrm{R} \$$ 8,5 milhões.
\end{abstract}

A Tigre possui uma estrutura formal e em grupo, e, associada ao papel da liderança, pode ser classificada em estrutura do time "peso leve”. Isso se deve ao fato do gerente do projeto se encontrar em um nível médio dentro da empresa, com pouca influência na organização. Porém, o Gerente de $P \& D$ da Tigre afirma que, nem mesmo ele tem poder de decisão de investimento, pois todas as decisões devem ser aprovadas pela alta administração. Nisso, a Tigre diverge dos conceitos da estrutura do time "peso leve”. Outra característica que vai de acordo com a estrutura desse time, é que as pessoas que o compõem encontram-se alocadas em suas áreas específicas, não há uma área própria para cada projeto.

Embora a Tigre tenha algumas características da classificação da estrutura do time como "peso leve”, esta parece um pouco errada quando se pensa nas estruturas de Clark e Wheelwright (1993), onde as distâncias hierárquicas eram imensas, e as reuniões eram os únicos momentos para se discutirem os projetos. Estas por sua vez aconteciam muito raramente.

O arranjo físico é por projeto que está sendo desenvolvido; existem pessoas fixas em cada projeto, como também cargos e funções que variam de projeto para projeto. No entanto, estão todos localizados em uma área comum. A formação do time é feita logo após a aprovação do projeto no P1, sendo formado por membros da diretoria, gerente funcional, responsável pela engenharia, gerente de projeto e especialistas. As áreas que participam são marketing, vendas, tecnologia, produção, finanças e logística.

É na fase de organização do desenvolvimento do produto que a Tigre procura identificar o que será preciso de investimentos com os novos projetos, como infra-estrutura, ferramentas e treinamento. Inicialmente a empresa começou utilizando conceitos de como gerir o desenvolvimento de novos produtos através da International Organization for 
Standardization - ISO. Atualmente estão alinhados com o Project Management Body of Knowledge - PmBok. Utiliza conceitos de GDP bastante atuais, como, equipe multidisciplinar, engenharia simultânea, o funil de desenvolvimento de Clark e Wheelwright (1993) e o stage-gate de Cooper, que são representados pelos portões de avaliação da alta gerência, para aprovação ou exclusão do projeto.

O Quadro 40 apresenta as decisões que a Tigre toma na fase de Organização do Desenvolvimento do Produto.

Quadro 40 - Decisões Tigre - organização do desenvolvimento do produto

\begin{tabular}{|c|c|c|}
\hline $\begin{array}{l}\text { Organização do } \\
\text { Projeto de } \\
\text { Desenvolvimento } \\
\end{array}$ & $\begin{array}{c}\text { Decisões para organização de projetos de } \\
\text { desenvolvimento }\end{array}$ & Decisões Tigre \\
\hline $\begin{array}{l}\text { Organização do } \\
\text { Desenvolvimento } \\
\text { do Produto }\end{array}$ & $\begin{array}{l}\text { - Time - membros da diretoria, gerente funcional, } \\
\text { responsável pela engenharia, gerente de projeto, } \\
\text { especialistas e parceiros (ROZENFELD et al, } \\
\text { 2006); áreas - marketing, vendas, tecnologia, } \\
\text { produção e finanças (COOPER et al, 2002b). } \\
\text { - Estrutura de desenvolvimento - individual ou } \\
\text { em grupo; formal ou informal (ROZENFELD et al, } \\
\text { 2006). Estruturas associadas ao papel da liderança - } \\
\text { time funcional, peso leve, peso pesado ou } \\
\text { autônomo (CLARK; WHEELWRIGHT, 1993; } \\
\text { ROZENFELD et al, 2006). Arranjo físico - em } \\
\text { área comum ou cada um em seu setor } \\
\text { (KRISHNAN; ULRICH, 2001). } \\
\text { - Investimentos - infra-estrutura, ferramentas e } \\
\text { treinamento (CLARK; WHEELWRIGHT, 1993). } \\
\text { - Processo de desenvolvimento - abordagem } \\
\text { tradicional de desenvolvimento, engenharia } \\
\text { simultânea, funil de desenvolvimento e stage-gate } \\
\text { (CLARK; WHEELWRIGHT, 1993). }\end{array}$ & $\begin{array}{l}\text { - Time - membros da diretoria, } \\
\text { gerente funcional, responsável } \\
\text { pela engenharia, gerente de } \\
\text { projeto, especialistas; áreas - } \\
\text { marketing, vendas, tecnologia, } \\
\text { produção e finanças. } \\
\text { - Estrutura de desenvolvimento } \\
\text { - em grupo; formal. Estruturas } \\
\text { associadas ao papel da liderança - } \\
\text { peso leve. Arranjo físico - em } \\
\text { área comum. } \\
\text { - Investimentos - infra-estrutura, } \\
\text { ferramentas e treinamento. } \\
\text { - Processo de desenvolvimento } \\
\text {-engenharia simultânea, funil de } \\
\text { desenvolvimento e stage-gate. }\end{array}$ \\
\hline
\end{tabular}

\subsubsection{Gerenciamento do projeto}

Essa fase inicia-se com os projetos ordenados, para que a área de P\&D inicie o planejamento de cada um deles. Deve-se ressaltar que todas as decisões tomadas nessa etapa devem estar acordadas com a área de marketing e aprovadas pelo comitê estratégico. Após a aprovação do projeto pela diretoria no P1, definem-se seus líderes, responsáveis pela montagem de seu escopo e cronograma. Seus atores passam a se envolver e a conhecer os objetivos e conceitos que estão relacionados com os novos produtos. A área de $P \& D$, na figura do especialista de produto, é quem prepara o termo de abertura, o escopo e faz a gerência do projeto, como também faz seu follow-up, conforme metodologia adotada pela empresa. Nesses planos é que são indicados o tempo de desenvolvimento, as etapas e requisitos próprios de cada produto. 
Devido ao poder limitado dos líderes dos projetos, e até mesmo do gerente de P\&D, foi inserido no processo a metodologia de gates (portões), momentos para aprovação ou não de uma decisão, a qual é tomada pelo Comitê Estratégico da Tigre, formado por seus diretores. Esse Comitê reúne-se uma vez por mês. Deve-se ressaltar que o desenvolvimento de um produto está sob a liderança da área de $\mathrm{P} \& \mathrm{D}$, no entanto, só se tomará uma decisão com a aprovação do marketing. Essas duas áreas trabalham conjuntamente dentro desse processo.

Os mesmos critérios que a Tigre lança mão para ordenamento dos projetos são utilizados com a finalidade de descarte. Possuem critérios quantitativos e qualitativos, são eles: margem de contribuição, tempo de retorno do investimento, potenciais estratégicos, grau de complexidade e inovação.

Outro ponto de decisão nessa fase é em relação à comunicação. A integração do time é multifuncional, como já foi apresentado anteriormente. Conforme Frishammar (2005), o time pode interagir e/ou colaborar entre si, no caso da Tigre, ocorrem as duas coisas de forma equilibrada, já que existem as reuniões formais e as conversas informais sobre os projetos. E, por fim, de acordo com Clark e Wheelwright (1993), a comunicação pode se dar de duas maneiras, monólogo ou diálogo. Na Tigre se caracteriza como diálogo, e acontece nas fases iniciais do projeto.

A citada empresa lança mão do Balance Scorecard - BSC, com a finalidade de controlar seus projetos acabados. Isso é feito através de três indicadores de desempenho. Um deles é o faturamento com produtos novos; o outro, muito importante, é o tempo para lançar o produto, chamado de time to market, ou seja, identificada a oportunidade, em quanto tempo se consegue colocá-lo no mercado. E o outro indicador é a taxa de sucessos dos lançamentos. Isso acontece devido à postura inovadora da Tigre, é o que diz o gerente de P\&D da empresa.

O Quadro 41 apresenta as decisões para gerenciamento dos projetos na Tigre, levando em consideração a literatura pesquisada.

Quadro 41 - Decisões Tigre - gerenciamento do projeto

\begin{tabular}{|c|c|c|}
\hline $\begin{array}{c}\text { Organização do } \\
\text { Projeto de } \\
\text { Desenvolvimento }\end{array}$ & $\begin{array}{c}\text { Decisões para organização de projetos de } \\
\text { desenvolvimento }\end{array}$ & Decisões Tigre \\
\hline
\end{tabular}




\begin{tabular}{|c|c|c|}
\hline $\begin{array}{l}\text { Gerenciamento do } \\
\text { Projeto }\end{array}$ & $\begin{array}{l}\text { - Monitoramento e controle - através de planos, } \\
\text { formal, atuação do gerente e envolvimento, e } \\
\text { compromisso da alta administração (BROWN; } \\
\text { EISENHARDT, 1995; CLARK; WHEELWRIGHT, } \\
\text { 1993; ROZENFELD et al, 2006; GRIFFIN, 1997). } \\
\text { - Priorização dos projetos, tempo de } \\
\text { desenvolvimento, seqüência das atividades, e } \\
\text { marcos do projeto - planejamentos com auxílio do } \\
\text { PERT e CPM; cronograma (KRISHNAN; ULRICH, } \\
\text { 2001; ROZENFELD et al, 2006). } \\
\text { - Descarte de projetos - critérios para descarte; } \\
\text { check list (COOPER et al, 2002b). } \\
\text { - Comunicação - integração funcional ou } \\
\text { multifuncional (CLARK; WHEELWRIGHT, 1993); } \\
\text { interação e/ou colaboração (FRISHAMMAR, } \\
\text { 2005); e monólogo ou diálogo, que acontece nas } \\
\text { fases iniciais do projeto (CLARK; } \\
\text { WHEELWRIGHT, 1993). } \\
\text { - Desempenho - qualidade do projeto, tempo para } \\
\text { colocar o produto no mercado e produtividade; } \\
\text { planejado x o que efetivamente aconteceu (CLARK; } \\
\text { WHEELWRIGHT, 1993; CLARK; FUJIMOTO, } \\
\text { 1991). }\end{array}$ & $\begin{array}{l}\text { - Monitoramento e controle - } \\
\text { através de planos, formal, } \\
\text { atuação do gerente e } \\
\text { envolvimento e compromisso da } \\
\text { alta administração. } \\
\text { - Priorização dos projetos, } \\
\text { tempo de desenvolvimento, } \\
\text { seqüência das atividades e } \\
\text { marcos do projeto - } \\
\text { planejamentos; cronograma. } \\
\text { - Descarte de projetos - } \\
\text { critérios para descarte; check } \\
\text { list. } \\
\text { - Comunicação - integração } \\
\text { multifuncional; interação e } \\
\text { colaboração; e diálogo, que } \\
\text { acontece nas fases iniciais do } \\
\text { projeto. } \\
\text { - Desempenho - qualidade do } \\
\text { projeto, tempo para colocar o } \\
\text { produto no mercado e } \\
\text { produtividade; planejado x o que } \\
\text { efetivamente aconteceu. }\end{array}$ \\
\hline
\end{tabular}

\subsubsection{Etapas de desenvolvimento}

Neste item serão apresentadas as etapas do processo de desenvolvimento de novos produtos na Tigre, o qual se subdivide em quatro etapas, a primeira é a identificação de oportunidades, seguido do desenvolvimento do projeto, try-out e, por fim, o lançamento. A descrição das etapas será feita com base na classificação apresentada por Krishnan e Ulrich (2001), que se subdivide em cinco etapas: desenvolvimento do conceito; projeto da cadeia de suprimentos; projeto do produto; teste e validação de desempenho; e ramp-up e lançamento. O Quadro 42 combina as etapas de Krishnan e Ulrich (2001) com as etapas da Tigre.

Quadro 42 - Quadro comparativo etapas Krishnan e Ulrich (2001) versus etapas Tigre

\begin{tabular}{|l|l|}
\hline \multicolumn{1}{|c|}{ Etapas Krishnan e Ulrich (2001) } & \multicolumn{1}{c|}{ Etapas Tigre } \\
\hline Desenvolvimento do Conceito & \multirow{2}{*}{ Desenvolvimento } \\
\cline { 1 - 1 } Projeto da Cadeia de Suprimentos & \\
\hline Projeto do Produto & Try-out \\
\hline Teste e Validação de Desempenho & Lançamento \\
\hline Ramp-up e Lançamento &
\end{tabular}

\section{a) Desenvolvimento do conceito}


As três primeiras etapas do processo de GDP indicado por Krishnan e Ulrich (2001) se resumem a uma etapa do processo de desenvolvimento da Tigre, que por sua vez se subdivide em três outras etapas: projeto conceitual, projeto preliminar e projeto detalhado. Sendo que o projeto conceitual faz referência às decisões tomadas na etapa de desenvolvimento do conceito de Krishnan e Ulrich (2001), o projeto preliminar ao projeto da cadeia de suprimentos e o projeto detalhado ao projeto do produto, como pode ser observado no Quadro 42.

Essa subetapa constitui-se na definição do projeto conceitual, ou seja, momento de desenvolvimento do conceito do produto. A interação de todos os envolvidos no processo começa já nessa etapa. A área de P\&D irá aperfeiçoar o projeto, acrescentando informações sobre preço, mercado, produtos similares e complementares, componentes, investimentos, normas relacionadas ao produto, indicar quem é o cliente, consumidor e suas necessidades. Feito isso, a área de P\&D vai a campo para fazer a validação do conceito com a ajuda de protótipos, caso necessário, colhendo assim informações sobre as necessidades de seus clientes e consumidores.

Com isso, a participação do cliente e/ou consumidor no processo acontece somente de forma indireta. De acordo com o Gerente de P\&D, essa etapa é de fundamental importância, pois refletirá na aceitação do conceito pelo consumidor. Nessa etapa também são definidas a arquitetura do produto, sua forma física e projeto industrial, obtidos por meio da prototipagem virtual. O conceito central, já esboçado anteriormente, também será aperfeiçoado, este proveniente dos seguintes inputs: tecnologia, serviço, projeto, valor, mercado consumidor e sustentabilidade.

Com o protótipo é possível identificar a arquitetura do produto, sua forma física e esboçar seu projeto industrial, como também seus componentes e variações. É considerada uma fase fast track, pois é feita rapidamente e, caso se identifique que não é um projeto viável, é abortado logo nesse primeiro momento. O Quadro 43 traz, de forma sucinta, as decisões que a Tigre procura tomar nessa etapa.

Quadro 43 - Decisões Tigre - desenvolvimento do conceito

\begin{tabular}{|c|c|c|}
\hline $\begin{array}{c}\text { Etapas segundo } \\
\text { Krishnan e Ulrich } \\
(2001)\end{array}$ & $\begin{array}{c}\text { Decisões das etapas do processo de } \\
\text { desenvolvimento }\end{array}$ & Decisões Tigre \\
\hline
\end{tabular}




\begin{tabular}{|c|c|c|}
\hline $\begin{array}{l}\text { Desenvolvimento do } \\
\text { Conceito }\end{array}$ & $\begin{array}{l}\text { - Interação de todos os envolvidos no processo } \\
\text { (SMITH; REINERTSEN, 1998). } \\
\text { - Clientes e consumidores finais - participação } \\
\text { no processo de desenvolvimento; utilização de } \\
\text { ferramentas para conhecer as necessidades do } \\
\text { mercado, como QFD (GRIFFIN; HAUSER, } \\
\text { 1993). } \\
\text { - Escopo detalhado do produto - tecnologias } \\
\text { disponíveis e necessárias; normas; patentes e } \\
\text { legislação relacionada ao produto; identificar } \\
\text { quem é o cliente, o consumidor e suas } \\
\text { necessidades; requisitos do produto; produtos } \\
\text { concorrentes e similares; serviços agregados ao } \\
\text { produto; objetivos ou metas que o produto deve } \\
\text { atender; preço; e outras informações relevantes } \\
\text { para a empresa (ROZENFELD et al, 2006, p.213; } \\
\text { SMITH; REINERTSEN, 1998; VON HIPPEL, } \\
\text { 1986; THOMKE; VON HIPPEL, 2002; SMITH; } \\
\text { REINERTSEN, 1998; COOPER et al, 2002a; } \\
\text { SLAUGHTER, 1991); congelamento das } \\
\text { características em etapas iniciais ou finais } \\
\text { (ROZENFELD et al, 2006; BACON et al, 1994 } \\
\text { apud KRISHNAN; ULRICH, 2001); Conceito } \\
\text { central - input - technology-driven concept; } \\
\text { service concept; design-driven concept; value- } \\
\text { driven concept; customer- and market-driven } \\
\text { concept (BACKMAN et al, 2007). } \\
\text { - Arquitetura do produto, forma física e } \\
\text { projeto industrial - desenho virtual ou croqui } \\
\text { (KRISHNAN; ULRICH, 2001). } \\
\text { - Variações do produto - quais serão oferecidas, } \\
\text { componentes compartilhados entre as variações } \\
\text { (KRISHNAN; ULRICH, 2001). }\end{array}$ & $\begin{array}{l}\text { - Interação de todos os envolvidos } \\
\text { no processo. } \\
\text { - Clientes e consumidores finais - } \\
\text { participação no processo de } \\
\text { desenvolvimento; utilização de } \\
\text { ferramentas para identificar suas } \\
\text { necessidades. } \\
\text { - Escopo detalhado do produto - } \\
\text { tecnologias disponíveis e } \\
\text { necessárias; normas; patentes e } \\
\text { legislação relacionada ao produto; } \\
\text { identificar quem é o cliente, o } \\
\text { consumidor e quais suas } \\
\text { necessidades; requisitos do produto; } \\
\text { produtos concorrentes e similares; } \\
\text { serviços agregados ao produto; } \\
\text { objetivos ou metas que o produto } \\
\text { deve atender; preço; e outras } \\
\text { informações relevantes para a } \\
\text { empresa; congelamento das } \\
\text { características em etapas finais; } \\
\text { Conceito central - input - } \\
\text { technology-driven concept; service } \\
\text { concept; design-driven concept; } \\
\text { value-driven concept; customer- } \\
\text { and market-driven concept. } \\
\text { - Arquitetura do produto, forma } \\
\text { física e projeto industrial - } \\
\text { croqui. } \\
\text { - Variações do produto - quais } \\
\text { serão oferecidas, componentes } \\
\text { compartilhados entre as variações. }\end{array}$ \\
\hline
\end{tabular}

\section{b) Projeto da cadeia de suprimentos}

Com o projeto conceitual feito, elabora-se seu relatório técnico, atividade de responsabilidade do P\&D. Nessa fase, o projeto começa a ser modelado, definem-se quais componentes serão produzidos internamente e quais serão comprados prontos, e quem os projetará e desenvolverá, analisam-se os concorrentes e o mercado, identifica-se a matéria-prima que será utilizada, quanto se investirá, se existe máquina apropriada para realizar o projeto internamente, e equipamentos necessários.

Para que a área de P\&D consiga fornecer informações reais sobre os recursos da empresa, é feita uma análise, sob a ótica da logística e planejamento, tomando-se por base os investimentos necessários. Indica-se o que a empresa possui de equipamentos, recursos, local de armazenamento, rede de distribuição e Centro de Distribuição - CD. Ao fim dessa etapa, a 
área de $\mathrm{P} \& \mathrm{D}$ deve ter em mãos um relatório de mercado, um relatório técnico, fluxos mapeados de todo o processo e um protótipo virtual.

Vale ressaltar que é nessa fase que se lança mão da engenharia simultânea, onde informalmente os atores do projeto conversam entre si, para o detalhamento do projeto, adiantando atividades relacionadas com a etapa seguinte. Essa técnica foi inserida na empresa com a finalidade de reduzir o tempo de desenvolvimento e abolir as grandes reuniões, as quais só acontecem uma vez na semana com os líderes dos projetos, apenas para seu acompanhamento formal. Sempre são levados os relatórios de cada projeto, onde são repassados todos os pontos.

É importante ressaltar que, apesar de serem identificados os possíveis fornecedores, tecnologia e equipamentos necessários, e analisada toda a cadeia de suprimentos, nenhum contrato é fechado, conseqüentemente, nada é adquirido. O Quadro 44 apresenta as decisões que a Tigre toma na etapa de Projeto da Cadeia de Suprimentos.

Quadro 44 - Decisões Tigre - projeto da cadeia de suprimentos

\begin{tabular}{|c|c|c|}
\hline $\begin{array}{c}\text { Etapas segundo } \\
\text { Krishnan e Ulrich } \\
\quad(2001)\end{array}$ & $\begin{array}{c}\text { Decisões das etapas do processo de } \\
\text { desenvolvimento }\end{array}$ & Decisões Tigre \\
\hline $\begin{array}{l}\text { Projeto da Cadeia de } \\
\text { Suprimentos }\end{array}$ & $\begin{array}{l}\text { - Componentes - projetados internamente ou } \\
\text { comprados prontos; quem projetará, } \\
\text { desenvolverá e produzirá (KRISHNAN; } \\
\text { ULRICH, 2001). } \\
\text { - Cadeia física de suprimentos - } \\
\text { configuração, incluindo o local de junção dos } \\
\text { componentes; seleção de fornecedores das } \\
\text { tecnologias e equipamentos; sistema de } \\
\text { produção e distribuição; custos diretos de } \\
\text { produção; custos entre fornecimento e } \\
\text { demanda (KRISHNAN; ULRICH, 2001). }\end{array}$ & $\begin{array}{l}\text { - Componentes - projetados } \\
\text { internamente ou comprados prontos; } \\
\text { quem projetará, desenvolverá e } \\
\text { produzirá. } \\
\text { - Cadeia física de suprimentos - } \\
\text { configuração, incluindo o local de } \\
\text { junção dos componentes; seleção de } \\
\text { fornecedores das tecnologias e } \\
\text { equipamentos; sistema de produção e } \\
\text { distribuição; custos diretos de produção; } \\
\text { custos entre fornecimento e demanda. }\end{array}$ \\
\hline
\end{tabular}

\section{c) Projeto do produto}

No início dessa etapa é feita a escolha de três soluções para cada projeto. As alternativas são apresentadas para o marketing a fim de auxiliar na identificação da melhor opção. Por meio de programas específicos para desenvolvimento dos protótipos virtuais, a área de $\mathrm{P} \& \mathrm{D}$, na pessoa do projetista, aperfeiçoa a solução escolhida, acrescentando e ajustando as 
informações presentes no relatório técnico. Nessa etapa, a Tigre já realiza testes com os protótipos, analisando questões técnicas, funcionais, de resistência e, claro, estéticas.

Ao fim dessa fase, a área de P\&D tem o projeto detalhado do produto, contendo informações sobre ele e seus componentes, material que será utilizado, ferramentas e equipamentos necessários, planos do processo e desenhos finais com as tolerâncias das medidas. Esta subetapa fecha a etapa de Desenvolvimento do processo de GDP da Tigre.

O projeto detalhado finalizado, entra então no P2. Esse portão constitui-se na apresentação feita pela área de P\&D com todo o projeto detalhado do novo produto. Essas informações são compiladas em forma de apresentação, na qual devem conter todos os pontos apresentados no $\mathrm{P} 1$, com os ajustes e acréscimos que houve na etapa de desenvolvimento do produto. Indicase os objetivos, características, posicionamento do produto frente aos concorrentes, análise do produto de determinado concorrente, competitividade, vantagens, economias, cronogramas e prazo para lançamento.

Feito isso, a alta administração autoriza ou não a continuidade do projeto. Aprovado, inicia-se o processo de aquisição de todos os investimentos planejados. Também são verificadas as necessidades de aquisição de insumos e embalagens, eventuais desenvolvimentos, para complemento do projeto. Como, por exemplo, os manuais para manuseio do produto e treinamento. Paralelamente, todo o material de suporte está sendo produzido pela área de marketing, no entanto, só será apresentado no P3, após a etapa de Teste e Validação de Desempenho.

O Quadro 45 apresenta, resumidamente, as decisões que a Tigre toma na etapa de Projeto do Produto.

Quadro 45 - Decisões Tigre - projeto do produto

\begin{tabular}{|c|l|l|}
\hline $\begin{array}{c}\text { Etapas segundo } \\
\text { Krishnan e Ulrich } \\
(2001)\end{array}$ & \multicolumn{1}{|c|}{$\begin{array}{c}\text { Decisões das etapas do processo de } \\
\text { desenvolvimento }\end{array}$} & \multicolumn{1}{c|}{ Decisões Tigre } \\
\hline Projeto do Produto & $\begin{array}{l}\text { - Especificação dos parâmetros do projeto } \\
\text { - projeto detalhado dos componentes; relação } \\
\text { entre os componentes do produto; seleção de } \\
\text { material e de processo e projeto das } \\
\text { ferramentas e equipamentos; planos de } \\
\text { processo; desenhos finais com tolerâncias } \\
\text { (ROZENFELD et al, 2006). } \\
\text { - Embalagem - avaliação da distribuição do }\end{array}$ & $\begin{array}{l}\text { - Especificação dos parâmetros do } \\
\text { componentes; relação entre os } \\
\text { componentes do produto; seleção de } \\
\text { material e de processo, e projeto das } \\
\text { ferramentas e equipamentos; planos de } \\
\text { processo; desenhos finais com } \\
\text { tolerâncias. }\end{array}$ \\
\hline
\end{tabular}




\begin{tabular}{|l|l|l|}
\hline & produto, incluindo transporte e entrega; & - Embalagem - avaliação da \\
definição das formas e sinalizações das & distribuição do produto, incluindo \\
embalagens dos produtos; projeção da & transporte e entrega; definição das \\
embalagem; planejamento do processo de & formas das embalagens dos produtos; \\
& embalagem (ROZENFELD et al, 2006). & projeção da embalagem; planejamento \\
& - Material de suporte do produto - criação & do processo de embalagem. \\
do manual de operação do produto, do & - Material de suporte do produto - \\
& material de treinamento e do manual de \\
& descontinuidade do produto (ROZENFELD do material de treinamento. \\
& et al, 2006). & \\
\hline
\end{tabular}

\section{d) Teste e validação de desempenho}

Após a passagem pelo P2, tudo o que foi planejado no projeto é adquirido, para que possa ser iniciada a etapa de try-out. Essa etapa deixa de ser responsabilidade da área de P\&D e passa a ser da engenharia. É feito um teste na linha de produção, para que todos conheçam e aprendam a manusear algum novo equipamento ou ferramenta. Os primeiros produtos são novamente submetidos a testes, avaliando seu tamanho, funcionamento, fabricação, projeto industrial, durabilidade, encaixe e finalização, e custos de produção. A avaliação da reação dos consumidores só será feita na etapa final.

Outro ponto de decisão apresentado pela literatura estudada, como pode ser observado no Quadro 46, são questões relacionadas com o tipo do protótipo, o processo de construção e seus benefícios. Na Tigre, essas decisões não são tomadas nessa etapa, isso é definido no plano de cada projeto. A classificação para o tipo de protótipo não se adequa à Tigre. O processo de construção dos protótipos varia de acordo com a etapa em que se encontra o projeto, podendo ser virtual, prototipagem rápida (experimentação real) ou, ainda, protótipos de gesso, como poder ser observado no Quadro 38, e ocorre paralelamente ao processo, desde as etapas iniciais. Os protótipos contribuem para a identificação de oportunidades, aprendizado da organização, testa a comunicação entre os membros do projeto e auxilia na resolução de conflitos.

A Tigre afirma que os protótipos virtuais servem como meio de coleta de informações reais do projeto, pois atualmente existem programas que possibilitam sua visualização externa, como também interna. A empresa indica que com esse recurso conseguiu reduzir ainda mais o tempo de desenvolvimento, pois antes tinha de fazer os protótipos de gesso já nessas etapas iniciais. É importante notar que os protótipos acompanham todo o processo de 
desenvolvimento, contribuindo para a identificação de oportunidades, para o aprendizado da organização, para a formação de novas capacidades, ajudando na solução de problemas durante o desenvolvimento. Além de testar a comunicação entre os membros do projeto e auxiliar na resolução de conflitos.

Ao fim dessa etapa, o projeto entra no P3, onde a área de marketing apresenta para o comitê executivo as propostas relacionadas ao lançamento do produto. Nessa reunião há um forte apelo para o preço e posicionamento do produto. São analisados dados financeiros, indicadas como serão feitas as comunicações internas e externas, e se terá alguma política promocional para seu lançamento.

O Quadro 46 apresenta as decisões que a Tigre toma na etapa de Teste e Validação de Desempenho.

Quadro 46 - Decisões Tigre - teste e validação de desempenho

\begin{tabular}{|c|c|c|}
\hline $\begin{array}{l}\text { Etapas segundo } \\
\text { Krishnan e Ulrich } \\
\text { (2001) }\end{array}$ & Decisões das etapas do processo de desenvolvimento & Decisões Tigre \\
\hline $\begin{array}{l}\text { Teste e Validação de } \\
\text { Desempenho }\end{array}$ & $\begin{array}{l}\text { - Prototipagem para validação - em relação a } \\
\text { funcionamento, tamanho e fabricação (KRISHNAN; } \\
\text { ULRICH, 2001); avalia reações dos consumidores, } \\
\text { projeto industrial, durabilidade, encaixe e finalização, e } \\
\text { custos de produção (ROZENFELD et al, 2006; } \\
\text { CLARK; WHEELWRIGHT, 1993). } \\
\text { - Teste em pequena escala do projeto - produção } \\
\text { piloto (CLARK; WHEELWRIGHT, 1993); definição } \\
\text { dos processos de produção e manutenção } \\
\text { (ROZENFELD et al, 2006). } \\
\text { - Tipo de protótipo - rápida resposta à engenharia, } \\
\text { sistema de solução integrado (periódico), ou replicação } \\
\text { da produção cedo (CLARK; WHEELWRIGHT, 1993). } \\
\text { - Processo de construção dos protótipos - simulação } \\
\text { virtual, prototipagem rápida (experimentação real), e } \\
\text { protótipos de papelão ou argila (CLARK; } \\
\text { WHEELWRIGHT, 1993; THOMKE, 1998; } \\
\text { SRINIVASAN et al, 1997; BECKER et al, 2005); } \\
\text { seqüencial ou paralela; prototipagem em etapas iniciais } \\
\text { do projeto (SRINIVASAN et al, 1997). } \\
\text { - Benefícios do protótipo - contribuem para a } \\
\text { identificação de oportunidades; aprendizado da } \\
\text { organização; formação de novas capacidades; testa a } \\
\text { comunicação entre os membros do projeto; auxilia na } \\
\text { resolução de conflitos (CLARK; WHEELWRIGHT, } \\
\text { 1993). }\end{array}$ & $\begin{array}{l}\text { - Prototipagem para } \\
\text { validação - em relação a } \\
\text { funcionamento, tamanho e } \\
\text { fabricação; projeto industrial, } \\
\text { durabilidade, encaixe e } \\
\text { finalização, e custos de } \\
\text { produção. } \\
\text { - Teste em pequena escala } \\
\text { do projeto - produção piloto; } \\
\text { definição dos processos de } \\
\text { produção e manutenção. } \\
\text { - Processo de construção dos } \\
\text { protótipos - simulação } \\
\text { virtual, prototipagem rápida; e } \\
\text { protótipos de papelão ou } \\
\text { argila; paralela; prototipagem } \\
\text { em etapas iniciais do projeto. } \\
\text { - Benefícios do protótipo - } \\
\text { contribuem para a } \\
\text { identificação de } \\
\text { oportunidades; aprendizado } \\
\text { da organização; testa a } \\
\text { comunicação entre os } \\
\text { membros do projeto; auxilia } \\
\text { na resolução de conflitos. }\end{array}$ \\
\hline
\end{tabular}




\section{e) Ramp-up e lançamento}

Aprovado o pacote de comunicação, interno e externo, e adquiridas as tecnologias e equipamentos necessários é dado início ao lançamento do produto. O pacote de comunicação depende da complexidade e perfil do produto. O desenho dos processos de venda e distribuição, as informações sobre concorrentes, a definição da forma como será feito o atendimento ao cliente e assistência técnica, tudo é elaborado paralelamente ao processo. $\mathrm{O}$ tempo para lançamento do produto foi definido nas etapas iniciais do processo, nessa etapa só será verificado se foi cumprido.

A Tigre possui uma forma padrão para oficializar essa entrada do produto no mercado. Inicia com a entrega de um arquivo em PDF, o qual é enviado a toda a força de vendas da empresa, com um resumo de todo o projeto, suas vantagens, objetivos, características, preço bruto, código de barras, IPI, dentre outras informações que sejam relevantes para conhecimento do novo produto. Contém ainda dicas de como expor o produto, e como apresentá-lo e vendê-lo, determinando quais argumentos utilizar, quais características devem ser realçadas, quais os maiores benefícios, além de simulação de perguntas técnicas e indicação de todos os serviços que agregam o produto.

Para o lançamento externo, a empresa possui toda uma definição de quais pontos deve começar a apresentar a nova linha, dos locais que são considerados formadores de opinião; locais de teste do produto, pois nesse momento o próprio lançamento é um teste no mercado. E, aos poucos, esses produtos vão sendo distribuídos para outros pontos. No Quadro 47 contém as decisões que a Tigre toma na etapa de Ramp-up e Lançamento.

É necessário lembrar que os primeiros produtos vendidos, no período de três meses após o lançamento, entram em quarentena, o que serve para a Tigre como teste de mercado e avaliação do projeto. Em relação ao acompanhamento do produto pelo time, este já findou na etapa de projeto do produto, quando foi assumido pela área de marketing.

Quadro 47 - Decisões Tigre - ramp-up e lançamento

\begin{tabular}{|c|c|c|}
\hline $\begin{array}{c}\text { Etapas segundo } \\
\text { Krishnan e Ulrich } \\
(2001)\end{array}$ & $\begin{array}{c}\text { Decisões das etapas do processo de } \\
\text { desenvolvimento }\end{array}$ & \multicolumn{1}{c|}{ Decisões Tigre } \\
\hline $\begin{array}{c}\text { Ramp-up e } \\
\text { Lançamento }\end{array}$ & $\begin{array}{c}\text { - Teste de mercado - nível de realização; } \\
\text { seqüência de introdução dos produtos no mercado }\end{array}$ & $\begin{array}{l}\text { - Teste de mercado - seqüência de } \\
\text { introdução dos produtos no }\end{array}$ \\
\hline
\end{tabular}




\begin{tabular}{|l|l|l|}
\hline & (CLARK; WHEELWRIGHT, 1993). & mercado. \\
- Lançamento - tempo para o lançamento do & - Lançamento - tempo para o \\
produto; como e quando o concorrente entrará ou & lançamento do produto; como e \\
entrou no mercado; finalização do & quando o concorrente entrará ou \\
desenvolvimento do projet; desenho dos & entrou no mercado; desenho dos \\
processos de venda e distribuição; atendimento & processos de venda e distribuição; \\
do cliente e assistência técnica; campanhas de & atendimento do cliente e assistência \\
marketing (ROZENFELD et al, 2006). & técnica; campanhas de marketing. \\
- Ramp-up - aumento da produção (CLARK; & - Ramp-up - aumento da produção. \\
WHEELWRIGHT, 1993; ROZENFELD et al, & - Ao fim, cessa o \\
2006). & acompanhamento do produto \\
- Ao fim, cessa ou continua o & pelo time. \\
& acompanhamento do produto pelo time & \\
(ROZENFELD et al, 2006). & \\
\hline
\end{tabular}

\subsubsection{Conclusões}

A Tigre é uma empresa que há 67 anos iniciou suas atividades, e desde então procurou desenvolver novos produtos, novos negócios, como também novos mercados. Apesar de a empresa ter excluído durante oito anos a área de desenvolvimento, esta voltou totalmente reestruturada e muito mais organizada. Essa retomada pode ser considerada como um momento de ruptura de conceitos e valores da empresa. Dos 5.200 funcionários, 100 atuam na área de desenvolvimento, responsáveis pelas novidades ofertadas ao mercado.

Alguns pontos relacionados ao seu processo merecem realce, pois se destacam na maneira que realizam determinada atividade. Em primeiro lugar, deve ser ressaltada a maneira como a Tigre enxerga a inovação, tratada como estratégia de crescimento, tendo como bandeira “Inovar, fazer acontecer e acreditar que é possível”. Em relação ao processo de GDP, hoje já possui uma estrutura de desenvolvimento madura e, por essa razão, há mais investimento na etapa de captação de idéias. Esse é um ponto chave na Tigre.

Antes, a empresa deixava que as idéias chegassem; hoje, ao contrário, as idéias são buscadas, procuradas nas mais diversas fontes. A forma mais recente que se adotou foi a técnica da observação in loco, onde o pessoal da área de desenvolvimento se insere na casa dos consumidores da Tigre para conhecer suas necessidades reais. A questão é que o processo de captação deixou de ser reativo, não se pensa somente na complementação da linha, ao contrário, buscam-se informações, hoje são proativos. E afirma-se que com o aumento na eficácia da captação da oportunidade, aumentará o sucesso de seus projetos. 
Outro ponto que deve ser levantado, em relação a essa fase de Estratégia e Planejamento do Produto, é a forma que a alta administração avalia as idéias, lançando mão de critérios quali e quantitativos, são eles: margem de contribuição, tempo de retorno do investimento, potenciais estratégicos, grau de complexidade e inovação. A Tigre, no momento da aprovação do projeto, dá uma atenção especial ao seu potencial estratégico, pois, muitas vezes, apesar do tempo de retorno do investimento ser maior e do projeto não ser inovador, é essencial para um outro projeto, que tem grande relevância nesses critérios.

Todos os novos produtos da Tigre entram em “quarentena” na Assistência Técnica assim que lançados. Isso significa que qualquer reclamação de campo que aconteça durante os primeiros três meses do produto no mercado será atendida pelo próprio engenheiro da assistência técnica interna da Tigre. Além disso, a empresa possui um profissional treinado e capacitado em cada cidade, a fim de solucionar problemas que porventura aconteçam. Tem um universo em média de 100 pessoas que fazem esse pós. Então, nos casos de lançamentos de produtos novos, a Tigre faz questão de que o engenheiro vá ao local pessoalmente.

Uma coisa que a empresa percebeu foi a importância dessa etapa acontecer antes da formação do estoque, pois caso sejam necessários ajustes, estes serão feitos, sem grandes prejuízos. Essa é a forma que a Tigre encontrou para fazer melhorias nos seus produtos, logo após seu lançamento. Outros aprendizados são utilizados em produtos futuros, podendo ser a evolução para uma nova linha.

A fim de controlar seus projetos acabados, a Tigre utiliza três indicadores de desempenho: faturamento com novos produtos e o tempo para lançá-lo, ambos citados por Clark e Wheelwright (1993), e o último é a taxa de sucesso dos lançamentos, para que conheçam, cada vez mais, seus acertos.

No que se refere às etapas de desenvolvimento do projeto, há um grande alinhamento com a literatura estudada, visto que as decisões referentes a cada etapa coincidem, quase que por completo, com o processo de GDP da Tigre.

Caso seja necessário algum replanejamento do projeto, a Tigre possui uma estrutura bem formalizada. É na etapa de desenvolvimento do produto que devem ser identificadas necessidades de reestruturação e, caso isso aconteça, dependendo do grau de modificação, 
retornará para o P1, ou será modificado e dado continuidade. Só retorna para o início quando o impacto no prazo ou no investimento for muito grande. 


\section{APRESENTAÇÃo COMPARADA dos RESUltados}

A apresentação comparada dos resultados obtidos com a presente pesquisa será dividida em quatro itens, na seguinte ordem: histórico, tipo de produto, segmentação do mercado, e a gestão do desenvolvimento de produtos, que por sua vez, se subdivide em estratégia e planejamento do produto, organização do desenvolvimento do produto, gerenciamento do produto, e etapas do processo de GDP.

A partir do Quadro 48 podem-se observar características das quatro empresas fundamentais para realizar uma comparação entre elas.

\begin{tabular}{|c|c|c|c|c|}
\hline & Dorfle & Deca & Cocrica & Tirno \\
\hline $\begin{array}{l}\text { Seguidora ou } \\
\text { Líder }\end{array}$ & Seguidora & Líder & Líder & Líder \\
\hline $\begin{array}{l}\text { Orientação de } \\
\text { mercado }\end{array}$ & B2C & B2C & B2C & $\mathrm{B} 2 \mathrm{~B} / \mathrm{B} 2 \mathrm{C}$ \\
\hline $\begin{array}{c}\text { Tempo no } \\
\text { mercado (ano) }\end{array}$ & 29 & 61 & $\begin{array}{c}68 \\
\text { (aproximadamente) }\end{array}$ & 67 \\
\hline $\begin{array}{l}\text { Número de } \\
\text { funcionários }\end{array}$ & 250 & 3.000 & 2.199 & 5.200 \\
\hline $\begin{array}{c}\text { Número de } \\
\text { funcionários } \\
\text { P\&D }\end{array}$ & 7 & 60 & 21 & 100 \\
\hline $\begin{array}{l}\text { Número de } \\
\text { produtos }\end{array}$ & 630 & 6.200 & $\begin{array}{c}73 \text { coleções }+1.200 \\
\text { acessórios }\end{array}$ & 6.000 \\
\hline $\begin{array}{l}\text { Lançamentos } \\
\text { anuais }\end{array}$ & 50 & $\begin{array}{c}90 \\
\text { (em 2007) }\end{array}$ & 272 & $\begin{array}{c}279 \\
\text { (em 2005) }\end{array}$ \\
\hline
\end{tabular}

\subsection{Histórico comparado das empresas pesquisadas}

Todas as quatro empresas têm a inovação como fator fundamental para seu crescimento e manutenção no mercado, porém em diferente grau. A Perflex é uma empresa mais nova, de 1979, e bem menor que as outras três, mas possui uma estrutura organizada, porém informal, que funciona de forma efetiva no desenvolvimento de novos materiais de construção. Por ser uma empresa seguidora, sua inovação constitui-se de produtos novos para a empresa, não para o mercado. 
O caso da Deca se assemelha mais com as outras empresas, Cecrisa e Tigre, mais antigas, líderes de mercado e bastante sedimentadas nas suas áreas de atuação. A Deca demonstrou em sua história, até os dias atuais, que a procura pelo diferencial faz parte de sua política, através da aquisição de novas plantas, de tecnologia, de recursos em geral. Possui os mais diversos concorrentes, devido a sua vasta e diversificada linha de produtos.

A Cecrisa também indica em sua história a forte preocupação em inovar e, além disso, ser pioneira seja no uso de uma nova tecnologia, ou da oferta de um novo produto. Isso é alcançado por meio de sua intenção estratégica, que diz que deve procurar agregar permanentemente valor aos seus clientes, usar a inovação como vantagem competitiva e desenvolver seus profissionais.

E, por fim, a Tigre, que reativou sua área de desenvolvimento e tomou a inovação como estratégia principal da empresa, proporcionada pelas diversas pesquisas e estudos realizados. Recentemente, a empresa passou por uma reestruturação que lhe proporcionou melhoria na comunicação e maior agilidade no desenvolvimento de novos produtos. A inovação é vista como valor, ou seja, com a inovação é possível se manter na liderança. Hoje, conforme os entrevistados, a meta de crescimento da empresa está pautada em três pilares: novos produtos, novos negócios e novos mercados. Isso é alcançado por meio da oferta de linhas completas de produtos, identificando e antecipando-se às necessidades do cliente.

\subsection{Tipo de produto das empresas pesquisadas}

Os produtos da Perflex são os metais sanitários, distribuídos em misturadores, torneiras, acessórios para banheiro, chuveiros, duchas manuais, duchas higiênicas, sifões, flexíveis, registros e válvulas. Com cerca de 630 itens compondo sua carteira, procura lançar, anualmente, 50 novos produtos, o que corresponde a duas linhas completas.

A Deca também produz metais sanitários, mas acrescenta a sua carteira de produtos as louças sanitárias. No entanto, para a presente pesquisa, levaram-se em consideração suas linhas de metais sanitários. Em 2007, lançou aproximadamente 90 novos produtos, alguns voltados para o segmento econômico, e outros compõem uma linha ecológica. Tem um portfólio de mais de 1.200 itens de louças sanitárias e mais de 5.000 itens de metais sanitários. 
A Cecrisa produz porcellanato, pisos, azulejos e revestimentos de fachadas, o que soma 73 coleções com mais 1.200 acessórios, ou peças especiais. Em 2007, foram lançadas 11 novas coleções, as quais contêm 272 produtos, distribuídos em de fundo e de acessórios. Conforme o diretor executivo da empresa (CECRISA, 2008), a Portinari consolidou, no ano de 2007, sua posição de liderança em inovação e design no setor cerâmico nacional.

Através de uma política de pesquisa e desenvolvimento centrada na oferta de soluções completas nos segmentos em que atua, a Tigre oferece uma linha extensa de produtos para a construção civil. Em 2005, foram lançados 279 novos produtos, ou, cerca de um a cada dia útil. Com seu portfólio de mais de seis mil itens, possui soluções integrais em: instalações prediais, infra-estrutura e irrigação.

\subsection{Segmentação do mercado}

A Perflex direciona seus produtos e pesquisas para o consumidor final (B2C), devido ao perfil do seu produto. O metal sanitário é um produto que não exige grandes recomendações técnicas para sua compra, caso em que o consumidor identifica a melhor opção para sua casa, por meio do design da peça. Por ter uma segmentação B2C, procura estabelecer uma relação mais próxima com o cliente com a finalidade de gerenciá-la e extrair oportunidades para sua carteira de produtos. O mesmo acontece com a Deca, que atua no mesmo setor industrial.

No caso da Cecrisa, apesar de ser outro tipo de produto, também está relacionado com a segmentação de mercado da Perflex e da Deca. Através dos produtos Cecrisa é possível perceber essa procura pela proximidade com o cliente, e uma das razões é a sua preocupação com o design.

A Tigre é a que se diferencia das outras empresas estudadas, pois seu direcionamento é para um consumidor intermediário (B2B). Nesse caso, no momento da compra, a especificação e a influência de um especialista contam muito. Por essa razão, a Tigre considera o projetista, o engenheiro, o arquiteto e o instalador como atores fundamentais para esse processo. Todavia, nos últimos quatro anos, tem desenvolvido práticas direcionadas também para o consumidor final (B2C). 


\subsection{Gestão do desenvolvimento de produtos}

O processo de GDP na Perflex é formalizado, porém não existe nenhum documento que descreva como isso deve acontecer. Apesar dessa falta de formalização, a empresa adquiriu com o tempo experiência, o que proporcionou a identificação de etapas básicas para o desenvolvimento de seus projetos, como pode ser observado no Quadro 49.

A Deca lança mão da engenharia simultânea e dos times multifuncionais para desenvolver seus novos produtos. A empresa relata que com a aplicação desses conceitos foi possível diminuir o tempo de desenvolvimento de três anos para um tempo médio de oito a dez meses e também reduzir o índice de abortamento de projetos inacabados.

Na Cecrisa a estrutura de desenvolvimento existe há mais de 20 anos, evoluindo sempre na procura por novas técnicas e novas formas de desenvolver as suas coleções. Recentemente, em 2002, foram contratados consultores internacionais em design, com a finalidade de agregar conhecimento e informações para as etapas inicias do processo.

Em 2002, a área de desenvolvimento da Tigre foi reativada, acompanhada de novos conceitos, de uma nova estrutura e de novos desafios. Como cada uma das empresas estudadas possui etapas diferentes, é importante posicioná-las, conforme as etapas de Krishnan e Ulrich (2001), para auxiliar a apresentação e, posterior análise das informações (Quadro 49).

Quadro 49 - Etapas de Krishnan e Ulrich (2001) versus etapas das empresas pesquisadas

\begin{tabular}{|c|c|c|c|c|}
\hline \multicolumn{5}{|c|}{ ETAPAS } \\
\hline $\begin{array}{l}\text { Krishnan e } \\
\text { Ulrich (2001) }\end{array}$ & Perflex & Deca & Cecrisa & Tigre \\
\hline $\begin{array}{l}\text { Pré- } \\
\text { desenvolvimento }\end{array}$ & $\begin{array}{l}\text { Identificação de } \\
\text { Oportunidades e } \\
\text { Seleção das Idéias } \\
\text { Planejamento do } \\
\text { Produto }\end{array}$ & $\begin{array}{l}\text { Identificação de } \\
\text { Oportunidades e } \\
\text { Seleção das Idéias }\end{array}$ & $\begin{array}{l}\text { Levantamento e } \\
\text { Seleção de Idéias }\end{array}$ & $\begin{array}{l}\text { Identificação de } \\
\text { Oportunidades }\end{array}$ \\
\hline $\begin{array}{l}\text { Desenvolvimento } \\
\text { do Conceito }\end{array}$ & $\begin{array}{l}\text { Desenvolvimento } \\
\text { do Conceito }\end{array}$ & $\begin{array}{l}\text { Desenvolvimento } \\
\text { do Conceito } \\
\text { Planejamento do } \\
\text { Produto }\end{array}$ & $\begin{array}{l}\text { Elaboração do } \\
\text { Anteprojeto }\end{array}$ & $\begin{array}{l}\text { Desenvolvimento: } \\
\text { Projeto Conceitual }\end{array}$ \\
\hline $\begin{array}{l}\text { Projeto da Cadeia } \\
\text { de Suprimentos }\end{array}$ & \multirow{2}{*}{$\begin{array}{l}\text { Engenharia do } \\
\text { Produto e do } \\
\text { Processo de } \\
\text { Produção }\end{array}$} & \multirow{2}{*}{$\begin{array}{l}\text { Engenharia do } \\
\text { Produto }\end{array}$} & \multirow{2}{*}{$\begin{array}{l}\text { Desenvolvimento } \\
\text { do Produto e Mix } \\
\text { Promocional }\end{array}$} & $\begin{array}{l}\text { Desenvolvimento: } \\
\text { Projeto Preliminar }\end{array}$ \\
\hline Projeto do Produto & & & & $\begin{array}{l}\text { Desenvolvimento: } \\
\text { Projeto Detalhado }\end{array}$ \\
\hline Teste e Validação & Avaliação do & Engenharia do & Realização de & Try-out \\
\hline
\end{tabular}




\begin{tabular}{|c|c|c|c|c|}
\hline de Desempenho & Projeto & Processo & $\begin{array}{l}\text { Semi-industriais e } \\
\text { Confeç̧ão de } \\
\text { Material } \\
\text { Promocional } \\
\end{array}$ & \\
\hline $\begin{array}{l}\text { Ramp-up e } \\
\text { Lançamento }\end{array}$ & $\begin{array}{l}\text { Lançamento e } \\
\text { Ramp-up }\end{array}$ & $\begin{array}{l}\text { Lançamento e } \\
\text { Ramp-up }\end{array}$ & $\begin{array}{l}\text { Lançamento das } \\
\text { Coleções }\end{array}$ & Lançamento \\
\hline $\begin{array}{l}\text { Pós- } \\
\text { desenvolvimento }\end{array}$ & & & $\begin{array}{ll}\text { Verificação da } \\
\text { Eficácia do } \\
\text { Lançamento } \\
\text { Acompanhamento } \\
\text { dos Resultados } \\
\text { Comerciais }\end{array}$ & \\
\hline
\end{tabular}

\subsubsection{Conceito da GDP}

A literatura afirma que GDP vai desde a identificação de oportunidades até sua transformação em um produto disponível no mercado (KAMINSKI, 2000; KRISHNAN; ULRICH, 2001; BROWN; EISENHARDT, 1995; CLARK; WHEELWRIGHT, 1993; AMARAL et al, 2006). Sendo que, conforme Krishnan e Ulrich (2001), existem quatro diferentes perspectivas nas áreas de projeto e desenvolvimento: marketing, organizações, engenharia e administração da produção. Cada empresa está mais alinhada com uma ou outra perspectiva.

Conforme o Gerente Industrial da Perflex, é preciso primeiro criar um conceito, reproduzi-lo em caráter de projeto e, por fim, materializar esse desejo, sempre munido de protótipos e testes no mercado para que se tenha a certeza de que as expectativas de seus consumidores foram atendidas ou mesmo superadas. Um dos supervisores de engenharia complementa que faz parte também do processo de desenvolvimento de produtos o seu lançamento no mercado, sendo que a área responsável por essa etapa é a área comercial, representada no time pelo Diretor da Perflex.

A Perflex possui uma perspectiva mais de marketing, pois considera seu produto como um conjunto de atributos, e uma de suas métricas de desempenho é se o produto está adequado ao mercado, e ainda, se o desenvolvimento é feito com a participação do mercado. No entanto, também possui métricas de desempenho que se referem à perspectiva da administração da produção, como custo total do projeto, e utilização da capacidade produtiva.

A Deca também afirma que seu processo de GDP inicia com a identificação de uma oportunidade de mercado, seja ela uma inovação ou apenas uma melhoria contínua, até a sua transformação em um produto final e sua colocação no mercado. A Deca enxerga seu produto 
como um conjunto de atributos, e tem como paradigma a utilidade para o cliente como uma função dos atributos do produto, ambas características da perspectiva de marketing. No entanto, a Deca também enxerga o produto como uma seqüência de desenvolvimento, referente à perspectiva da administração da produção. As métricas de desempenho da Deca são: adequação ao mercado, utilidade para o consumidor, desempenho técnico, capacidade de inovar, custo total, o que mescla conhecimentos da perspectiva de marketing, engenharia de projeto e administração da produção. Contudo, dentre estas áreas a que se destaca na Deca é a de marketing.

A Cecrisa entende que a GDP vai desde a identificação do que o mercado quer ou nem mesmo pensou em ter, criando o desejo de comprar um produto, por estar na moda, tendo o design como fator determinante na decisão de compra. Porém, não se esquece da tecnologia, seja a partir de uma matéria-prima diferente, ou da aplicação de uma tecnologia já existente e utilizada pela empresa de uma maneira diversa, ou ainda uma tecnologia que esteja em alta no mercado. Assim, transforma todas essas informações em um conjunto que faça sentido, podendo a partir daí gerar idéias para produtos futuros.

Pode-se observar que o produto na Cecrisa é visto como um conjunto de atributos, o que está sob a perspectiva de marketing. Duas métricas usadas são a avaliação do desempenho técnico do produto e a capacidade de inovar, referindo-se à área de engenharia do projeto. A seleção de material e fornecedores e a administração do projeto são fatores críticos de sucesso na Cecrisa, características da perspectiva da administração da produção.

A GDP na Tigre está muito relacionada com a perspectiva da administração da produção, pois enxerga o produto como uma seqüência de desenvolvimento. Suas métricas de desempenho são eficiência, tempo de desenvolvimento, utilização da capacidade produtiva e custo total. Algumas variáveis de decisão são seqüência e cronograma do processo de desenvolvimento, e ponto de diferenciação no processo de produção. E conta ainda com a seleção de material e fornecedores e a administração do projeto como fatores críticos de sucesso. No entanto, também enxerga seu produto como um conjunto de atributos, tendo como métricas a adequação ao mercado, a participação de mercado e a utilidade do produto para o consumidor. E um fator crítico de sucesso, que atualmente tem sido bastante explorado para seu aperfeiçoamento, é na coleta e no entendimento das necessidades dos clientes, que são características da perspectiva de marketing. 


\subsubsection{Estratégia e planejamento do produto}

No que diz respeito às atividades realizadas na definição da estratégia e planejamento do produto, as quatro empresas apresentam características similares e distintas, como será apresentado a seguir. Esta indica que as metas e objetivos de desenvolvimento devem ser traçados a partir das previsões tecnológicas e de mercado, para que com isso possa ser elaborado o plano agregado de projetos. Clark e Wheelwright (1993) indicam ainda que durante todo esse processo, os projetos devem ser alterados, de acordo com as modificações que acontecerem na estratégia tecnológica e de mercado da empresa.

Primeiramente, será feita uma análise no que se refere à estratégia de mercado e tecnológica de cada uma das empresas.

Na Perflex, cada área elabora seu planejamento anual baseado na estratégia de alinhamento com as novidades do mercado, sendo bimestralmente revisado. No entanto, não possui uma estratégia de mercado e uma tecnológica formal, definindo seus objetivos de desenvolvimento a partir da estratégia da empresa e das informações do mercado, obtidas pelo Diretor através de tendências e moda do setor, observadas nas feiras e eventos e na análise dos projetos anteriores da empresa.

No caso da Deca, são feitas as previsões tecnológicas e de mercado, conforme estratégia geral da empresa. Na estratégia de mercado são indicadas características das oportunidades identificadas, como funcionalidade, segmento, cvi (custo variável individual) meta, se é uma inovação radical ou incremental, sempre dando um realce à inovação que está sendo feita. Essas oportunidades são identificadas pelas áreas de marketing e assistência técnica, como também pela área de $P \& D$. A estratégia tecnológica é traçada com base na estratégia de mercado, indicando a tecnologia que será necessária, e a que dará vantagem competitiva.

Os inputs de desenvolvimento da Cecrisa são: inovação própria por criação de nossos profissionais; inovação com inspiração em setores afins que estão mais "perto” da moda tecidos, móveis, eletrodomésticos; inovação que vem de novas tecnologias de matériasprimas; inovações que vêm de novas tecnologias de equipamentos; e o desenvolvimento reativo - reinterpretar o sucesso da grande concorrência internacional. Todas as 
oportunidades identificadas são compiladas na estratégia de mercado e tecnológica da empresa, para que assim sejam definidos os objetivos de desenvolvimento. A estratégia de mercado contém informações sobre os produtos que serão ofertados, público-alvo e forma que serão disponibilizados; e define número, tempo e relações de produtos diferenciados. Com isso em mãos, traça-se a estratégia tecnológica, a qual indica a tecnologia necessária e a que dará vantagem competitiva para a empresa, e ainda a fonte externa e interna da tecnologia.

No caso da Tigre, as estratégias de mercado e tecnológica são elaboradas com base em informações coletadas das mais diversas fontes. A empresa passou bastante tempo desenvolvendo novos produtos pensando na complementação de suas linhas, o que fez com que hoje tenha o maior portfólio de produtos nos três negócios em que atua. Atualmente, deixou de trabalhar orientada a produto, para trabalhar orientada a mercado. Com isso, ampliou o seu programa de relacionamento com seus clientes e consumidores finais, e passou a fazer observações in loco, ou seja, vai até a casa de seus consumidores para conhecer suas reais necessidades.

No que se refere ao plano agregado de projetos, a Perflex avalia todas as suas idéias com base nos recursos disponíveis na empresa, e no tempo de início de conclusão do projeto, para que assim sejam selecionados os três projetos que serão desenvolvidos no ano, compostos, cada um deles, por 20 a 30 produtos. Não há na composição do portfólio de produtos que serão ofertados, grandes inovações. Isso se deve à deficiência na identificação de oportunidades, à ausência de uma área de P\&D e por ser uma empresa seguidora. Seu portfólio é formado, geralmente, por projetos topológicos, com mudanças indicadas pela área de vendas e industrial, como também para ajustes ao estilo de vida do segmento que se direciona; e por projetos de melhoria contínua. Vale ressaltar que essas inovações são novidades para o portfólio de produtos da empresa, mas não para o mercado.

Para definição da carteira de novos produtos, a área de marketing da Deca procura mesclar projetos de inovação e melhoria contínua, baseando-se nos anos anteriores, nas previsões e estratégia da empresa. É composto por projetos derivativos, dividindo-se entre topológicos e incrementais; e de inovação. As mudanças topológicas são alimentadas tanto por informações provenientes das áreas de marketing e vendas, como também de adaptações ao modo de vida de seus consumidores. As incrementais são modificações na parte técnica do produto. Seus 
projetos de inovação são compostos por inovações desenvolvidas internamente pelo pessoal da área do laboratório, como também da aquisição de novas máquinas e equipamentos. Para a definição dos projetos, levam-se em consideração os recursos necessários e por quanto tempo serão utilizados.

A definição dos projetos na Cecrisa passa por dois momentos de seleção. Primeiro, todas as idéias são apresentadas e discutidas em uma reunião composta pelos consultores, gerentes de produto e marketing estratégico, pelo pessoal da área de marketing e da área de desenvolvimento de produtos, e pelo controller. Dessa reunião são selecionadas dez idéias, que serão apresentadas para a diretoria, e onde será definido o portfólio de novos produtos. É a partir do cronograma dos projetos, dos recursos disponíveis, do grau de inovação e do retorno financeiro que eles serão selecionados e priorizados. A maioria de suas melhorias incrementais são topológicas, baseadas em suas duas fontes de informações, mercado e estilo de vida do consumidor. No entanto, há também uma forte presença de projetos radicais, desenvolvidos tanto internamente, como obtidos por meio da aquisição de novas máquinas e equipamentos.

O resultado do processo de identificação de idéias na Tigre é, cerca de, 80 projetos, dos quais, após a avaliação feita pela diretoria, sobram pouco mais da metade. Para esse fim, a Tigre anlisa os dados financeiros, os recursos necessários para os projetos, e o tempo de desenvolvimento. No que diz respeito à ordenação dos projetos, utiliza dados qualitativos e quantitativos, margem de contribuição, tempo de retorno do investimento, potenciais estratégicos, grau de complexidade e inovação. Seus projetos caracterizam-se como incrementais, topológicos e radicais. As incrementais são mudanças técnicas, resultantes de algum ajuste, solicitação do cliente, facilidade de manuseio. As topológicas caracterizam-se como modificações realizadas nos produtos para adequação a diferentes tipos de clientes, o que ocorre com certa freqüência na Tigre. E as radicais são provenientes de pesquisas internas ou da aquisição de novas máquinas e equipamentos.

No que se refere aos aprendizados e melhorias para projetos futuros, a Perflex procura melhorar as capacidades envolvidas no processo e o próprio processo em si, por meio do preenchimento de fichas de avaliação do projeto, elaboradas por cada área envolvida no seu desenvolvimento. Além disso, a área de marketing se encarrega de coletar informações com 
os representantes comerciais e lojas para serem identificadas necessidades de alguma modificação na linha, coletando informações sobre aceitação do produto e volume de vendas.

Na Deca e na Cecrisa tudo é feito informalmente, não existe um documento ou uma estrutura fixa e formal para identificação e registro dos aprendizados e melhorias para os próximos projetos, somente os documentos que registram problemas técnicos nos produtos que já estão no mercado, gerando assim a necessidade do desenvolvimento de novos projetos. As empresas também fazem melhorias constantes no processo e nas capacidades envolvidas.

A Tigre por sua vez possui uma estrutura diferenciada, no sentido de que o produto entra em “quarentena” na Assistência Técnica logo após o seu lançamento. Com isso, todas as reclamações serão atendidas de imediato e as modificações serão logo feitas nos próximos produtos a serem produzidos. Por essa razão, a Tigre não forma estoque antes dessa fase de “teste” do produto no mercado. Outros aprendizados posteriores são utilizados em produtos futuros, podendo ser a evolução do produto para uma nova linha.

No Quadro 50 é apresentada, de forma resumida, as decisões tomadas pelas quatro empresas pesquisadas na fase de Estratégia e Planejamento do Produto.

Quadro 50 - Decisões Perflex, Deca, Cecrisa e Tigre - estratégia e planejamento do produto

\begin{tabular}{|c|c|c|c|}
\hline Decisões Perflex & Decisões Deca & Decisões Cecrisa & Decisões Tigre \\
\hline $\begin{array}{l}\text { - Estratégia de Mercado } \\
\text { - produtos que serão } \\
\text { ofertados, público-alvo. } \\
\text { - Estratégia Tecnológica } \\
\text { - tecnologia necessária; } \\
\text { tecnologia que dê } \\
\text { vantagem competitiva; } \\
\text { tempo para capacitação. } \\
\text { - Plano Agregado de } \\
\text { Projetos - define } \\
\text { prioridades; escolha do } \\
\text { projeto e definição de } \\
\text { quando começam e } \\
\text { terminam; recursos } \\
\text { disponíveis. } \\
\text { - Aprendizados e } \\
\text { melhorias para projetos } \\
\text { futuros - melhoria das } \\
\text { capacidades envolvidas } \\
\text { no processo e o próprio } \\
\text { processo em si. }\end{array}$ & $\begin{array}{l}\text { - Estratégia de Mercado } \\
\text { - produtos que serão } \\
\text { ofertados; público-alvo. } \\
\text { - Estratégia Tecnológica } \\
\text { - tecnologia necessária; } \\
\text { tecnologia que dê } \\
\text { vantagem competitiva. } \\
\text { - Plano Agregado de } \\
\text { Projetos - prioridades; } \\
\text { escolha do projeto e } \\
\text { definição de quando } \\
\text { começam e terminam; } \\
\text { recursos disponíveis. } \\
\text { - Aprendizados e } \\
\text { melhorias para projetos } \\
\text { futuros - melhoria das } \\
\text { capacidades envolvidas } \\
\text { no processo e do próprio } \\
\text { processo em si. }\end{array}$ & $\begin{array}{l}\text { - Estratégia de Mercado } \\
\text { - produtos que serão } \\
\text { ofertados, público-alvo e } \\
\text { forma que serão } \\
\text { disponibilizados; define } \\
\text { número, tempo, } \\
\text { freqüência e relações de } \\
\text { produtos diferenciados. } \\
\text { - Estratégia Tecnológica } \\
\text { - tecnologia necessária; } \\
\text { tecnologia que dê } \\
\text { vantagem competitiva; } \\
\text { fonte externa e interna. } \\
\text { - Plano Agregado de } \\
\text { Projetos - prioridades; } \\
\text { escolha do projeto e } \\
\text { definição de quando } \\
\text { começam e terminam; } \\
\text { recursos disponíveis. } \\
\text { - Aprendizados e } \\
\text { melhorias para projetos } \\
\text { futuros - melhoria das } \\
\text { capacidades envolvidas } \\
\text { no processo e do próprio }\end{array}$ & $\begin{array}{l}\text { - Estratégia de Mercado } \\
\text { - produtos que serão } \\
\text { ofertados, público-alvo e } \\
\text { forma que serão } \\
\text { disponibilizados; define } \\
\text { número, tempo, } \\
\text { freqüência e relações de } \\
\text { produtos diferenciados. } \\
\text { - Estratégia Tecnológica } \\
\text { - tecnologia necessária; } \\
\text { tecnologia que dê } \\
\text { vantagem competitiva; } \\
\text { fonte externa e interna; } \\
\text { tempo para capacitação; } \\
\text { maturação da tecnologia. } \\
\text { - Plano Agregado de } \\
\text { Projetos - prioridades; } \\
\text { escolha do projeto e } \\
\text { definição de quando } \\
\text { começam e terminam; } \\
\text { recursos disponíveis. } \\
\text { - Aprendizados e } \\
\text { melhorias para projetos } \\
\text { futuros - melhoria das }\end{array}$ \\
\hline
\end{tabular}




\begin{tabular}{|l|l|l|l|}
\hline & processo em si. & $\begin{array}{l}\text { capacidades envolvidas } \\
\text { no processo e do próprio } \\
\text { processo em si. }\end{array}$ \\
\hline
\end{tabular}

\subsubsection{Organização do desenvolvimento do produto}

Nesse item será analisado como está o sistema social e o ambiente necessário para o desenvolvimento de um projeto. Primeiro, questiona-se sobre a composição do time de desenvolvimento e as áreas envolvidas no processo. De acordo com Rozenfeld et al (2006, p. 49) o time pode ser formado por membros da diretoria, gerente funcional, responsável pela engenharia, gerente de projetos, especialistas e parceiros. As áreas que podem mesclar seus conhecimentos para o desenvolvimento de um produto são: marketing, vendas, tecnologia, produção e finanças (COOPER et al, 2002b), dentre outras.

Na Perflex, o time multifuncional é composto pelo diretor, gerente industrial, arquiteta, supervisor de engenharia, tecnólogo e projetista. As áreas envolvidas são marketing, vendas, tecnologia, produção e finanças. Na Deca o time também é multifuncional, com a participação da designer, engenheiro, projetista e planejamento, assim como todas as áreas necessárias para o desenvolvimento do projeto: marketing, vendas, tecnologia, produção, finanças e qualquer outra área que julgar necessária.

O time de desenvolvimento na Cecrisa é composto pelas seguintes funções: controller; consultor italiano; consultora em moda e design; consultora em cerâmica; gerente de desenvolvimento do produto; gerente de produtos e marketing estratégico; e área de design. Sob responsabilidade de cada uma das funções citadas existem pessoas que auxiliam em todo o processo, da produção, engenharia, laboratório, marketing estratégico e trade-marketing e finanças.

No caso da Tigre, sua equipe multidisciplinar tem como piso de formação o nível técnico. O time é formado por membros da diretoria, gerente de produto e gerente de P\&D, projetista, e especialistas das áreas de engenharia, produção, laboratório, marketing, finanças e logística, que, no entanto, não participarão de todo o processo, mas serão chamados quando necessário.

Em relação à estrutura de desenvolvimento, pode ser individual ou em grupo; formal ou informal. E ainda há uma classificação, conforme Clark e Wheelwright (1993), da estrutura 
associada ao papel da liderança. Na Perflex, a estrutura é formal e o time trabalha em grupo, mas durante o desenvolvimento de um projeto, não existe uma área própria para o time. Cada componente fica alocado em sua área de trabalho. O gerente do projeto, supervisor de engenharia, tem poder limitado e encontra-se em um nível médio da empresa, atua mais como um supervisor do projeto. Além do fato de ter o diretor da empresa presente constantemente no processo, tomando ele próprio as decisões. Nenhuma das classificações da estrutura associada ao papel da liderança se ajustam à Perflex.

A estrutura do time na Deca é formal e em grupo. Em relação à estrutura associada ao papel da liderança, nenhuma das opções serve para classificar a gerência da Deca. Primeiro sua estrutura é funcional, o gerente do projeto é de nível médio, com pouca influência na organização, e todo o projeto será acompanhado de perto pela alta administração, com sua participação em todas as decisões. Essas classificações não parecem adequar-se, pois são empresas relativamente pequenas se comparadas às empresas utilizadas na pesquisa de Clark e Wheelwirght (1993), onde as distâncias hierárquicas são enormes.

Na Cecrisa, a estrutura do time também é formal e em grupo, porém, sua estrutura associada ao papel da liderança é diferente. Dentro da classificação de Clark e Wheelwright (1993) e de Rozenfeld et al (2006), a Cecrisa não se encaixa em nenhuma das estruturas. Na empresa designaram uma função para controlar e servir como elo entre os projetos e a alta administração, o controller, que tem acesso direto e responsabilidade pelo trabalho de todos os envolvidos no projeto. Também responde por todos os projetos que estão em andamento na empresa, de modo que está no mesmo nível do Gerente de Desenvolvimento de Produtos e tem pouca influência na organização.

A Tigre possui uma estrutura formal e em grupo, e, associada ao papel da liderança, pode ser classificada em estrutura do time "peso leve”. Isso se deve ao fato do gerente do projeto se encontrar em um nível médio dentro da empresa, com pouca influência na organização. Porém, o Gerente de $P \& D$ da Tigre afirma que, nem mesmo ele tem poder de decisão de investimento, pois todas as decisões devem ser aprovadas pela alta administração. Nisso, a Tigre diverge dos conceitos da estrutura do time “peso leve”. Outra característica que vai de acordo com a estrutura desse time, é que as pessoas que o compõem encontram-se alocadas em suas áreas específicas, não há uma área própria para cada projeto. 
Embora a Tigre tenha algumas características da estrutura do time "peso leve”, esta parece um pouco errada quando se pensa nas empresas utilizadas na pesquisa de Clark e Wheelwright (1993), onde as distâncias hierárquicas eram incomensuráveis, tendo as reuniões como os únicos momentos para discutirem os projetos, as quais aconteciam muito raramente, o que não é o caso da Tigre.

É nesse momento também que a literatura indica que as empresas podem definir possíveis investimentos em infra-estrutura, ferramentas e treinamento. Em todas as empresas é feito um esboço do que pode ser necessário para os projetos. Na Cecrisa e na Tigre consegue-se especificar um pouco mais essas informações, devido ao grau de detalhamento que é feito na identificação de oportunidades.

Deve-se procurar definir também o tipo de processo de desenvolvimento que será empregado. As empresas estudadas possuem um processo de GDP único e, por essa razão, nada é definido nessa etapa sobre o tipo do processo. Na Perflex, o processo de desenvolvimento traz conceitos da abordagem tradicional de desenvolvimento, que, conforme Clark e Wheelwright (1993), ocorre de forma seqüencial; e do stage-gate, que se apresenta na parada após cada etapa para análise dos resultados e aprovação, pela alta administração, para início da etapa seguinte. O funil de Clark e Wheelwright (1993) não é utilizado na empresa, pois o processo ocorre similar a um tubo, no qual entra um produto identificado no mercado como de grande potencial, que será aperfeiçoado, produzido e lançado.

O processo de desenvolvimento na Deca ocorre similar ao stage-gate, tendo os protótipos como portões de passagem para o estágio seguinte, utilizando conceitos da engenharia simultânea. A designer indica que com a estrutura atual foi possível a definição de metas e objetivos de desenvolvimento mais desafiadores. Essa estrutura é utilizada tanto quando a idéia é gerada pelo marketing da empresa, como quando partir da área de P\&D. A estrutura também será a mesma para o desenvolvimento de produtos de exportação, em que muitas vezes apenas se fazem ajustes em produtos desenvolvidos para o mercado brasileiro, sendo apenas uma inovação incremental.

O processo de desenvolvimento dos projetos de inovação ocorre similar a um túnel e não a um funil, pois eles inserem uma idéia e trabalham em cima dela para gerar um produto 
inovador. Nos outros casos, de melhorias contínuas, já se tem um produto, o qual é aperfeiçoado e modificado.

O processo de desenvolvimento da Cecrisa engloba conceitos da engenharia simultânea e stage-gate. A engenharia simultânea está presente, por exemplo, na etapa de Elaboração do Anteprojeto, quando paralelamente ao desenvolvimento do conceito do produto inicia-se a geração das primeiras idéias do mix promocional da nova coleção. Lança-se mão do funil de desenvolvimento de Clark e Wheelwright (1993), com a finalidade de gerar um produto a partir de várias idéias, provenientes de diferentes fontes, o que corresponde ao segundo modelo. E o stage-gate refere-se aos momentos em que o projeto é avaliado pela alta administração, a fim de aprová-lo para a etapa seguinte.

Inicialmente a Tigre começou utilizando conceitos de como gerir o desenvolvimento de novos produtos através da International Organization for Standardization - ISO. Atualmente está alinhada com o Project Management Body of Knowledge - PmBok. Utiliza conceitos de GDP bastante atuais, como equipe multidisciplinar, engenharia simultânea, o funil de desenvolvimento de Clark e Wheelwright (1993) e o stage-gate de Cooper et al (2002b), que são representados pelos portões de avaliação da alta gerência para aprovação ou exclusão do projeto. No caso do funil de desenvolvimento, a Tigre trabalha com o modelo chamado “inovador e focado”, e sua maior característica é a expansão ao máximo da "boca” do funil, o que é feito com a estruturação cada vez maior da etapa de identificação de oportunidades. E em relação ao processo do stage-gate, a Tigre vale-se do modelo que é utilizado para empresas maiores, que tem projetos de alto risco, conforme Ilustração 7.

Quadro 51 - Decisões Perflex, Deca, Cecrisa e Tigre - organização do desenvolvimento do produto

\begin{tabular}{|l|l|l|l|}
\hline \multicolumn{1}{|c|}{ Decisões Perflex } & \multicolumn{1}{c|}{ Decisões Deca } & \multicolumn{1}{c|}{ Decisões Cecrisa } & \multicolumn{1}{c|}{ Decisões Tigre } \\
\hline - Time - diretor, gerente & - Time - membros da & - Time - membros da & - Time - membros da \\
funcional, responsável & diretoria, gerente & diretoria, gerente & diretoria, gerente \\
pela engenharia, & funcional, responsável & funcional, responsável & funcional, responsável \\
especialistas; áreas - & pela engenharia, gerente & pela engenharia, gerente & pela engenharia, gerente \\
marketing, vendas, & de projeto, especialistas. & de projeto, especialistas; & de projeto, especialistas; \\
tecnologia, produção e & Áreas - marketing, & áreas - marketing, & áreas - marketing, \\
finanças. & tecnologia, produção e & vendas, tecnologia, & vendas, tecnologia, \\
- Estrutura de & finanças. & produção e finanças. & produção e finanças. \\
desenvolvimento - em & - Estrutura de & - Estrutura de & - Estrutura de \\
grupo; formal. Arranjo & desenvolvimento - em & desenvolvimento - em & desenvolvimento - em \\
físico - cada um em seu & grupo; formal. Arranjo & grupo; formal. Arranjo & grupo; formal. Estruturas \\
setor. & físico - em área comum. & físico - em área comum. & associadas ao papel da \\
- Investimentos - infra- & - Investimentos - infra- & - Investimentos - infra- & liderança - peso leve. \\
estrutura, ferramentas e & estrutura, ferramentas e & estrutura, ferramentas e & Arranjo físico - em área \\
\hline
\end{tabular}




\begin{tabular}{|l|l|l|l|}
\hline $\begin{array}{l}\text { treinamento. } \\
\text { - Processo de } \\
\text { desenvolvimento - } \\
\text { abordagem tradicional } \\
\text { de desenvolvimento e } \\
\text { stage-gate. }\end{array}$ & $\begin{array}{l}\text { treinamento. } \\
\text { - Processo de } \\
\text { desenvolvimento - } \\
\text { engenharia simultânea e } \\
\text { stage-gate. }\end{array}$ & $\begin{array}{l}\text { treinamento. } \\
\text { - Processo de } \\
\text { desenvolvimento - } \\
\text { engenharia simultânea, } \\
\text { funil de } \\
\text { desenvolvimento e } \\
\text { stage-gate. }\end{array}$ & $\begin{array}{l}\text { comum. } \\
\text { - Investimentos - infra- } \\
\text { estrutura, ferramentas e } \\
\text { treinamento. } \\
\text { - Processo de } \\
\text { desenvolvimento - } \\
\text { engenharia simultânea, } \\
\text { funil de } \\
\text { desenvolvimento e } \\
\text { stage-gate. }\end{array}$ \\
\hline
\end{tabular}

\subsubsection{Gerenciamento do projeto}

As decisões que compõem a gestão do processo estão diretamente relacionadas com o tempo planejado, seqüência de desenvolvimento das atividades, os principais marcos e protótipos do projeto, os critérios de descarte de projetos, os mecanismos de comunicação entre os membros do time, a medição do desempenho e tudo o que estiver relacionado com o monitoramento e controle do projeto.

A empresa deve procurar definir quem irá monitorar e controlar o projeto. No caso da Perflex, ninguém tem total responsabilidade por todo o produto, sua gerência é feita pelo gerente industrial e controlado pelo supervisor de engenharia, contando ainda com a participação do diretor da empresa, o tomador de decisões, atuando ativamente em todo o processo. Na Deca e na Tigre quem monitora o projeto é o próprio projetista, responsável por fazer o design da nova linha de produtos. Essa é uma estratégia interessante que as duas empresas encontraram, pois os projetistas precisam estar presentes durante todo o desenvolvimento, já que o protótipo acompanha o projeto, nada mais certo do que eles controlarem-no.

Por seu turno, na Cecrisa existe uma função própria para controlar o projeto, o controller. Ele elabora o cronograma e faz com que seja cumprido. Responde para o gerente de produto e marketing estratégico, para o diretor de operações e para o gerente de desenvolvimento de produtos. É o representante dos times que estará em contato direto com a alta administração.

A prioridade de desenvolvimento de um produto, na Perflex, é definida pelo marketing que, por sua vez, se baseia nas necessidades do mercado e na percepção do diretor sobre o mercado consumidor. Na Deca, a priorização dos projetos de melhoria contínua é feita pela 
estimativa de retorno; e das inovações, pelo marketing, que avalia o mercado consumidor para saber se está pronto para receber a inovação.

Na Cecrisa, analisa-se o projeto em dois pólos: pelo grau de inovação e se é vendável. Em cada marco, o projeto será analisado, pela alta administração, com base nesses dois critérios. Dependendo do momento, será dado mais ênfase para um ou outro ponto.

Os critérios de seleção e priorização de projetos são essenciais para a definição de um portfólio de novos produtos bem-sucedidos. Por essa razão, as empresas devem procurar utilizar, além dos critérios quantitativos de mercado, os critérios qualitativos, caso da Tigre. Seus critérios proporcionam uma avaliação do tempo de retorno do investimento e da margem de contribuição, do potencial estratégico, do grau de complexidade e inovação. A importância do potencial estratégico se dá, pois a Tigre possui um projeto para cada produto e, quase sempre, vários projetos correspondem a uma só linha, sendo assim complementares e essenciais.

Outra decisão de gerenciamento é o tempo planejado para cada etapa do processo de desenvolvimento. Nas quatro empresas, os tempos de desenvolvimento são quase sempre o mesmo, com uma pequena variação de projetos de melhoria contínua para projetos radicais. É interessante notar que na Perflex, Deca e Cecrisa o tempo total de desenvolvimento é fixado de acordo com as feiras que expõem seus novos produtos durante o ano.

A definição dos marcos, protótipos e etapas do projeto, como também da comunicação formal entre os membros do time é detalhada no cronograma de cada empresa, servindo para seu monitoramento e controle. São, praticamente, sempre posicionados no mesmo lugar. As diferenças se dão de acordo com o tipo do projeto. No Quadro 49 são descritas as etapas e subetapas do processo de GDP da Perflex, da Deca, da Cecrisa e da Tigre, indicando também os marcos e protótipos do projeto, e os momentos em que são feitas as comunicações formais no processo.

Os marcos, nas quatro empresas estudadas, funcionam como paradas, onde será feita a aprovação, pela alta administração, do resultado da etapa. Aprovado, passa-se para a etapa seguinte, porém isso não quer dizer que o que foi decidido não poderá mais ser modificado, as mudanças podem ser feitas até em etapas finais do processo. 
Os protótipos, tanto na Perflex, na Deca, na Cecrisa e na Tigre, servem como meio de comunicação, e acompanham praticamente todo o processo de desenvolvimento. É interessante notar os momentos em que cada empresa faz o seu protótipo virtual, em algum outro material, e com a matéria-prima que será utilizada no produto final. O Quadro 52 apresenta os momentos de cada protótipo nas quatro empresas.

A Perflex não possui uma estrutura com critérios formais para descarte de projetos, isso poderá acontecer em qualquer momento do processo, desde que sejam explicadas, comprovadas e analisadas pela alta administração, as razões que motivam a sua descontinuação. Na Deca e na Cecrisa, caso o projeto não saia como o esperado, e não esteja adequado à estratégia da empresa, será abortado, independente da etapa em que este se encontre.

Na Tigre, os mesmos critérios usados para ordenamento dos projetos são utilizados com a finalidade de descarte. A empresa possui critérios quantitativos e qualitativos, são eles: margem de contribuição, tempo de retorno do investimento, potenciais estratégicos, grau de complexidade e inovação. Se os projetos não estiverem adequados aos critérios estabelecidos, serão abortados, sempre e somente sob avaliação da alta administração.

Outro ponto de decisão nessa fase é em relação à comunicação. As quatro empresas atuam da mesma forma, porém em diferente grau. Conforme Frishammar (2005), o time pode interagir e/ou colaborar entre si. Nas referidas empresas ocorrem as duas maneiras de forma equilibrada, já que existem as reuniões formais e as conversas informais sobre os projetos. E, por fim, de acordo com Clark e Wheelwright (1993), a comunicação pode se dar de duas maneiras, através de monólogo ou diálogo. Nas quatro empresas, se caracteriza como diálogo, e acontece nas fases iniciais do projeto.

Somente a Deca inicia a comunicação entre os envolvidos na segunda etapa do processo, que ainda é uma etapa inicial, mas não é a primeira, de desenvolvimento do conceito. O que, de acordo com ela, funciona perfeitamente, pois ao iniciar-se a interação dos componentes do time, já existe em mãos um protótipo do novo produto, direcionando as discussões e esclarecendo dúvidas. 
Vale ressaltar, que a comunicação nas empresas acontece formal e informalmente. Frishammar (2005) afirma que o nível de integração depende tanto do momento que o processo da GDP se encontra, quanto do tipo do produto. É o que acontece com as empresas estudadas. Nas etapas iniciais do processo há uma integração maior entre o marketing e a área de desenvolvimento de produtos da empresa. Já nas etapas finais a integração é maior com a produção. A análise da comunicação na Perflex, Deca, Cecrisa e Tigre, conforme os critérios de Clark e Wheelwright (1993), demonstra que ela é rica, realizada cara a cara, com a utilização de modelos gráficos, que facilitam a interação; é mais freqüente; ocorre nos dois sentidos, ou seja, na base do diálogo; e acontece desde as fases iniciais do projeto. O que não poderia ser diferente, já que tratam-se de empresas relativamente pequenas se comparadas às empresas pesquisadas por Clark e Wheelwright (1993).

Clark e Wheelwright (1993) e Clark e Fujimoto (1991) indicam quatro dimensões para avaliar o desempenho de projetos: tempo para colocar o produto no mercado, produtividade, qualidade do projeto e planejado versus o que efetivamente aconteceu. No caso da Perflex, o desempenho é medido por meio da qualidade do projeto e do planejado versus o que efetivamente aconteceu.

A Deca procura comparar o que ficou planejado no briefing e na ficha técnica com o que efetivamente aconteceu, porém não é uma atividade formalizada. Mede ainda a performance do produto no mercado, por meio da avaliação das metas de vendas estipuladas para cada vendedor. No caso da Cecrisa, além do acompanhamento dos resultados comerciais, é feita uma verificação da eficácia do lançamento, para se obter uma análise da qualidade do projeto e se o que foi planejado efetivamente aconteceu.

A Tigre vai um pouco além do que as outras empresas, pois mede o faturamento com produtos novos, o tempo para colocar o produto no mercado e a taxa de sucessos, com o auxílio do BSC. Analisa se o que foi planejado aconteceu, avaliando assim a qualidade do projeto.

Quadro 52 - Protótipo no processo de GDP das empresas pesquisadas

\begin{tabular}{|c|l|l|l|}
\hline Perflex & \multicolumn{1}{|c|}{ Deca } & \multicolumn{1}{c|}{ Cecrisa } & \multicolumn{1}{c|}{ Tigre } \\
\hline 1. Identificação de & 1. Identificação de & 1. Levantamento e & 1. Identificação de \\
\hline
\end{tabular}




\begin{tabular}{|c|c|c|c|}
\hline $\begin{array}{l}\text { Oportunidades e Seleção } \\
\text { das Idéias } \\
\text { 2. Planejamento do } \\
\text { Produto } \\
\text { 3. Desenvolvimento do } \\
\text { Conceito do Produto } \\
\text { Protótipo Virtual } \\
\text { 4. Engenharia do Produto } \\
\text { e do Processo de } \\
\text { Produção } \\
\text { Protótipo em Metal } \\
\text { Maciço } \\
\text { Produção Piloto } \\
\text { 5. Avaliação do Projeto } \\
\text { 6. Lançamento e Ramp- } \\
\text { up }\end{array}$ & $\begin{array}{l}\text { Oportunidades } \\
\text { 2. Desenvolvimento do } \\
\text { Conceito do Produto } \\
\text { Protótipo Virtual } \\
\text { Protótipo em Isopor } \\
\text { 3. Planejamento do } \\
\text { Produto } \\
\text { 4. Engenharia do Produto } \\
\text { Protótipo em Metal } \\
\text { 5. Engenharia do Processo } \\
\text { Produção Piloto } \\
\text { 6. Lançamento e Ramp-up }\end{array}$ & $\begin{array}{l}\text { Seleção de Idéias } \\
\text { 2. Elaboração do Ante- } \\
\text { projeto } \\
\text { 3. Desenvolvimento do } \\
\text { Produto e Mix } \\
\text { Promocional } \\
\text { Protótipo Virtual } \\
\text { Protótipo com matéria- } \\
\text { prima em processo } \\
\text { produtivo de } \\
\text { laboratório } \\
\text { 4. Realização de Semi- } \\
\text { industriais e Confecção } \\
\text { de Material Promocional } \\
\text { Produção Piloto } \\
\text { 5. Lançamento das } \\
\text { Coleções } \\
\text { 6. Verificação da } \\
\text { Eficácia do Lançamento } \\
\text { 7. Acompanhamento das } \\
\text { Vendas }\end{array}$ & $\begin{array}{l}\text { Oportunidades } \\
\text { 2. Desenvolvimento do } \\
\text { Conceito } \\
\text {-Projeto Conceitual } \\
\text {-Projeto Preliminar } \\
\text { Protótipo Virtual } \\
\text {-Projeto Detalhado } \\
\text { Protótipo Virtual } \\
\text { Protótipo em Gesso } \\
\text { 3. Try-out } \\
\text { Produção Piloto } \\
\text { 4. Lançamento e Ramp- } \\
\text { up }\end{array}$ \\
\hline
\end{tabular}

Quadro 53 - Decisões Perflex, Deca, Cecrisa e Tigre - gerenciamento do projeto

\begin{tabular}{|c|c|c|c|}
\hline Decisões Perflex & Decisões Deca & Decisões Cecrisa & Decisões Tigre \\
\hline $\begin{array}{l}\text { - Monitoramento e } \\
\text { controle - através de } \\
\text { planos, formal, atuação } \\
\text { do gerente e } \\
\text { envolvimento e } \\
\text { compromisso da alta } \\
\text { administração. } \\
\text { - Priorização dos } \\
\text { projetos, tempo de } \\
\text { desenvolvimento, } \\
\text { seqüência das } \\
\text { atividades e marcos do } \\
\text { projeto - cronograma. } \\
\text { - Descarte de projetos - } \\
\text { critérios para descarte. } \\
\text { - Comunicação - } \\
\text { integração } \\
\text { multifuncional; interação } \\
\text { e colaboração; diálogo, } \\
\text { que acontece nas fases } \\
\text { iniciais do projeto. } \\
\text { - Desempenho - } \\
\text { qualidade do projeto, } \\
\text { planejado x o que } \\
\text { efetivamente aconteceu. }\end{array}$ & $\begin{array}{l}\text { - Monitoramento e } \\
\text { controle - através de } \\
\text { planos, formal, atuação } \\
\text { do gerente e } \\
\text { envolvimento da alta } \\
\text { administração. } \\
\text { - Priorização dos } \\
\text { projetos, tempo de } \\
\text { desenvolvimento, } \\
\text { seqüência das } \\
\text { atividades, e marcos do } \\
\text { projeto - planejamento; } \\
\text { cronograma. } \\
\text { - Descarte de projetos - } \\
\text { critérios para descarte. } \\
\text { - Comunicação - } \\
\text { integração } \\
\text { multifuncional; interação } \\
\text { e colaboração; diálogo, } \\
\text { que acontece nas fases } \\
\text { iniciais do projeto. } \\
\text { - Desempenho - } \\
\text { qualidade do projeto; } \\
\text { planejado x o que } \\
\text { efetivamente aconteceu. }\end{array}$ & $\begin{array}{l}\text { - Monitoramento e } \\
\text { controle - através de } \\
\text { planos, formal, atuação } \\
\text { do gerente e } \\
\text { envolvimento e } \\
\text { compromisso da alta } \\
\text { administração. } \\
\text { - Priorização dos } \\
\text { projetos, tempo de } \\
\text { desenvolvimento, } \\
\text { seqüência das } \\
\text { atividades, e marcos do } \\
\text { projeto - planejamentos; } \\
\text { cronograma. } \\
\text { - Descarte de projetos - } \\
\text { critérios para descarte. } \\
\text { - Comunicação - } \\
\text { integração } \\
\text { multifuncional; interação } \\
\text { e colaboração; e diálogo, } \\
\text { que acontece nas fases } \\
\text { iniciais do projeto. } \\
\text { - Desempenho - } \\
\text { qualidade do projeto; } \\
\text { planejado x o que } \\
\text { efetivamente aconteceu. }\end{array}$ & $\begin{array}{l}\text { - Monitoramento e } \\
\text { controle - através de } \\
\text { planos, formal, atuação } \\
\text { do gerente e } \\
\text { envolvimento e } \\
\text { compromisso da alta } \\
\text { administração. } \\
\text { - Priorização dos } \\
\text { projetos, tempo de } \\
\text { desenvolvimento, } \\
\text { seqüência das } \\
\text { atividades, e marcos do } \\
\text { projeto - planejamentos; } \\
\text { cronograma. } \\
\text { - Descarte de projetos - } \\
\text { critérios para descarte; } \\
\text { check list. } \\
\text { - Comunicação - } \\
\text { integração } \\
\text { multifuncional; interação } \\
\text { e colaboração; e diálogo, } \\
\text { que acontece nas fases } \\
\text { iniciais do projeto. } \\
\text { - Desempenho - } \\
\text { qualidade do projeto, } \\
\text { tempo para colocar o } \\
\text { produto no mercado e } \\
\text { produtividade; planejado } \\
\text { x o que efetivamente } \\
\text { aconteceu. }\end{array}$ \\
\hline
\end{tabular}




\subsubsection{Etapas de desenvolvimento}

As etapas adotadas nesta dissertação foram as indicadas por Krishnan e Ulrich (2001): desenvolvimento do conceito, projeto da cadeia de suprimentos, projeto do produto, teste e validação de desempenho, e ramp-up e lançamento. Serão analisadas neste item quais as decisões tomadas pelas quatro empresas estudadas em cada uma das etapas, procurando avaliar o alinhamento de suas práticas com a literatura apresentada. Com isso, serão identificadas práticas que sejam comuns às empresas e características da IMC.

\subsubsection{Desenvolvimento do conceito}

Rozenfeld et al (2006) indica que na etapa de Desenvolvimento do Conceito define-se o escopo detalhado do produto, contendo informações sobre a tecnologia disponível e necessária para o projeto, normas, patentes e legislação relacionada ao produto, identificação do cliente e do consumidor, e suas necessidades, requisitos do produto, produtos concorrentes e similares, serviços agregados ao produto, variações do produto e conceito central (BACKMAN et al, 2007). São definidas também a arquitetura do produto, a forma física e o projeto industrial, através de um desenho virtual ou croqui (KRISHNAN; ULRICH, 2001).

O primeiro item citado no Quadro 54 se refere à interação ou não de todos os envolvidos no processo desde as etapas iniciais. $\mathrm{Na}$ Perflex, todas as funções necessárias para o desenvolvimento do projeto são reunidas no time desde a etapa de Desenvolvimento do Conceito. No caso da Deca, a interação de todos os componentes do time só se inicia na terceira etapa do processo, Engenharia do Produto, que, nas etapas do processo de GDP de Krishnan e Ulrich (2001) corresponde à etapa de Projeto da Cadeia de Suprimentos e Projeto do Produto. Esta empresa acredita que deixa para convocar o time após o desenvolvimento do conceito, pois acredita que com um protótipo em mãos e uma idéia já inicialmente trabalhada pela designer ambos servirão como um recurso de comunicação que facilitará a identificação de modificações, de equipamentos necessários, como também auxiliará na definição de quais áreas realmente são necessárias para o desenvolvimento do projeto.

A Cecrisa e a Tigre contam com a participação de todos os envolvidos no processo desde o início dessa etapa. Smith e Reinertsen (1998) afirmam que devido à incerteza presente nessas 
fases iniciais, a interação entre diferentes departamentos pode ser problemática, mas, para melhorar esse relacionamento, procura-se realizar as etapas por meio de processos formais, com o controle efetivo do projeto.

Smith e Reinertsen (1998) asseguram que nessa fase inicial a empresa deve procurar especificar o máximo possível o produto, para que mais na frente não sejam acrescentadas informações adicionais, que venham a retardar o processo de desenvolvimento. Na Perflex se especifica quem é o cliente, suas necessidades, requisitos do produto, produtos concorrentes e similares, objetivos ou metas que o produto deve atender, preço, e seu conceito central, com base no input, customer- and market-driven concept e sustentabilidade.

Essas informações poderão ser modificadas até as etapas finais do projeto, porém deve-se, conforme Smith e Reinertsen (1998), procurar especificar bem o projeto, pois quaisquer modificações adicionadas posteriormente podem parecer inocentes, mas talvez adicionem complexidade e, conseqüentemente, mais tempo ao ciclo. Além das informações que a Perflex especifica no seu projeto, a Deca adiciona as tecnologias disponíveis e necessárias para o seu desenvolvimento.

A Cecrisa estabelece como meta para essa etapa dar substância conceitual e mercadológica às novas linhas de produtos e integrar as várias ações a elas relacionadas. Primeiro é feita a conceituação da linha, que contém o nome, o tema, a relevância, a funcionalidade, o mercado- alvo, a linguagem estética, o estilo de vida, as palavras-chave para associação de idéias, a imagem ícone da linha, o que poderá ser utilizada nas peças promocionais da linha, se se caracteriza como inovação ou incremental, e qual é o diferencial, e ainda testemunhos sobre a atualidade da idéia.

Nesse mesmo documento da Cecrisa são descritas a estrutura da linha, com indicação do processo produtivo, as características técnicas e estéticas do produto e de seus complementos e da embalagem. Faz-se uma sondagem do mercado para identificar o potencial da linha, e analisam-se os preços dos produtos concorrentes, para definição do preço do produto. E, por fim, é feita a proposta inicial do mix promocional. O conceito central baseia-se nos seguintes inputs: tecnologia, projeto, valor, consumidor e sustentabilidade. 
Na Tigre, o projeto também é bem detalhado, mas essa especificação é resultado da etapa de identificação de idéias. A área de P\&D aperfeiçoa o projeto rapidamente, acrescentando informações sobre preço, mercado, produtos similares e complementares, componentes, investimentos, normas e patentes relacionadas ao produto, e detalhamento do consumidor e de suas necessidades. O conceito central do produto é definido com base nos seguintes inputs: tecnologia, serviço, projeto, valor, consumidor e sustentabilidade. Nada é congelado nessa etapa, mas as informações são coletadas com bastante cuidado e criteriosamente, evitando modificações posteriores.

Algumas empresas inserem no processo de desenvolvimento seus clientes e consumidores, a fim de melhorar essa etapa (VON HIPPEL, 1986; THOMKE; VON HIPPEL, 2002; SMITH; REINERTSEN, 1998; COOPER et al, 2002a). No entanto, nenhuma das empresas pesquisadas lança mão dessa técnica. Na Perflex, o cliente não é indiretamente inserido no processo, pois a cada marco do projeto a área de marketing realiza um teste do produto no mercado.

Na Deca, nessa etapa não há nenhum contato com o consumidor, nem o inserindo no processo, nem de forma indireta. No caso da Cecrisa, também não se insere o consumidor em nenhum momento do processo, pois acredita que não conseguirá desenvolver produtos inovadores com a participação direta ou indireta do consumidor.

Nessa etapa, a Tigre não insere mais o consumidor, mas na etapa de identificação das idéias o consumidor participa ativamente do processo, caso em que um funcionário da empresa se insere em sua residência, a fim de conhecer suas reais necessidades. Então, de modo geral, pode-se considerar a participação do consumidor no processo.

No que se refere à arquitetura do produto, forma física, projeto industrial e variações, as empresas, de acordo com Krishnan e Ulrich (2001), podem obtê-los por meio de desenhos virtuais ou croquis. Na Perflex, Cecrisa e Tigre isso é alcançado por meio de desenhos virtuais, enquanto que na Deca, primeiro é feito um protótipo virtual e depois um croqui, realizado em laboratório interno da empresa. A Deca afirma que nessa etapa é necessário fazer o croqui, pois muitas vezes se idealiza um projeto e, ao desenvolver o croqui, não se alcança o objetivo. 
Esses desenhos virtuais e o croqui auxiliam na definição de quais componentes serão compartilhados dentre as variações do produto, que deverão ser balanceadas de acordo com a heterogeneidade das preferências dos consumidores e a padronização do projeto e da produção.

No Quadro 54 contém as decisões que a Perflex, Deca, Cecrisa e Tigre tomam na etapa de desenvolvimento do conceito do produto.

Quadro 54 - Decisões Perflex, Deca, Cecrisa e Tigre - desenvolvimento do conceito

\begin{tabular}{|c|c|c|c|}
\hline Decisões Perflex & Decisões Deca & Decisões Cecrisa & Decisões Tigre \\
\hline $\begin{array}{l}\text { - Interação de todos os } \\
\text { envolvidos no processo. } \\
\text { - Clientes e } \\
\text { consumidores finais - } \\
\text { utilização de ferramentas } \\
\text { para conhecer as } \\
\text { necessidades do } \\
\text { mercado. } \\
\text { - Escopo detalhado do } \\
\text { produto - identificar } \\
\text { quem é o cliente, o } \\
\text { consumidor e suas } \\
\text { necessidades; requisitos } \\
\text { do produto; produtos } \\
\text { concorrentes e similares; } \\
\text { objetivos ou metas que o } \\
\text { produto deve atender; } \\
\text { preço; congelamento das } \\
\text { características em etapas } \\
\text { finais; Conceito central } \\
\text { - customer- and market- } \\
\text { driven concept. } \\
\text { - Arquitetura do } \\
\text { produto, forma física e } \\
\text { projeto industrial - } \\
\text { desenho virtual. } \\
\text { - Variações do produto } \\
\text { - quais serão, } \\
\text { componentes } \\
\text { compartilhados entre as } \\
\text { variações. }\end{array}$ & $\begin{array}{l}\text { - Clientes e } \\
\text { consumidores finais - } \\
\text { utilização de ferramentas } \\
\text { para conhecer as } \\
\text { necessidades dos } \\
\text { consumidores. } \\
\text { - Escopo detalhado do } \\
\text { produto - tecnologias } \\
\text { disponíveis e } \\
\text { necessárias; identificar } \\
\text { quem é o cliente, o } \\
\text { consumidor e quais suas } \\
\text { necessidades; requisitos } \\
\text { do produto; produtos } \\
\text { concorrentes e similares; } \\
\text { serviços agregados ao } \\
\text { produto; objetivos ou } \\
\text { metas que o produto } \\
\text { deve atender; preço; } \\
\text { congelamentos das } \\
\text { características em etapas } \\
\text { finais; Conceito central } \\
\text { - customer- and market- } \\
\text { driven concept. } \\
\text { - Arquitetura do } \\
\text { produto, forma física e } \\
\text { projeto industrial - } \\
\text { croqui. } \\
\text { - Variações do produto } \\
\text { - quais serão oferecidas, } \\
\text { componentes } \\
\text { compartilhados entre as } \\
\text { variações. }\end{array}$ & $\begin{array}{l}\text { - Interação de todos os } \\
\text { envolvidos no processo. } \\
\text { - Clientes e } \\
\text { consumidores finais - } \\
\text { utilização de ferramentas } \\
\text { para conhecer essas } \\
\text { necessidades. } \\
\text { - Escopo detalhado do } \\
\text { produto - tecnologias } \\
\text { disponíveis e } \\
\text { necessárias; identificar } \\
\text { quem é o cliente, o } \\
\text { consumidor e suas } \\
\text { necessidades; requisitos } \\
\text { do produto; produtos } \\
\text { concorrentes e similares; } \\
\text { serviços agregados ao } \\
\text { produto; objetivos ou } \\
\text { metas que o produto } \\
\text { deve atender; preço; e } \\
\text { outras informações } \\
\text { relevantes para a } \\
\text { empresa; congelamento } \\
\text { das características em } \\
\text { etapas finais. Conceito } \\
\text { central - input - } \\
\text { technology-driven } \\
\text { concept; design-driven } \\
\text { concept; value-driven } \\
\text { concept; customer- and } \\
\text { market-driven concept. } \\
\text { - Arquitetura do } \\
\text { produto, forma física e } \\
\text { projeto industrial - } \\
\text { desenho virtual. } \\
\text { - Variações do produto } \\
\text { - quais serão oferecidas, } \\
\text { componentes } \\
\text { compartilhados entre as } \\
\text { variações. }\end{array}$ & $\begin{array}{l}\text { - Interação de todos os } \\
\text { envolvidos no processo. } \\
\text { - Clientes e } \\
\text { consumidores finais - } \\
\text { participação no processo } \\
\text { de desenvolvimento; } \\
\text { utilização de ferramentas } \\
\text { para identificar suas } \\
\text { necessidades. } \\
\text { - Escopo detalhado do } \\
\text { produto - tecnologias } \\
\text { disponíveis e } \\
\text { necessárias; normas; } \\
\text { patentes e legislação } \\
\text { relacionada ao produto; } \\
\text { identificar quem é o } \\
\text { cliente, o consumidor e } \\
\text { quais suas necessidades; } \\
\text { requisitos do produto; } \\
\text { produtos concorrentes e } \\
\text { similares; serviços } \\
\text { agregados ao produto; } \\
\text { objetivos ou metas que o } \\
\text { produto deve atender; } \\
\text { preço; e outras } \\
\text { informações relevantes } \\
\text { para a empresa; } \\
\text { congelamento das } \\
\text { características em etapas } \\
\text { finais; Conceito central } \\
\text { - input - technology- } \\
\text { driven concept; service } \\
\text { concept; design-driven } \\
\text { concept; value-driven } \\
\text { concept; customer- and } \\
\text { market-driven concept. } \\
\text { - Arquitetura do } \\
\text { produto, forma física e } \\
\text { projeto industrial - } \\
\text { croqui. } \\
\text { - Variaç̃es do produto }\end{array}$ \\
\hline
\end{tabular}




\begin{tabular}{|l|l|l|}
\hline & & $\begin{array}{l}\text { - quais serão oferecidas, } \\
\text { componentes } \\
\text { compartilhados entre as } \\
\text { variações. }\end{array}$ \\
\hline
\end{tabular}

\subsubsection{Projeto da cadeia de suprimentos}

As atividades da fase de projeto da cadeia de suprimentos envolvem o fluxo interno e externo de materiais. Nessa etapa serão selecionados os fornecedores, como também os projetos dos sistemas de produção e distribuição, quais projetos serão produzidos e/ou desenvolvidos internamente.

Na Perflex, na Deca e na Cecrisa a etapa de Projeto da Cadeia de Suprimentos é feita juntamente com a etapa de Projeto do Produto. Nos casos individuais a discussão dessa etapa foi feita junto com a etapa de Projeto do Produto, porém para a melhor compreensão, a apresentação dos dados será feita nesse item. Isso aconteceu devido ao fato de a classificação de etapas adotadas no trabalho, as etapas de Krishnan e Ulrich (2001), não ser temporal, mas sim baseada nas tomadas de decisões dentro do processo de desenvolvimento.

Nessa etapa definem-se quais componentes serão projetados internamente ou comprados prontos e quem os projetará, desenvolverá e produzirá. A Perflex só resolve essas questões na etapa seguinte, pois inicialmente é definida a parte externa do produto e posteriormente a parte interna.

Na Deca, tudo é feito pelo projetista responsável pelo projeto, alguns produtos são padronizados no mercado e, por essa razão, são comprados prontos, e outros são desenvolvidos por seus fornecedores. Vale ressaltar, que a Deca possui um sistema bastante criterioso para seleção de seus fornecedores, mas isso não é responsabilidade da área de desenvolvimento.

A Cecrisa consegue definir muito bem nessa etapa, considerando que esta acontece junto com a etapa de Projeto do Produto, quem serão seus fornecedores, quais componentes comprarão e quais produzirão internamente, e quem os projetará, desenvolverá e produzirá. Isso se deve ao fato de a empresa realizar nessa etapa a chamada “montagem do produto”, onde é realizada a prototipagem em cerâmica, simulando o processo produtivo no laboratório interno 
da empresa, onde já são utilizadas a matéria-prima e os equipamentos necessários para a produção da nova coleção.

A Tigre se diferencia das outras empresas, pois não realiza essa etapa junto com a seguinte e está bastante alinhada com as decisões de Krishnan e Ulrich (2001).

O ponto principal de decisão nessa etapa é sobre a cadeia física de suprimentos. A Perflex preocupa-se em identificar, após a etapa de Projeto do Produto, a configuração da cadeia física de suprimentos, selecionando os possíveis fornecedores das tecnologias e equipamentos, o sistema de produção e distribuição, e os custos diretos de produção.

$\mathrm{Na}$ Deca, essa etapa corresponde à etapa de Engenharia do Processo, onde o projeto detalhado na ficha técnica é entregue para a engenharia. Serão produzidas as peças e ferramentas necessárias; serão definidos os fornecedores para a compra dos componentes, tecnologia e equipamentos indicados no projeto; e será decidido, ainda, o sistema de produção e distribuição dos produtos. Com base nisso, os custos diretos de produção serão obtidos.

Na Cecrisa, como já foi dito, nessa etapa é feita uma simulação do processo produtivo no laboratório interno da empresa com a geração de um protótipo em cerâmica. Nesse momento a empresa já define os fornecedores, tanto da matéria-prima, quanto dos equipamentos e tecnologia. E, quando necessário, já identifica o local de junção dos componentes e o sistema de distribuição.

Na Tigre, para que a área de P\&D consiga fornecer informações reais sobre os recursos da empresa, é feita uma análise, sob a ótica da logística e planejamento, tomando-se por base os investimentos necessários. O resultado da análise indica o que a empresa possui de equipamentos, recursos, local de armazenamento, rede de distribuição, e Centro de Distribuição - CD. Ao fim dessa etapa, a área de P\&D deve ter em mãos um relatório de mercado, um relatório técnico, os fluxos mapeados de todo o processo e um protótipo virtual.

Convém destacar que é nessa fase que se lança mão da engenharia simultânea, onde informalmente os atores do projeto conversam entre si, para o detalhamento do projeto, adiantando atividades relacionadas com a etapa seguinte. Essa cultura foi inserida na 
empresa, com a finalidade de abolir as grandes reuniões, as quais só acontecem uma vez na semana com os líderes dos projetos, apenas para seu acompanhamento formal. Sempre são levados os relatórios de cada projeto, em que são repassados todos os pontos. A engenharia simultânea também proporciona um tempo menor de desenvolvimento, já que duas etapas são levadas paralelamente.

O Quadro 55 apresenta as decisões que a Perflex, Deca, Cecrisa e Tigre tomam na etapa de Projeto da Cadeia de Suprimentos.

Quadro 55 - Decisões Tigre - projeto da cadeia de suprimentos

\begin{tabular}{|l|l|l|l|}
\hline \multicolumn{1}{|c|}{ Decisões Perflex } & \multicolumn{1}{c|}{ Decisões Deca } & \multicolumn{1}{c|}{ Decisões Cecrisa } & \multicolumn{1}{c|}{ Decisões Tigre } \\
\hline - Componentes - & - Componentes - & - Componentes - & - Componentes - \\
projetados internamente & projetados internamente & projetados internamente & projetados internamente \\
ou comprados prontos; & ou comprados prontos; & ou comprados prontos; & ou comprados prontos; \\
quem projetará, & quem projetará; & quem projetará, & quem projetará, \\
desenvolverá e produzirá. & desenvolverá e produzirá. & desenvolverá e produzirá. & desenvolverá e produzirá. \\
- Cadeia física de & - Cadeia física de & - Cadeia física de & - Cadeia física de \\
suprimentos - & suprimentos - & suprimentos - & suprimentos - \\
configuração, incluindo o o & configuração, incluindo o & configuração, incluindo o & configuração, incluindo o \\
local de junção dos & local de junção dos & local de junção dos & local de junção dos \\
componentes; seleção de & componentes; seleção de & componentes; seleção de & componentes; seleção de \\
fornecedores das & fornecedores das & fornecedores das & fornecedores das \\
tecnologias e & tecnologias e & tecnologias e & tecnologias e \\
equipamentos; sistema de & equipamentos; sistema de & equipamentos; sistema de & equipamentos; sistema de \\
produção e distribuição; & produção e distribuição; & produção e distribuição. & produção e distribuição; \\
custos diretos de & custos diretos de & & custos diretos de \\
produção; custos entre & produção; custos entre & & produção; custos entre \\
fornecimento e demanda. & fornecimento e demanda. & & fornecimento e demanda. \\
\hline
\end{tabular}

\subsubsection{Projeto do produto}

Essa é a etapa de detalhamento final do projeto do produto, que se constitui na especificação dos parâmetros do projeto, a relação entre componentes do produto, incluindo seleção de material e de processo e projeto das ferramentas e equipamentos necessários para o desenvolvimento dos novos produtos. Rozenfeld et al (2006, p. 297) indica que é nessa etapa que serão feitos os desenhos finais com tolerâncias, os planos de processo, os projetos de embalagem e o material de suporte do produto.

Na Perflex, o detalhamento do projeto será finalizado somente depois de aprovada, pela diretoria e pelo mercado, o design do produto e depois de aprovado, novamente pela diretoria e pelo mercado, o produto como um todo, o que inclui design e parte técnica. No caso da Deca, o detalhamento do projeto só findará após a elaboração do protótipo em metal e sua 
posterior aprovação pela diretoria. Com esse protótipo, definem-se os componentes e suas relações, seleciona-se o material, o processo e o projeto das ferramentas e equipamentos, os planos de processo, e os desenhos finais com tolerâncias.

No caso da Cecrisa, todas as decisões definidas para essa etapa já foram concretizadas, faltando efetivar somente os testes semi-industriais. As peças produzidas servirão para a realização de testes no produto, e também como amostras para composição do mix promocional. Ao fim dessa etapa, o processo tecnológico e equipamentos estarão testados e aprovados, e o mix promocional pronto.

Na Tigre, a etapa Projeto do Produto é denominada Projeto Detalhado do Produto. Até esse momento foram feitos somente protótipos virtuais. No entanto, pode-se considerar como parte dessa etapa a aprovação do protótipo virtual e o desenvolvimento do protótipo em gesso. Com isso, tem-se o projeto detalhado, que será entregue para a engenharia. Aqui também há conformidade com as decisões indicadas por Rozenfeld et al (2006).

A embalagem na Perflex é produzida fora da empresa. Por essa razão, sua aquisição é definida juntamente com a indicação dos fornecedores dos componentes dos produtos. $\mathrm{O}$ processo de embalagem é localizado em uma área específica da empresa, sendo assim, não é preciso definir seu processo, ele é fixo.

A Deca avalia, nessa etapa, a distribuição do produto, incluindo transporte e entrega, para definição das formas e sinalizações das embalagens dos produtos. O processo de embalagem é feito na empresa, em área específica.

Em relação à embalagem, desde a etapa de desenvolvimento do conceito que a Cecrisa procura identificar a necessidade de algo diferente, analisando facilidades para distribuição do produto, já que se caracteriza como um produto de difícil manuseio, devido ao seu tamanho e peso. Geralmente, não é necessária nenhuma alteração, uma vez que os tamanhos são padronizados.

Com o projeto detalhado finalizado, a alta administração da Tigre autoriza ou não a continuidade do projeto. Aprovado, inicia-se o processo de aquisição de todos os investimentos planejados. Também é verificada a necessidade de aquisição de insumos e 
embalagens, definida a partir da avaliação da distribuição do produto, incluindo transporte e entrega, e ainda a definição das formas e do processo de embalagem.

O material de suporte produzido pela Perflex é o manual de instalação do produto, assim como na Deca. A Cecrisa e a Tigre elaboram, além desse, o manual do material de treinamento, além de manuais completos de como realizar o treinamento para manuseio dos produtos, venda e negociação. O Quadro 56 apresenta as decisões da etapa de Projeto do Produto na Perflex, Deca, Cecrisa e Tigre.

Quadro 56 - Decisões Perflex, Deca, Cecrisa e Tigre - projeto do produto

\begin{tabular}{|c|c|c|c|}
\hline Decisões Perflex & Decisões Deca & Decisões Cecrisa & Decisões Tigre \\
\hline $\begin{array}{l}\text { - Especificação dos } \\
\text { parâmetros do projeto } \\
\text { - projeto detalhado dos } \\
\text { componentes; relação } \\
\text { entre os componentes do } \\
\text { produto; seleção de } \\
\text { material e de processo e } \\
\text { projeto das ferramentas e } \\
\text { equipamentos; planos de } \\
\text { processo; desenhos finais } \\
\text { com tolerâncias. } \\
\text { - Embalagem - projeção } \\
\text { da embalagem; } \\
\text { planejamento do } \\
\text { processo de embalagem. }\end{array}$ & $\begin{array}{l}\text { - Especificação dos } \\
\text { parâmetros do projeto } \\
\text { - projeto detalhado dos } \\
\text { componentes; relação } \\
\text { entre os componentes do } \\
\text { produto; seleção de } \\
\text { material e de processo, e } \\
\text { projeto das ferramentas e } \\
\text { equipamentos; planos de } \\
\text { processo; desenhos finais } \\
\text { com tolerâncias. } \\
\text { - Embalagem - } \\
\text { avaliação da distribuição } \\
\text { do produto, incluindo } \\
\text { transporte e entrega; } \\
\text { definição das formas e } \\
\text { sinalizações das } \\
\text { embalagens dos } \\
\text { produtos; projeção da } \\
\text { embalagem; } \\
\text { planejamento do } \\
\text { processo de embalagem. }\end{array}$ & $\begin{array}{l}\text { - Especificação dos } \\
\text { parâmetros do projeto } \\
\text { - projeto detalhado dos } \\
\text { componentes; relação } \\
\text { entre os componentes do } \\
\text { produto; seleção de } \\
\text { material e de processo e } \\
\text { projeto das ferramentas e } \\
\text { equipamentos; planos de } \\
\text { processo; desenhos finais } \\
\text { com tolerâncias. } \\
\text { - Embalagem -projeção } \\
\text { da embalagem; } \\
\text { planejamento do } \\
\text { processo de embalagem. } \\
\text { - Material de suporte do } \\
\text { produto - criação do } \\
\text { material de treinamento. }\end{array}$ & $\begin{array}{l}\text { - Especificação dos } \\
\text { parâmetros do projeto } \\
\text { - projeto detalhado dos } \\
\text { componentes; relação } \\
\text { entre os componentes do } \\
\text { produto; seleção de } \\
\text { material e de processo e } \\
\text { projeto das ferramentas e } \\
\text { equipamentos; planos de } \\
\text { processo; desenhos finais } \\
\text { com tolerâncias. } \\
\text { - Embalagem - } \\
\text { avaliação da distribuição } \\
\text { do produto, incluindo } \\
\text { transporte e entrega; } \\
\text { definição das formas das } \\
\text { embalagens dos } \\
\text { produtos; projeção da } \\
\text { embalagem; } \\
\text { planejamento do } \\
\text { processo de embalagem. } \\
\text { - Material de suporte do } \\
\text { produto - criação do } \\
\text { material de treinamento. }\end{array}$ \\
\hline
\end{tabular}

\subsubsection{Teste e validação de desempenho}

Krishnan e Ulrich (2001) indicam que a produção piloto deve ser feita nessa etapa do processo, no entanto a Perflex faz o teste em pequena escala na etapa anterior, pois nessa só é feita a avaliação do projeto. O try-out de implantação na Deca é realizado com o acompanhamento dos primeiros lotes produzidos. Esse acompanhamento se deve ao fato de ser a primeira vez que a linha de produção está lidando com os novos produtos, equipamentos, tecnologias, etc. 
Na Cecrisa, o try-out do processo é denominado de "testes semi-industriais". Todas as peças que são produzidas vão para estoque, e servirão de amostra para teste, mostruário para as lojas que venderão a nova coleção, showrooms, ou seja, não serão vendidas. A etapa de tryout do projeto da Tigre deixa de ser responsabilidade da área de P\&D e passa para a de engenharia. Esse teste é feito para que todos aprendam a manusear algum novo equipamento ou ferramenta e para verificar se o processo está pronto para produzir em maior escala.

Essa etapa é denominada na Perflex de Avaliação do Projeto, constitui-se na elaboração da ficha técnica do produto, onde serão detalhados todos os pontos necessários para a sua produção. Essa ficha é entregue para a engenharia e para a área de custos da empresa, que irão analisar a viabilidade da nova linha e testar os produtos para verificar sua adequação aos padrões técnicos da empresa, o que inclui funcionamento, tamanho e fabricação; as normas nacionais e internacionais, caso seja necessário; e durabilidade, encaixe, finalização e custos de produção. Em sendo aprovada, é repassada mais uma vez para a área comercial, que dará a aprovação final, iniciando assim a sua produção.

Na Deca, selecionam-se três a quatro peças da produção inicial para serem testadas pelo laboratório interno da empresa. Avalia-se seu funcionamento, tamanho e fabricação, além da durabilidade, encaixe e finalização. São também realizados com esses produtos os testes de campo, dentro da própria fábrica ou mesmo na casa dos funcionários e em restaurantes de rodovias, pois devido ao grande giro de pessoas nesses locais, assim é possível realizar vários testes em menor tempo.

Os produtos da Cecrisa que foram produzidos servirão de amostra para teste em relação a funcionamento, tamanho, fabricação, projeto industrial, durabilidade, encaixe, finalização e custos de produção. A reação dos consumidores também é testada quando da entrega dessas amostras nos pontos de venda e em showrooms da própria Cecrisa.

Os primeiros produtos produzidos nessa etapa na Tigre são submetidos a testes, avaliando seu tamanho, funcionamento, fabricação, projeto industrial, durabilidade, encaixe e finalização, e custos de produção. A avaliação da reação dos consumidores só será feita na etapa final do processo. 
Em relação ao tipo do protótipo, nenhuma das classificações de Clark e Wheelwright (1993) se adapta às empresas ora estudadas, pois essas categorias foram estabelecidas em realidades diferentes, com empresas maiores, muito mais estruturadas e hierarquizadas. No caso do processo de construção de protótipos na Perflex, ocorre paralelamente ao desenvolvimento e pode ser virtual, ou prototipagem rápida (experimentação real), e irá variar de acordo com a etapa que o projeto se encontra. Esse tipo de processo contribui para a identificação de oportunidades, para o aprendizado da organização, além de testar a comunicação entre os membros do projeto e auxiliar na resolução de conflitos.

Na Deca, os protótipos podem ser construídos virtualmente, por experimentação real, ou protótipos em isopor, mas sempre concomitantemente ao seu desenvolvimento. Nesse sentido2, auxilia na identificação de oportunidades, no aprendizado da organização, na formação de novas capacidades, e ainda testa a comunicação entre os membros do projeto e ajuda na resolução de conflitos.

O processo de construção dos protótipos na Cecrisa varia também de acordo com a etapa em que se encontra o projeto, podendo ser virtual, ou prototipagem rápida (experimentação real), mas sempre paralelo ao seu desenvolvimento. Dessa forma, concorre para a identificação de oportunidades, para o aprendizado da organização, testa a comunicação entre os membros do projeto e auxilia na resolução de conflitos.

A Tigre igualmente constrói seus protótipos paralelos ao desenvolvimento, sendo que em determinados momentos serão virtuais, em outras fases poderá ser prototipagem rápida ou, ainda, protótipos de gesso. A Tigre afirma que os protótipos virtuais servem como meio de coleta de informações reais do projeto, pois atualmente existem programas que possibilitam sua visualização externa, como também interna. A empresa indica que com esse recurso conseguiu reduzir ainda mais o seu tempo de desenvolvimento, pois antes tinha de fazer os protótipos de gesso já nessas etapas iniciais. Com os protótipos é possível identificar oportunidades, aprender coisas novas, formar novas capacidades, testar a comunicação e ajudar na solução de problemas.

Quadro 57 - Decisões Perflex, Deca, Cecrisa e Tigre - teste e validação de desempenho

\begin{tabular}{|l|l|l|l|}
\hline \multicolumn{1}{|c|}{ Decisões Perflex } & \multicolumn{1}{c|}{ Decisões Deca } & \multicolumn{1}{c|}{ Decisões Cecrisa } & \multicolumn{1}{c|}{ Decisões Tigre } \\
\hline $\begin{array}{l}\text { - Prototipagem para } \\
\text { validaçãa - em relação a }\end{array}$ & $\begin{array}{l}\text { - Prototipagem para } \\
\text { validação - em relação a }\end{array}$ & $\begin{array}{l}\text { - Prototipagem para } \\
\text { validação - em relação a }\end{array}$ & $\begin{array}{l}\text { - Prototipagem para } \\
\text { validação - em relação a }\end{array}$ \\
\hline
\end{tabular}




\begin{tabular}{|c|c|c|c|}
\hline $\begin{array}{l}\text { funcionamento, tamanho } \\
\text { e fabricação; avalia } \\
\text { reações dos } \\
\text { consumidores, projeto } \\
\text { industrial, durabilidade, } \\
\text { encaixe e finalização, e } \\
\text { custos de produção. } \\
\text { - Teste em pequena } \\
\text { escala do projeto - } \\
\text { produçãa piloto; } \\
\text { definição dos processos } \\
\text { de produção e } \\
\text { manutenção. } \\
\text { - Processo de } \\
\text { construção dos } \\
\text { protótipos - simulação } \\
\text { virtual, prototipagem } \\
\text { rápida; paralela; } \\
\text { prototipagem em etapas } \\
\text { iniciais do projeto. } \\
\text { - Benefícios do } \\
\text { protótipo - contribuem } \\
\text { para a identificação de } \\
\text { oportunidades; } \\
\text { aprendizado da } \\
\text { organização; testa a } \\
\text { comunicação entre os } \\
\text { membros do projeto; } \\
\text { auxilia na resolução de } \\
\text { conflitos. }\end{array}$ & $\begin{array}{l}\text { funcionamento, tamanho } \\
\text { e fabricação; avalia } \\
\text { reações dos } \\
\text { consumidores, projeto } \\
\text { industrial, durabilidade, } \\
\text { encaixe e finalização, e } \\
\text { custos de produção. } \\
\text { - Teste em pequena } \\
\text { escala do projeto - } \\
\text { produção piloto; } \\
\text { definição dos processos } \\
\text { de produção e } \\
\text { manutenção. } \\
\text { - Processo de } \\
\text { construção de } \\
\text { protótipos - simulação } \\
\text { virtual, prototipagem } \\
\text { rápida, e protótipos de } \\
\text { isopor; paralela; } \\
\text { prototipagem em etapas } \\
\text { iniciais do projeto. } \\
\text { - Benefícios do } \\
\text { protótipo - contribuem } \\
\text { para a identificação de } \\
\text { oportunidades; } \\
\text { aprendizado da } \\
\text { organização; formação de } \\
\text { novas capacidades; testa } \\
\text { a comunicação entre os } \\
\text { membros do projeto; } \\
\text { auxilia na resolução de } \\
\text { conflitos. }\end{array}$ & $\begin{array}{l}\text { funcionamento, tamanho } \\
\text { e fabricação; avalia } \\
\text { reações dos } \\
\text { consumidores, projeto } \\
\text { industrial, durabilidade, } \\
\text { encaixe e finalização, e } \\
\text { custos de produção. } \\
\text { - Teste em pequena } \\
\text { escala do projeto - } \\
\text { produção piloto; } \\
\text { definição dos processos } \\
\text { de produção e } \\
\text { manutenção. } \\
\text { - Processo de } \\
\text { construção dos } \\
\text { protótipos - simulação } \\
\text { virtual, prototipagem } \\
\text { rápida (experimentação } \\
\text { real); paralela; } \\
\text { prototipagem em etapas } \\
\text { iniciais do projeto. } \\
\text { - Benefícios do } \\
\text { protótipo - contribuem } \\
\text { para a identificação de } \\
\text { oportunidades; } \\
\text { aprendizado da } \\
\text { organização; formação de } \\
\text { novas capacidades; testa } \\
\text { a comunicação entre os } \\
\text { membros do projeto; } \\
\text { auxilia na resolução de } \\
\text { conflitos. }\end{array}$ & $\begin{array}{l}\text { funcionamento, tamanho } \\
\text { e fabricação; projeto } \\
\text { industrial, durabilidade, } \\
\text { encaixe e finalização, e } \\
\text { custos de produção. } \\
\text { - Teste em pequena } \\
\text { escala do projeto - } \\
\text { produção piloto; } \\
\text { definção dos processos } \\
\text { de produção e } \\
\text { manutenção. } \\
\text { - Processo de } \\
\text { construção dos } \\
\text { protótipos - simulação } \\
\text { virtual, prototipagem } \\
\text { rápida (experimentação } \\
\text { real), e protótipos de } \\
\text { papelão ou argila; } \\
\text { paralela; prototipagem } \\
\text { em etapas iniciais do } \\
\text { projeto. } \\
\text { - Benefícios do } \\
\text { protótipo - contribuem } \\
\text { para a identificação de } \\
\text { oportunidades; } \\
\text { aprendizado da } \\
\text { organização; formação de } \\
\text { novas capacidades; testa } \\
\text { a comunicação entre os } \\
\text { membros do projeto; } \\
\text { auxilia na resolução de } \\
\text { conflitos. }\end{array}$ \\
\hline
\end{tabular}

\subsubsection{Ramp-up e lançamento}

Na etapa de ramp-up e lançamento Clark e Wheelwright (1993) indicam a possibilidade de realizar o teste de mercado do produto, e Rozenfeld et al (2006) indicam pontos de decisão no lançamento e ramp-up.

O teste de mercado na Perflex é feito na etapa anterior, como já foi indicado. O nível de realização é pequeno, uma vez que a área de marketing leva o produto para alguns poucos pontos de venda para avaliação. Na Deca, o teste de mercado só acontece quando o produto é lançado.

Na Cecrisa, o próprio lançamento do produto se confunde com o teste no mercado, visto que ao ser lançado, sua produção só será aumentada se tiver sucesso no mercado. Dessa forma, a empresa evita a formação de estoques inviáveis. Na Tigre, os primeiros produtos lançados 
entram em “quarentena”, e são acompanhados de perto por profissionais capacitados, para identificar possíveis problemas que possam ser modificados antes de saírem desse período. A vantagem é que a empresa não forma estoques de produtos que possam estar defeituosos, e aproveitam para avaliar a sua aceitação no mercado.

Ao iniciar a produção na Perflex, todo o plano de lançamento está traçado e os materiais prontos para serem distribuídos. A divulgação tem início em lojas previamente selecionadas, que variam de acordo com o perfil do produto. Ali são deixados mostruários da nova linha de produtos, e então os pedidos começam a ser feitos.

A última etapa do processo da Deca constitui-se no lançamento do produto. Inicialmente é divulgado o lançamento para todos os colaboradores da Deca, em especial para os vendedores, através de uma IA (Instrução Administrativa). Apesar de todos já estarem cientes da existência do produto, essa IA é enviada com a finalidade de sedimentar e passar maiores detalhes sobre preço, tamanho, vantagens, novas tecnologias, e locais de venda. Após sua divulgação interna, é feita a divulgação externa da nova linha de produtos. Desde a formação do time, que a área comercial trabalha paralelamente com a função de desenvolver o merchandising, desenhar o processo de distribuição dos novos produtos, definir como será a exposição no ponto de venda, dentre outros pontos de decisão que envolvem a divulgação do novo produto.

Com tudo finalizado, inicia-se o lançamento interno e externo das novas coleções da Cecrisa. Para o pessoal interno, as coleções podem ser apresentadas por meio de treinamentos, através de teleconferência, gravações de DVD’s com um dos consultores ministrando uma palestra sobre a nova coleção, e também treinamentos feitos pelos consultores para arquitetos, donos de lojas, e todos aqueles que fazem parte do processo de compra final dos produtos da empresa, no Brasil. O lançamento externo começa com a apresentação da coleção nas feiras internacionais, como a Covery, Bologna e Revestir. Depois, todo o material é distribuído para os revendedores, para que o apresentem aos seus clientes. As áreas responsáveis são o Marketing Estratégico e o Trade-marketing.

Na Tigre, o lançamento é feito primeiro internamente, com a distribuição de um PDF, o qual é enviado para toda a força de vendas da empresa, com um resumo de todo o projeto, suas vantagens, objetivos, características, preço bruto, código de barras, argumentos de venda, 
simulação de perguntas técnicas sobre o produto e apresentação de todos os serviços que agregam o produto. Depois se faz o lançamento externo.

E o acompanhamento do produto pelo time só acontece até a etapa anterior, dessa etapa em diante é de total responsabilidade da área de marketing da empresa. Paralelamente às etapas anteriores do processo, a área de marketing vai desenvolvendo as campanhas para lançamento da nova linha. Quando é iniciada a produção, todo o plano de lançamento está traçado e os materiais prontos para serem distribuídos. A divulgação tem início com a seleção de lojas específicas para lançar o produto, que varia de acordo com o perfil deste. Os mostruários da nova linha são deixados nas lojas, e aos poucos os pedidos começam a ser feitos. A área comercial vai repassando as coordenadas para a produção, indicando a quantidade de peças que devem ser produzidas.

O ramp-up das quatro empresas será feito de acordo com solicitações da área de marketing, e dependerá da aceitação do produto pelo mercado consumidor.

Por fim, a empresa deve procurar definir se o time continuará ou não acompanhando o produto no mercado (ROZENFELD et al, 2006). Na Perflex, o acompanhamento é interrompido na etapa anterior, quando então é assumido pela área de marketing. Na Deca, na Cecrisa e na Tigre, o acompanhamento do produto pelo time é finalizado nessa etapa. O Quadro 58 apresenta as decisões da etapa de ramp-up e lançamento da Perflex, Deca, Cecrisa e Tigre.

Quadro 58 - Decisões Perflex, Deca, Cecrisa e Tigre - ramp-up e lançamento

\begin{tabular}{|c|c|c|c|}
\hline Decisões Perflex & Decisões Deca & Decisões Cecrisa & Decisões Tigre \\
\hline $\begin{array}{l}\text { - Teste de mercado - } \\
\text { nível de realização. } \\
\text { - Lançamento - desenho } \\
\text { dos processos de venda e } \\
\text { distribuição; campanhas } \\
\text { de marketing. } \\
\text { - Ramp-up - aumento da } \\
\text { produção. } \\
\text { - Ao fim, cessa o } \\
\text { acompanhamento do } \\
\text { produto pelo time. }\end{array}$ & $\begin{array}{l}\text { - Teste de mercado - } \\
\text { seqüência de introdução } \\
\text { dos produtos no mercado. } \\
\text { - Lançamento - tempo } \\
\text { para o lançamento do } \\
\text { produto; como e quando } \\
\text { o concorrente entrará ou } \\
\text { entrou no mercado; } \\
\text { desenho dos processos de } \\
\text { venda e distribuição; } \\
\text { atendimento do cliente e } \\
\text { assistência técnica; } \\
\text { campanhas de marketing. } \\
\text { - Ramp-up - aumento da } \\
\text { produção. } \\
\text { - Ao fim, cessa o }\end{array}$ & $\begin{array}{l}\text { - Teste de mercado - } \\
\text { seqüência de introdução } \\
\text { dos produtos no mercado. } \\
\text { - Lançamento - tempo } \\
\text { para o lançamento do } \\
\text { produto; como e quando } \\
\text { o concorrente entrará ou } \\
\text { entrou no mercado; } \\
\text { desenho dos processos de } \\
\text { venda e distribuição; } \\
\text { atendimento do cliente e } \\
\text { assistência técnica; } \\
\text { campanhas de marketing. } \\
\text { - Ramp-up - aumento da } \\
\text { produção. } \\
\text { - Ao fim, cessa o }\end{array}$ & $\begin{array}{l}\text { - Teste de mercado - } \\
\text { seqüência de introdução } \\
\text { dos produtos no mercado } \\
\text { - Lançamento - tempo } \\
\text { para o lançamento do } \\
\text { produto; como e quando } \\
\text { o concorrente entrará ou } \\
\text { entrou no mercado; } \\
\text { desenho dos processos de } \\
\text { venda e distribuição; } \\
\text { atendimento do cliente e } \\
\text { assistência técnica; } \\
\text { campanhas de marketing. } \\
\text { - Ramp-up - aumento da } \\
\text { produção. } \\
\text { - Ao fim, cessa o }\end{array}$ \\
\hline
\end{tabular}


acompanhamento do acompanhamento do acompanhamento do produto pelo time. produto pelo time. produto pelo time. 


\section{ANÁLISE}

A verificação do nível de aderência entre os processos das empresas pesquisadas e o arcabouço teórico será executada sob as seguintes óticas: Projetos de Desenvolvimento de Novos Produtos na IMC; Pré-desenvolvimento; Desenvolvimento; e Pós-desenvolvimento.

É importante ressaltar, novamente, que a Perflex se diferencia bastante das outras três empresas (Deca, Cecrisa e Tigre), no que diz respeito a tamanho, número de funcionários, estrutura da área de desenvolvimento e investimentos em inovação. É uma empresa de organização informal, que ainda possui um processo de GDP pouco estruturado. Ao passo que as outras empresas são líderes de mercado, possuem um forte direcionamento para inovação, o que lhes exige uma organização maior na área de desenvolvimento de novos produtos.

Outro ponto que deve ser destacado, antes de ser iniciada a análise final, é sobre a segmentação de mercado das empresas estudadas. Observou-se que, não obstante a Tigre direcionar-se para o consumidor intermediário (B2B), diverge somente na forma de obtenção das informações, o que apenas gera uma necessidade de ampliação dessa estrutura de captação de idéias. E, mesmo com esse direcionamento, atualmente realiza pesquisas constantes com seu mercado consumidor, B2C. Por esse motivo, essa pequena diferença existente entre as empresas estudadas será destacada somente no item que fizer referência à etapa de identificação de oportunidades, demonstrando como é realizado esse processo de captação de idéias com o consumidor intermediário e o final.

\subsection{Projetos de desenvolvimento de novos produtos na IMC}

Observou-se que as quatro empresas desenvolvem projetos derivativos, com um grande direcionamento para projetos topológicos. No caso da Deca, Cecrisa e Tigre, que possuem áreas de pesquisa e desenvolvimento formalizadas e organizadas, elas contêm também em seu portfólio projetos de inovação, novos para o mercado, e não simplesmente novos para a empresa, seja pela utilização de uma nova máquina ou equipamento, ou pelo 
desenvolvimento interno de um produto. As mudanças topológicas são a grande maioria, alimentadas tanto por informações provenientes das áreas de marketing e vendas, como de adaptações ao modo de vida de seus consumidores. Enquanto que as incrementais são modificações na parte técnica do produto.

\subsection{Gestão do desenvolvimento de produtos}

No Quadro 49 é possível constatar que cada empresa possui etapas próprias de desenvolvimento, dentre elas a Tigre é a empresa que mais se alinha à literatura estudada. Apesar desta falta de alinhamento, as decisões trazidas pela literatura como essenciais para gerir o desenvolvimento de um novo produto são tomadas em momentos diferentes, de forma mais simples. O item seguinte trará a discussão sobre onde os casos estudados estão alinhados com a literatura, e onde não estão, e ainda quais características se mantiveram presentes nos quatro casos, sugerindo uma tendência da GDP na IMC.

\subsubsection{Pré-desenvolvimento}

O pré-desenvolvimento engloba questões referentes à estratégia e planejamento do produto, organização do desenvolvimento do produto e gerenciamento do projeto. No Quadro 59, são indicadas todas as decisões tomadas na etapa de pré-desenvolvimento, que se repete por todos os casos estudados.

Quadro 59 - Decisões comuns à Perflex, Deca, Cecrisa e Tigre - pré-desenvolvimento

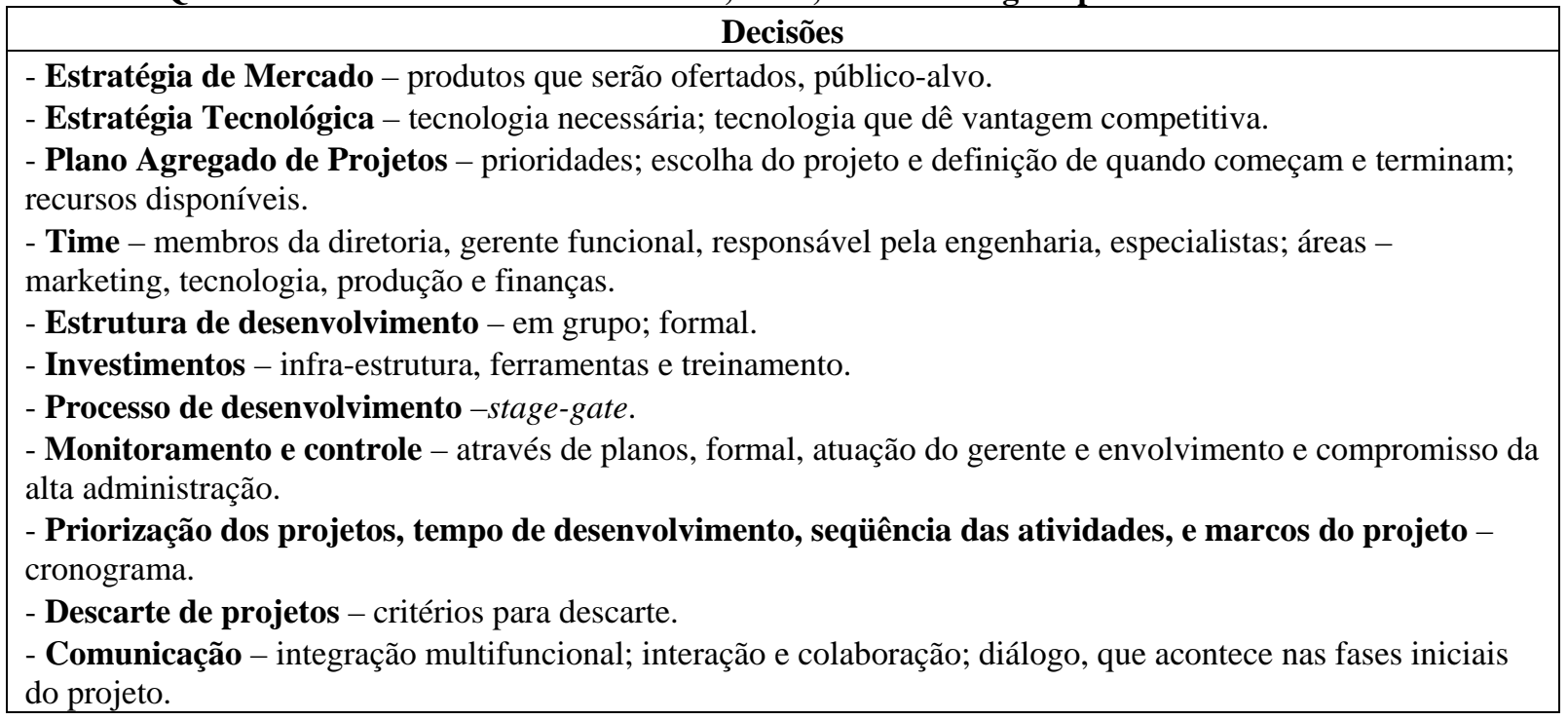


Na estratégia de mercado não há decisões sobre número, tempo e taxa de mudança da plataforma. Isso acontece, não por uma deficiência do processo, mas sim pela falta de aplicabilidade desta decisão à realidade da IMC. Em outras palavras, os produtos da IMC permanecem no mercado por um longo tempo, o que impossibilita a definição de quando poderá ser interrompido. Outra decisão que não é comum a todas as empresas é a que se refere à forma como os produtos serão disponibilizados e a que define número, tempo, freqüência e relação de produtos diferenciados. Nesse caso, a Cecrisa e a Tigre inserem essas informações em suas estratégias, procurando dessa forma detalhar o máximo possível as idéias.

Em relação à estratégia tecnológica, todas as quatro empresas pesquisadas indicam a tecnologia necessária para o novo produto e a que dará vantagem competitiva. São decisões essenciais para se analisar a viabilidade inicial da idéia, por isso, tomadas por todas as empresas. A Cecrisa e a Tigre informam também, nessa etapa, as fontes externas e internas da idéia, tecnologia. Essas fontes são as mais diversas possíveis nessas duas indústrias.

A Cecrisa e a Tigre se destacam nessa etapa do processo, pela diversidade de inputs de desenvolvimento e pela extrema organização e dedicação especiais. A literatura diz que se deve procurar estruturar o máximo possível essa etapa, obtendo as mais diversas informações para ampliação da boca do funil de desenvolvimento de Clark e Wheelwright (1993). No caso da Cecrisa, uma nova idéia pode nascer a partir de uma criação proveniente de seus profissionais ou de setores afins, que estão mais perto da moda (tecidos, móveis, eletrodomésticos), como também de novas tecnologias de matérias-primas, equipamentos e máquinas. Pode ainda surgir a partir do desenvolvimento reativo, na tentativa de reinterpretar o sucesso da concorrência internacional. É interessante notar, que a busca é feita mesmo fora de seu setor de atuação, pois se acredita que os outros setores citados exercem forte influência em seus produtos.

A Tigre recentemente acrescentou ao seu processo de captação de idéias uma nova forma de aproximar-se de seus consumidores finais, a pesquisa feita por meio da observação in loco, ou seja, o funcionário da empresa vai até à casa de seus consumidores para conhecer suas reais necessidades. Mesmo a empresa sendo direcionada para o consumidor intermediário, de intermediários, acredita que deve procurar conhecer as necessidades de seu mercado 
consumidor. De forma a complementar essa mudança, passou a trabalhar orientada a mercado e não mais a produto.

No caso da Perflex e da Deca, quem identifica essas oportunidades é o marketing e a assistência técnica. As idéias são provenientes do mercado, de necessidades apresentadas através de pesquisas de marketing ou através de problemas ou dificuldades técnicas. Nessas duas empresas, as idéias também podem surgir da aquisição de uma nova tecnologia e, no caso da Deca, pode surgir algo no laboratório interno da empresa, onde são desenvolvidas novas tecnologias para seus produtos.

As decisões que se relacionam com o plano agregado de projetos comuns às quatro empresas são as prioridades estabelecidas para escolha dos projetos, definição de quando começam e terminam, conforme os recursos disponíveis. Nesse caso, as empresas estudadas englobam todas as decisões indicadas na literatura estudada.

A literatura trata do time em relação à sua composição e áreas envolvidas. Nesse sentido, todas as empresas em estudo se preocuparam em tomar decisões essenciais que contribuíssem para o desenvolvimento de um novo produto. Vale ressaltar que apenas a Perflex não insere em seu processo o pessoal de vendas, o que pode ser interessante para o acompanhamento do processo de desenvolvimento, podendo paralelamente produzir as peças publicitárias e todo o material necessário para divulgação do produto no mercado.

A estrutura de desenvolvimento em grupo e do tipo formal é comum nas quatro empresas. Em relação à classificação da estrutura associada ao papel da liderança, esta não se aplica à Perflex, à Deca nem à Cecrisa, somente à Tigre, sendo mais similar à estrutura “peso leve”. Embora a Tigre tenha algumas características da classificação da estrutura do time como “peso leve”, esta parece pouco apropriada quando se pensa nas empresas utilizadas na pesquisa de Clark e Wheelwright (1993), onde as distâncias hierárquicas são excepcionais, e onde as reuniões eram os únicos momentos para a discussão dos projetos, as quais aconteciam muito raramente. Ao contrário da Tigre.

Na Cecrisa, a situação é um pouco diferente. Lá designou-se uma função para controlar e servir como elo entre os projetos e a alta administração, o controller. Ele tem acesso direto e responsabilidade pelo trabalho de todos os envolvidos no projeto, é responsável por todos os 
projetos que estão em andamento na empresa. Encontra-se no mesmo nível do gerente de desenvolvimento de produtos e tem pouca influência na organização. É o responsável efetivo do projeto.

A estrutura da Cecrisa diferencia-se do que é apresentado pela literatura, mas é uma estrutura que funciona muito bem, conforme a empresa. O controller tem conhecimento profundo de todos os projetos em andamento, o que proporciona tomadas de decisão conscientes em relação à alocação de recursos, aquisições, tudo o que estiver relacionado com o planejamento agregado dos projetos. Funcionaria para empresas que tenham poucos projetos em andamento.

O arranjo físico da área de desenvolvimento é diferente apenas na Perflex, onde as pessoas ficam alocadas em áreas diferentes. Na Deca, Tigre e Cecrisa existe uma área comum para todos, o que facilita a comunicação, a interação e a integração. É importante ressaltar que não é uma área apenas para os membros de um projeto, mas para todas as áreas que estão diretamente relacionadas com o desenvolvimento de produtos, como engenharia, projeto, planejamento e desenvolvimento.

Todos os investimentos necessários para o desenvolvimento de um novo produto são analisados pelas quatro empresas. Somente a Perflex possui uma deficiência na definição dessas informações, devido a não possuir um processo de busca de informações organizado.

O processo de desenvolvimento utilizado pelas quatro empresas é o stage-gate de Cooper et al (2002b). Estas estabeleceram seus marcos para tomada de decisão e análise do projeto. O funil de Clark e Wheelwright (1993) não é utilizado nem na Perflex nem na Deca. O processo de desenvolvimento dos projetos de inovação nas duas empresas citadas ocorrem similar a um túnel e não a um funil, pois eles inserem uma idéia e trabalham em cima dela para gerar um produto inovador. Nos outros casos, de melhorias contínuas, já se tem um produto, o qual é aperfeiçoado e modificado.

A Deca, a Cecrisa e a Tigre utilizam também a engenharia simultânea que está presente, por exemplo no caso da Cecrisa, na etapa de Elaboração do Anteprojeto, quando paralelamente ao desenvolvimento do conceito do produto inicia-se a geração das primeiras idéias do mix promocional da nova coleção. A Cecrisa lança mão ainda do funil de desenvolvimento, mas a 
Tigre faz uso desta técnica de forma mais ampla, pois procura expandir o máximo possível a "boca” do funil, o que é feito com a estruturação cada vez maior da etapa de identificação de oportunidades.

O monitoramento e controle do projeto são feitos nas empresas pesquisadas da mesma maneira, por meio de planos formais, com a atuação do gerente e envolvimento e compromisso da alta administração. Na Perflex, por ser uma empresa pequena, o diretor, que é o tomador de decisões, está presente ativamente no processo, sendo quase que desnecessária a atuação do gerente industrial, como gerente do projeto. Na Deca, Cecrisa e Tigre o monitoramento dos projetos é feito mensalmente pela alta administração, tendo em cada uma das empresas pessoas responsáveis pelo cumprimento do cronograma de cada projeto. No caso da Cecrisa, como já citado anteriormente, existe o controller, que cumpre com esta função.

A priorização dos projetos, o tempo de desenvolvimento, a seqüência das atividades e os marcos são definidos ou em planos e/ou em cronogramas. A Perflex vale-se somente dos cronogramas, enquanto as outras empresas utilizam tanto os cronogramas, quanto os planejamentos. Quanto maior o número de informações para se tomar decisões, para controle do projeto, mais efetivo e eficiente ele será.

É interessante notar que a Perflex e a Deca possuem uma estrutura de priorização de desenvolvimento bastante simples, o que pode prejudicar a escolha dos novos produtos. Priorizam seus projetos de acordo com indicações da área de marketing. A Cecrisa aperfeiçoa o processo e lança mão de dois critérios: grau de inovação e se é vendável. Em cada marco, o projeto será analisado com base nesses dois pólos, dependendo do momento, a alta administração dará mais ênfase para um ou outro ponto.

A literatura indica que é necessário elaborarem-se planos para auxílio na identificação dos melhores projetos; a Tigre possui esses planos, mas utiliza critérios qualitativos e quantitativos para essa seleção. Seus critérios proporcionam uma avaliação do tempo de retorno do investimento e da margem de contribuição, do potencial estratégico, do grau de complexidade e inovação. A importância do potencial estratégico se dá, pois a Tigre possui um projeto para cada produto e, freqüentemente, vários projetos correspondem a uma só linha, sendo assim complementares e essenciais. 
A maior dificuldade, porém, está na definição de critérios confiáveis para descarte de projetos fracos, com pouca probabilidade de sucesso. Os mesmos critérios utilizados para priorização de projetos são também utilizados para descarte. Isso se deve à falta de um check list com pontos essenciais que os projetos devem ter.

Outro ponto de decisão nessa fase é em relação à comunicação. As quatro empresas atuam da mesma forma, porém em diferentes graus. Nas etapas iniciais do processo há uma integração maior entre o marketing e a área de desenvolvimento de produtos da empresa. Já nas etapas finais, a integração é maior com a produção. A comunicação da Perflex, Deca, Cecrisa e Tigre, conforme os critérios de Clark e Wheelwright (1993), é rica, realizada cara a cara, com a utilização de modelos gráficos, que facilitam a interação; é mais freqüente e ocorre nos dois sentidos, ou seja, um diálogo; e acontece desde as fases iniciais do projeto. Isso se deve ao fato de serem empresas relativamente pequenas em comparação com as utilizadas na pesquisa de Clark e Wheelwright (1993).

\subsubsection{Desenvolvimento}

Nesse item serão analisadas as etapas que fazem parte do desenvolvimento do produto: desenvolvimento do conceito, projeto da cadeia de suprimentos, projeto do produto, teste e validação de desempenho, e ramp-up e lançamento.

\subsubsection{Desenvolvimento do conceito}

Quadro 60 - Decisões comuns à Perflex, Deca, Cecrisa e Tigre - desenvolvimento do conceito

\begin{tabular}{|l|}
\hline Decisões \\
\hline - Clientes e consumidores finais - utilização de ferramentas para conhecer as necessidades do mercado. \\
- Escopo detalhado do produto - identificar quem é o cliente, o consumidor e suas necessidades; requisitos do \\
produto; produtos concorrentes e similares; objetivos ou metas que o produto deve atender; preço; \\
congelamento das características em etapas finais; Conceito central - customer- and market-driven concept. \\
- Variações do produto - quais serão, componentes compartilhados entre as variações. \\
\hline
\end{tabular}

Na etapa de desenvolvimento do conceito do produto, a interação entre todos os envolvidos no projeto deve acontecer, para que problemas futuros que inviabilizem o projeto sejam eliminados. Na Perflex, Cecrisa e Tigre a participação acontece desde essa etapa. No caso da 
Deca, a interação de todos os componentes do time só inicia na terceira etapa do processo, Engenharia do Produto, que, nas etapas do processo de GDP de Krishnan e Ulrich (2001), corresponde à etapa de Projeto da Cadeia de Suprimentos e Projeto do Produto.

A Deca acredita que é melhor convocar o time após o desenvolvimento do conceito, pois um protótipo em mãos e uma idéia já inicialmente trabalhada pela designer servirão como um recurso de comunicação que facilitará a identificação de modificações, de equipamentos necessários, como também irá auxiliar na definição de quais áreas realmente são necessárias para o desenvolvimento do projeto.

Smith e Reinertsen (1998) asseguram que nessa fase inicial a empresa deve procurar complementar as informações, para que mais na frente não sejam acrescentadas informações adicionais, que venham a retardar o processo de desenvolvimento. Com essa finalidade, as empresas estudadas lançam mão de ferramentas que auxiliam na identificação das necessidades dos clientes e consumidores finais. Porém, nenhuma empresa insere o consumidor nesse processo.

É nessa etapa que o projeto deve ser detalhado de forma que contenham o máximo de informações possível, a fim de auxiliar no seu desenvolvimento. As quatro empresas identificam o cliente, o consumidor e suas necessidades, indicam os requisitos do produto, produtos concorrentes e similares, as metas que o produto deve atender, e o preço que pretendem praticar. A Cecrisa e a Tigre acrescentam ao escopo do projeto informações sobre tecnologias disponíveis e necessárias, serviços agregados ao produto e outras informações relevantes para a empresa.

A Cecrisa possui uma estrutura bastante organizada para compilar todas as informações sobre o novo projeto, o Anteprojeto. Estabelece como meta para essa etapa dar substância conceitual e mercadológica às novas linhas de produtos e integrar as várias ações a elas relacionadas. Primeiro é feita a conceituação da linha, que contém o nome, tema, relevância, funcionalidade, mercado-alvo, linguagem estética, estilo de vida, palavras-chave para associação de idéias, a imagem ícone da linha, o que poderá ser utilizado nas peças promocionais da linha, se se caracteriza como inovação ou incremental, qual o diferencial, e ainda testemunhos sobre a atualidade da idéia. 
Nesse mesmo documento da Cecrisa são descritas a estrutura da linha, com indicação do processo produtivo, as características técnicas e estéticas do produto, de seus complementos e da embalagem. Faz-se uma sondagem do mercado para identificar o potencial da linha, e analisam-se os preços dos produtos concorrentes para definição do preço do produto. Por fim, é feita a proposta inicial do mix promocional.

Na Tigre, o projeto também é bem detalhado, conseqüência da vasta busca de informações realizada na etapa de identificação de idéias. A área de $P \& D$ aperfeiçoa o projeto rapidamente, acrescentando informações sobre preço, mercado, produtos similares e complementares, componentes, investimentos, normas e patentes relacionadas ao produto, e detalhamento do consumidor e de suas necessidades. Observa-se que o cuidado no detalhamento das informações tanto na Cecrisa, quanto na Tigre é bastante rigoroso, pois consideram essa etapa como uma das principais. Entendem que, com o escopo bem definido, a realização das etapas seguintes acontecerão de maneira mais simples.

Em todas as empresas as decisões poderão ser modificadas até as etapas finais do projeto, por isso deve-se, conforme Smith e Reinertsen (1998), procurar especificar bem o projeto, pois quaisquer modificações adicionadas posteriormente podem parecer inocentes, mas talvez adicionem complexidade e, conseqüentemente, mais tempo ao ciclo.

Agopyan (2007) ${ }^{24}$ afirma que a IMC tem como principal input o market-driven concept, o que é confirmado pelas empresas estudadas. No entanto, para definição do conceito central do produto, a Cecrisa e a Tigre lançam mão, também, dos inputs technology-driven concept, design-driven concept, e value-driven concept. A Tigre ainda utiliza o service-concept. Na literatura apresentada, identificou-se que atualmente o desenvolvimento sustentável é um dos pontos que está sendo considerado na definição dos conceitos dos novos produtos na IMC, o que pode ser confirmado pelos casos estudados.

No que se refere à arquitetura do produto, forma física, projeto industrial e variações, as empresas, de acordo com Krishnan e Ulrich (2001), podem obtê-los por meio de desenhos virtuais ou croquis. Na Perflex, Cecrisa e Tigre isso é alcançado por meio de desenhos virtuais, enquanto que na Deca, primeiro é feito um protótipo virtual e depois um croqui,

\footnotetext{
${ }^{24}$ O Prof. Vahan Agopyan, membro da banca de qualificação desta dissertação, deu esta contribuição durante o processo de qualificação.
} 
realizado em laboratório interno da empresa. A Deca afirma que nessa etapa é necessário fazer o croqui, pois muitas vezes se idealiza um projeto e ao desenvolver o croqui o resultado não é o almejado.

\subsubsection{Projeto da cadeia de suprimentos}

As atividades da fase de projeto da cadeia de suprimentos envolvem o fluxo interno e externo de materiais. O Quadro 61 apresenta todas as decisões comuns às quatro empresas que se referem à etapa de Projeto da Cadeia de Suprimentos.

Quadro 61 - Decisões comuns à Perflex, Deca, Cecrisa e Tigre - projeto da cadeia de suprimentos Decisões

- Componentes - projetados internamente ou comprados prontos; quem projetará, desenvolverá e produzirá. - Cadeia física de suprimentos - configuração, incluindo o local de junção dos componentes; seleção de fornecedores das tecnologias e equipamentos; sistema de produção e distribuição; custos diretos de produção; custos entre fornecimento e demanda.

Na Perflex, na Deca e na Cecrisa a etapa de Projeto da Cadeia de Suprimentos é feita juntamente com a etapa de Projeto do Produto. Nos casos individuais, a discussão dessa etapa foi feita junto com a etapa de Projeto do Produto, porém, para a melhor compreensão, a análise foi feita nesse item.

Em relação aos componentes todas as quatro empresas procuram definir quais projetos serão feitos internamente e quais serão comprados prontos, definindo caso necessário, quem projetará, desenvolverá e produzirá. Em relação à cadeia física de suprimentos indicam sua configuração, a forma que selecionarão os fornecedores das tecnologias e equipamentos e o sistema de produção e distribuição.

Um ponto que merece destaque é que a Cecrisa consegue definir muito bem, nessa etapa, considerando que esta acontece junto com a etapa de Projeto do Produto, quem serão seus fornecedores, quais componentes comprarão e quais produzirão internamente, e quem os projetará, desenvolverá e produzirá. Isso se deve ao fato de a empresa realizar nessa etapa a chamada "montagem do produto", onde é realizada a prototipagem em cerâmica, simulando o processo produtivo no laboratório interno da empresa, onde já são utilizadas a matéria-prima e os equipamentos necessários para a produção da nova coleção. Obtendo assim informações precisas de custos de produção e entre fornecimento e demanda. 
No caso da Tigre, para que a área de $P \& D$ consiga fornecer informações reais sobre os recursos da empresa, é feita uma análise, sob a ótica da logística e planejamento, tomando por base os investimentos necessários. Nesse particular, a empresa possui equipamentos, recursos, local de armazenamento, rede de distribuição e Centro de Distribuição - CD. Ao fim dessa etapa, a área de $\mathrm{P} \& \mathrm{D}$ deve ter em mãos um relatório de mercado, um relatório técnico, os fluxos mapeados de todo o processo e um protótipo virtual.

A definição dessas informações antes de passar para a etapa seguinte é de grande importância, pois possibilita à empresa o investimento e, por conseguinte, dar continuidade ao desenvolvimento, consciente de que será possível sua produção, armazenamento e distribuição.

\subsubsection{Projeto do produto}

É nessa etapa que o projeto será detalhado, contendo todas as informações finais para produção do novo produto.

\section{Quadro 62 - Decisões comuns à Perflex, Deca, Cecrisa e Tigre - projeto do produto}

\section{Decisões}

- Especificação dos parâmetros do projeto - projeto detalhado dos componentes; relação entre os componentes do produto; seleção de material e de processo e projeto das ferramentas e equipamentos; planos de processo; desenhos finais com tolerâncias.

- Embalagem - projeção da embalagem; planejamento do processo de embalagem.

Todas as decisões indicadas pela literatura como essenciais para a realização dessa etapa, no que se refere à especificação dos parâmetros do projeto, são tomadas pelas quatro empresas. Ao fim dessa etapa, na Cecrisa, o processo tecnológico e equipamentos estarão testados e aprovados, e o mix promocional pronto.

Essa etapa na Tigre é denominada Projeto Detalhado do Produto. É importante observar que até esse momento, foram feitos somente protótipos virtuais. No entanto, pode se considerar como parte dessa etapa a aprovação do protótipo virtual e o desenvolvimento do protótipo em gesso. 
A projeção da embalagem e o planejamento do processo de embalagem também são decisões comuns a todas as empresas. Sendo que na Deca e na Tigre também se definem questões como avaliação da distribuição do produto, incluindo o transporte e a entrega, e definição das formas e sinalizações das embalagens dos novos produtos.

Vale ressaltar que na Cecrisa tudo o que se refere à embalagem começa a ser pensado desde a etapa de desenvolvimento do conceito, analisando-se facilidades para distribuição do produto, já que se caracteriza como um produto de difícil manuseio, devido ao seu tamanho e peso. $\mathrm{Na}$ maioria das vezes, não é necessária nenhuma alteração, uma vez que os tamanhos são padronizados. Essa informação é de extrema importância quando há constantes modificações nas embalagens dos produtos que determinada empresa comercializa, caso essas alterações sejam pequenas, a participação de pessoas da área de embalagem pode ser postergada para etapas finais do processo.

O material de suporte do produto comum a todas as empresas é o manual de instalação, que não é oferecido pela literatura. No entanto, a Cecrisa e a Tigre elaboram também o manual do material de treinamento. Nessas duas empresas são elaborados manuais completos de como realizar o treinamento para manuseio dos produtos, além de manuais que auxiliam no processo de venda do produto, fornecendo dicas de como vender e como negociar.

\subsubsection{Teste e validação de desempenho}

Quadro 63 - Decisões comuns à Perflex, Deca, Cecrisa e Tigre - teste e validação de desempenho

\begin{tabular}{|l|}
\hline \multicolumn{1}{|c|}{ Decisões } \\
\hline - Prototipagem para validação - em relação a funcionamento, tamanho e fabricação; projeto industrial, \\
durabilidade, encaixe e finalização; e custos de produção. \\
- Teste em pequena escala do projeto - produção piloto; definição dos processos de produção e manutenção. \\
- Processo de construção dos protótipos - simulação virtual, prototipagem rápida; paralela; prototipagem em \\
etapas iniciais do projeto. \\
- Benefícios do protótipo - contribuem para a identificação de oportunidades; aprendizado da organização; \\
testa a comunicação entre os membros do projeto; auxilia na resolução de conflitos.
\end{tabular}

As decisões tomadas nessa etapa do processo nas empresas Perflex, Deca e Cecrisa confundem-se com as decisões da etapa anterior. Krishnan e Ulrich (2001) indicam que a produção piloto deve ser feita nessa etapa, no entanto, a Perflex faz o teste em pequena escala na etapa anterior, e nesta só é feita a avaliação do projeto. O try-out de implantação na Deca é 
realizado com o acompanhamento dos primeiros lotes produzidos. Esse acompanhamento se deve ao fato de ser a primeira vez que a linha de produção está lidando com os novos produtos, equipamentos, tecnologias, etc.

Na Cecrisa, o try-out do processo é denominado de "testes semi-industriais". Todas as peças que são produzidas vão para estoque e servirão de amostra para teste, de mostruário para as lojas que venderão a nova coleção, showrooms, ou seja, não serão vendidas. A etapa de tryout do projeto da Tigre deixa de ser responsabilidade da área de P\&D e passa a ser da engenharia. Esse teste é feito para que todos aprendam a manusear algum novo equipamento ou ferramenta e para verificar se o processo está pronto para ser produzido em maior escala.

A produção piloto ou a produção acompanhada do processo são essenciais para identificação de necessidades de alteração de algum componente, tecnologia, de realização dos treinamentos para manuseio dos novos equipamentos e ferramentas. De forma geral, para aprendizado de como produzir os novos produtos.

É interessante perceber que os produtos produzidos nessa etapa não são revertidos para venda, mas sim para a realização de testes laboratoriais, a fim de se verificar funcionamento, tamanho e fabricação, projeto industrial, durabilidade, encaixe e finalização. Na Deca, o teste é feito em laboratório e nos banheiros da própria fábrica, na casa dos funcionários ou em restaurantes de rodovias, devido ao grande giro de pessoas nesses locais, pois assim é possível realizar vários testes em menor tempo.

Além de ser utilizado para a realização de testes laboratoriais, os produtos da Cecrisa servirão também como amostra para os pontos de venda e showrooms da própria empresa. Porém, a Cecrisa afirma que não realiza teste de mercado, de forma que os produtos sejam novidade para todos, inclusive para seus funcionários. Os primeiros produtos produzidos nesta etapa na Tigre são submetidos a testes, avaliando seu tamanho, funcionamento, fabricação, projeto industrial, durabilidade, encaixe e finalização, e custos de produção. A avaliação da reação dos consumidores só será feita na etapa final do processo.

Em relação ao tipo do protótipo, nenhuma das classificações de Clark e Wheelwright (1993) se alinha às empresas pesquisadas, pois estas categorias foram estabelecidas em realidades diferentes, com empresas maiores, muito mais estruturadas e hierarquizadas. O processo de 
construção dos protótipos varia de acordo com a etapa em que se encontra o projeto, podendo ser virtual, prototipagem rápida (experimentação real) ou protótipos em isopor, nas quatro empresas. A prototipagem ocorre em todas as empresas paralela a todo o processo, acompanhando-o desde as etapas iniciais. Ocorre concomitantemente ao processo, desde as primeiras etapas, o que proporciona às empresas diversas vantagens, no que contribui para a identificação de oportunidades, aprendizado da organização, formação de novas capacidades, além de testar a comunicação entre os membros do projeto e auxiliar na resolução de conflitos.

A Perflex já realiza nessa etapa o teste de mercado com uma abrangência pequena, já que a área de marketing leva o produto para alguns poucos pontos de venda para avaliação.

\subsubsection{Ramp-up e lançamento}

Na etapa de ramp-up e lançamento, Clark e Wheelwright (1993) indicam a possibilidade de realizar o teste do produto no mercado, e Amaral et al (2006) indicam pontos de decisão no lançamento e ramp-up.

\section{Quadro 64 - Decisões comuns à Perflex, Deca, Cecrisa e Tigre - ramp-up e lançamento}

\begin{tabular}{|l|}
\hline \multicolumn{1}{|c|}{ Decisões } \\
\hline - Lançamento - desenho dos processos de venda e distribuição; campanhas de marketing. \\
- Ramp-up - aumento da produção. \\
- Ao fim cessa o acompanhamento do produto pelo time.
\end{tabular}

O teste de mercado na Perflex é feito na etapa anterior, como já foi indicado. O nível de realização é pequeno, já que a área de marketing leva o produto para alguns poucos pontos de venda para avaliação. Na Deca, o teste de mercado só acontece quando o produto é lançado. Na Cecrisa e na Tigre, o próprio lançamento do produto se confunde com o teste no mercado e, nesse caso, só será aumentada a produção se o produto tiver sucesso no mercado, com isso a empresa evita a formação de estoques inviáveis.

A Tigre, além disso, possui um sistema em que todos os primeiros produtos lançados entram em “quarentena”, e são acompanhados de perto por profissionais capacitados, para identificarem possíveis problemas nos produtos que possam ser modificados antes de saírem 
desse período. A vantagem desse processo é que a empresa não forma estoques de produtos que possam estar defeituosos e aproveitam para avaliar a sua aceitação no mercado.

No lançamento do produto, as decisões comuns aos casos estudados são em relação ao desenho dos processos de venda e distribuição e as campanhas de marketing. No caso da Deca, Cecrisa e Tigre, além desses pontos, também são definidos o tempo para o lançamento do produto, como e quando o concorrente entrará ou entrou no mercado, e como será feito o atendimento do cliente, e a assistência técnica do produto.

Na Deca e na Tigre o lançamento é feito inicialmente para o pessoal interno. Inicialmente é divulgado o lançamento do produto para todos os colaboradores da Deca, em especial para os vendedores, através de uma Instrução Administrativa - IA. Apesar de todos já estarem cientes da existência do produto, essa IA é enviada com a finalidade de sedimentar e passar maiores detalhes sobre preço, tamanho, vantagens, novas tecnologias e locais de venda. Após sua divulgação interna, é feita a divulgação externa da nova linha.

A Cecrisa preza pela surpresa no lançamento do produto, por essa razão, as novas coleções só serão conhecidas nas feiras e eventos do setor. Após essa primeira exposição é que os produtos serão apresentados para o pessoal interno por meio de treinamentos, através de teleconferência, gravações de DVD's com um dos consultores ministrando uma palestra sobre a nova coleção, e também com treinamentos feitos pelos consultores para arquitetos, donos de lojas, e todos aqueles que fazem parte do processo de compra final dos produtos da empresa, no Brasil.

Na Tigre, o lançamento é feito primeiro internamente, com a distribuição de um PDF, o qual é enviado para o pessoal de vendas da empresa, com um resumo de todo o projeto, suas vantagens, objetivos, características, preço bruto, código de barras, argumentos de venda, simulação de perguntas técnicas sobre o produto e todos os serviços que agregam o produto. Depois é feito o lançamento externo.

O ramp-up das quatro empresas será feito de acordo com solicitações da área de marketing e dependerá da aceitação do produto pelo mercado consumidor. 
Por fim, a empresa deve procurar definir se o time continuará ou não acompanhando o produto no mercado (ROZENFELD et al, 2006). Na Perflex, o acompanhamento é interrompido na etapa anterior, quando é assumido pela área de marketing. Na Deca, Cecrisa e Tigre o acompanhamento do produto pelo time é finalizado nessa etapa.

\subsubsection{Pós-desenvolvimento}

No pós-desenvolvimento podem ser consideradas duas decisões apresentadas pela literatura pesquisada: aprendizados e melhorias para projetos futuros e avaliação do desempenho dos projetos. O Quadro 65 apresenta as decisões comuns às quatro empresas estudadas.

Quadro 65 - Decisões comuns à Perflex, Deca, Cecrisa e Tigre - pós-desenvolvimento

\section{Decisões}

- Aprendizados e melhorias para projetos futuros - melhoria das capacidades envolvidas no processo e o próprio processo em si.

- Desempenho - qualidade do projeto, planejado x o que efetivamente aconteceu.

No que se refere aos aprendizados e melhorias para projetos futuros, as quatro empresas estudadas procuram realizar melhorias nas capacidades envolvidas no processo e no próprio processo em si. Sendo que a Tigre realiza essa atividade de uma forma diferenciada e que merece destaque. Logo após o lançamento, o produto entra em "quarentena” na Assistência Técnica. Com isso, todas as reclamações além de serem atendidas de imediato, são feitas as modificações nos produtos a serem produzidos. Por essa razão, a Tigre não forma estoque antes dessa fase de "teste" do produto no mercado. Outros aprendizados posteriores são utilizados em produtos futuros, podendo ser a evolução do produto para uma nova linha.

Clark e Wheelwright (1993) e Clark e Fujimoto (1991) indicam quatro dimensões para avaliar o desempenho de projetos: tempo para colocar o produto no mercado, produtividade, qualidade do projeto e planejado versus o que efetivamente aconteceu. As quatro empresas avaliam seus projetos de acordo com a qualidade, e também quanto à análise do que foi planejado versus o que efetivamente aconteceu. A Tigre vai um pouco além e mede o faturamento com produtos novos, o tempo para colocar o produto no mercado e a taxa de sucessos com o auxílio do BSC. Analisa se o que foi planejado de fato aconteceu, avaliando assim a qualidade do projeto. 


\section{CONSIDERAÇÕES FINAIS, LIMITAÇÕES E IMPLICAÇÕES GERENCIAIS}

É fator essencial para o sucesso das empresas entender como funcionam as forças do ambiente de negócios e de sua competência em converter de forma habilidosa esse conhecimento em produtos e serviços que ofereçam valor superior aos consumidores. Empresas inovadoras, que utilizam a inovação para diferenciar seus produtos e serviços dos concorrentes, têm grandes vantagens sobre as outras.

As empresas líderes de mercado da IMC têm procurado se adequar às normas técnicas, reduzir a cópia de produtos estrangeiros em favor do desenvolvimento de design próprio, e modernizar a gestão empresarial e a gestão da qualidade com o emprego de técnicas organizacionais avançadas. Essa é uma realidade que pôde ser comprovada pelos casos apresentados nesta dissertação.

Porém, a inovação traz consigo muita incerteza, o que exige que o processo seja cuidadosamente gerenciado e os experimentos muito bem projetados e controlados. A intensa competitividade entre as empresas somada aos consumidores mais conscientes exige que os produtos surpreendam e impressionem seu mercado. Por essa razão, cada vez mais aumenta o número de pesquisas com o intuito de identificar práticas bem- sucedidas para determinados mercados ou produtos, mas deve-se lembrar que não existe uma melhor forma de organizar e gerenciar um projeto, cada tecnologia, cada mercado, cada empresa exige diferentes estruturas e processos organizacionais (TIDD et al, 1999).

Este trabalho propôs-se a estudar o processo de gestão do desenvolvimento de um novo produto na indústria de materiais de construção. Buscou-se com isso identificar o grau de formalização, as etapas e as características da GDP na IMC, e ainda as convergências e divergências entre os casos práticos e a literatura levantada. Com essa finalidade foram levantados, na teoria e na prática, os aspectos relevantes da gestão do desenvolvimento de um novo produto, tendo a IMC como objeto de estudo desta dissertação.

É importante lembrar também que esta pesquisa direcionou-se para a indústria da construção de edifícios, comerciais e residenciais. E, mais especificamente, segundo a classificação de 
Cardoso et al (2002), componentes dessa indústria, pois geram associação e/ou montagem e podem ter algum grau de serviços incorporados ao seu fornecimento.

A visão da teoria estudada foi, então, contraposta à realidade observada em campo. Perceberam-se algumas similaridades, como também alguns pontos que podem ser considerados característicos da IMC. O setor está bem mais estruturado do que se tem conhecimento, pode-se observar essa afirmação a partir da descrição dos casos, onde foi apresentada, de forma detalhada, toda a estruturação do processo de GDP nessas empresas.

Observou-se com essa pesquisa que o setor de componentes da IMC já não é mais um setor ultrapassado, mas sim um setor que tem se destacado cada vez mais no desenvolvimento de novas tecnologias, iniciando um processo de readequação de suas estruturas. O que proporciona um maior investimento em inovação e em novas técnicas organizacionais.

Apesar de apenas uma das empresas ser de pequeno porte, percebe-se que ela não está tão aquém dos conceitos relacionados com a GDP, porém o processo ainda é feito informalmente. Já a Deca, Cecrisa e Tigre possuem processos formalizados, que trazem conceitos e técnicas atuais, e procuram inserir alterações constantemente para seu aperfeiçoamento. A Tigre é a que se encontra mais formalizada, seguida da Cecrisa, que possui processos e características bem organizados, mas diferenciados do que se vê na literatura. E a Deca está procurando a estruturação, mas ainda precisa ordenar melhor seu processo.

Podem-se observar no Anexo $\mathrm{C}$ as decisões comuns às quatro empresas, em cada uma das etapas do processo de GDP. Dentre estas empresas percebeu-se que a Cecrisa e a Tigre se destacam, em diversos momentos do processo, por realizarem atividades que vão além do que a literatura levantada indica.

Seguindo uma ordem cronológica do processo de desenvolvimento, um ponto que deve ser destacado é o processo de captação de idéias e informações feito pela Cecrisa e Tigre. Ambas possuem uma estrutura completa e organizada. A Tigre está ainda mais à frente desse processo de aproximação com o consumidor final, lançando mão de técnicas como a observação in loco e o processo interativo de geração de idéias utilizado por empresas como IDEO. 
Na etapa de desenvolvimento do conceito do produto, a Cecrisa se destaca pelas informações que acredita serem necessárias para iniciar o projeto. Procura, com isso, dar substância conceitual e mercadológica às novas linhas de produtos e integrar as várias ações a elas relacionadas. Insere, além das informações levantadas na literatura sobre GDP, posições sobre imagem da linha, o que poderá ser utilizado nas peças promocionais da linha, e ainda testemunhos sobre a atualidade da idéia.

Na próxima etapa, Projeto da Cadeia de Suprimentos, observou-se que a Tigre foi a única empresa, dentre as pesquisadas, a realizar um processo de obtenção de informações sobre a logística da empresa, avaliando equipamentos e recursos disponíveis, local de armazenamento, rede de distribuição e centros de distribuição.

Outro destaque da Cecrisa está no que diz respeito à montagem do produto, a qual realiza em etapas iniciais do processo, com a utilização tanto da matéria-prima final, quanto do processo produtivo que será utilizado. Tudo feito em laboratório interno ou nas indústrias de seus fornecedores.

Aqui se deve fazer referência à Deca, no que diz respeito ao lançamento interno do produto, a qual divulga a novidade para todos os funcionários da empresa por meio de uma Instrução Administrativa - IA, com a finalidade de sedimentar e passar maiores detalhes sobre o produto, como: preço, tamanho, vantagens, novas tecnologias e locais de venda. Na Cecrisa as coleções podem ser apresentadas por meio de treinamentos, realizados com o auxílio de teleconferências, gravações de DVD's, com um dos consultores ministrando uma palestra sobre a nova coleção, e também treinamentos feitos pelos consultores para arquitetos, donos de lojas e todos aqueles que fazem parte do processo de compra final dos produtos da empresa, no Brasil.

Já na Tigre, o lançamento interno é feito com a distribuição de um PDF, o qual é enviado para todo o pessoal de vendas da empresa, com um resumo de todo o projeto, suas vantagens, objetivos, características, preço bruto, código de barras, argumentos de venda, simulação de perguntas técnicas sobre o produto e todos os serviços que agregam o produto. Depois é feito o lançamento externo. 
Na etapa final a Tigre possui uma estrutura diferenciada, onde logo após o lançamento do produto, entra em “quarentena” na Assistência Técnica. Com isso, todas as reclamações além de serem atendidas de imediato, são feitas as modificações nos produtos a serem produzidos. Por essa razão, a Tigre não forma estoque antes dessa fase de "teste” do produto no mercado. Como forma de analisar a efetividade do lançamento, vai além do que as outras empresas, medindo o faturamento com produtos novos, o tempo para colocar o produto no mercado e a taxa de sucessos, com o auxílio do BSC.

Apesar dos pontos tratados acima não serem coincidentes entre todas as empresas analisadas, destacam-se pelo alinhamento com a literatura proposta, ou por irem além do que esta indica.

É importante destacar um detalhe que foi observado ao realizar-se a tentativa de classificação das empresas conforme critérios indicados por Clark e Wheelwright (1993). No que se refere à estrutura associada ao papel da liderança, somente a Tigre possui características similares à estrutura "peso leve”. Mesmo assim esta empresa parece desviar-se um pouco quando comparada às empresas pesquisadas por Clark e Wheelwright (1993), onde as distâncias hierárquicas eram imensas e as reuniões eram os únicos momentos para a discussão dos projetos, as quais aconteciam raramente.

Outra classificação é a do tipo de protótipo. Clark e Wheelwright (1993) indicam três categorias, sendo que nenhuma delas se encaixa perfeitamente nas empresas estudadas, o que se deve às grandes diferenças que existem entre as empresas estudadas nesta dissertação e as do trabalho realizado por Clark e Wheelwright (1993). Dessa forma, pode-se perceber a falta de aplicabilidade dessas classificações para empresas menores, empresas onde as distâncias hierárquicas são claramente muito pequenas.

E, finalmente, deve-se observar que os projetos derivativos, com um grande direcionamento para projetos topológicos, são predominantes neste setor. No caso da Deca, Cecrisa e Tigre, que possuem áreas de pesquisa e desenvolvimento formalizadas e organizadas, elas contêm também em seu portfólio projetos de inovação, novos para o mercado, e não simplesmente novos para a empresa, seja pela utilização de uma nova máquina ou equipamento, ou pelo desenvolvimento interno de um produto. No entanto, em menor quantidade que os projetos topológicos. 
Com este estudo foi possível conhecer a realidade das indústrias de materiais de construção, a qual não se encontra em más condições, pelo contrário, está atualizada com os novos conceitos que envolvem o tema deste trabalho, gestão do desenvolvimento de novos produtos, com um processo e uma estrutura formal e organizada.

\subsection{Limitações}

A principal limitação desta pesquisa reside no fato de, como pesquisa exploratória, ter uma amostra não-probabilística, não podendo ser considerada representativa para o universo em questão. Outra limitação está relacionada com o fato de ser uma pesquisa inicial, bastante ampla, impossibilitando um maior aprofundamento nos diversos pontos analisados.

Além disso, a respeito dos entrevistados, é importante ressaltar que inicialmente foram selecionados gerentes da área de desenvolvimento e um representante do time de desenvolvimento, gerente do projeto de preferência. No entanto, as diferenças nas estruturas organizacionais das empresas, a facilidade de acesso da pesquisadora e a disposição dos entrevistados em participar do estudo representaram questões fundamentais. Além disso, a forma com que foram realizadas as entrevistas divergiu de um caso para outro.

Outra limitação da pesquisa diz respeito às etapas de desenvolvimento selecionadas como base para a pesquisa. Escolheu-se trabalhar com as etapas de Krishnan e Ulrich (2001), pois eles fizeram um levantamento de uma vasta literatura existente sobre a GDP, resultando em aproximadamente 200 artigos na pesquisa final. Desta, identificaram etapas geradas a partir de decisões relacionadas, não se referindo à ordem temporal do processo de desenvolvimento.

Por esta razão, o presente estudo, o qual tem como objetivo conhecer o processo de GDP na IMC, adotou essa estrutura, já que com isso seria possível conhecer as principais características desse processo nas empresas e setor estudados, identificando as decisões realizadas em cada momento. Do ponto de vista metodológico, Krishnan e Ulrich (2001) deram ênfase nesses aspectos interessantes para a pesquisa, no entanto, não enfatizam o projeto do sistema, perdendo-se um pouco a ordem temporal dos fatos. 


\subsection{Sugestões para trabalhos futuros}

- Avaliar se os pontos identificados nesta dissertação se confirmam em outras indústrias de componentes da IMC.

- Realizar a mesma pesquisa nas indústrias de aglomerados e sistemas.

- Aplicar o mesmo estudo a indústrias direcionadas para construção pesada, de forma a verificar convergências e divergências.

- Aprofundar a pesquisa procurando conhecer os fatores críticos de sucesso no processo de GDP deste setor.

- Gerar um modelo de GDP para a IMC.

- Realizar a mesma pesquisa somente com empresas pequenas, procurando identificar convergências e divergências no processo.

\subsection{Implicações gerenciais}

Algumas observações podem ser feitas, como por exemplo, o caso da Perflex, que, apesar da informalidade na realização do processo de GDP, possui uma estrutura que funciona. Muitas vezes a empresa não se dá conta da importância de registrar esses conhecimentos. Isso pode ser-lhe prejudicial futuramente, pois, caso determinado colaborador, que detenha algum conhecimento-chave, deixar a empresa, poderá prejudicar seu desempenho futuro nessa área específica.

Pôde ser observado a partir dos casos que, quanto mais antiga a empresa e quanto maior em tamanho e número de funcionários, maior o grau de formalização. A formalização não parece ser necessária, por exemplo, para o caso da Perflex, mas para empresas que estão caminhando para melhor organização do seu processo de inovação, como a Deca, que precisa preocuparse continuamente com estruturas mais organizadas, como já está fazendo.

Uma grande vantagem das pequenas empresas como Perflex é a participação ativa do diretor em todas as decisões, pois não precisam esperar por reuniões formais para que dúvidas ou problemas sejam resolvidos, tudo pode ser solucionado ali, em questão de minutos. São essas vantagens que as empresas devem saber utilizar de forma eficiente e proativa. No caso das outras três organizações que fizeram parte da pesquisa, apesar de serem empresas maiores, as 
distâncias hierárquicas não eram tão grandes, mas suficientes para exigirem gerentes mais ativos das áreas envolvidas no projeto.

A comunicação é fator fundamental para o bom andamento das atividades, e quando não é bem utilizada, a burocracia emperra o sistema. Organizar e documentar atividades são procedimentos cansativos, mas necessários para perenizar conhecimentos na empresa.

Um cuidado que as empresas devem ter é em relação à centralização das decisões, como acontece na Perflex e na Deca. As decisões de desenvolver ou lançar um produto ficam sob a responsabilidade da área de marketing. Apesar de essa área conter informações sobre o mercado, indicando quando este está preparado ou não, podem acontecer momentos que, embora o mercado aparentemente não indique a necessidade de um novo produto, seu lançamento poderá ser um sucesso. 


\section{REFERÊNCIAS}

AGOPYAN, V. Melhor que parece. Revista Construção. São Paulo, n. 2686, p. 6-11, Ago. 1999.

AGOPYAN, V. Construção rompendo paradigmas. In: FARIA, C. P. (Org.). Inovação em construção civil: monografias. São Paulo: Instituto UNIEMP, 2005.

ASSOCIAÇÃO BRASILEIRA DA INDÚSTRIA DE MATERIAIS DE CONSTRUÇÃO - ABRAMAT. São Paulo, 2008. Disponível em: <http://www.abramat.org.br>. Acesso em: 15/04/2008.

; FUNDAÇÃO GETÚlio VARGAS PROJETOS - FGV PROJETOS. A cadeia produtiva da construção e o mercado de materiais. São Paulo, Ago. 2007a. Disponível em: <http://www.abramat.org.br>. Acesso em: 24/08/07.

; __ Análise setorial Abramat. São Paulo, Ago. 2007b. Disponível em: $<$ http://www.abramat.org.br>. Acesso em: 24/08/07.

; __ Suplemento integrante do boletim análise setorial Abramat: $30 \mathrm{mil}$ novos postos de trabalho na indústria de materiais. São Paulo, Fev. 2008. Disponível em: $<$ http://www.abramat.org.br>. Acesso em: 27/06/08.

ASSOCIAÇÃO BRASILEIRA DE NORMAS TÉCNICAS - ABNT. Normalização. 2006. Disponível em: <http://www.abnt.org.br>. Acesso em: 10/04/2008.

ASSOCIAÇÃO NACIONAL DOS COMERCIANTES DE MATERIAL DE CONSTRUÇÃO - ANAMACO. Dados do setor, 2006. Disponível em: $<$ http://www.anamaco.com.br>. Acesso em: 20/11/2007.

ASSOCIAÇÃO NACIONAL DE FABRICANTES DE CERÂMICA PARA REVESTIMENTO - ANFACER. Dados do setor, 2006. Disponível em: <http://www.anfacer.org.br>. Acesso em: 18/02/2008.

BACKMAN, M.; BÖRJESSON, S.; SETTERBERG, S. Working with concepts in the fuzzy front end: exploring the context for innovation for different types of concepts at Volvo Cars. R\&D Management, v. 37, n. 1, p. 17-28, 2007.

BACON, G.; BECKMAN, S.; MOWERY, D.; WILSON, E. Managing product definition in high technology industries: a pilot study. California Management Review. v. 36, p. 32-56, spring 1994 apud KRISHNAN, V.; ULRICH, K. T. Product development decisions: a review of the literature. Management Science. v. 47, n. 1, p. 1-21, Jan. 2001.

BECKER, M. C.; SALVATORE, P.; ZIRPOLI, F. The impact of virtual simulation tools on problem-solving and new product development organization. Research Policy, v. 34, p. 1302-1321, Aug. 2005.

BOECHAT, Y. Tigre cria marca para nova linha de produto. São Paulo, 21/08/2007. Disponível em: <http://www.abramat.org.br/> . Acesso em: 02/09/2008. 
BROWN, S.; EISENHARDT, K. Product Development: past research, present findings and future directions. The Academy of Management Review. v.20, n.2, p.343-378, Apr. 1995.

CAMACHO, J. S. Reaprendendo a construir. In: FARIA, C. P. (Org.). Inovação em construção civil: coletânea de artigos. São Paulo: Instituto UNIEMP, 2005.

CAMARGO JR., A. S. Engenharia Simultânea: uma comparação entre as aboradagens "point -based" e "set-based". São Paulo, 2003. Tese (Doutorado em Administração) Programa de Pós-Graduação em Administração, Departamento de Administração, Faculdade de Economia, Administração e Contabilidade da Universidade de São Paulo.

CARDOSO, L. R. de A.; ABIKO, A. K.; GONÇALVES, O. M. Estudo prospectivo da cadeia produtiva da construção civil no Brasil: produção e comercialização de unidades habitacionais. In: ENCONTRO NACIONAL DE TECNOLOGIA DO AMBIENTE CONSTRUÍDO, 9., maio 2002, Foz do Iguaçu, PR. Anais... Foz do Iguaçu, PR: ANTAC, 2002.

O futuro da indústria da construção civil: resultados de uma pesquisa de prospeç̧ão tecnológica para a cadeia produtiva da construção habitacional. São Paulo: PCCPOLI, 2005.

CATÁlogo DE PRODUTOS DECA. Catálogo de Produtos Deca - São Paulo. São Paulo, 2007.

CECRISA. Criciúma, Santa Catarina, 2008. Disponível em: <http://www.cecrisa.com.br>. Acesso em: 15/02/2008.

CHANDY, R.; HOPSTAKEN, B.; NARASIMHAN, O.; PRABHU, J. From invention to innovation: conversion ability in product develpment. Journal of Marketing Research. v. 43, p. 494-508, Aug. 2006.

CHUA, S. Meeting the customers' silent needs. Manufacturers' Monthly. Australia: Reed Business Information Australia, Sep. 2006.

CLARK, K. B.; WHEELWRIGHT, S. C. Managing new product and process development: Text and Cases. New York: The Free Press, 1993.

COELHO, L. Tecnologia contra o desperdício. Revista Arquitetura e Urbanismo. São Paulo: PINI, ano 22, n. 161, p. 82-86, Ago. 2007.

COMPANHIA DE DESENVOLVIMENTO HABITACIONAL E URBANO - CDHU. Qualihab. São Paulo, 2007. Disponível em: <http://www.cdhu.sp.gov.br>. Acesso em: 31/08/07.

COOPER, R. G.; EDGETT, S. J.; KLEINSCHMIDT, E. J. Optimizing the stage-gate process: what best-practice companies do-I. Industrial Research Institute. p. 21- 27, Oct.. 2002a. Ebsco Publishing.

do-II. Industrial Research Institute. p. 43-49, Dec. 2002b. Ebsco Publishing.

Optimizing the stage-gate process: what best-practice companies 
COOPER, D. R.; SCHINDLER, P. S. Métodos de pesquisa em administração. 7. ed. Porto Alegre: Bookman, 2003.

ASSOCIAÇÃO BRASILEIRA DE CIMENTO PORTLAND - ABCP. 2006. Disponível em: < http://www.abcp.org.br/comunidade/>. Acesso em: 09/06/2008.

DA CAMARA, M. R. G.; BERGAMASCO, F. L. Competitividade e inovação de construção civil de Londrina. In: SEMINÁRIO LATINO-IBEROAMERICANO DE GESTIÓN TECNOLÓGICA, 11., out. 2005, Salvador. Anais... Salvador: ALTEC, 2005.

Nichos x vícios do mercado: visão empreendedora na construção civil. In: SIMPÓSIO DE GESTÃO DA INOVAÇÃO TECNOLOGICA, 22., 2002, Salvador. Anais... Salvador: ANPAD, 2002.

DALCUL, A. L. P. C. Novas tecnologias e relações de trabalho na construção civil. In: SBRAGIA, R.; MARCOVITCH, J.; VASCONCELLOS, E. (Org.). Gestão da inovação tecnológica: anais do XVIII simpósio de gestão da inovação tecnológica. São Paulo: Tec-Art Editora, 1994.

DECA. São Paulo, 2007. Disponível em:<http://www.deca.com.br>. Acesso em: 22/09/2007.

DULAIMI, M. F. The challenge of customer orientation in the construction industry. Construction Innovation. n. 5, p. 3-12, 2005.

ENFOQUE. 2008. Disponível em: <http://www.enfoque.com.br>. Acesso em: 23/02/2008.

EISENHARDT, K.; TABRIZI, B. N. Accelerating adaptive processes: product innovation in the global computer industry. Administrative Science Quarterly, v. 40, n. 1, p. 84-110, 1995.

Building theories from case studies. Academy of Management Review. v. 14, n. 4, p. 5-13, 1989.

FARIA, C. P. (Org.). Inovação em construção civil: coletânea de artigos. São Paulo: Instituto UNIEMP, 2005a.

FARIA, C. P. (Org.). Inovação em construção civil: monografias. São Paulo: Instituto UNIEMP, 2005b.

FERREIRA, A. B. H. Novo aurélio século XXI: o dicionário da língua portuguesa. 3. ed. ver. ampl. Rio de Janeiro: Nova Fronteira, 1999.

FERREIRA, A. G. G. A influência dos processos de desenvolvimento de produto no desempenho inovador das empresas. São Paulo, 2007. Dissertação (Mestrado em Administração) - Programa de Pós-Graduação em Administração, Departamento de Administração, Faculdade de Economia, Administração e Contabilidade da Universidade de São Paulo.

FRISHAMMAR, J. Managing information in new product development: a literature review. International Journal of Innovation and Technology Management. v. 2, n. 3, p. 259-275, Aug. 2005. 
GANEM, C.; SANTOS, E. M. dos (Org.). Brasil inovador: o desafio empreendedor: 40 histórias de sucesso de empresas que investem em inovação. Brasília: IEL - NC, 2006.

GANN, D. M. Innovation in the construction sector. In: DODGSON, M; ROTHWELL, R. The handbook of industrial innovation. USA: E. Elgar, 1994.

GARCIA, R.; CALANTONE, R. A critical look at technological innovation typology and innovativeness terminology: a literature review. The Journal of Product Innovation Management, vol. 19, p. 110-132, 2002 apud FERREIRA, A. G. G. A influência dos processos de desenvolvimento de produto no desempenho inovador das empresas. São Paulo, 2007. Dissertação (Mestrado em Administração) - Programa de Pós-Graduação em Administração, Departamento de Administração, Faculdade de Economia, Administração e Contabilidade da Universidade de São Paulo.

GARCIA, F.; FARINA, E. M. M. Q.; ALVES, M. C. Padrão de concorrência e competitividade da indústria de materiais de construção. São Paulo: Singular, 1997.

GIL, A. C. Métodos e técnicas de pesquisa social. São Paulo: Atlas, 1995.

GIL, A. C. Como elaborar projetos de pesquisa. 4. ed. 9. reimpr. São Paulo: Atlas, 2007.

GODOY, A. S. Introdução à pesquisa qualitativa e suas possibilidades. Revista de Administração de Empresas. São Paulo: RAE, v. 35, n. 2, p. 57-63, 1995a.

Pesquisa qualitativa: tipos fundamentais. Revista de Administração de Empresas. São Paulo: RAE, v. 35, n. 3, p. 20-29, 1995b.

GRIFFIN, A.; HAUSER, J. The voice of the customer. Marketing Science. v. 12, n. 1, winter 1993.

HALMAN, J. I. M.; HOFER, A. P.; Van VUUREN, W. Platform-driven development of product families: linking theory with practice. The Journal of Product Innovation Management. v. 20, p. 149-162, 2003.

HARGADON, A; SUTTON, R. I. Technology brokering and innovation in a product development firm. Administrative Science Quarterly. v. 42, n. 4, p. 716-749, Dec. 1997.

HOLOFOTE COMUNICAÇÃO. São Paulo, 2007. Disponível em: $<$ http://www.holofote.com>. Acesso em: 06/11/2007.

HUTT, M. D. B2B: gestão de marketing em Mercado industriais e organizacionais. 7. ed. Porto Alegre: Bookman, 2002.

IANSITI, M. Shooting the rapids: managing product development in turbulent environments. California Management Review. v. 38, n. 1, p. 37-58, fall 1995.

JARDIM, G. T. C.; CAMPOS, A. S. Light steel framing: uma aposta do setor siderúrgico no desenvolvimento tecnológico da construção civil. In: FARIA C. P. (Org.). Inovação em construção civil: monografias. São Paulo: Instituto UNIEMP, 2005.

KAMINSKI, P. C. Desenvolvendo produtos com planejamento, criatividade e qualidade. Rio de Janeiro: Livros Técnicos e Científicos, 2000. 
KLEINKNECHT, A.; Van der PANNE, G.; Van BEERS, C. Success and failure of innovation: a literature review. International Journal of Innovation Management. v. 7, n. 3, p. 309-338, Sep. 2003.

KOTLER, P. Administração de Marketing. 10a. ed. São Paulo: Prentice Hall, 2000.

KRISHNAN, V.; ULRICH, K. T. Product development decisions: a review of the literature. Management Science. v. 47, n. 1, p. 1-21, Jan. 2001.

LINO, F. A construção civil rumo à industrialização. In: FARIA C. P. (Org.). Inovação em construção civil: monografias. São Paulo: Instituto UNIEMP, 2005.

MAIDIQUE, M. A.; ZIRGER, B. J. A model of new product development: an empirical test. Management Science. v. 36, n.7, p. 867-883, Jul. 1990.

MARTINS, M. G. Implantação de inovações tecnológicas no setor da construção: a visão do fornecedor. In: SIMPÓSIO DE GESTÃ̃O DA INOVAÇÃO TECNOLÓGICA, 22., Nov. 2002, Bahia. Anais... Bahia: ANPAD, 2002.

MIOZZO, M.; IVORY, C. Restructuring in the british construction industry: implications of recent changes in project management and technology. Technology Analysis \& Strategic Management. v. 12, n. 4, p. 513-531, Dec. 2000.

MORICONI et al. O varejo de material de construção no Brasil: mecanismos operacionais. São Paulo: DVS Editora, 2006 apud PROENÇA, M. C. de A. Gestão da marca ao longo da cadeia de valor: um estudo de caso no mercado de varejo de material de construção. São Paulo, 2007. Tese (Doutorado em Administração) - Programa de Pós- Graduação em Administração, Departamento de Administração, Faculdade de Economia, Administração e Contabilidade da Universidade de São Paulo.

NÚCLEO DE ENSINO E PESQUISA DA ALVENARIA ESTRUTURAL - NEPAE. Nepae. Ilha Solteira, São Paulo, 2006. Disponível em: <http://www.nepae.feis.unesp.br>. Acesso em: 15/03/07.

OLIVEIRA, O. J. S. (Org.). Gestão da qualidade: tópicos avançados. São Paulo: Pioneira Thomson, 2004.

PAVITT, K. Sectoral patterns of technical change: towards a taxonomy and a theory. Science Policy. v. 13, p. 343-373, 1984.

PERFLEX. São Paulo, 2007. Disponível em: <http://www.perflex.com.br>. Acesso em: 08/10/07.

PORTAL EXAME. Além das fronteiras. 2006. Disponível em: $<$ http://www.portalexame.abril.com.br/revista/exame/edicoes/0871/mm/m0082728.html>.

Acesso em: 11/11/07 apud TIGRE. Joinville, Santa Catarina, 2007. Disponível em: <http://www.tigre.com.br>. Acesso em: 11/10/2007.

PROENÇA, M. C. de A. Gestão da marca ao longo da cadeia de valor: um estudo de caso no mercado de varejo de material de construção. São Paulo, 2007. Tese (Doutorado em Administração) - Programa de Pós- Graduação em Administração, Departamento de 
Administração, Faculdade de Economia, Administração e Contabilidade da Universidade de São Paulo.

REVISTA ANAMACO. Prêmio Anamaco 2006: os melhores de material de construção. São Paulo: Grau 10 Editora, Jun. 2006.

RICHARDSON, R. J. (Org.). Pesquisa social: métodos e técnicas. São Paulo: Atlas, 1999.

ROCHA LIMA, J. J. Qualidade na construção civil: conceitos e referenciais. Working paper, Escola Politécnica da USP, [1997].

ROZENFELD, H.; AMARAL, D. C.; FORCELLINI, F. A.; TOLEDO, J. C. de; SILVA, S. L. da; ALliPRANDINI, D. H.; SCALICE, R. K. Desenvolvimento de produtos: uma referência para a melhoria do processo. São Paulo: Saraiva, 2006.

SANDERSON, S.; UZUMERI, M. Managing product families: the case of the Sony Walkman. Research Policy. v. 24, p. 761-782, 1995.

SATTLER, M. A. Atividades do NORIE na área de edificações e comunidades sustentáveis. In: FARIA C. P. (Org.). Inovação em construção civil: monografias. São Paulo: Instituto UNIEMP, 2005.

SCHUMPETER, J. Capitalism, socialism, and democracy. Harper: New York, 1942.

SINDICATO DA INDÚSTRIA DE ARTEFATOS DE METAIS NÃO FERROSOS NO ESTADO DE SÃO PAULO - SIAMFESP. São Paulo, 2008. Disponível em: $<$ http://www.siamfesp.org.br>. Acesso em: 23/03/2008.

SILVA, R. T. Inovação na construção civil brasileira: o papel da arquitetura na abertura de novas perspectivas. In: FARIA, C. P. (Org.). Inovação em construção civil: coletânea de artigos. São Paulo: Instituto UNIEMP, 2005.

SLAUGHTER, E. S. “Rapid” innovation and integration of components: comparison of user and manufacturer innovations trhrough a study of residential construction. Massachusetts, Jun. 1991. Thesis (Doctor of Philosophy) - Management of technology in civil engineering and management, Massachusetts Institute of Technology.

SMITH, P. G.; REINERTSEN, D. G. Desenvolvendo produtos na metade do tempo: a agilidade como fator decisivo diante da globalização do mercado. São Paulo: Futura, 1998.

SOBRAL, M. C. Gestão do desenvolvimento de produtos: um contraste entre desenvolvimento conjunto e desenvolvimento interno. Dissertação de Mestrado da FEA-USP. São Paulo, 2003.

SOUZA, R. de. Qualidade no setor da construção. In: OLIVEIRA, O. J. S. (Org.). Gestão da qualidade: tópicos avançados. São Paulo: Pioneira Thomson, 2004.

SRINIVASAN, V.; LOVEJOY, W. S; BEACH, D. Integrated product design for marketability and manufacturing. Journal of Marketing Research. v. 34, p. 154-163, Feb. 1997. 
TIDD, J.; BESSANT, J.; PAVITT, K. Managing innovation: integrating technological, market and organizational change. England: Wiley, 1999.

TIGRE. Joinville, Santa Catarina, 2007. Disponível em: <http://www.tigre.com.br>. Acesso em: 11/10/2007.

THOMKE, S.; VON HIPPEL, E. Customers as innovators: a new way to create value. Harvard Business Review. p. 74-81, Apr. 2002.

Enlightened experimentation: the new imperative for innovation. Harvard Business Review. p. 67-75, Feb. 2001a.

Managing digital design at BMW. Design Management Journal. v. 12, n. 2, p. 2028, spring, 2001b.

Managing experimentation in the design of new products. Management Science. v. 44, n. 6, p. 743-762, Jun. 1998.

TORGAL, F. P.; JALALI, S. Construção sustentável: o caso dos materiais de construção. In: CONGRESSO NACIONAL DA CONSTRUÇÃO, 3., Dez. 2007, Coimbra, Portugal. Anais... Coimbra, Portugal: CONGRESSO NACIONAL DA CONSTRUÇÃO, 2007.

UNIÃO NACIONAL DA CONSTRUÇÃO - UNC; FUNDAÇÃO GETÚLIO VARGAS FGV. A construção do desenvolvimento sustentado: a importância da construção na vida econômica e social do país. Ago. 2006. Disponível em: <http://www.fiesp.com.br>. Acesso em: 15/06/07.

VALERI, S. G. Estudo do processo de revisão de fases no processo de desenvolvimento de produtos em uma indústria automotiva. São Carlos, 2000. Dissertação (Mestrado em Engenharia da Produção) - Programa de Pós-graduação em Engenharia, Departamento de Engenharia, Escola de Engenharia de São Carlos da Universidade de São Paulo.

VERGANTI, R. Inovação pelo design. Harvard Business Review, p. 66-73, Ago. 2007.

VON HIPPEL, E. Lead users: a source of novel product concepts. Management Science. v. 32, n. 7, p. 791-805, Jul. 1986.

YIN, R., K. Estudo de caso: Planejamento e Métodos. 3. ed. Porto Alegre: Bookman, 2005. 


\section{APÊNDICES}

APÊNDICE 1 - Decisões de desenvolvimento de produtos segundo Krishnan e Ulrich (2001) APÊNDICE 2 - Protocolo do estudo de caso

APÊNDICE 3 - Roteiro de entrevista inicial - Diretor ou Gerente da carteira de projetos APÊNDICE 4 - Roteiro da entrevista com gerentes de projetos individuais

APÊNDICE 5 - Carta de apresentação para empresas

APÊNDICE 6 - Quadro resumo das decisões comuns à Perflex, Deca, Cecrisa e Tigre 
APÊNDICE 1 - Decisões de desenvolvimento de produtos segundo Krishnan e Ulrich (2001)






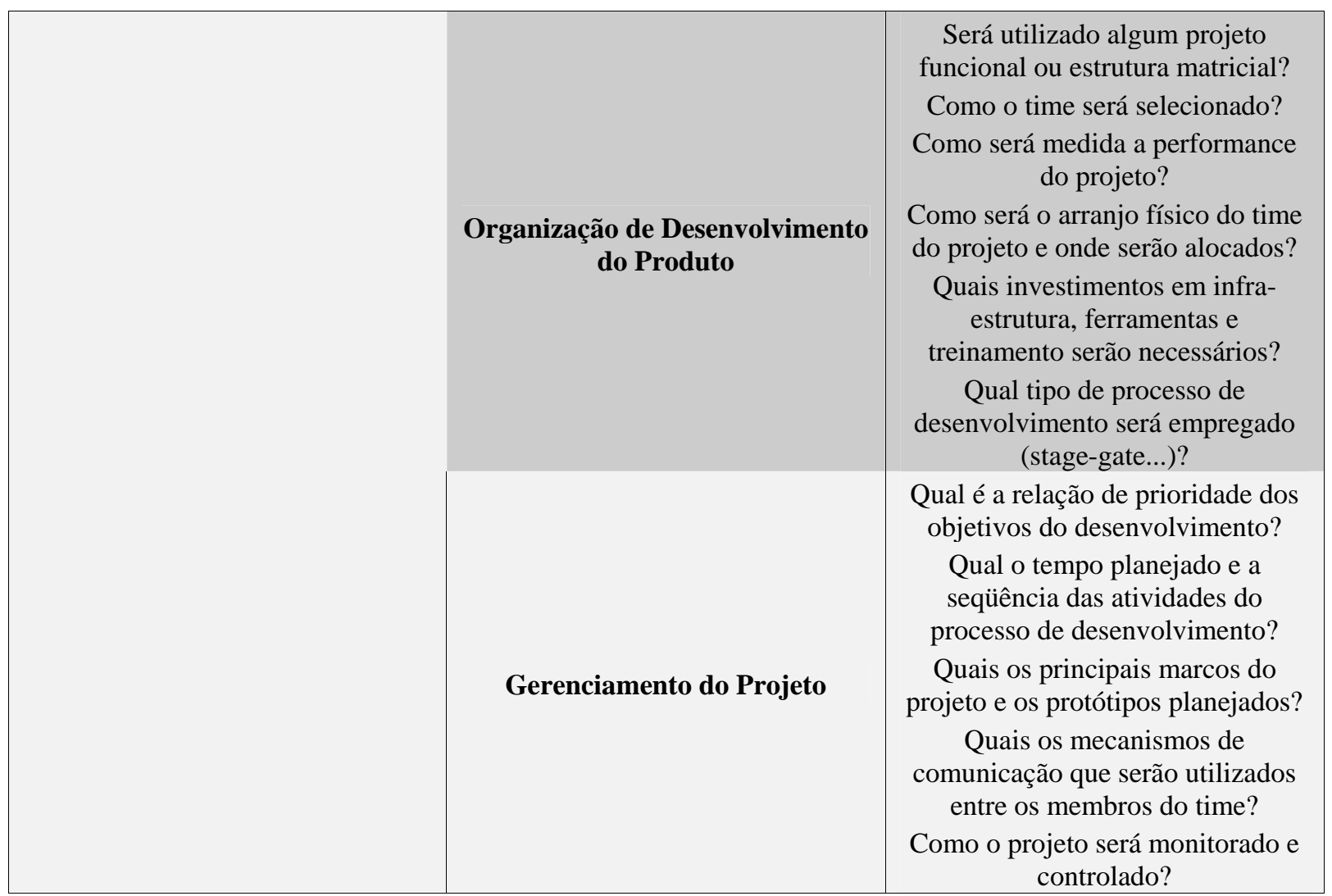




\section{APÊNDICE 2 - Protocolo do estudo de caso}

O presente protocolo foi utilizado como guia dos passos e regras gerais na condução da pesquisa, complementado com a descrição dos eventos relativos à mesma.

\section{A) Visão geral do Projeto:}

O objetivo deste estudo é identificar a estrutura, as práticas e as técnicas de GDP utilizadas na IMC, com o intuito de identificar o grau de formalização do processo nesse setor. Por se constituir em pesquisa inicial no setor em questão, não será possível analisar as práticas mais adequadas para este, mas sim responder à seguinte pergunta de pesquisa:

“Como é realizado o processo de gestão do desenvolvimento de um novo produto na indústria de materiais de construção?”

Os objetivos específicos desta pesquisa podem ser resumidos nos seguintes itens:

- identificar o grau de formalização da GDP na IMC;

- identificar as etapas da GDP na IMC;

- identificar convergências e divergências entre os casos práticos e a literatura levantada;

- identificar características da GDP peculiares à IMC.

Responsável pela pesquisa: Pesquisadora: Daniela Dutra da Costa

Critérios para escolha dos casos estudados: Para definição da população susceptível a participar do estudo, são propostos os seguintes critérios:

- Indústrias de materiais de construção.

- Empresas que ganharam o primeiro lugar, como melhores indústrias de materiais de construção, no $16^{\circ}$ Prêmio Anamaco, e que tenham sido indicadas, tanto pelas pequenas, e médias empresas, como pelos grandes clientes, em, no mínimo, três das 52 categorias existentes (Anexo B).

As empresas selecionadas, mediante os critérios acima indicados foram: Lorenzetti; Deca; e Tigre. Foram enviados para os contatos de cada empresa uma carta de apresentação que objetivava apresentar o estudo realizado e convidá-las para participar deste estudo. O modelo 
de carta de apresentação enviado consta dos Apêndices (Apêndice 5 - Carta de apresentação). No entanto, após contato direto com tais empresas, por meio de telefonemas e e-mails, somente a Deca e a Tigre decidiram participar da pesquisa. De forma a acrescentar mais uma empresa ao estudo, a banca de qualificação desta dissertação indicou alguns novos nomes, mantendo o perfil das empresas selecionadas anteriormente, como: Quartzolit Weber, Celite e Cecrisa. As três aceitaram participar da pesquisa, porém após a realização da primeira entrevista na Celite, percebeu-se que esta possuía diversas limitações na disponibilização de informações essenciais para a análise final da pesquisa, e por essa razão foi excluída do estudo.

A quarta empresa que fez parte desta pesquisa foi a Perflex. Inicialmente havia sido selecionada apenas para validação do questionário, no entanto as informações coletadas foram tão ricas, que se resolveu inseri-la na análise final desta dissertação. Portanto, as empresas que fizeram parte desta pesquisa foram: Perflex, Deca, Cecrisa e Tigre.

Unidades de Análise: O estudo se dividirá em duas unidades de análise: nível de gerência da carteira de projetos e nível de gerência de projetos individuais. A análise destas duas subunidades pretende dar uma visão geral do processo de gestão do desenvolvimento de novos produtos na indústria de materiais de construção, podendo assim responder a questão e os objetivos da pesquisa.

\section{B) Procedimentos de Campo:}

Aspectos metodológicos: Pesquisa de natureza exploratória com uso do método de casos múltiplos incorporados (unidades múltiplas de análise).

Instrumento de coleta de dados: Roteiro de entrevista. As entrevistas foram conduzidas pela autora e gravadas (sob autorização dos entrevistados), com transcrição posterior, para a análise dos dados obtidos, assim como anotações de observações que se fizeram pertinentes. Na Perflex a entrevista foi realizada com o Gerente Industrial e o Supervisor de Engenharia, também responsável pelo time de desenvolvimento. No caso da Deca, o contato foi feito com a Designer, responsável pela primeira etapa do processo de GDP, e também participante ativa do time, como também com o chefe da área de Planejamento. Na Cecrisa, primeiramente foi realizada uma entrevista com o Diretor Executivo e, posteriormente, com o Gerente de 
Produtos e Marketing Estratégico. E, por fim, na Tigre os entrevistados foram o Gerente de Produtos e Marketing, o Gerente de P\&D e o Coordenador de Oportunidades.

Organização de dados: Banco de dados para cada uma das empresas, incluindo os documentos, gravações, registros e anotações.

\section{C) Questões respondidas e possíveis fontes de evidências:}

Questões respondidas e possíveis fontes de evidências

\begin{tabular}{|c|c|}
\hline QUESTÕES & $\begin{array}{c}\text { POSSÍVEIS FONTES DE DADOS } \\
\text { Entrevista - Site das empresas - Notícias } \\
\text { divulgadas na mídia }\end{array}$ \\
\hline Participação de Mercado & $\begin{array}{c}\text { diva empresa } \\
\text { Filosofia da empresa }\end{array}$ \\
$\begin{array}{c}\text { Entrevistas - Organograma da empresa - } \\
\text { estudos sobre o segmento } \\
\text { Observação direta }\end{array}$ \\
Como é realizada a GDP & $\begin{array}{c}\text { Entrevistas - Documentos sobre ações } \\
\text { desenvolvidas - Documentos de planejamento de } \\
\text { ação }\end{array}$ \\
\hline
\end{tabular}

\section{D) Plano de análise de dados e relatório de estudo de caso:}

Análise de dados: A estratégia de análise de dados utilizada será a de descrição de caso. Nesta estratégia a análise dos dados deve buscar desenvolver uma estrutura descritiva do caso estudado. O que se espera é encontrar resultados semelhantes (replicação literal), pois serão analisadas indústrias de materiais de construção semelhantes, que possuem processos formalizados de gestão de desenvolvimento de novos produtos.

Guia para o relatório de cada caso: Apresentação escrita dos dados coletados e das conclusões relevantes. 
APÊNDICE 3 - Roteiro de entrevista inicial - Diretor ou Gerente da carteira de projetos

\section{A) DADOS DA EMPRESA E DO ENTREVISTADO:}

1. Data, hora:

2. Entrevistado, cargo:

3. Tempo de trabalho na organização:

4. Tempo de atuação no cargo:

5. Telefone:

6. Email:

7. A empresa faz parte de uma holding? Qual?

8. Número de funcionários?

9. Participação da empresa no mercado? Fonte?

10. Faturamento anual (indicar em escala)?

11. Quanto investe em inovação?

12. Quantas e quais linhas de produtos a empresa possui?

13. Número de produtos lançados no ano anterior?

14. Qual o percentual do faturamento anual da empresa com novos produtos?

\section{B) GESTÃo DO DESENVOLVIMENTO DE NOVOS PRODUTOS}

15. O que entende por gestão do desenvolvimento de novos produtos?

16. Como são definidas as metas e objetivos anuais do desenvolvimento (previsão tecnológica e de mercado, alinhamento com a estratégia)? Como são comunicadas a todas as pessoas da organização?

17. Existem mapas, painéis ou documentos que demonstram a relação do projeto com a estratégia de negócios da empresa?

18. Existe um time responsável pelos projetos (composição, participação da alta administração, representante de clientes, recompensas, estrutura organizacional)?

19. Quais as responsabilidades do gerente de desenvolvimento de produtos?

20. Descreva o processo da GDP (planejamento, etapas claras, documentações, avaliações do projeto, abordagem de desenvolvimento, monitoramento).

21. Existem estágios e portões?

22. Qual etapa a empresa considera mais importante?

23. Qual o ponto mais importante na definição do conceito do produto (design ou tecnologia)?

24. Quem influencia mais no design e na tecnologia (lojistas, usuários finais, arquitetos, construtoras)? 
25. São utilizadas algumas dessas ferramentas para auxiliar na organização do projeto: QFD, DFM, plano agregado de projetos e mapas funcionais?

26. Há quanto tempo o modelo da GDP vem sendo utilizado? O que levou a essa formalização, a industrialização da IC? Foi conseqüência de algum programa de qualidade?

27. Os clientes (arquitetos, lojistas) conhecem o modelo de GDP utilizado pela empresa? Se sim, como ele foi difundido?

28. Ocorreram mudanças na estrutura da GDP nos últimos anos (pessoas, práticas, etc.)? Quais fatores determinaram estas mudanças? Quando foi a última?

29. Existem indicadores de desempenho para o GDP da empresa?

30. A empresa possui quantos projetos em andamento? Existe algum gráfico de controle do portfólio de projetos ativos?

31. Qual o tipo de projeto predominante (incremental, topológico, radical, de plataforma ou desenvolvimento avançado? A empresa possui alguma nomenclatura específica para cada tipo de projeto?

32. Cite o exemplo de um produto lançado recentemente e de um projeto em andamento.

33. Indique dificuldades, melhorias, investimentos e aprendizados de cada caso citado. Existe alguma forma de registro?

34. Quais técnicas e critérios são utilizados para o descarte dos projetos fracos? Existe algum check-list? Caso sim, posso ter acesso?

35. Como se dá a comunicação entre os membros do time? Há integração e colaboração?

36. Os gerentes das demais áreas funcionais foram envolvidos com as atividades do GDP? Alguma sugestão de melhoria do GDP vinda de um gerente funcional foi implementada durante o desenvolvimento?

37. É bom ou não padronizar as atividades da GDP?

AGRADECER A COLABORAÇÃO E PERGUNTAR SE POSSO ENTRAR EM CONTATO, CASO SURJAM OUTRAS DÚVIDAS. 
APÊNDICE 4 - Roteiro da entrevista com gerentes de projetos individuais

\section{A) Dados do ENTREVistado:}

1. Data, hora:

2. Entrevistado, cargo:

3. Tempo de trabalho na organização:

4. Tempo de atuação no cargo:

5. Telefone:

6. Email:

\section{B) GESTÃo DO DESENVOLVIMENTO DE NOVOS PRODUTOS}

7. O que o Sr. entende por gestão do desenvolvimento de novos produtos?

8. Existe um time responsável por cada projeto (composição, participação da alta administração, representante de clientes, estrutura organizacional, recompensas)?

9. Como se dá a comunicação entre os membros dos projetos (integração ou interação)?

10. Descreva o processo da GDP (planejamento, etapas claras, documentações, avaliações do projeto, abordagem de desenvolvimento, monitoramento).

11. São utilizadas algumas dessas ferramentas para auxiliar na organização do projeto: QFD, DFM, plano agregado de projetos e mapas funcionais?

B.1) ETAPAS DO PROJETO

12. Existem estágios e portões? Quais?

38. Qual etapa a empresa considera mais importante?

39. Qual o ponto mais importante na definição do conceito do produto (design ou tecnologia)?

13. Quem influencia mais no design e na tecnologia (lojistas, usuários finais, arquitetos, construtoras)?

14. Quais especificações do produto são definidas nas fases iniciais do projeto?

15. Essas especificações podem ser modificadas no decorrer do desenvolvimento do projeto? Essa é uma prática da empresa (não congelar as especificações nas fases iniciais) ou foi um caso atípico?

16. Até que etapa as especificações podem ser modificadas? Isso acarreta em algum problema?

17. O time tem conhecimento para qual público o produto está sendo desenvolvido?

18. O líder do projeto tinha poder de decisão sobre o projeto? Em que nível? 
19. O conceito do produto é definido baseando-se em que input: tecnologia, serviço, design do produto, valores centrais da empresa, mercado consumidor ou oportunidade de negócio?

20. Algum componente do produto é produzido fora da empresa? Caso sim, por que (custos)? E onde é feita a junção dos componentes? Em que etapa isso é definido?

21. Como é selecionado o fornecedor? Em que etapa isso é definido?

22. É necessário adquirir nova tecnologia, equipamentos, programas de capacitação?

23. É realizado algum teste em pequena escala do projeto? Se sim, houve a participação dos clientes para validação?

24. São definidos os valores finais dos parâmetros do projeto (dimensões)?

25. É definida a configuração dos componentes e suas relações?

26. Há prototipagem do projeto? Se sim, ela ocorre de forma seqüencial ou paralela a outras etapas?

27. A prototipagem é feita dentro da empresa? Se não, onde?

28. Que tipo de protótipo (virtual, em escala real, ou de argila, papelão, etc)? Alguma razão específica para adoção desse método?

29. O protótipo auxilia na comunicação entre as áreas, na solução de problemas e na resolução de conflitos?

30. Descreva como é realizado o plano de teste de mercado e de lançamento do produto?

31. Descreva como é realizado o plano de ramp-up?

32. Como é medida a performance de cada projeto?

33. Existia duração estimada para cada atividade do GDP? Como eram verificadas as causas e justificados os atrasos? Havia metodologia para re-planejamento das atividades?

34. Indique dificuldades, melhorias e aprendizados dos projetos que já gerenciou. Existe alguma forma de registro dessas informações?

35. É bom ou não padronizar as atividades da GDP?

AGRADECER A COLABORAÇÃO E PERGUNTAR SE POSSO ENTRAR EM CONTATO, CASO SURJAM OUTRAS DÚVIDAS. 
APÊNDICE 5 - Carta de apresentação para empresas

São Paulo, [data]

$\grave{A}$

[nome da empresa]

Ref.: PESQUISA ACADÊMICA - A GESTÃO DO DESENVOLVIMENTO DE
PRODUTOS NA INDÚSTRIA DE MATERIAIS DE CONSTRUÇÃO

A minha orientanda, Daniela Dutra da Costa, está desenvolvendo uma pesquisa acadêmica - como parte do projeto de mestrado da Faculdade de Administração, Economia e Contabilidade / FEA USP - visando aprofundar o conhecimento sobre a gestão do desenvolvimento de produtos - GDP - na indústria de materiais de construção - IMC. O objetivo desta pesquisa é examinar a seguinte pergunta: "Como é realizado o processo de gestão do desenvolvimento de um novo produto na indústria de materiais de construção?”.

Desta forma, foram selecionadas algumas empresas que se destacam nesse setor, sendo a [nome da empresa] um dos casos a serem analisados por sua importância e liderança no segmento estudado. Para tanto, será necessária a realização de algumas entrevistas com executivos que estejam envolvidos no processo da GDP, como consta no protocolo de pesquisa enviado anteriormente à empresa. Cada entrevista terá duração de aproximadamente 35 minutos feitas pessoalmente por minha orientada (Daniela Dutra da Costa) no local, dia e horário indicados pelo entrevistado.

As entrevistas têm por objetivo:

- Identificar as etapas da GDP na IMC.

- Identificar o grau de formalização da GDP na IMC.

- Identificar convergências e divergências entre os casos práticos e a literatura levantada.

- Identificar características da GDP peculiares à IMC.

Ressalto que essa pesquisa é exclusivamente para fins acadêmicos sem nenhum tipo de conotação ou uso comercial.

Contando com sua colaboração, desde já agradeço.

Prof. Dr. Paulo Tromboni de Souza Nascimento 


\section{APÊNDICE 6 - Quadro resumo das decisões comuns à Perflex, Deca, Cecrisa e Tigre}

\begin{tabular}{|c|c|}
\hline Processo de GDP & Decisões \\
\hline Pré-desenvolvimento & $\begin{array}{l}\text { - Estratégia de Mercado - produtos que serão ofertados, público alvo. } \\
\text { - Estratégia Tecnológica - tecnologia necessária; tecnologia que dê vantagem } \\
\text { competitiva. } \\
\text { - Plano Agregado de Projetos - prioridades; escolha do projeto e definição de quando } \\
\text { começam e terminam; recursos disponíveis. } \\
\text { - Time - membros da diretoria, gerente funcional, responsável pela engenharia, } \\
\text { especialistas; áreas - marketing, tecnologia, produção e finanças. } \\
\text { - Estrutura de desenvolvimento - em grupo; formal. } \\
\text { - Investimentos - infra-estrutura, ferramentas e treinamento. } \\
\text { - Processo de desenvolvimento - stage-gate. } \\
\text { - Monitoramento e controle - através de planos, formal, atuação do gerente e } \\
\text { envolvimento e compromisso da alta administração. } \\
\text { - Priorização dos projetos, tempo de desenvolvimento, seqüência das atividades, e } \\
\text { marcos do projeto - cronograma. } \\
\text { - Descarte de projetos - critérios para descarte. } \\
\text { - Comunicação - integração multifuncional; interação e colaboração; diálogo, que } \\
\text { acontece nas fases iniciais do projeto. }\end{array}$ \\
\hline $\begin{array}{l}\text { Desenvolvimento do } \\
\text { Conceito }\end{array}$ & $\begin{array}{l}\text { - Clientes e consumidores finais - utilização de ferramentas para conhecer as } \\
\text { necessidades do mercado. } \\
\text { - Escopo detalhado do produto - identificar quem é o cliente, o consumidor e suas } \\
\text { necessidades; requisitos do produto; produtos concorrentes e similares; objetivos ou metas } \\
\text { que o produto deve atender; preço; congelamento das características em etapas finais; } \\
\text { Conceito central - customer- and market-driven concept. } \\
\text { - Variações do produto - quais serão, componentes compartilhados entre as variações. }\end{array}$ \\
\hline $\begin{array}{l}\text { Projeto da Cadeia de } \\
\text { Suprimentos }\end{array}$ & $\begin{array}{l}\text { - Componentes - projetados internamente ou comprados prontos; quem projetará, } \\
\text { desenvolverá e produzirá. } \\
\text { - Cadeia física de suprimentos - configuração, incluindo o local de junção dos } \\
\text { componentes; seleção de fornecedores das tecnologias e equipamentos; sistema de } \\
\text { produção e distribuição; custos diretos de produção; custos entre fornecimento e demanda. }\end{array}$ \\
\hline Projeto do Produto & $\begin{array}{l}\text { - Especificação dos parâmetros do projeto - projeto detalhado dos componentes; } \\
\text { relação entre os componentes do produto; seleção de material e de processo e projeto das } \\
\text { ferramentas e equipamentos; planos de processo; desenhos finais com tolerâncias. } \\
\text { - Embalagem - projeção da embalagem; planejamento do processo de embalagem. }\end{array}$ \\
\hline $\begin{array}{l}\text { Teste e Validação de } \\
\text { Desempenho }\end{array}$ & $\begin{array}{l}\text { - Prototipagem para validação - em relação a funcionamento, tamanho e fabricação; } \\
\text { projeto industrial, durabilidade, encaixe e finalização, e custos de produção. } \\
\text { - Teste em pequena escala do projeto - produção piloto; definição dos processos de } \\
\text { produção e manutenção. } \\
\text { - Processo de construção dos protótipos - simulação virtual, prototipagem rápida; } \\
\text { paralela; prototipagem em etapas iniciais do projeto. } \\
\text { - Benefícios do protótipo - contribuem para a identificação de oportunidades; } \\
\text { aprendizado da organização; testa a comunicação entre os membros do projeto; auxilia na } \\
\text { resolução de conflitos. }\end{array}$ \\
\hline $\begin{array}{l}\text { Ramp-up e } \\
\text { Lançamento }\end{array}$ & $\begin{array}{l}\text { - Lançamento - desenho dos processos de venda e distribuição; campanhas de marketing. } \\
\text { - Ramp-up - aumento da produção. } \\
\text { - Ao fim cessa o acompanhamento do produto pelo time. }\end{array}$ \\
\hline Pós-desenvolvimento & $\begin{array}{l}\text { - Aprendizados e melhorias para projetos futuros - melhoria das capacidades } \\
\text { envolvidas no processo e o próprio processo em si. } \\
\text { - Desempenho - qualidade do projeto, planejado x o que efetivamente aconteceu. }\end{array}$ \\
\hline
\end{tabular}




\section{ANEXOS}

ANEXO A - Produtos contemplados com a redução do IPI

ANEXo B - Lista dos vencedores do $1^{\circ}$ colocado do $16^{\circ}$ Prêmio Anamaco 
ANEXo A - Produtos contemplados com a redução do IPI

\begin{tabular}{|c|c|c|}
\hline ITENS DESONERADOS & $\begin{array}{l}\% \\
\text { ALÍQUOTA } \\
\text { ANTERIOR }\end{array}$ & $\begin{array}{l}\% \\
\text { ALÍQUOTA } \\
\text { ATUAL }\end{array}$ \\
\hline $\begin{array}{l}\text { Tintas e vernizes, à base de polímeros sintéticos ou de polímeros naturais } \\
\text { modificados, dispersos ou dissolvidos em meio aquoso }\end{array}$ & $10 \%$ & $5 \%$ \\
\hline Tintas e vernizes à base de poliésteres & $10 \%$ & $5 \%$ \\
\hline $\begin{array}{l}\text { Tintas e Vernizes, à base de polímeros sintéticos ou de polímeros naturais } \\
\text { modificados, dispersos ou dissolvidos em meio aquoso }\end{array}$ & $10 \%$ & $5 \%$ \\
\hline Tintas & $10 \%$ & $5 \%$ \\
\hline Vernizes & $10 \%$ & $5 \%$ \\
\hline Indutos utilizados em pintura( massas niveladoras) & $10 \%$ & $5 \%$ \\
\hline Outros tipos de indutos utilizados em pintura (seladoras) & $10 \%$ & $5 \%$ \\
\hline Cimentos e Argamassas (refratários) & $10 \%$ & $5 \%$ \\
\hline Argamassas e concretos (betões) não refratários & $10 \%$ & $5 \%$ \\
\hline Tubos rígidos de plástico & $5 \%$ & $0 \%$ \\
\hline Acessórios de tubos de plásticos & $5 \%$ & $0 \%$ \\
\hline Banheiras, banheiras para ducha, pias e lavatórios de plástico & $10 \%$ & $5 \%$ \\
\hline Assentos e tampas, de sanitários de plástico & $10 \%$ & $5 \%$ \\
\hline Caixas de descarga e artigos semelhantes & $10 \%$ & $5 \%$ \\
\hline $\begin{array}{l}\text { Reservatórios, cisternas, cubas e recipientes análogos, de capacidade superior } \\
\text { a } 300 \text { litros de plástico }\end{array}$ & $5 \%$ & $0 \%$ \\
\hline Portas, janelas, e seus caixilhos, alizares e soleiras de plástico & $5 \%$ & $0 \%$ \\
\hline Janelas, janelas de sacada e respectivos caxilhos e alizares de madeira & $5 \%$ & $0 \%$ \\
\hline Portas e respectivos caixilhos, alizares e soleiras de madeira & $5 \%$ & $0 \%$ \\
\hline $\begin{array}{l}\text { Ladrilhos e placas (lajes), para pavimentação ou revestimento, não vidrados } \\
\text { nem esmaltados, de cerâmica; cubos, pastilhas e artigos semelhantes, para } \\
\text { mosaicos, não vidrados nem esmaltados, de cerâmica, mesmo com suporte }\end{array}$ & $10 \%$ & $5 \%$ \\
\hline $\begin{array}{l}\text { Ladrilhos e placas (lajes), para pavimentação ou revestimento, vidrados ou } \\
\text { esmaltados, de cerâmica; cubos, pastilhas e artigos semelhantes, para } \\
\text { mosaicos, vidrados ou esmaltados, de cerâmica, mesmo suporte }\end{array}$ & $10 \%$ & $5 \%$ \\
\hline $\begin{array}{l}\text { Pias, lavatórios, colunas para lavatórios, banheiros, bidês, sanitários, caixas de } \\
\text { descarga ( reservatório de autoclismo), mictórios e aparelhos fixos } \\
\text { semelhantes para usos sanitários, de cerâmica }\end{array}$ & $10 \%$ & $5 \%$ \\
\hline Vidro float & $10 \%$ & $5 \%$ \\
\hline Fio-máquina de ferro ou aços não ligados & $5 \%$ & $0 \%$ \\
\hline $\begin{array}{l}\text { Barras de ferros ou aços não ligados, simplesmente forjadas, laminadas, } \\
\text { estiradas ou estrudadas, a quente, incluídas as que tenham sido submetidas à } \\
\text { torção pós laminagem }\end{array}$ & $5 \%$ & $0 \%$ \\
\hline Cantoneiras para telhados & $5 \%$ & $0 \%$ \\
\hline Portas e janelas, e seus caixilhos, alizares e soleiras de ferro ou aço & $5 \%$ & $0 \%$ \\
\hline Material para andaimes, para armações (cofragens) e para escoamentos & $5 \%$ & $0 \%$ \\
\hline Chapas, barras, perfis, tubos e semelhantes, próprios para construções & $5 \%$ & $0 \%$ \\
\hline Pias e lavatórios, de aços inoxidáveis & $10 \%$ & $5 \%$ \\
\hline Portas, janelas, e seus alizares e soleiras de alumínio & $5 \%$ & $0 \%$ \\
\hline Válvulas de retenção & $12 \%$ & $5 \%$ \\
\hline Torneiras e válvulas dos tipos utilizados em banheiros ou cozinhas & $12 \%$ & $5 \%$ \\
\hline Válvulas tipo gaveta & $12 \%$ & $5 \%$ \\
\hline Válvulas tipo globo & $12 \%$ & $5 \%$ \\
\hline Válvulas tipo esfera & $12 \%$ & $5 \%$ \\
\hline Outros tipos de válvulas & $12 \%$ & $5 \%$ \\
\hline
\end{tabular}


Duchas e chuveiros elétricos

$10 \%$

$5 \%$

$10 \%$

$5 \%$

$5 \%$

$0 \%$

Munidos de peças de conexão

$5 \%$

Outros tipos de fios e cabos

$0 \%$

FONTE: ABRAMAT; FGV PROJETOS, 2007a, p. 24. 
AneXo B - Lista dos vencedores do $1^{\circ}$ colocado do $16^{\circ}$ Prêmio Anamaco

\begin{tabular}{|c|c|c|c|}
\hline \multirow[b]{2}{*}{ SEGMENTOS } & \multicolumn{3}{|c|}{ PRIMEIRO LUGAR } \\
\hline & PULVERIZAÇÃO & $\begin{array}{l}\text { GRANDES } \\
\text { CLIENTES }\end{array}$ & AMBOS \\
\hline Argamassas colantes & - & - & Quartzolit Weber \\
\hline $\begin{array}{l}\text { Armários para banheiros e } \\
\text { cozinhas }\end{array}$ & - & - & Astra \\
\hline $\begin{array}{l}\text { Aquecedores de passagem } \\
\text { à gás }\end{array}$ & - & - & LORENZETTI \\
\hline Assentos sanitários & - & - & Astra \\
\hline Blocos de concreto celular & - & - & Precon \\
\hline Cadeados & - & - & Pado \\
\hline $\begin{array}{c}\text { Caixas d’água de } \\
\text { polietileno e fibra de vidro }\end{array}$ & - & - & Torres - Fortlev \\
\hline $\begin{array}{c}\text { Cales hidratadas para } \\
\text { argamassa }\end{array}$ & - & - & Votorantim \\
\hline Cimentos & - & - & Votorantim \\
\hline Colas em geral & - & - & Henkel \\
\hline $\begin{array}{l}\text { Conexões de PVC para } \\
\text { água fria } \\
\end{array}$ & - & - & TIGRE \\
\hline $\begin{array}{c}\text { Conexões de ferro } \\
\text { galvanizadas }\end{array}$ & - & - & Tupy \\
\hline $\begin{array}{c}\text { Discos abrasivos de corte e } \\
\text { desbaste }\end{array}$ & - & - & Norton \\
\hline Discos diamantados & Norton / Bosch & Norton & - \\
\hline Disjuntores residenciais & - & - & $\begin{array}{l}\text { Pial Legrand / } \\
\text { LORENZETTI } \\
\end{array}$ \\
\hline $\begin{array}{c}\text { Duchas, chuveiros e } \\
\text { torneiras elétricas }\end{array}$ & - & - & LORENZETTI \\
\hline $\begin{array}{l}\text { EPI - Equipamentos de } \\
\text { proteção individual }\end{array}$ & - & - & $3 \mathrm{M}$ \\
\hline Esmaltes sintéticos & - & - & Tintas Coral \\
\hline Fechaduras em geral & - & - & Aliança Metalúrgica \\
\hline Fechaduras de alto padrão & - & - & Pado \\
\hline Fios e cabos elétricos & Nambei & $\begin{array}{c}\text { Sil Fios e Cabos } \\
\text { Elétricos } \\
\end{array}$ & - \\
\hline Fitas crepe & - & - & $3 \mathrm{M}$ \\
\hline Forros de PVC & Tigre & Plásticos Vipal & - \\
\hline Furadeiras elétricas & - & - & Bosch \\
\hline Impermeabilizantes & - & - & Vedacit - Otto Baumgart \\
\hline $\begin{array}{c}\text { Interruptores, plugues e } \\
\text { tomadas } \\
\end{array}$ & Fame & Pial Legrand & - \\
\hline Lâmpadas & GE & Osram & - \\
\hline Lixas e abrasivos & - & - & Norton \\
\hline Louças sanitárias & - & - & Roca Brasil \\
\hline Luminárias & - & - & Taschibra \\
\hline $\begin{array}{c}\text { Mantas asfálticas para } \\
\text { impermeabilização }\end{array}$ & - & - & Vedacit - Otto Baumgart \\
\hline Massas prontas & Votorantim & Quartzolit Weber & - \\
\hline $\begin{array}{l}\text { Metais sanitários } \\
\text { economizadores }\end{array}$ & - & - & DECA \\
\hline
\end{tabular}




\begin{tabular}{|c|c|c|c|}
\hline $\begin{array}{c}\text { Metais sanitários não } \\
\text { economizadores }\end{array}$ & - & - & DECA \\
\hline Molas para portas & - & - & Coimbra \\
\hline $\begin{array}{c}\text { Pias, cubas e tanques de } \\
\text { material sintético }\end{array}$ & - & - & A. J. Rorato \\
\hline Pincéis e rolos para pintura & Pincéis Atlas & Pincéis Tigre & - \\
\hline Portas e esquadrias de aço & - & - & Sasazaki \\
\hline $\begin{array}{c}\text { Portas e esquadrias de } \\
\text { alumínio }\end{array}$ & - & - & Sasazaki \\
\hline Portas sanfonadas de PVC & Hanna Plásticos & Plásticos Vipal & - \\
\hline Porteiros eletrônicos & - & - & HDL \\
\hline Pregos & - & - & Gerdau \\
\hline Rejuntamentos cerâmicos & - & - & Quartzolit Weber \\
\hline Revestimentos cerâmicos & Delta & Eliane & DECA \\
\hline Sistemas de descarga & - & - & - \\
\hline Telhas de fibrocimento & Eternit & Brasilit / Eternit & - \\
\hline Tintas para teto e parede & Suvinil & Tintas Coral & Sherwin-Williams \\
\hline Tintas para pisos & - & - & TIGRE \\
\hline $\begin{array}{c}\text { Tubos de PVC para água } \\
\text { fria }\end{array}$ & - & - & TIGRE \\
\hline Tubos e conexões para & - & - & Gerdau \\
\hline água quente & - & - & - \\
\hline Vergalhões de aço & Akzo Nobel & Tintas Coral & \\
\hline Vernizes & & & \\
\hline
\end{tabular}

